Portland State University

PDXScholar

\title{
"I Should Have Moved Somewhere Else": the Impacts of Gentrification on Transportation and Social Support for Black Working-Poor Families in Portland, Oregon
}

Steven Anthony Howland Portland State University

Follow this and additional works at: https://pdxscholar.library.pdx.edu/open_access_etds

Part of the Transportation Commons, and the Urban Studies and Planning Commons Let us know how access to this document benefits you.

\section{Recommended Citation}

Howland, Steven Anthony, "'I Should Have Moved Somewhere Else": the Impacts of Gentrification on Transportation and Social Support for Black Working-Poor Families in Portland, Oregon" (2020). Dissertations and Theses. Paper 5479.

https://doi.org/10.15760/etd.7353

This Dissertation is brought to you for free and open access. It has been accepted for inclusion in Dissertations and Theses by an authorized administrator of PDXScholar. Please contact us if we can make this document more accessible: pdxscholar@pdx.edu. 
"I Should Have Moved Somewhere Else": The Impacts of Gentrification on Transportation and Social Support for Black Working-Poor Families in Portland, Oregon

\title{
by
}

Steven Anthony Howland

A dissertation submitted in partial fulfillment of the requirements for the degree of

\author{
Doctor of Philosophy \\ in \\ Urban Studies
}
Dissertation Committee:
Karen Gibson, Chair Jennifer Dill
Greg Schrock
Amy Lubitow

Portland State University

2020 
(C) 2020 Steven Anthony Howland 


\begin{abstract}
Portland has faced a mass displacement of Black households from the historically segregated area of Albina through various phases of urban renewal, urban deterioration, and gentrification. A substantial number of them have moved to East Portland, a suburban segment of the City of Portland that was unincorporated county land prior to the 1990's. As Black people have left Albina, the roots of Blackness there have eroded from the area as businesses and churches catering to them have also closed as a result of lost patrons.
\end{abstract}

In this study I interviewed 27 low-income working-age Black people with children with the sample divided between Albina and East Portland. I talked to them about how they got around, the places they were going, the people in their lives that help them get by, and how it has all been affected by gentrification. I evaluated their interviews through the theories of social reproduction and social exclusion with an emphasis on geographic differences in lived experiences between Albina and East Portland.

I found that people in Albina were better resourced, on average, to accomplish their daily life maintenance. Through easier transportation (including a higher rate of car ownership), better and stronger social support networks, and a higher density of nearby destinations, Albina residents could get around faster, easier, and accomplish more in a day. East Portlanders struggled far more. Clustering of destinations around the western edge of East Portland put those destinations out of reach for most of them. Support networks for people in East Portland featured a lot of friends and family that had also been displaced, but their 
networks there were under-resourced. They often had to turn to their network living in Albina for their more critical needs like childcare, but it took a lot more effort to utilize.

Overall, the cultural rootedness of Albina appeared to be eroding as more and more Black people left and were being replaced by high-end shops, restaurants, and White people. Safety concerns on transit was leading to huge declines in willingness to use transit. This was spurred in part by the racially-motivated murders on MAX, but mostly because of their encounters with homeless people and people with untreated mental illnesses which also spilled over into overt racist acts against them or their children. And while East Portland has had a lot of investments in road safety, it is the distance between destinations that has really hurt their ability to survive. As East Portland continues to grow with more lowincome people of color, more attention needs to go to the urban development of the area to make life a little easier for them. 


\section{Acknowledgements}

I want to thank my committee for being patient with me in getting this done. It was a long ride. I also want to thank my writing group of Jamaal Green, Amy Coplen, Steve Marotta, and Andree Tremoulet for helping in get words on the page. And lastly, I want to thank my family for giving me all the support and encouragement I needed to finish. It was not easy, and I appreciate the help each of you gave me along the way. This would not be finished if not for you. And specifically, for my dad who will not be able to read this or celebrate this achievement with me. He was my primary inspiration for studying urban planning and that has led me all the way through my Ph.D.

This dissertation was funded in part through the National Institute of Transportation and Communities Dissertation Fellowship and the Maurie Clark Endowed Fellowship. 


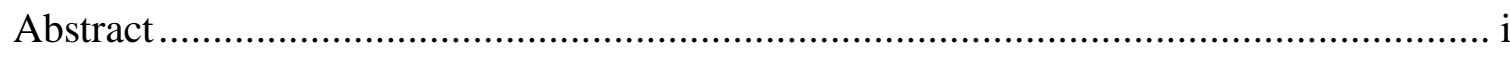

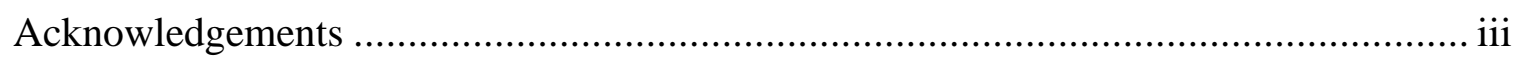

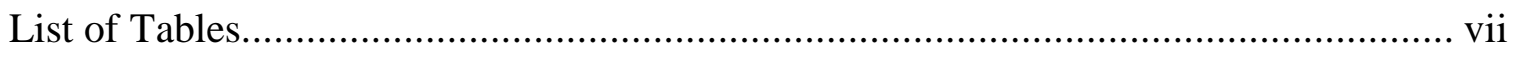

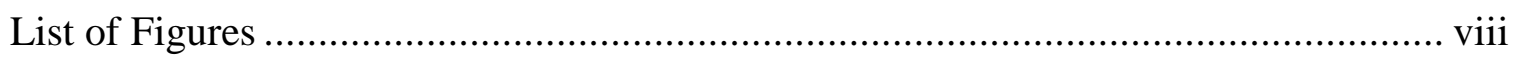

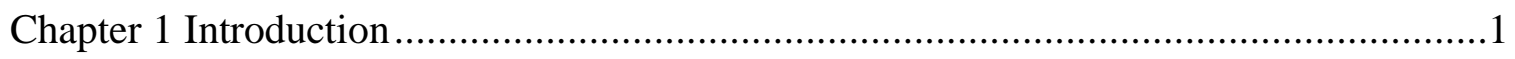

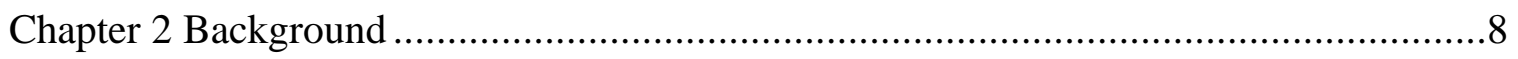

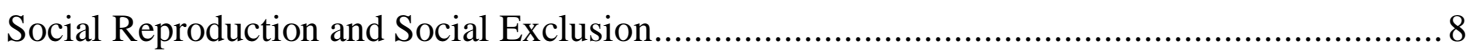

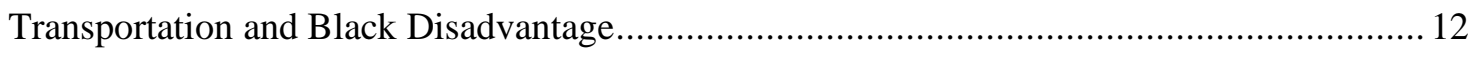

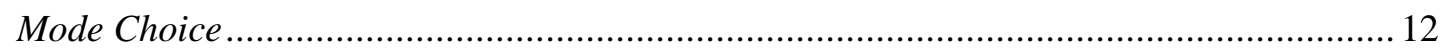

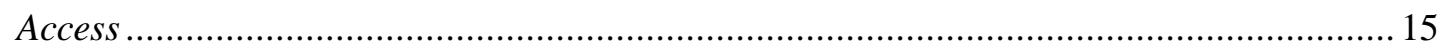

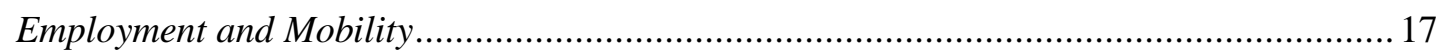

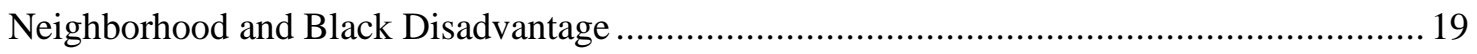

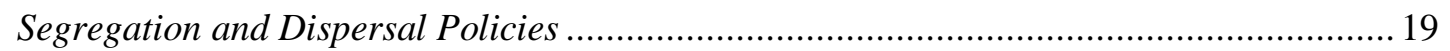

Social Support Networks and Coping with Poverty.............................................................. 23

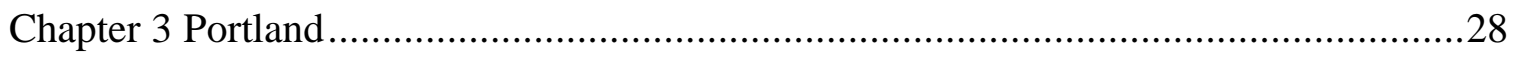

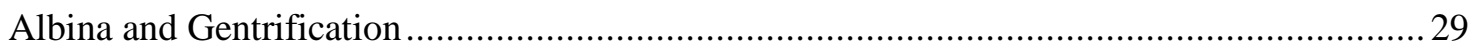

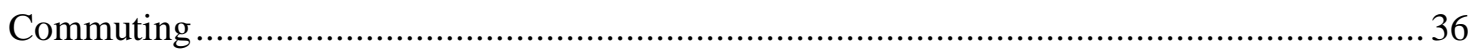

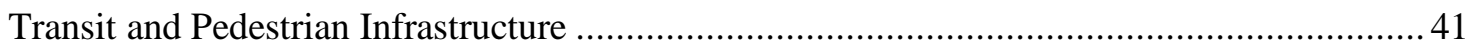

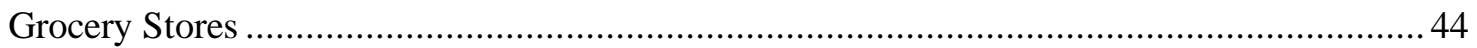

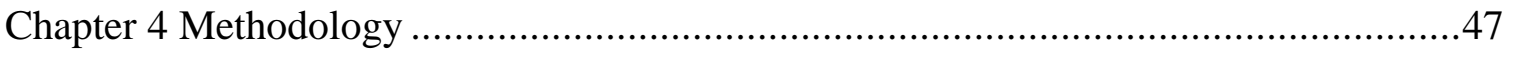

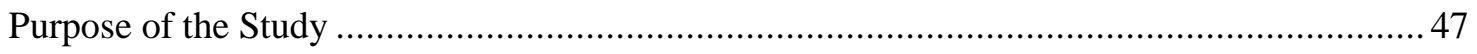

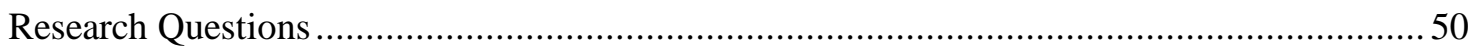

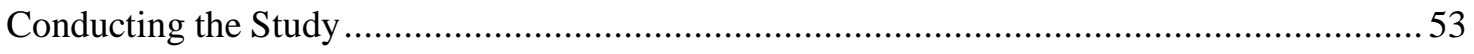

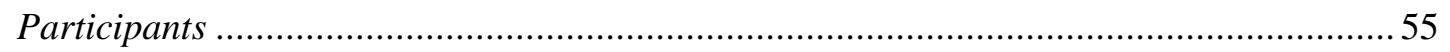

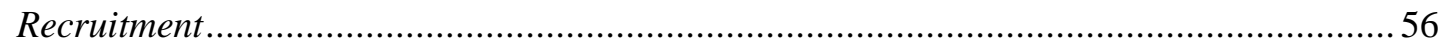

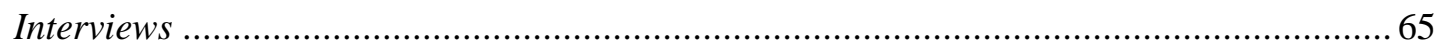

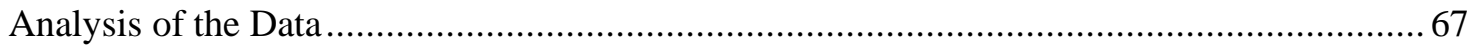

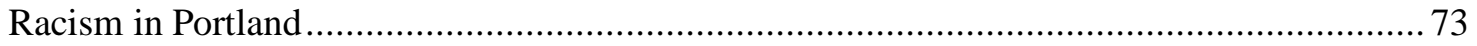

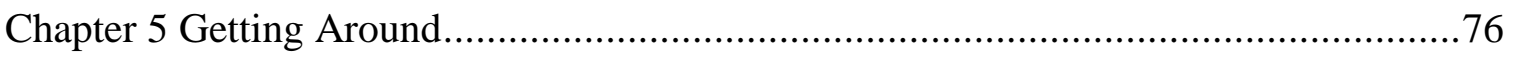

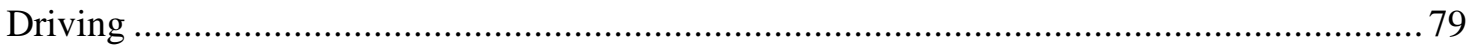

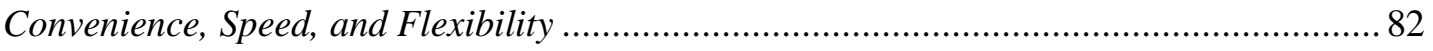




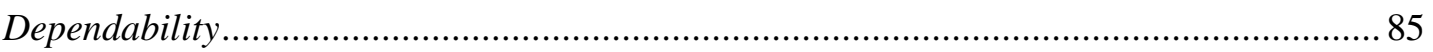

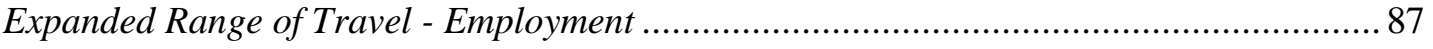

Expanded Range of Travel - Shopping ........................................................................ 90

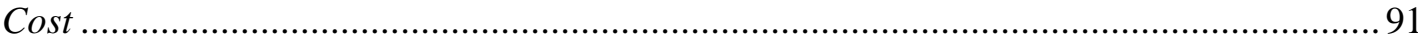

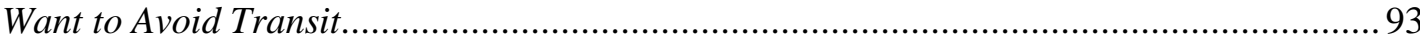

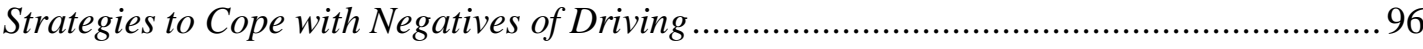

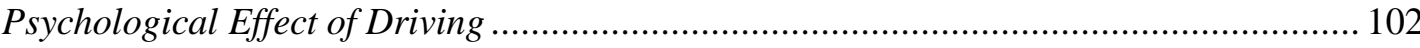

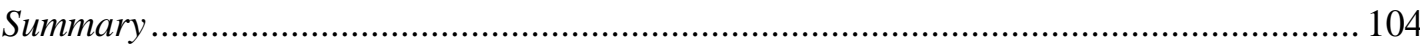

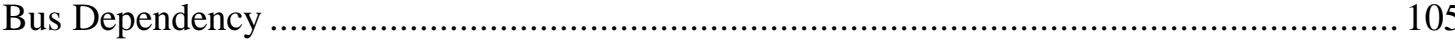

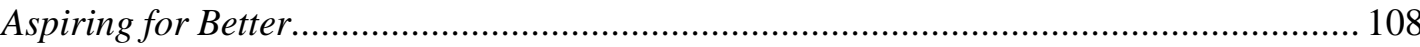

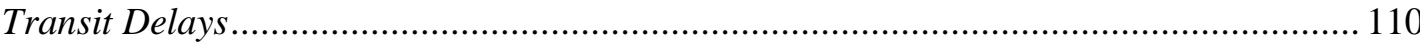

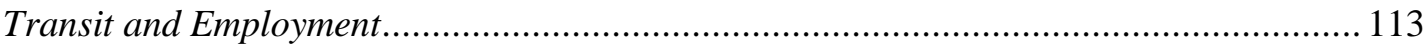

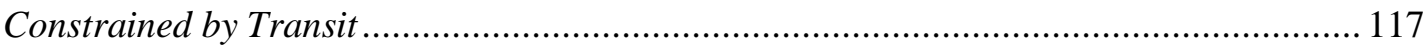

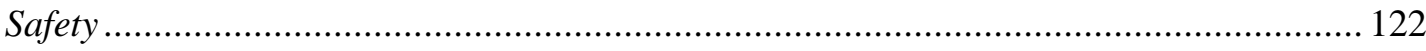

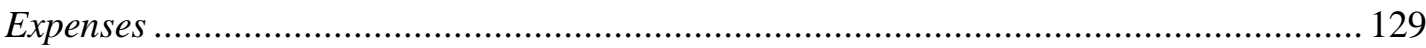

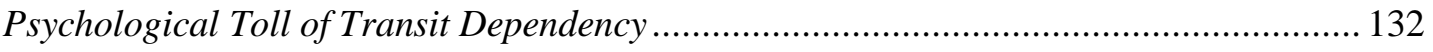

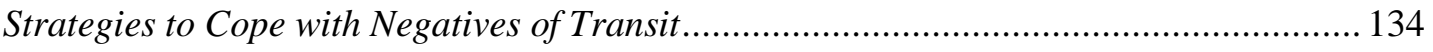

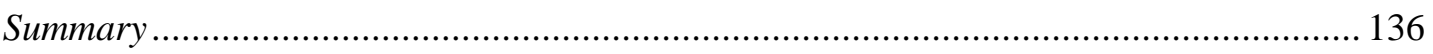

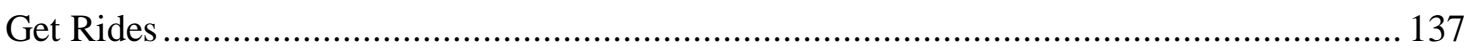

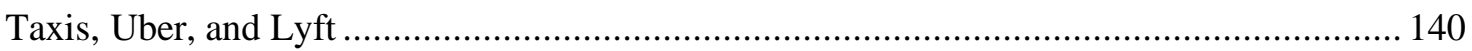

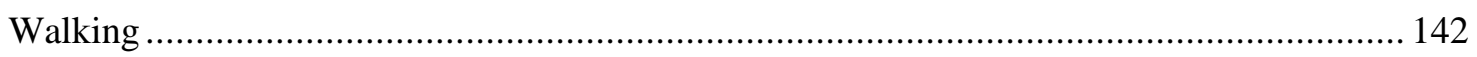

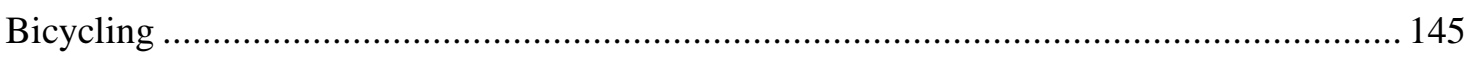

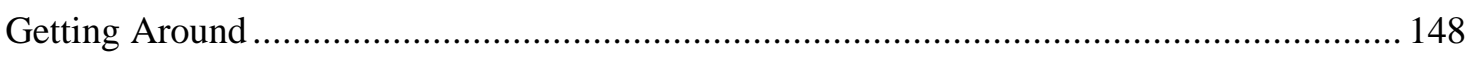

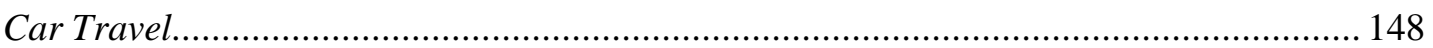

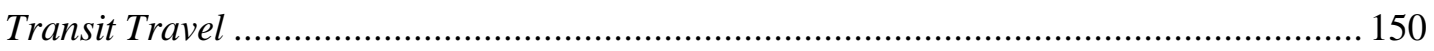

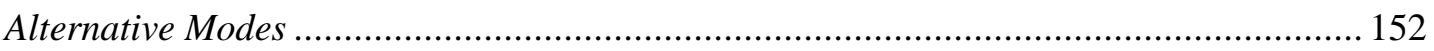

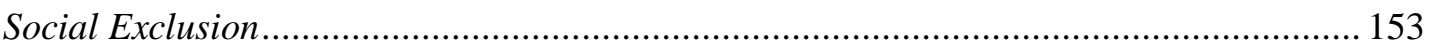

Chapter 6 Neighborhoods, People, and Gentrification......................................... 157

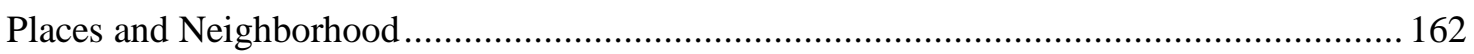

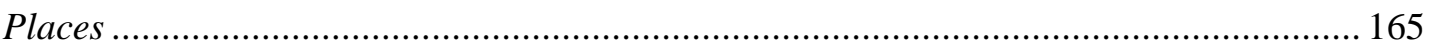

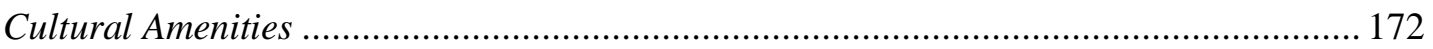

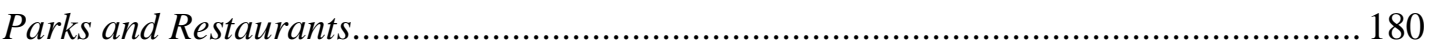

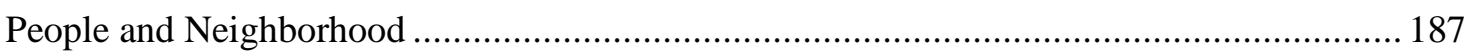




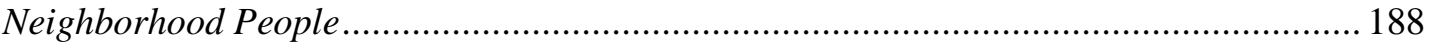

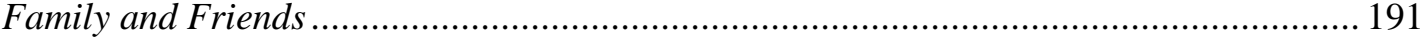

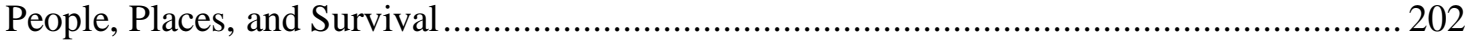

Chapter 7 Social Reproduction and the Role of Gentrification and Transportation .......206

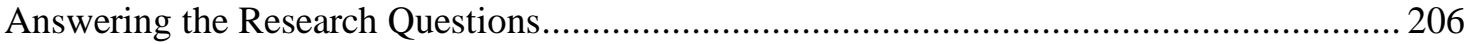

Demographic Effects on Travel and Making Ends Meet .................................................. 214

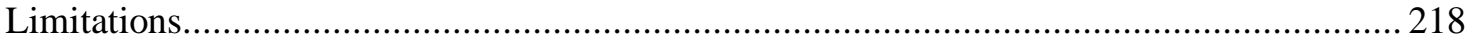

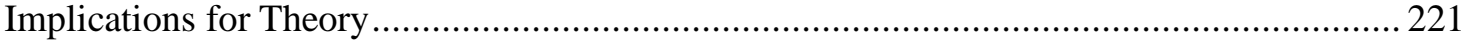

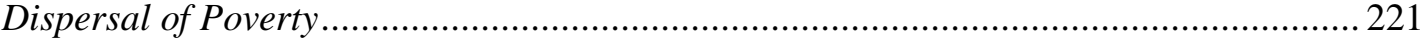

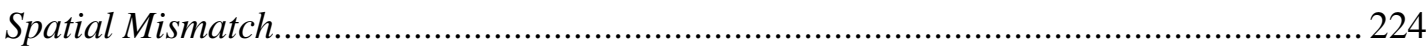

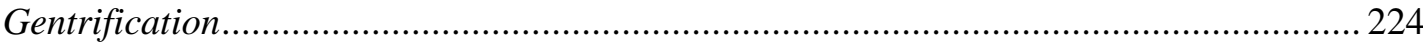

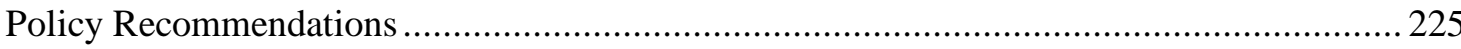

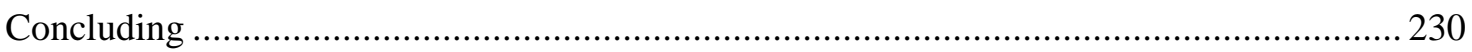

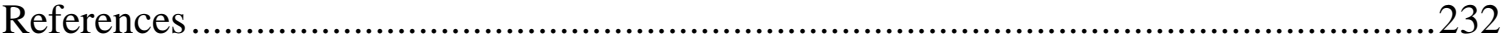

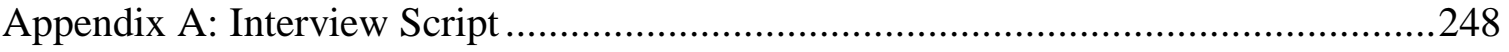




\section{List of Tables}

Table 3-1 Vehicles Available in Household by Race and Income, Multnomah County 2017

Table 4-1 Sample Demographics Part 1

Table 4-2 Sample Demographics Part 2

Table 4-3 Interview Coding $\quad 69$

Table 5-1 Mobility Chapter Findings Highlights 78

Table 5-2 Positives and Negatives for Driving $\quad 82$

Table 5-3 Positives and Negatives of Transit 108

Table 6-1 Places, People, and Gentrification Findings Highlights 160

Table 6-2 Where were they going? 165

Table 7-1 The Effects of Social Exclusion on Transit Dependent East Portlanders 209

Table 7-2 Implications of Social Exclusion for Transit Dependent Albina Residents 211 


\section{List of Figures}

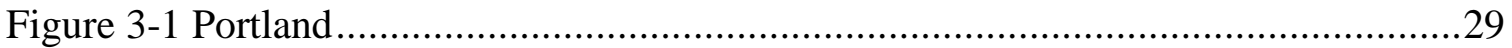

Figure 3-2 Black Population Geographic Shift, 1990-2017 ......................................31

Figure 3-3 Population Change by Race by Area 1990-2017 ........................................34

Figure 3-4 Percent Poverty within Race by Area, 2017 .........................................35

Figure 3-5 Commute Mode by Race and Household Income, Multnomah County 2017.38

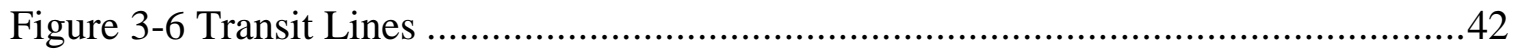

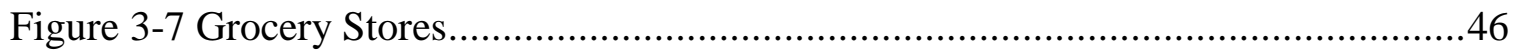

Figure 4-1: Conceptual Model ...............................................................52

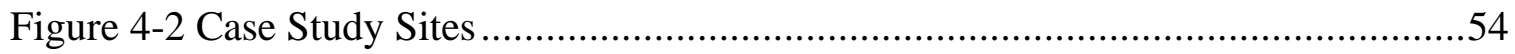

Figure 5-1: Conceptual Model - Chapter Highlights ............................................. 77

Figure 5-2 Portland Poverty Rates, 2017 f........................................................ 120

Figure 5-3 Social Exclusion by Mode and Place ................................................ 155

Figure 6-1: Conceptual Model - Chapter Highlights .......................................... 162

Figure 6-2 Grocery Destination by Area and Price .............................................. 168

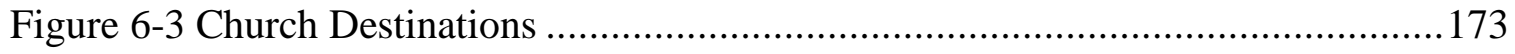

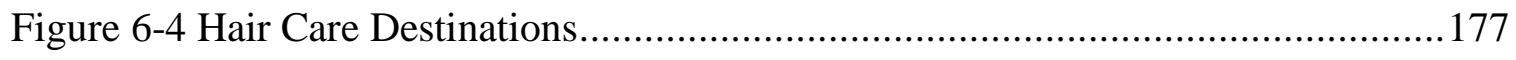

Figure 6-5 Parks and Restaurant Destinations ............................................... 182

Figure 6-6 Support Network Diagram by Geography ....................................... 192

Figure 7-1 Conceptual Model of Social Reproduction ..........................................212 


\section{Chapter 1 Introduction}

Cities across the United States have been paying more attention to equity in their policies and planning since the mid 2000's. Schrock et al. (2015) looked at climate action plans in cities across the U.S. and found that there has been a noticeable increase in cities incorporating equity goals in such plans, even if the goals were often of low-importance. That view is shared by Karner et al., (2016) who found that while there was increasing attention on transportation equity by academics, there was a noticeable lack of rigorous analyses on equity impacts. That is a troubling finding given equity is built into the law around transportation provision for anything receiving federal funds, which is nearly every major transportation project around highways and transit. Karner et al., (2016) described transportation equity along four components: participation, benefits, environment and quality of life burdens, and financial burdens/affordability. It means that transportation project planners should be as inclusive as possible in project planning. Planners should give their best effort to incorporate the ideas and needs of those most likely to benefit or be impacted by such projects. And the projects should be evaluated with a balance of benefits and costs that ensures the benefits go to those that need them the most while costs are not overly pushed onto those least able to adapt to them.

To understand transportation equity, it is important to understand how transportation affects the daily lives of people, particularly those with substantial disadvantages in nearly every aspect of their lives. Consistently, studies have found that Black populations have longer commutes both in time and distance (Gilbert, 1998; Giuliano, 2003), tend to have much less access to cars to overcome distance barriers put 
up by segregation (Giuliano, 2003; Karner et al., 2016; Kawabata \& Shen, 2007), are at a greater disadvantage to accessing goods and services based on where they live (Allard, 2017), and housing and transportation mode combine to make it more difficult for them to reach jobs (Blumenberg \& Ong, 2001; Kawabata \& Shen, 2007; Pendall et al., 2014). Lower incomes only make the disadvantage worse.

Low-income Black households have substantially shifted where they live as well. While prior to the 2000's most Black populations in cities across the U.S. were still relatively confined to historically segregated neighborhoods with some spillover to neighboring census tracts (Jargowsky, 1997). After 2000, there was a noticeable shift toward the suburbs (Covington et al., 2011; Haggerty, 2014; Kneebone \& Berube, 2013). The trend of suburbanization only furthers the difficulties related to the above issues as suburban locations are notoriously devoid of quality transit and have much longer distances to traverse for most goods and services. Suburbanization also removes them from neighborhoods where they can easily access cultural amenities and their social support networks, especially when their move to the suburbs was not voluntary (Goetz, 2010; Goetz \& Chapple, 2010; Kissane \& Clampet-Lundquist, 2012). The federal government and cities across the U.S. have pursued policies of poverty dispersal following failed efforts to revitalize ghettos through urban renewal. As such it is not that much of a surprise to see a growing suburbanization of poverty. What has been different with some cities was whether the move to the suburbs had been spurred by explicit city policy or private actors through gentrification. 
While still limited to a few places in the U.S., gentrification has had a profound impact on historically segregated Black neighborhoods where it has occurred. For neighborhoods that had gone decades with increasing vacancy, disinvestment, and crime, gentrification has brought massive amounts of investment, lowered vacancies and reduced rates of crime, as well as new problems related to affordability and feelings of belonging (Crump, 2002; Elliott-Cooper et al., 2019; Newman \& Wyly, 2006). There is considerable debate around displacement, what it means, and how prevalent it is, but it is happening. In general, gentrification is the flipping of a neighborhood from one populated largely by lowincome and often non-white people to one that was higher-income and often, but not always, whiter. Some researchers of gentrification found gentrification to be a good thing, overall (see Freeman, 2006; Freeman \& Braconi, 2004; Hamnett, 2003; Vigdor et al., 2002). They found limited movement of lower-class populations in gentrifying neighborhoods and those populations then got to enjoy the new services and amenities brought by the investment in the neighborhood. But other researchers of gentrification, led by the writings of Marcuse and Smith, have found gentrification causes many more harms to low-income and non-white populations (see Elliott-Cooper et al., 2019; Fullilove, 2004; Marcuse, 1986; Slater, 2009; Smith, 1996). Their primary argument was that removing people from their home was among the greatest harms that could be done. The disruption to their lives, social networks, schools, routines, and cultural access was a cost that could not be replaced. While most studies around gentrification have focused much more on class than race, historically segregated neighborhoods tend to be the most common areas of a city ripe for gentrification, but some exceptions exist and not all historically segregated 
neighborhoods are at threat of gentrification (Cortright \& Mahmoudi, 2014). Additionally, gentrifiers are not always white (Pattillo, 2007).

Transportation and housing have substantial implications on the ability of a household to socially reproduce. Social reproduction in its simplest terms is the ability of a family to provide for their needs (e.g. housing, food, clothing, and education) and raise their children for a healthy and successful life (Laslett \& Brenner, 1989). The decisions people make on a daily basis for providing for their basic survival take into account their resource, institutional, and psychological constraints for what they can and cannot do. Living in poverty adds substantial barriers to social reproduction, and being Black and poor only adds to the difficulties due to the ongoing racism in society (Edin \& Lein, 1997). Where people live and how they can get around intersect with social reproduction in nearly every aspect of their maintenance of daily life.

Like social reproduction, social exclusion focuses on the daily activities necessary to participate in society. But instead of identifying how people make ends meet, social exclusion focuses on the impediments to making ends meet (Church et al., 2000; Kenyon et al., 2002; Lucas, 2012). For low-income Black populations, the effects of racism, segregation, and sustained material hardship prevents their full participation in society. A society, which through suburbanization and orienting life and policy around the automobile assumes people will get around by a car and can travel long distances for their everyday life. They are thereby socially excluded from society, but we have limited knowledge as to the way this manifest in the lives of low-income Black populations or the effects it has on their life chances. 
To study these theoretical concepts as they relate to the lives of low-income Blacks, I centered my studies on Portland, Oregon. Portland has seen a massive amount of gentrification in its historically segregated Black district, the Albina District, with a noticeable shift of the Black population from the Albina District and surrounding census tracts to East Portland as gentrification, coupled with widespread growth across the city, led to major housing affordability problems. The Albina District was once heavily disinvested, had suffered through multiple waves of urban renewal that demolished thousands of homes, and was heavily affected by crime led by the crack epidemic - until it started to gentrify. Through gentrification, Albina has turned from an area of the city with the largest concentration of Black households to losing half its Black population and doubling its white population. During that population shift, development was taking off with thousands of apartments built, a new light-rail line was built, and the city substantially improved walking and biking infrastructure throughout the neighborhood. Meanwhile, East Portland, where a large portion of Black households displaced from Albina landed, was seeing very little city investment by comparison. It's suburban form of development mean transit was sparse and took much longer to get anywhere, businesses were few and far between, and the area was becoming more known for its crime, much as Albina was before gentrification took hold.

In this dissertation, I examine the transportation situation of low-income Black Portlanders with children and how their experience differs between Albina and East Portland. My analysis focused on the following questions:

1. How does access to their daily needs and services and their transportation choices affect low-income black households' strategies to make ends meet? 
a. What transportation options are they using? Why?

b. How do those choices affect their daily lives?

c. What tradeoffs do they make in deciding to use one mode over another?

2. How has gentrification and displacement affected strategies to make ends meet?

a. How has access to services and daily needs changed since they have been affected by gentrification (if at all)?

b. How has their interaction with and the composition of their social support network changed since they have noticed gentrification?

These questions are based around theories of social reproduction and social exclusion, and I based much of my discussion within that frame of thought.

In the following chapters I describe the experiences of 27 low-income working-age Black people with children living in two very different areas of Portland, Albina and East Portland. I interviewed them from April to December of 2017. Through those interviews, I asked about how they got around, the difficulties they faced in getting around, where they went regularly, why they chose those places and not others, who they considered part of their support system and how they utilized them, and how gentrification impacted the modes of travel, housing choice, places, and people in their lives. This dissertation covers a lot of ground from many different disciplines with a number of policy implications even when considering the multiple limitations in this study and results. From this study, I provide a combined effort to understand the travel behaviors of low-income Black populations in Portland with a geographical focus on social reproduction and social exclusion. This study gives a deeper understanding of the needs and disadvantages faced by Black populations in their housing and transportation choices in Portland. Furthering that understanding, the results presented here have implications for housing, transportation, land-use, and policing policies as well as providing insight into gaps of daily survival where new or expanded social safety net programs could help alleviate the difficulties of making 
ends meet. There are also implications for historical preservation and community development policies as it relates to maintaining Black culture and community in Portland.

In Chapter 2, I cover the theoretical grounding of this study in more detail than presented above. Chapter 3 lays out the situation in Portland to provide a contextual grounding for this study. In Chapter 4 I talk about who I recruited for this study, how I interviewed them, my own positionality in this study, and particular contextual issues in Portland that impacted my ability to adequately analyze certain parts of this study. The next two chapters are the empirical focus of this study. Chapter 5 presents results from analyzing how the participants of this study got around, the difficulties they faced, and the tradeoffs they made in choosing how they got around and maintaining their use of those modes. Chapter 6 focuses on results of where people were going focusing on grocery stores, cultural amenities, parks, and restaurants with attention to how they chose their destinations, what they had to do to get there, and the tradeoffs they made with their decisions. This chapter also covers their access and utilization of their social support networks. Chapter 7 wraps up the study by bring it all together to summarize how the travel behaviors and destination choices of low-income Black populations in Portland impacted their ability to socially reproduce and the extent of social exclusion they faced. 


\section{Chapter 2 Background}

This study was guided by a number of disciplines and the theories therein. In this chapter, I will cover as much of this theory in as brief a manner as possible to guide the reader through the main argument of this dissertation: in order to address Black disadvantage in our cities, we need to better understand how they socially reproduce and are socially excluded with a specific emphasis on the role of transportation in their ability to succeed. Aside from the core argument, I argue that gentrification has diminished the power, culture, and survivability of Black populations, at least in Portland.

In this chapter, I cover the theory of what is known and how we understand it around social reproduction, social support networks, poverty, transportation, the built environment, housing, gentrification, and economic development in terms of low-income Black populations. Combined, they produce a picture of what we have come to understand about how low-income Black populations get around, maintain mobility around their daily life needs, and the power structures and other impediments that contribute to difficulty in performing daily life maintenance.

\section{Social Reproduction and Social Exclusion}

Laslett and Brenner (1989, p. 382) explained social reproduction as "the activities and attitudes, behaviors and emotions, and responsibilities and relationships directly involved in the maintenance of life on a daily basis,". This definition puts front and center the idea that people have some consent in their lives over what they do and do not do for daily life maintenance. The decisions people make around their daily life maintenance are guided by their attitudes, behaviors, emotions, and responsibilities. But those decisions are 
also moderated by power structures beyond their control. Low-income Black populations have their power moderated by the perpetual discrimination in virtually every aspect of their lives. Discrimination impacts their ability to earn as much as their White peers (Daly et al., 2020; O'Neill, 1990); it impacts the education they and their children can expect to get (Hanushek et al., 2019); it impacts where they can live (Jargowsky, 1997; D. Massey \& Denton, 1993); it impacts where they feel comfortable shopping or going for socialization (Pittman, 2020); it impacts their daily psychological and physiological wellbeing (Bailey et al., 2017; Greer \& Spalding, 2017).

The government has the ability, power, and arguably the responsibility to support social reproduction by providing a robust social safety net (Bezanson \& Luxton, 2006). Help from the government could restore power through alleviation of time and monetary burdens in their lives. However, the neoliberal system of governing has taken away vital assistance for those that struggle to get by on a day-to-day basis. Even though no poor family has been able to support themselves from government support along, today, a struggling family finds it even more difficult due to the evisceration of public aid programs (Edin \& Shaefer, 2015). They instead need to work - a desired outcome of the neoliberal budget cutting. But in order for single parents to work, they need someone to watch over their children. Without childcare assistance to subsidize the cost of a private provider, a parent needs a friend or family member to watch their kid. That task is made difficult when friends and family are burdened by the same governing system. And when a single parent finds work, their job often provides an inadequate wage to make up the difference between what is left of the social safety net (which erodes in value or disappears completely with 
earned income) and what is needed to provide for their family. Their struggle is real and difficult.

While social reproduction theory examines how families make ends meet, social exclusion theory examines how the ability to make ends meet is impeded. Kenyon et al. (2002, pg. 209) described social exclusion as "the unique interplay of a number of factors, whose consequence is the denial of access, to an individual or group, to the opportunity to participate in the social and political life of the community, resulting in not only diminished material and non-material quality of life, but also tempered life chances, choices, and reduced citizenship." Like social reproduction, power structures are essential in understanding the relationship exclusion has on an individual. Each individual has certain powers out of their control that work against them to deny them access, and these power relationships work differently than a person making a decision to exclude themselves. Those with power, such as governmental actors, landlords, and capitalists to name a few, can exert their will to drastically change the outcome of people's lives. For the poor, they have generally lacked the collective power necessary to turn those decisions in their favor.

Social exclusion theory made its biggest impact in the United Kingdom where they adopted policy to reduce social exclusion. Through multiple studies of social exclusion by the government and academics there, mobility became the prominent focus for policy makers to try to make an impact on social exclusion (Church et al., 2000; Lucas, 2012). Transport exclusion focuses not on whether or not people have transport but whether their transport or lack thereof inhibits their access to key activities for daily maintenance and life success like employment, education, health, and social support networks (Lucas, 2012). 
Church et al. (2000, p. 198-200) described the factors of social exclusion as shown in and adapted from Kenyon et al al._(2002)_and L_uças_(2012,_pg._108):

\begin{tabular}{|c|c|}
\hline Forms of Exclusion & Description \\
\hline Physical & $\begin{array}{l}\text { Where physical barriers like vehicle or station } \\
\text { design, sidewalk design, bus schedule } \\
\text { information, inhibit the accessibility of transport } \\
\text { services. }\end{array}$ \\
\hline Geographical & $\begin{array}{l}\text { The location where a person lives prevents them } \\
\text { from accessing transport services. }\end{array}$ \\
\hline Facilities & $\begin{array}{l}\text { The distance of key facilities such as shops, } \\
\text { schools, health care, or leisure services from } \\
\text { where a person lives prevents their access. }\end{array}$ \\
\hline Economic & $\begin{array}{l}\text { The cost of the use of transportation can prevent } \\
\text { its use and impact access to facilities or } \\
\text { employment - and impact income. }\end{array}$ \\
\hline Time & $\begin{array}{l}\text { Other demands on time like childcare and } \\
\text { household maintenance reduces the time available } \\
\text { for travel. }\end{array}$ \\
\hline Fear & $\begin{array}{l}\text { Fear for personal safety prevents use of public } \\
\text { spaces and/or transport services. }\end{array}$ \\
\hline Space & $\begin{array}{l}\text { Where security or space management prevent } \\
\text { certain groups from accessing public spaces. }\end{array}$ \\
\hline Social Networks & $\begin{array}{l}\text { Where denial of access to a social network } \\
\text { prevents use of transportation, or the lack of } \\
\text { transportation prevents use of social networks. }\end{array}$ \\
\hline
\end{tabular}

Adapted from Church et al. (2000), Kenyon et al. (2002), Lucas (2012, pg. 108)

While social reproduction and social exclusion theorists do not really talk to one another, they are very much linked together. Both are concerned with the ability to conduct life's daily maintenance. What is notably absent from these theories is something prevalent in poverty theory which tends to assign personal blame on the choices people make. 
Instead, both theories focus on the power relationships between individuals and governmental and powerful private actors that suppress individual agency in where lowincome people can live, how they can get around, and where they can go for their daily life maintenance.

Social exclusion theory has shifted almost fully to researching transport disadvantage leading to social exclusion due to the interlinking nature of transport in dimensions of social exclusion. The rest of this literature review focuses issues of transportation, housing, and poverty and racism to further explain the problems facing Black families along the lines of social reproduction and social exclusion.

\section{Transportation and Black Disadvantage}

Transportation is a critical tool in conducting life's daily maintenance. However, access to transportation and what it can provide tends to be dependent upon race, income, and geography. This section covers the transportation trends among Black populations in the U.S. through studies on mode choice and access, and the impact of geography and income on choice and access.

\section{Mode Choice}

How someone gets around affects multiple aspects of their life. Mode choice affects household transportation expenditures, the amount of time they spend getting around each day, and the places they can feasibly get to. Where someone lives also affects the modes of transport available to them. Transit does not run everywhere. Nor do people feel safe walking in any environment. Given the level of disadvantage facing low-income Black populations based on where they can live and the resources available to them, mode choice has a drastic impact on their life outcomes. 
While the volume of research on how low-income Black populations get around would suggest they primarily use transit, they are more likely to drive than take transit just like every other demographic group (Clifton, 2004; Giuliano, 2005; Spears et al., 2013). Their use of transit is much higher than other groups though, and that leaves them especially exposed to a high level of disadvantage in how they get around.

Because segregation has substantially restricted where Black populations live in most U.S. cities, it has also limited their access to jobs (Ihlanfeldt \& Sjoquist, 1998; Kain, 1968) and shopping (Alwitt \& Donley, 1997; Chung \& Myers, 1999; Jeong \& Liu, 2019) in such neighborhoods. This means low-income Black populations living in historically segregated neighborhoods tend to have to travel further in order to reach basic goods and services. Those bound to transit tended to struggle to reach such destinations outside of their neighborhood (Clifton, 2004; Walker et al., 2010). Driving allowed people to access many more places with ease, and with that option available they would travel the extra distance rather than shop close (Bader et al., 2010; Clifton, 2004).

Mode choice has been heavily studied for whether neighborhood context affects how people get around. Generally, density matters, with densities at the destination having the most influence on whether someone drives or takes transit (Ewing \& Cervero, 2010). But many studies were problematized by issues of self-selection (Cao, 2015; Handy et al., 2006). And very few studies on neighborhood context and mode choice took into account race and income. For low-income Black populations, self-selection into a neighborhood has a wholly different meaning given their limited scope of choice in housing. 
Mode choice presented many difficulties for poor mothers too. Mothers still conduct the majority of domestic and childcare duties in the home, which also extends to their travel needs. In addition to transit being slower and reaching fewer destinations, women report heightened concerns for their safety on transit (Loukaitou-Sideris \& Fink, 2009; Yavuz \& Welch, 2010). Those concerns became heightened when chauffeuring their kids on transit (Loukaitou-Sideris, 2014; Lubitow et al., 2017). Transit was also not always accommodating to mothers having to bring along their children or push them in a stroller (McLaren, 2016). TriMet, the transit agency in Portland, Oregon, only began exploring a change in their stroller policy in 2020 so mothers would no longer have to fold up their stroller before getting on the bus. This particular issue creates many issues as mothers generally carry a lot of things with them when out with young children. Then to get on the bus they are required to remove their child from their stroller, fold up the stroller, get on the bus, pay for fare, sit down, and secure their child all before a bus driver pulls away from the stop. As McLaren (2016) showed, it was not uncommon for driver to pull away from the stop before a mother could secure their child resulting in their kid falling down or worse.

While car ownership greatly increases the accessibility of multiple realms of a person's life, they remain very costly. Car ownership can be especially costly for poor people as the cars they can purchase are typically older, prone to break down, and have lower gas mileage (Blumenberg \& Manville, 2004). That does not take away the issue of transit also being a costly way for the poor to get around (Agrawal et al., 2011; Lubitow et al., 2017). Bus riders can save money in most transit systems by purchasing a monthly 
pass, but that tends to be a hefty outlay at the beginning of the month, which most poor households cannot afford (Agrawal et al., 2011; Edin \& Lein, 1997; Lubitow et al., 2017).

Access

Part of the pattern of Black disadvantage is the difficulty of social reproduction due to the lack of places in which to get basic necessities or services. Research has consistently found that poor and predominantly Black neighborhoods had fewer retail and food establishments, and those they did have were of smaller size (Alwitt \& Donley, 1997; Meltzer \& Schuetz, 2012). Smaller stores typically meant higher prices as those store owners do not have economies of scale that lead to lower overhead costs and they tend to carry fewer store brand items that have lower prices. Alwitt and Donley (1997) looked at Chicago retail in poor neighborhoods and found high-income neighborhoods had nearly twice as many retail establishments as poor neighborhoods. The differential was especially prevalent among large grocery stores and supermarkets, large drug stores, banks, and liquor stores. Alwitt and Donley (1997) also found that to have the comparable number of establishments, residents of poor neighborhoods would have to travel over two miles outside their neighborhood for most retail and food establishments. They would have to travel over three miles for a comparable number of supermarkets, large grocery stores, and large drug stores. Melzer and Schuetz (2012) found similar results in New York. Their analysis also looked into the "healthiness" of food establishments and found poor and Black neighborhoods had the highest numbers of "unhealthy" establishments compared to White and Hispanic neighborhoods. Residents of Black neighborhoods also lived the furthest away from retail and had less diversity of options. While the distance was not huge (over $90 \%$ of residents in their study lived less than $1 / 4$ of a mile from a retail corridor), it 
was significantly different than the distances of Hispanic and White neighborhoods. Lower diversity of retail establishments results in lower choice in where to shop, possibly having to leave the neighborhood to find particular goods they want, and likely higher prices due to the lower amount of competition.

Beyond retail in general, many more researchers have focused specifically on grocery store access. This is due to the critical nature grocery stores play in survival and the diverse nature of types of stores, locations, prices, product availability, and its impacts on accessibility, family budgets, and healthy food availability. Chung and Myers (1999) found that poor neighborhoods had fewer chain groceries overall in Minneapolis, and that implicated the prices of available foods in poor neighborhoods as non-chain grocers charged much higher prices, around $\$ 16$ more per week for the same food. While the food stamp program has changed since they conducted their study and inflation has affected prices, that $\$ 16$ per week makes a huge difference considering the average SNAP (Supplemental Nutrition Assistance Program) household received \$256 per month in 2018 (CBPP, 2019). A quarter of their SNAP allowance could be taken just based on where they shop. Research has been consistent in finding a lack of chain grocers in Black and poor neighborhoods (Alwitt \& Donley, 1997; Chung \& Myers, 1999; Grengs, 2001; Jeong \& Liu, 2019; Kolak et al., 2018; Walker et al., 2010).

Transportation related to food access has received relatively less attention. McKenzie (2014) in a study of supermarket access in Portland, Oregon, found that people in inner high-poverty neighborhoods had the best access to supermarkets by transit while high-poverty outer neighborhoods (defined as more than five miles from the central core), 
were at the most disadvantage in accessing supermarkets by transit. In many studies, Black people were at a disadvantage in regards to access to supermarkets, with Black neighborhoods having either less access to stores when factoring in car ownership (Bader et al., 2010) or access to transit that connects to supermarkets (Grengs, 2001). Clifton (2004) in interviews with persons receiving WIC in Austin found most her participants had access to cars. They cited having a car as providing greater flexibility through timing and locations they could shop from, saving money on food, finding better quality food, and ease of carrying food back home. Clifton further found that reliance on cars often came with a need to develop secondary mobility strategies, typically in the form of getting rides or using transit. Most car owners chose to take transit if their car broke down, while getting rides was the most common strategy for those in zero-car households.

\section{Employment and Mobility}

One of the most notorious lines of research on employment and mobility is in the spatial mismatch hypothesis. The spatial mismatch hypothesis has been around for over 50 years when Kain (1968) suggested that segregation of Black populations coupled with job suburbanization created a spatial mismatch in which Black populations struggled to get jobs. Since he first brought up the idea of the spatial mismatch, there have been hundreds of studies on the theory. While a majority of the studies found support for the hypothesis, there are massive inconsistencies in how it was identified and the effect its existence (Blumenberg, 2004; Hu, 2015; Ihlanfeldt \& Sjoquist, 1998).

As low-income Black populations increasingly suburbanize, the spatial mismatch theory gets challenged even more. If low-income Black populations and jobs are 
suburbanized, does the hypothesis still work? Kneebone and Berube (2013) believed the hypothesis did still stand just in a different context. In their study of multiple regions across the U.S., they found that, on average, there was still a spatial mismatch as poverty populations and jobs were not locating in the same suburbs. And the lack of suburb-tosuburb transit in most regions made the mismatch potentially worse. Hu (2015), in a study of Los Angeles found that the inner-city poor had better job access than the suburban poor, but the suburbs were also very uneven in their quality of job access. However, their study was only testing job access by car. Poor populations with cars were much more likely to have a job (Blumenberg \& Hess, 2003; Gurley \& Bruce, 2005; Smart \& Klein, 2018), but car ownership typically came after someone got a job (Blumenberg \& Manville, 2004). Thus, to properly test the hypothesis, it should at least also test job accessibility by transit. Transportation barriers have a distinct effect on employment for people living in poverty. Blumenberg (2002) found that barriers to employment for people on welfare were compounded for each additional barrier a person had. The most significant employment barriers they found were low education level, caring for young children, and relying on transit. While their study did not conduct their analysis by race, other research suggested each of those barriers was more likely to occur with a Black woman than nearly any other demographic group (D. S. Massey, 2007). Thus, it could be expected that Black women would face the largest barriers to employment, especially when reliant on transit. As Smart and Klein (2018) found, only in cases with truly exceptional transit access does transit outweigh the benefits of car ownership on employment and earnings. And segregated neighborhoods rarely came with exceptional transit service. 


\section{Neighborhood and Black Disadvantage}

Where someone lives has a distinct effect on multiple life outcomes and the ability to overcome disadvantage. This is largely due to the ongoing segregation in U.S. cities by both income and race. In this section, I cover where low-income Black populations are tending to live and how that affects them in their ability to socially reproduce.

\section{Segregation and Dispersal Policies}

Segregation has disastrous consequences for residents living in segregated neighborhoods, especially following the 1960s. As economic downturns hurt the country as a whole, segregated neighborhoods were hit the hardest. On top of decades of concentrated poverty, developing public housing almost exclusively in segregated neighborhoods, massive disinvestment, and skyrocketing crime rates, segregated neighborhoods only got worse during the downturns of the 1970's as fewer people were able to find jobs and pathways out of poverty (Goetz \& Chapple, 2010; D. Massey \& Denton, 1993; Wilson, 1987). Following the passage of the Civil Rights Act and the Fair Housing Act in 1968, residents of segregated neighborhoods sought court ordered relief of the ills caused by segregation, many of which were being furthered by local housing authorities continuing to build public housing only in neighborhoods already inundated with public housing. Thus, began an era of dispersal policies that continue to this day.

The goal with dispersion from both the policy perspective and those that live in poverty was to provide people in poverty a better chance at life than living in a neighborhood of concentrated poverty would provide (Goetz \& Chapple, 2010). From the policy perspective though, the goals were typically more expansive. Neighborhoods of 
concentrated poverty tended to take massive amounts of money to turn around if they could be turned around at all through social policies (Crump, 2002). Additionally, high-poverty neighborhoods were seen as eyesores that stained the city's image and needed to have the poor removed in order to rehab the neighborhoods, which was aided by many of those neighborhoods being in highly desirable (if not for all the poor people) areas adjacent or near downtowns (Crump, 2002; Goetz, 2003).

One way cities moved the poor out of neighborhoods of concentrated poverty was through housing mobility programs. Since the 1970 's, several cities instituted housing mobility programs with the intention of dispersing poverty, and in particular Black poverty. Gautreaux, named after the plaintiff in a fair housing lawsuit against the Chicago Housing Authority (CHA) and the U.S. Department of Housing and Urban Development (HUD), was the first housing mobility program developed. Through a settlement in 1976, the court ordered CHA and HUD to make Section 8 housing vouchers available to former and current CHA residents only for use in neighborhoods where less than $30 \%$ of the population was Black. The program continued until 1998. Section 8 vouchers allowed residents to rent market-rate housing while only paying $30 \%$ of their income toward rent (notably, for most, this would be a substantial increase in rent over public housing). Most subsequent mobility programs operated similarly with distinctions based on what was considered a "good" versus "bad" neighborhood along the lines of race and poverty. The goal of the housing mobility programs such as Gautreaux, Moving to Opportunity (MTO), and Gautreaux Two was to disperse the poor and Black populations from their neighborhoods that were over represented in poverty and Black populations (referred to as disadvantaged neighborhoods) 
to neighborhoods thought to be of higher advantage or opportunity where poverty rates were lower and the population was mostly White (Boyd et al., 2010; Clampet-Lundquist \& Massey, 2008; Popkin et al., 2000).

Unlike many of the past housing mobility programs, Baltimore attempted something different with the Baltimore Mobility Program. In 2002, Baltimore began a housing mobility program that focused on services tied to ensuring housing stability. It covered rents that were up to $120 \%$ of fair market value, provided security deposit assistance, provided assistance to purchase a car, and vouchers were more flexible in crossing jurisdictional boundaries in the metropolitan area. Each household that opted to move received housing counseling to find them an appropriate place to live and help them adjust to life in that new area along with follow-up visits for two years to ensure everything was going well (Darrah \& DeLuca, 2014).

Housing mobility programs had a lot of mixed outcomes for households. Most residents that moved through those programs ended up back in low-opportunity neighborhoods within a few years (Boyd et al., 2010; Goetz, 2010; Sanbonmatsu et al., 2011). Pashup, Edin, Duncan, \& Burke (2005), in looking at why people moved back to low-opportunity neighborhoods, found that a lack of counseling services made it difficult to overcome the hurdles of learning to live in a new area or continue to find qualifying units for their Section 8 voucher. Housing issues topped the reasons of why people moved back, but that was closely followed by feelings of social isolation (Boyd et al., 2010). Kleit and Manzo (2006) found similar results from residents deciding whether to move when a HOPE VI project threatened their homes. However, the MTO program movers mostly 
faulted housing problems for why they moved back to low-opportunity neighborhoods (Briggs et al., 2010; Rosenblatt \& DeLuca, 2012). For the Baltimore Mobility Program, residents were more likely to stay in their high-opportunity neighborhood (Darrah \& DeLuca, 2014). The counseling services helped them overcome fears of getting around in the suburbs and it connected them to social services to make up for gaps in their needs that may be lost by moving away from their social support networks. But, Darrah \& DeLuca's study did not go into what tradeoffs households made in order to make their new suburban life work, especially in terms of transportation.

Alongside the housing mobility programs, HOPE VI was started in the 1990s as an effort to rehabilitate old and deteriorating public housing projects while keeping to a goal of dispersing those living in poverty. Most HOPE VI projects resulted in far fewer public housing units than existed before with market rate housing taking the place of those lost units (Goetz, 2003). Those displaced by a HOPE VI project were often given Section 8 vouchers to move elsewhere with the opportunity to move back when the project was completed. So, like the housing mobility programs, HOPE VI residents were displaced, but often with fewer programmatic elements dictating where they moved.

Unlike housing mobility programs though, the social support networks of movers from HOPE VI showed more deterioration. Buron et al. (2002) found that movers from HOPE VI projects were less likely to develop new social networks in their new neighborhood. Thus, they were more likely to lose their proximate source of social support by moving. In Philadelphia, Clampet-Lundquist (2004) found that HOPE VI movers were less likely to move to the suburbs because of the loss of close family and easy access to 
shopping and amenities. In Portland, there was a strong association between access to transit and having a strong social support network in whether movers felt they were adjusting well to their new home (Gibson, 2007b). In comparing MTO, HOPE VI, and regular movers, (Kissane \& Clampet-Lundquist, 2012) found that all movers did not seem to lose social ties and most were maintaining ties from their previous neighborhood. Alternatively, some movers did find relief in moving away from the pressures of their support networks.

Housing mobility programs and HOPE VI were state-sponsored acts to disperse poverty. However, less evidence exists for understanding dispersal through private action, such as when a landlord evicts and entire building to hike the rents or redevelop it. The evidence from state-sponsored dispersal programs showed that people unwillingly displaced from their neighborhoods of long-standing faced much higher hurdles to success in their lives even if some aspects of it may improve (Goetz, 2010). However, when private actors disperse poor populations, those households won't receive a Section 8 voucher that helps them afford housing somewhere else. And in the context of gentrification, the people displaced are likely moving from an area of new and possibly high-opportunity to one likely of lesser opportunity, which was opposite to the effect garnered from housing mobility programs.

\section{Social Support Networks and Coping with Poverty}

The difficulty of living in poverty means grasping for any possible way to continue surviving. For some low-income households the process of obtaining public benefits is too burdensome to bother doing (Lein et al., 2007). For others, public benefits help, but the 
inadequacy of the benefits requires households to develop strategies of conservation, selfsufficiency, and leveraging resources from their social support network among many other strategies to ensure they meet their daily needs (Edin \& Lein, 1997; Lein et al., 2007; Shipler, 2004; Shulman, 2003). Their social support networks tend to be the strongest means they have for survival even if they do not necessarily give them the leg up they need to get out of poverty (Halpern-Meekin et al., 2014). The help they seek from their networks comes in many forms not limited to food, childcare, cash, getting rides, and just having someone to talk to (Halpern-Meekin et al., 2014; Roschelle, 1997).

While most poor households employed strategies of some sort to cope with their lack of resources, some households were able to fare better than others by utilizing a strong social support network (Edin \& Lein, 1997; González de la Rocha, 1994; Lein \& Sussman, 1983; Stack, 1975). For instance, Turney and Harknett (2010) found that Black women in disadvantaged neighborhoods were more likely to get help from their networks than Black women in advantaged neighborhoods. That was generally because they remained close to their networks of support if they stayed in the disadvantaged neighborhood. And Black women that moved to advantaged neighborhoods often did not form new relationships of support in their new neighborhoods (Goetz, 2010; Kissane \& Clampet-Lundquist, 2012). For those that became detached from their social support networks, especially family members, they tended to struggled (Edin \& Lein, 1997; González de la Rocha, 1994; Roschelle, 1997; Stack, 1975). Evidence from dispersal programs supported that notion through the number of households that moved back to high-poverty neighborhoods nearer to their support networks (Goetz, 2010; Jeon, 2019; Kissane \& Clampet-Lundquist, 2012). 
They could only make help from their support network go so far though. Social support networks among poor households tended to be unreliable (Halpern-Meekin et al., 2014). When everyone was struggling to get by, there was only so much to go around (Heflin et al., 2011). As such, poor households tapped into other strategies to make ends meet. Their strategies revolved around ways to save money rather than cutting back entirely on something. For many low-income mothers, saving money took the form of cutting coupons, seeking out informal services, or transitioning to alternatives of something (e.g. eating ramen noodles instead of ground beef) (Heflin et al., 2011). However, sometimes that was not enough. In leaner times, low-income mothers would cut out phone or cable or something else seen as less necessary (Edin \& Lein, 1997; Heflin et al., 2011). Sometimes their strategies had to dig deeper such as cutting back on food, letting utilities get shut off, or delaying big purchases or fixes for as long as possible (Edin \& Lein, 1997; Halpern-Meekin et al., 2014; Heflin et al., 2011).

While research on strategies to cope with material hardship is limited, it is rarer to find research on strategies to cope with transportation disadvantage. Edin and Lein (1997) and Stack (1975) had limited tidbits about how families both mitigated transport disadvantage and utilized transport to mitigate other needs. Their findings showed that lowincome mothers would walk to avoid the cost of the bus or a taxi, but taxis were also used often in order to get back from the grocery store or to make appointments quickly. Clifton (2004) similarly found use of taxis was important to overcome transport disadvantages when it came to grocery shopping. Aside from trying to limit travel, poor households 
tended to rely on their social support networks a lot for rides (Agrawal et al., 2011; Edin \& Lein, 1997; Roschelle, 1997; Stack, 1975).

Agrawal et al. (2011) had the most thorough examination of transport strategies among the poor. In their study, they identified four primary categories in which people would manage their transportation expenses: modifications to travel behavior, creative cost-covering, careful management of expenditures, and reductions in non-transportation spending so more money could be spent on transportation. Among the strategies people used, they found that households would cut back on travel in order to afford a better mode such as owning a car or taking a taxi. People would also choose to go to places closer to home in order to save time and avoid having to take transit. Utilizing their support network was also among the top ways people got around. Like mitigating other hardships, people also cut back in other areas of their life like entertainment and food in order to continue affording transportation.

There is clearly a need for much more study in the area of hardship mitigation in the lives of the poor. It is especially needed in transportation research. What was notably absent in most studies around hardship mitigation was analysis along racial lines. Given past research from Roschelle (1997), there were clear differences in how social networks were utilized based on race. How much that factors into the strategies people use to make ends meet, especially since the changes to the welfare system since Edin and Lein (1997) and Roschelle (1997) conducted their studies is still largely unknown.

The next chapter looks at Portland, Oregon as a case study site for exploring the issues discussed in this review of the literature. I discuss the history of Portland and its 
Black population in relation to housing segregation, gentrification, and suburbanization of Black poverty. Using that history, I set up the case for why Portland is the ideal place for this study. 


\section{Chapter 3 Portland}

Portland presents one of the few cities in the country in which to study the questions posed here. Rising housing prices and the gentrification of the historically Black area of the city, has displaced many Black residents to outer portions of the city where housing is cheaper, explained further later. Additionally, Portland has been well recognized for its bike culture, its growing array of carsharing programs. Such options make living without a car possible for many households, but the options are not universally distributed throughout the city. This study focuses on two areas of Portland: the Albina District (hereto referred to as Albina for brevity) and East Portland which is defined here as the area east of $82^{\text {nd }}$ Avenue to approximately the Gresham border. While not traditionally thought of as suburban, the area east of $82^{\text {nd }}$ Ave. was a non-incorporated part of Multnomah County that the city annexed over time between 1980 and 2000 (City of Portland, 2014). As such, this study will recognize the annexed area east of $82^{\text {nd }}$ Avenue as suburban. The following section describes the state of Black population in Albina and East Portland, the two study sites for this research. 


\section{Figure 3-1 Portland}

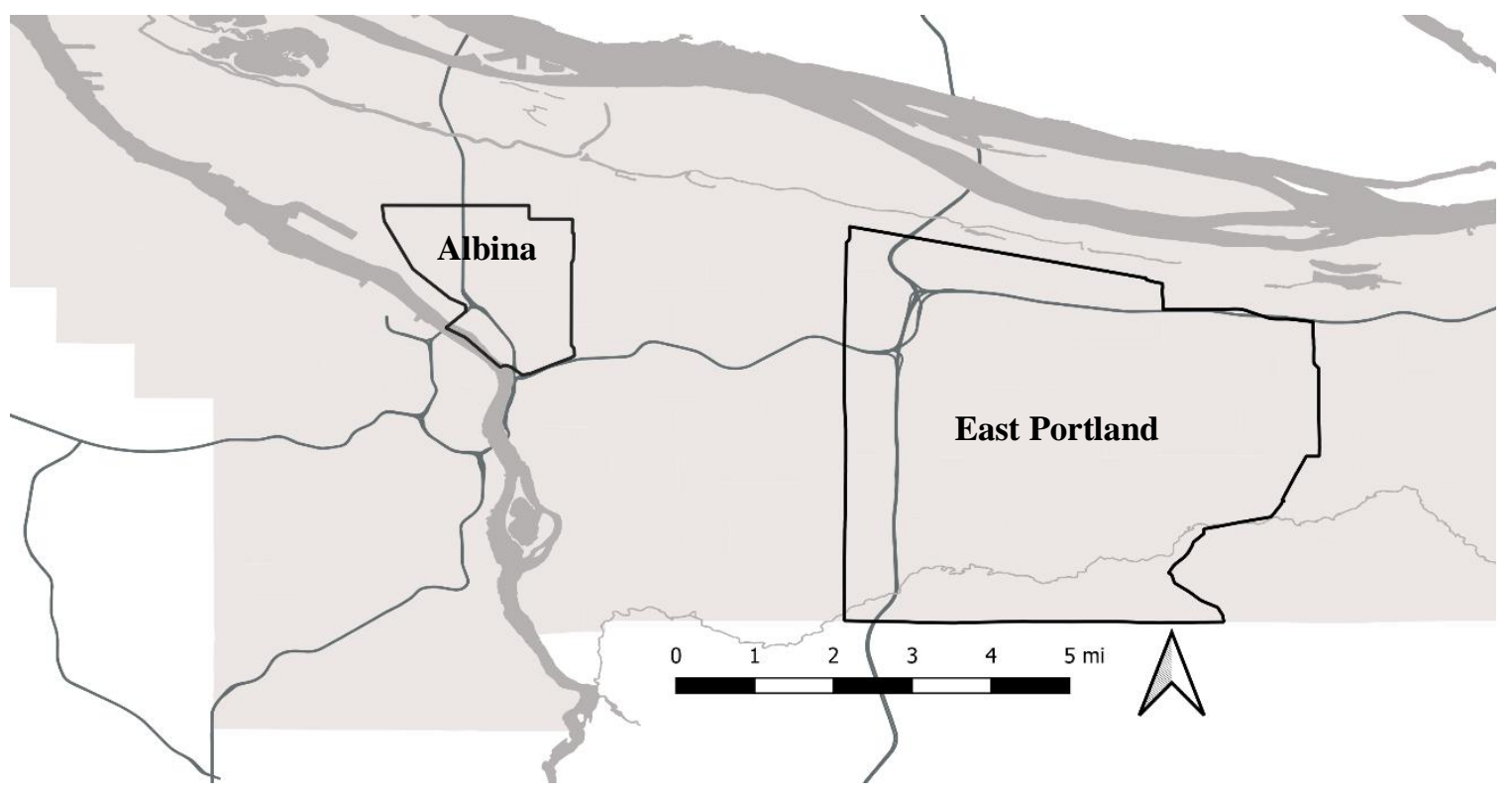

\section{Albina and Gentrification}

Portland's Black population has been historically confined to the area in north and northeast Portland known as Albina (Gibson, 2007a). There are some variations in how to geographically define Albina. For this study, I defined it as roughly the area from the Willamette River to the west, $15^{\text {th }}$ Ave to the east, I-84 to the south, and Rosa Parks to the north (See Figure 3-1). Like other historically racially segregated inner-city areas across the U.S., Albina faced its own share of problems from drugs, gangs, and widespread disinvestment from the 1960 's to the early 1990 's. Since then, the area has seen rapid reinvestment, an influx of higher income Whites, a dispersal of Black and low-income populations, and less crime (Coalition for a Livable Future, 2014; Gibson, 2007a). 
Before Albina became gentrified, it faced multiple government and private pressures to "fix" the blight ${ }^{1}$. Urban renewal destroyed over a thousand homes along with commercial structures that were the heart of Black commerce in Albina in order to build highways, clear land for an expansion of Emmanuel Hospital that never happened, and build a sports arena (the Memorial Coliseum). The White population of Albina declined substantially as Black households moved into other areas of the district after their homes were destroyed by urban renewal. Simultaneous to urban renewal, racism was preventing Black populations from getting work in a weak labor market, and banks were refusing to provide them with credit for home purchases or renovations. This sent Albina into a tail spin of decline as homes fell into disrepair and eventual abandonment. During the 1980's, Albina, like many other historically segregated areas across the U.S. was hit with the crack epidemic and gang violence.

With rising violence and declining living conditions through the community, Black households that could afford to move, did, leaving behind a community that was much poorer. In the 1990's, the rock bottom housing prices coupled with a renewed interest from city leaders and advocacy efforts from Black residents the area started to see White households return. However, the influx of White households to Albina brought housing prices up to a level that became unaffordable to the Black households still living in poverty. So started the next wave of Black households leaving Albina.

1 This history is a brief recounting of Karen Gibson's "Bleeding Albina: A History of Community Disinvestment, 1940-2000" which should be read for a full history of Albina's rise, fall, and early gentrification. 
Figure 3-2 Black Population Geographic Shift, 1990-2017

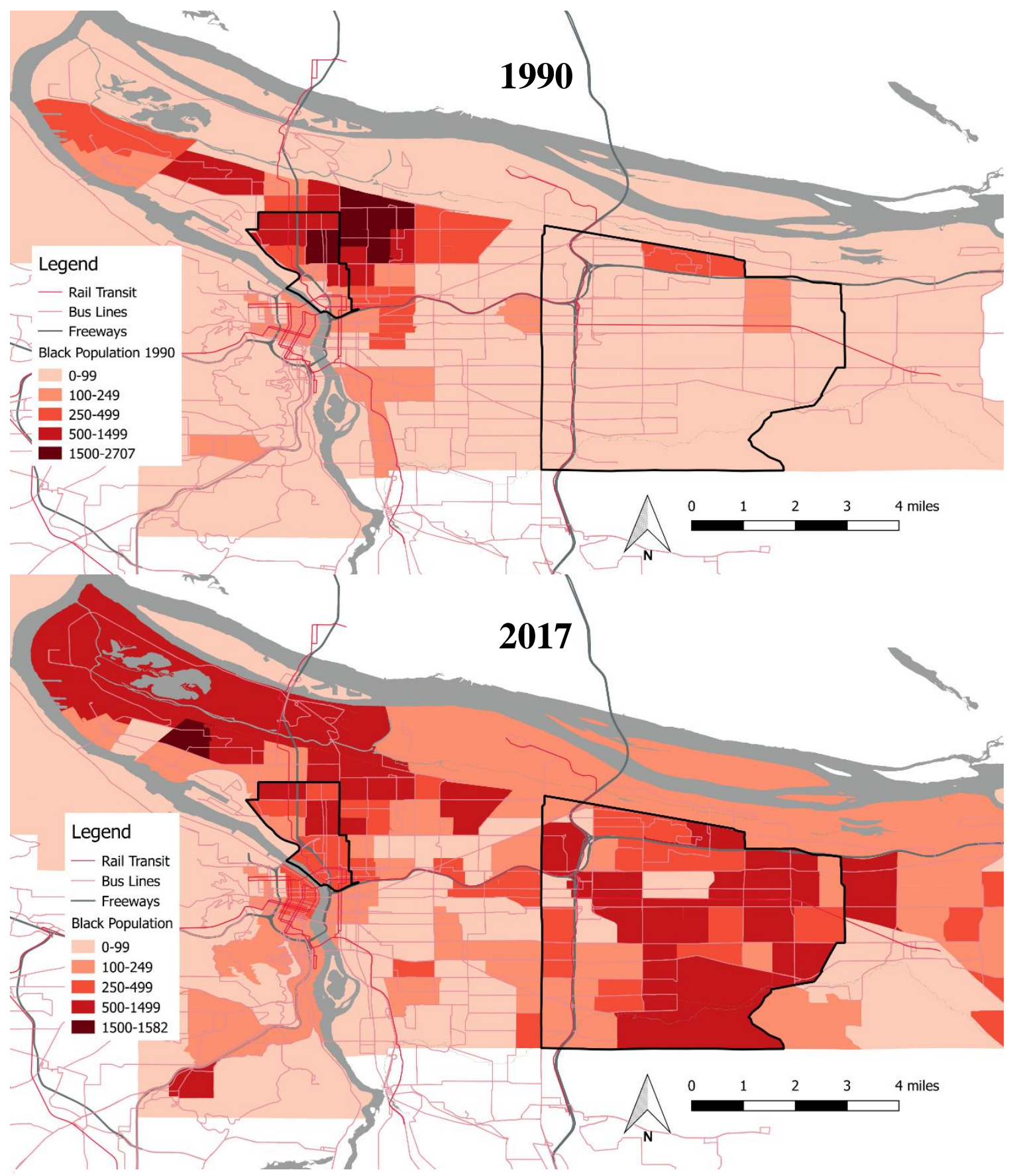

Source: IPUMS NHGIS, University of Minnesota, www.nhgis.org; U.S. Census Bureau Decennial Census, 1990; American Community Survey 5-year estimate 20132017 
Since 1990, Black households increasingly moved to neighborhoods east of $82^{\text {nd }}$ Avenue and to the eastern suburb of Gresham as increasing housing prices and redevelopment made Albina unaffordable to many low-income African-Americans along with price pressures extending to northern neighborhoods (Butz \& Zuberi, 2012; Coalition for a Livable Future, 2014; Gibson, 2007a). The shift in where the Black population lives in Portland is very evident when looking at Figure 3-2.

Figure 3-3 shows the percent change in the White, Black, and Total population of Albina, East Portland, and Multnomah County as a whole from 1990 to 2017. Given the transition to sample data for the 2017 data ( 2017 being the reference year used here to refer to the 5-year estimates provided by the American Community Survey for their 2013-2017 surveys), error bars were included in the graphic. However, the size of the increase of the Black population in East Portland suppressed the ability to view the margins of error of the estimated change in population. What is important to note is that the margin of error was much higher for the Black population than the other reference populations, but none of the errors were high enough to consider disqualifying the estimate.

Two major trends were going on in the Black population in Portland between 1990 and 2017: Albina was losing Black population at a rapid pace and East Portland was adding Black population at an even greater rate. Albina's Black population shrunk from 1990 when it held over $22 \%$ of the county Black population to less than $8 \%$ of the county Black population in 2017. In 1990 Albina was 38\% Black, but by 2017 it was less than 13\% 
Black. Meanwhile East Portland grew from 1.5\% Black to nearly 8\% Black in 2017. Although the proportion of Black persons living in East Portland was seemingly small, that growth in the Black population meant its share of the county's Black population increased from $6 \%$ to $38 \%$. East Portland's Black population grew nearly 8 -fold in this time period while Albina lost half its Black population (See Figure 3-3). While the Black population shifts were going on, Albina grew 31\% in total population, much of that growth coming from an influx of White households who nearly doubled in population in Albina, a classic signifier of gentrification (Freeman, 2006; Marcuse, 1986; Smith, 1996). 
Figure 3-3 Population Change by Race by Area 1990-2017

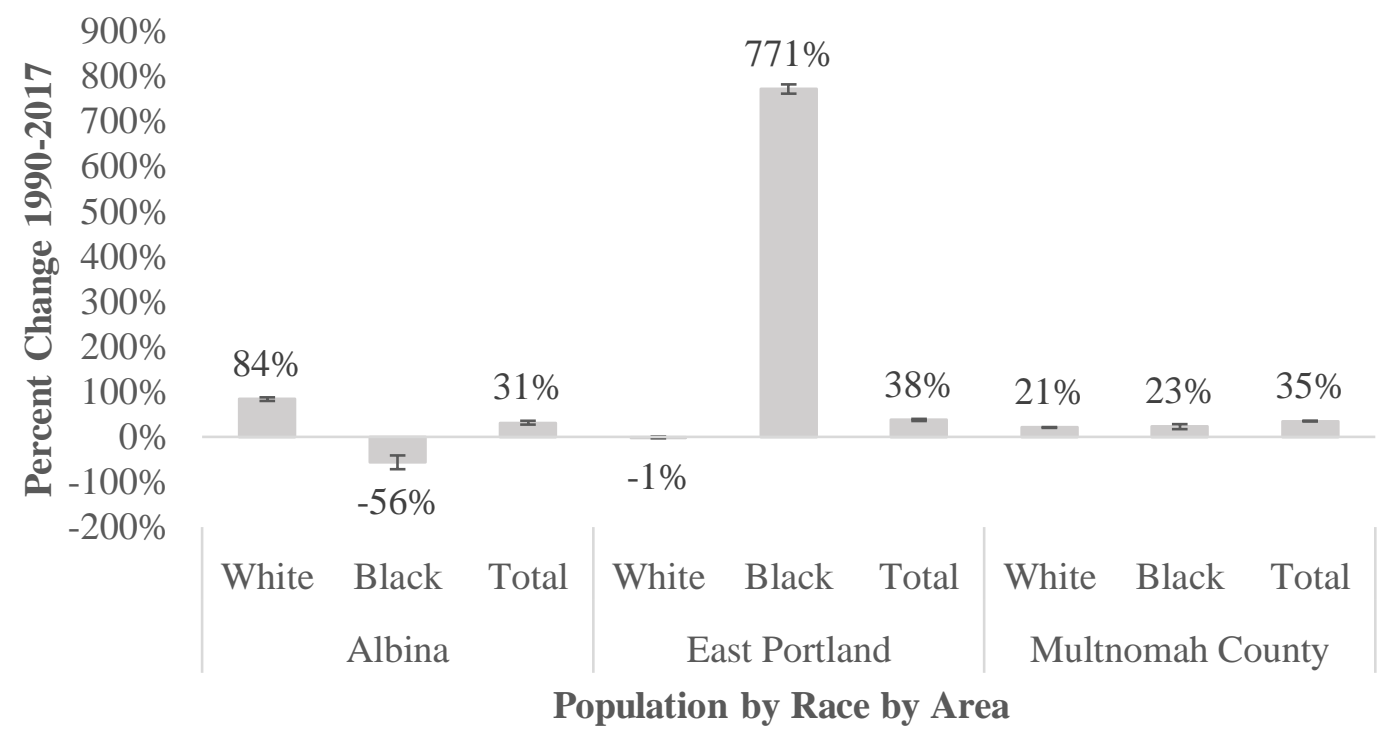

\begin{tabular}{lrr|rr|rr} 
& \multicolumn{2}{c|}{ Albina } & \multicolumn{2}{c|}{ East Portland } & \multicolumn{2}{c}{ Multnomah County } \\
& \multicolumn{1}{c}{1990} & \multicolumn{1}{c|}{2017} & \multicolumn{1}{c}{1990} & \multicolumn{1}{c}{2017} & \multicolumn{1}{c}{1990} & \multicolumn{1}{c}{2017} \\
\hline White & 11,299 & 20,756 & 139,151 & 137,762 & 507,890 & 613,778 \\
Black & 7,811 & 3,406 & 2,131 & 16,439 & 35,133 & 43,115 \\
Total & 20,662 & 27,170 & 151,225 & 208,039 & 583,887 & 788,459 \\
\hline
\end{tabular}

Source: IPUMS NHGIS, University of Minnesota, www.nhgis.org; U.S.

Census Bureau Decennial Census , 1990; American Community Survey 5-year estimate 2013-2017 
It was not just that Black people were being displaced from Albina, it appeared it was largely Black people living in poverty that were affected the most. I was not comfortable creating a map of poverty by race due to the high uncertainty of the data at the Census tract level (fewer than a quarter of the Census tracts in Multnomah County had confidence intervals on Black poverty estimates that did not straddle 0 ). But the view from Figure 3-4 suggested East Portland had become home to a near majority of the Black population living in poverty. In 1990, Albina contained $26 \%$ of the Black population living in poverty in the county while East Portland only contained 3\%. Albina also boasted a black poverty rate around double that in East Portland (36\% vs. 18\%). By 2017, those Figure 3-4 Percent Poverty within Race by Area, 2017

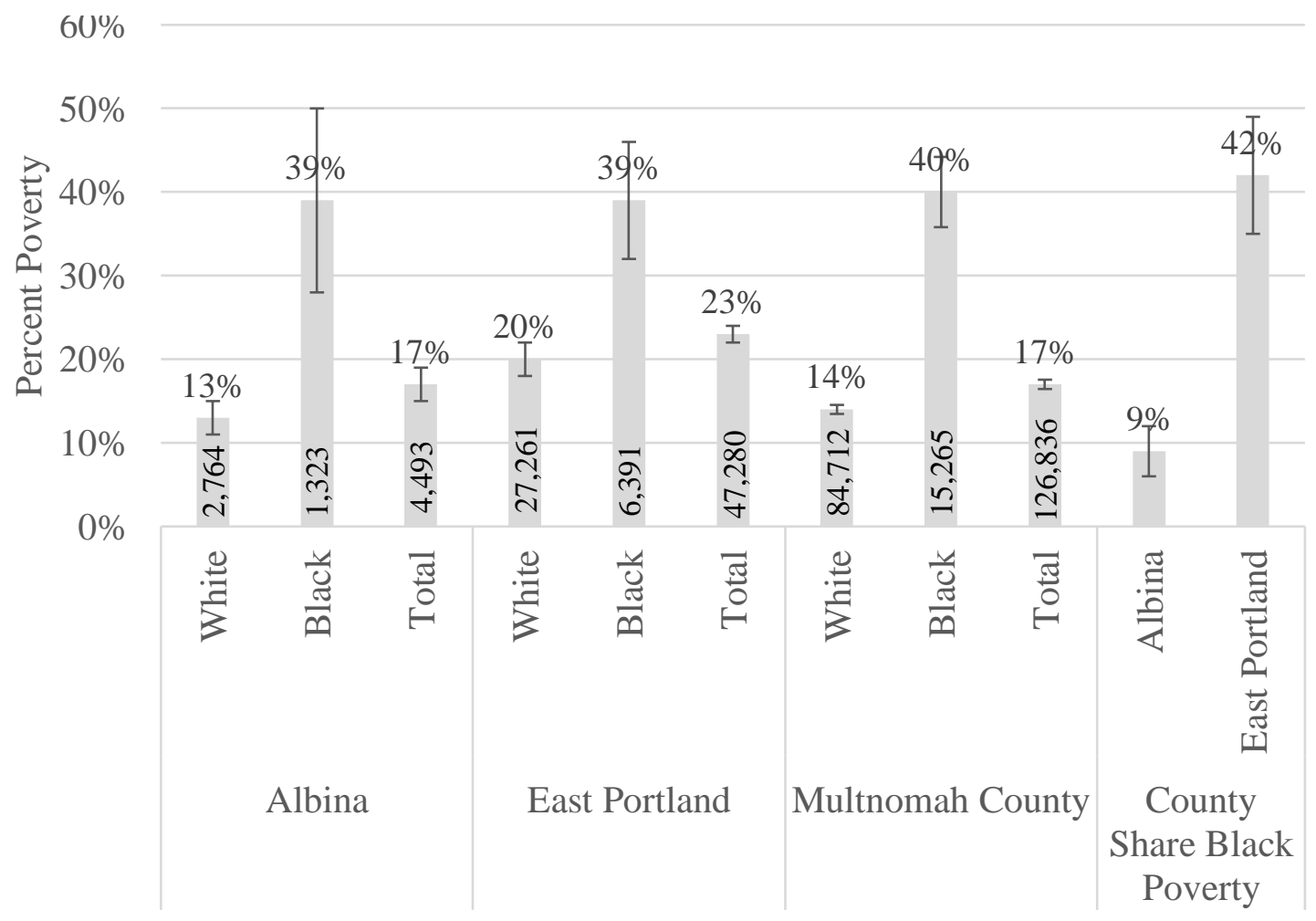

Source: IPUMS NHGIS, University of Minnesota, www.nhgis.org; American Community Survey 5-year Estimates 2013-2017 
numbers largely flipped between Albina and Portland. Gentrification has substantially shifted the Black poverty population around with East Portland absorbing a lot of the poor Black population needing a new place to live. Gentrification has not led to a class divide between Albina and East Portland with $39 \%$ of the Black population in both areas living in poverty. The biggest difference was just there were not that many Black people living in Albina anymore so the poverty does not stand out as much as it once did.

The growth of East Portland in both overall population and Black population coincided with the City of Portland annexing the area in multiple phases through the 1980s and 1990s (City of Portland, 2014). Given this was county territory before then, it did not have the same level of infrastructure investment as the rest of the City of Portland. The annexation of East Portland was agreed to by residents with the city promising large investments in infrastructure from sewer to roads and sidewalks and streetlighting among many other infrastructure needs. However, the only infrastructure investment that happened at a large-scale in the near-term with annexation was upgrading the sewer and water systems (Streckert, 2014). The reason this is all important to note is because populations in poverty, especially Black populations, tend to get around by transit. Without the necessary investments to make getting around feasible, the implications could be dire for the new-movers to East Portland.

\section{Commuting}

Figure 3-5 shows percent share of commute mode between Black and White populations at household incomes of less than $\$ 35,000, \$ 35-50,000$, and $\$ 50,000$ and more. Most apparent in the graph is the level of driving to work regardless of income. While low- 
income Black workers are less likely to drive to work than low-income White workers, the difference was fairly small ( $57 \%$ vs $61 \%$ ). Given the margins of error, it was not possible to say for certain whether there were statistically significant or even meaningful differences in share of people who drive. 
Figure 3-5 Commute Mode by Race and Household Income, Multnomah County 2017

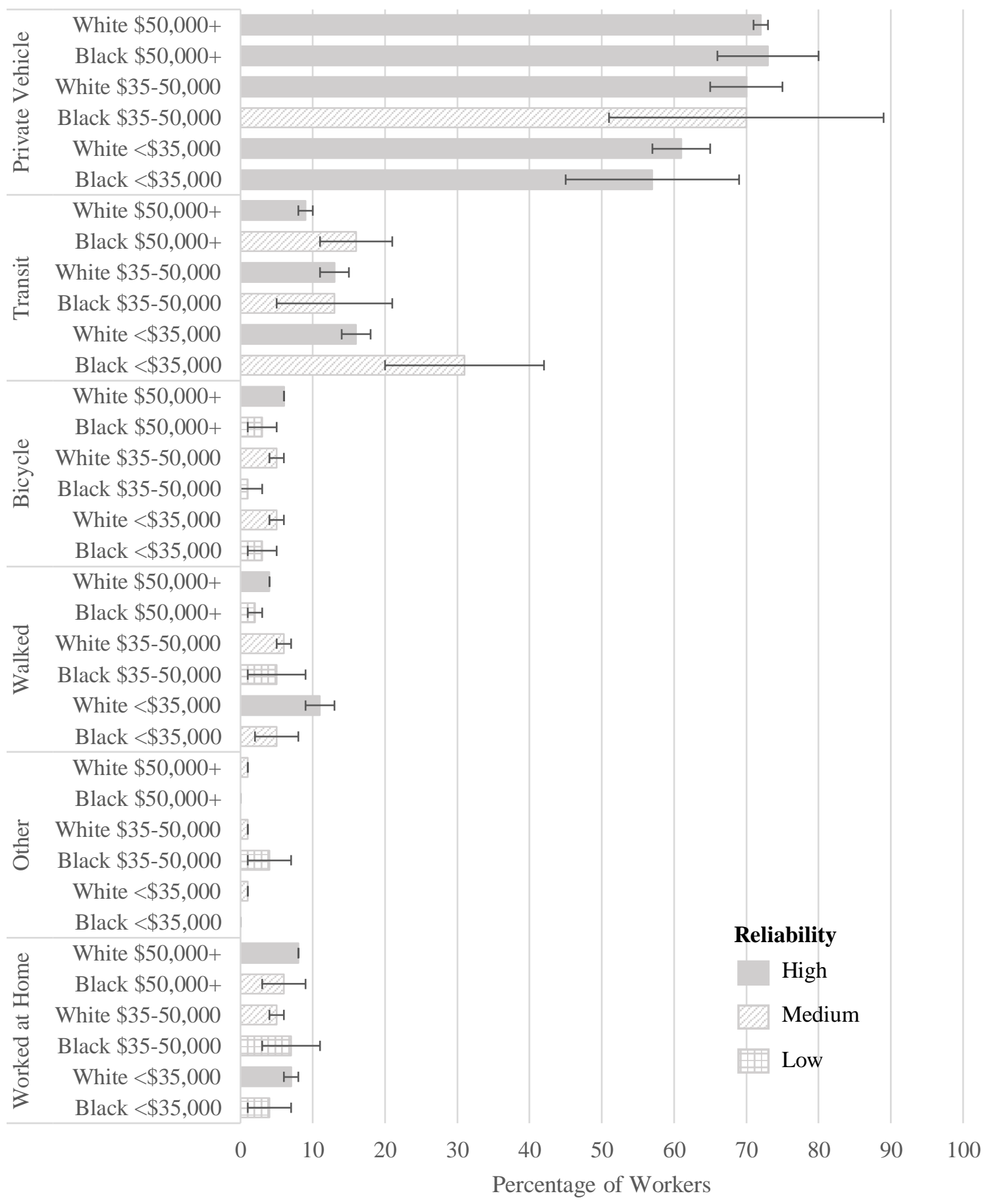

Note: Reliability is the coefficient of variation where Low $>=40+$, Medium 12-40, High $<=12$ (ESRI, 2014)

Source: IPUMS USA, University of Minnesota, www.ipums.org. ACS 2017, 5-year estimates 
Among the driving commute groups, low-income Black workers were least likely to drive, but the average estimate from the American Community survey still showed over half of them drove to work. High-income groups were the most likely driving commuters with not much difference in the share of White and Black commuters. Nearly three-quarters of them commuted by car compared to $57 \%$ for low-income Black commuters. Without factoring in the error, it would be easy to think the difference of driving between highincome White commuters and low-income Black commuters was a huge difference. The substantial amount of error, particularly for Black drivers, gave me hesitancy in taking that difference as fact.

Moving down Figure 3-5, the estimates from the American Community Survey got much less reliable. I expected to run into data reliability issues using the American Community Survey this way, but it was also the best data available. I stress the issue of the error in the data though because far too often the numbers are used and presented without consideration of the error (Jurjevich et al., 2018).

Based on Figure 3-5, low-income Black commuters were most likely to use transit. This follows national trends and was not much of a surprise. Again, the error leaves a lot of uncertainty in how big the share was and how different the share was between White and Black commuters. The very large difference between low-income Black and lowincome White transit commuters (31\% vs $16 \%)$ suggested that difference does actually exist. Having more accurate data would be very useful to better understand the differences between the groups. Following the Census Bureau's advice, the reliability problems in the data meant I did not conduct statistical tests to test the difference. While commuting data 
was also available through the Oregon Household Activity Survey, the data reliability of the survey for Black populations was exceptionally bad (Lubitow et al., 2019).

Surprisingly, the data reliability was not as terrible for looking at household vehicle availability by race and income. As such, the values presented in Table 3-1 were more trustworthy to take at face-value with consideration of the margin of error. Low-income Black populations were less likely to have a car in the household with around one-third of them living in no-car households compared to around one-quarter of low-income white populations. Low-income White households were much more likely to have two or more cars in the household. I was not certain as to what may drive this possibility, but it was likely due to the high share of low-income White populations living in the Portland area being college students. So, I was circumspect about their low-income status. Delving more into that question is beyond the scope of this research though.

Table 3-1 Vehicles Available in Household by Race and Income, Multnomah County 2017

HH Income $<\$ 35,000$

\begin{tabular}{lcccr}
\hline & No Car & One Car & 2+ Cars & Total \\
\hline Black & $33 \%( \pm 6 \%)$ & $52 \%( \pm 9 \%)$ & $15 \%( \pm 5 \%)$ & 18,662 \\
White & $23 \%( \pm 2 \%)$ & $48 \%( \pm 3 \%)$ & $29 \%( \pm 1 \%)$ & 120,973 \\
\hline
\end{tabular}

Total Population

\begin{tabular}{lcccr}
\hline & No Car & One Car & 2+ Cars & Total \\
\hline Black & $17 \%( \pm 3 \%)$ & $38 \%( \pm 5 \%)$ & $41 \%( \pm 4 \%)$ & 43,211 \\
White & $7 \%( \pm 0 \%)$ & $29 \%( \pm 1 \%)$ & $62 \%( \pm 1 \%)$ & 615,474 \\
\hline
\end{tabular}

Note: Percentages may not add to $100 \%$ due to missing values and rounding. Source: IPUMS USA, University of Minnesota, ACS 2017 5-year estimates.

Regardless of their household income, Black households were much more likely to live in no-car or one-car households compared to White populations. Still, over three- 
quarters of the Black population in Multnomah County lived in a household with at least one car. For poor households, one-third of poor Black households did not have a car compared to less than one-quarter of poor White households.

Given the level of error in the data for Black populations, I was unable to conduct these analyses geographically across the city. The ACS is a sample survey, and sampling small populations already creates data validity issues as seen in the above graphs. When those small populations are further split into smaller geographic units, the data is virtually unusable to say with any certainty whether any trends were real or an anomaly of the sample.

There is ample evidence that the built environment affects travel behavior (Handy, 1996; Handy et al., 2005; Zhang et al., 2012) and the built environment varies widely across a region. Beyond the built environment, logically it is difficult for someone to commute by transit when transit does not exist or exists in very limited capacity in an area. But with the data available, it is difficult if not impossible to look into geographic differences in travel behavior in Portland by race and income when using a secondary data source like the ACS.

\section{Transit and Pedestrian Infrastructure}

Among the areas the city neglected to invest in with its annexation of East Portland was transit. While the city does not directly control the transit agency, it has substantial influence on where new routes are placed and ensuring service is adequate for the population of the city. It was not until I started interviews for this study in 2017 that TriMet, the regional transit agency for Portland, announced new and better transit service coming 
to East Portland. Some of it had been in the works for quite some time with no real timeline on when improved service would arrive.

Figure 3-6 Transit Lines

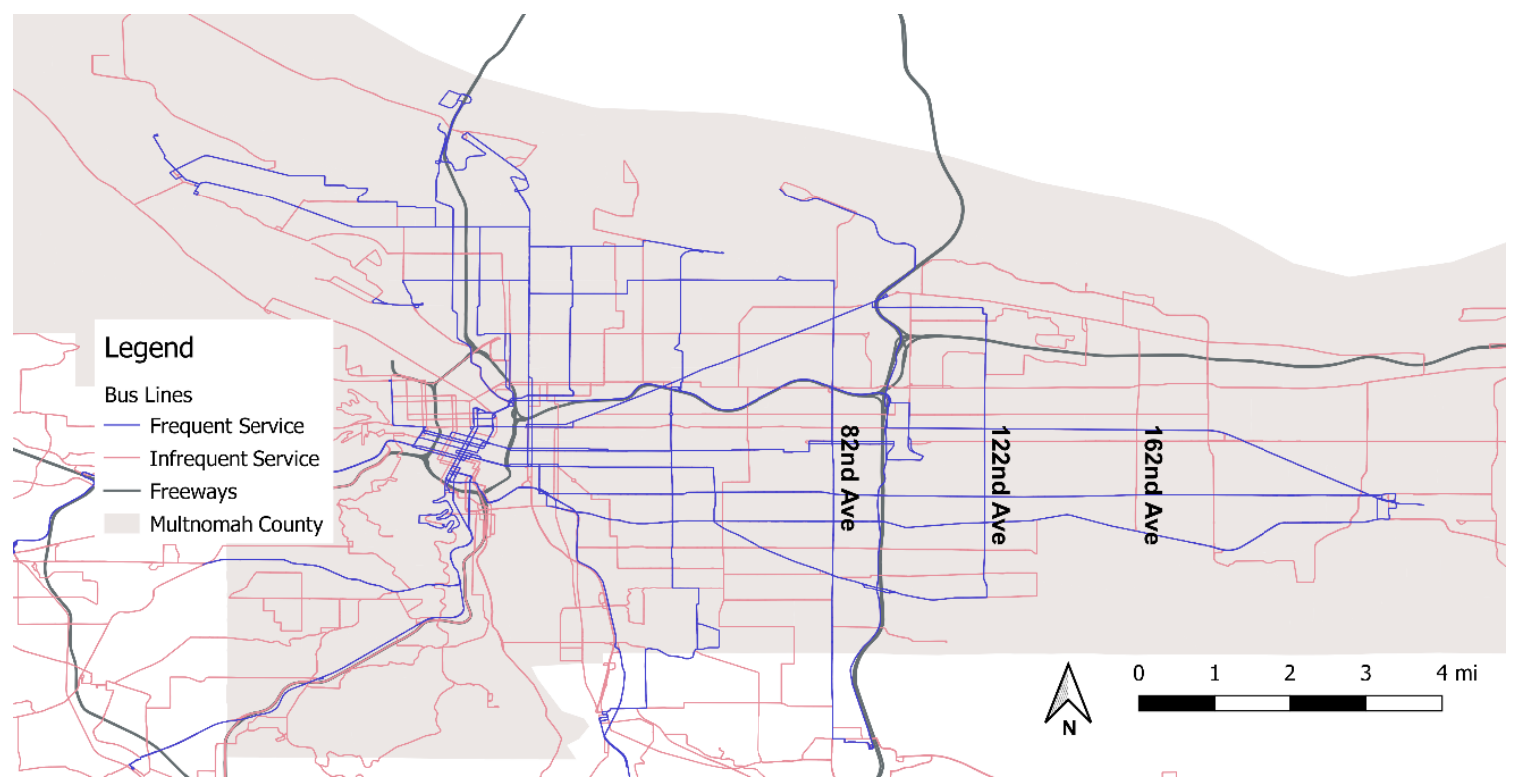

Figure 3-6 displays the transit options in Portland as of 2019 by transit line frequency. Lighter colored lines are infrequent service lines while darker lines are frequent service (defined by TriMet as vehicles arrive every 15 minutes for most of the day). TriMet's service includes a mix of bus lines and light-rail lines (MAX) as well as the streetcar. Between the time I started this study and 2019, TriMet added a bus line on $162^{\text {nd }}$ Ave and $181^{\text {st }}$ Ave and converted the $122^{\text {nd }}$ Ave line to frequent service. Thus, the situation in 2019 looked very different than when I was conducting interviews. Prior to the changes, very few high-frequency transit lines were available to low-income Black populations living east of $82^{\text {nd }}$ Ave, and those that were available only traveled east-west which made it particularly difficult to get around in East Portland. The high-frequency options that existed prior to the changes were the MAX Blue line light-rail route which traveled east- 
west between Hillsboro and Gresham and passed through Downtown Portland; a bus line on $82^{\text {nd }}$ Ave, which was the lone high frequency North-South bus line in East Portland on the western border of the study area; and a bus line on Powell/Division which traveled between Gresham and Downtown Portland. Meanwhile, Albina had more transit service, including three high-frequency bus lines and two light rail routes servicing four MAX lines. This service difference was especially stark considering Albina was nearly 10 times less in area than East Portland and contained about a quarter of its population.

As I was doing interviews in 2017, TriMet had already revealed they were adding the $162^{\text {nd }}$ Ave bus line, but the bus line did not start until about 6 months after my last interview was done. This allowed me to ask questions about people's knowledge about the line and whether they would use it, but not much beyond that. When it was announced, the proposed line's service hours were also much worse than what was actually implemented. The line currently has weekend service and runs until about 9pm whereas when it was proposed it was not expected to have weekend service or run past $6 \mathrm{pm}$. So, while I was able to get some data on the potential meaning of the bus line for folks, the relevance of the data was moderated by differences between what was proposed and implemented.

Although the non-frequent bus lines offer an improved level of service over having no service, non-frequent lines often have shorter schedules during the day, large headways (an hour or more between buses at points) during off-peak hours, and limited or no service on weekends. As such, relying on non-frequent transit lines can be an unaffordable burden for low-income populations. Even with the improved service in East Portland, the majority of the service available to people living there is through non-frequent routes. 
The impacts of poor transit service and the city's general lack of infrastructure investment is felt in part through the number of pedestrian deaths in East Portland compared to the rest of the city. In 2018, there were 34 traffic deaths in Portland and 23 of the deaths happened in East Portland (City of Portland, 2019a). Of those 23 that died on the roads of East Portland, 10 were pedestrians (out of 16 total pedestrian deaths in Portland that year). East Portland bore the overwhelming burden of road deaths in the city. Not a single road death happened in Albina in 2018 and since 2008 seven pedestrians have been killed by drivers.

Changes have been afoot for improving the pedestrian environment in East Portland. The East Portland Action Plan (EPAP), adopted in 2009 set in motion conversations and planning to improve the situation in East Portland. For instance, the East Portland in Motion Plan adopted in 2012, and a direct result of EPAP, had directed over \$200 million in investments in active transportation in East Portland through 2018 (City of Portland, 2018). In order for TriMet to agree to increase the $122^{\text {nd }}$ Ave bus to frequent service, TriMet required the City of Portland to make substantial investments in the pedestrian environment along the route (Anderson, 2014). That included sidewalk, crossing, and lighting improvements. Additionally, the city has incorporated an equity framework for infrastructure investments that had directed a much larger portion of infrastructure budgets toward East Portland.

\section{Grocery Stores}

The primary grocery stores in the Portland area are Safeway/Albertsons, Fred Meyer (Kroger), WinCo, New Seasons, Wal-Mart, and Grocery Outlet. WinCo and 
Grocery Outlet are known for their cheaper foods while New Seasons is more upscale, equivalent to a Whole Foods. I have mapped the locations of the grocery stores in Figure 3-7. It is important to recognize the scale between the two areas. Albina is about 4 sq. miles while East Portland is about 30 sq. miles. There is a large disparity in available grocery stores between the two areas. While stores in Albina are about one-mile apart on average, in East Portland the stores clustered much more with many stores separated by three miles or more.

This chapter described the situation in Portland for low-income Black populations and the issues involved with a disparate experience for Black populations depending on what part of the city they live. In the next chapter I describe how I framed my research into this phenomenon and how I conducted this study. 


\section{Figure 3-7 Grocery Stores}

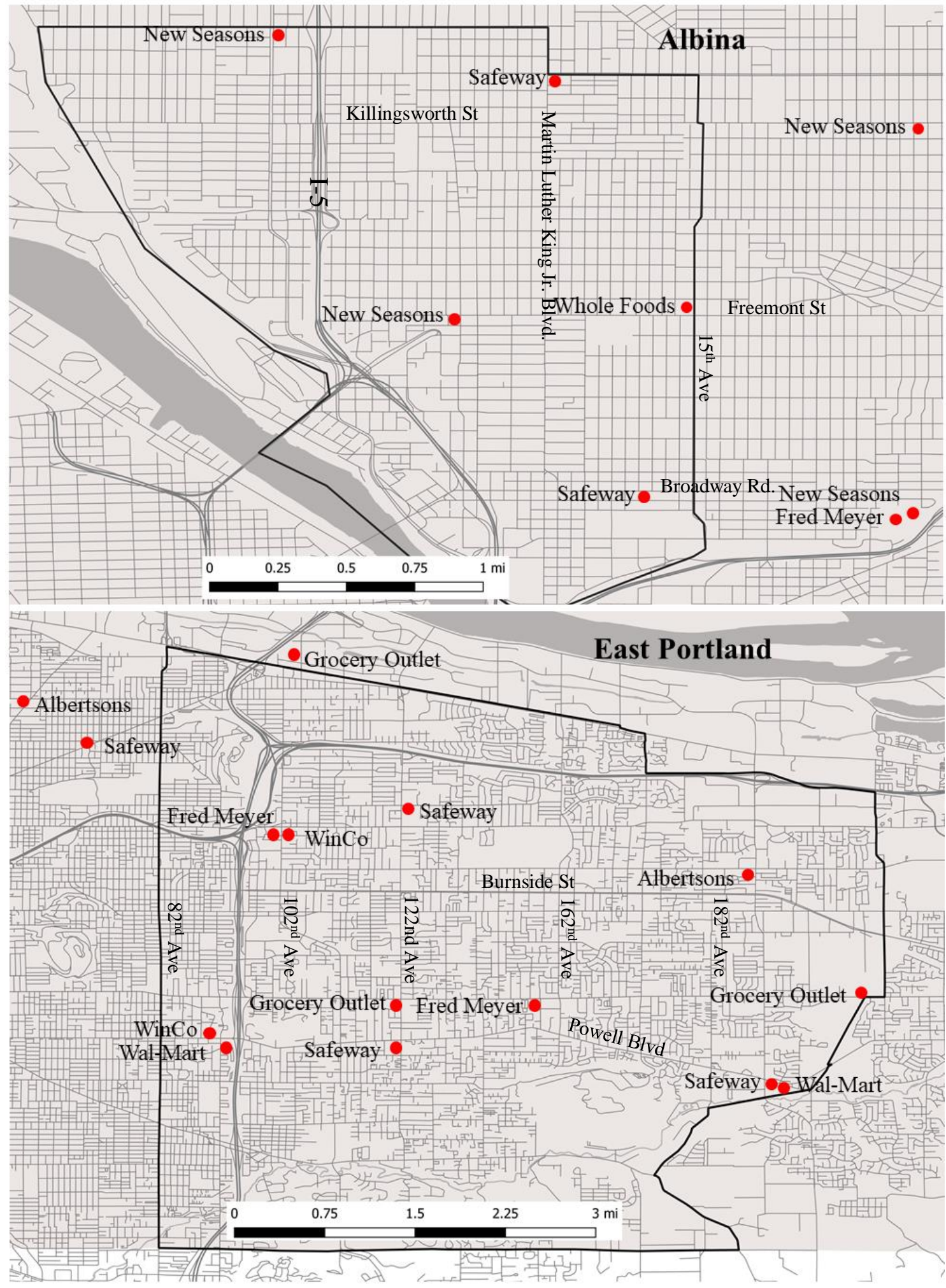




\section{Chapter 4 Methodology}

\section{Purpose of the Study}

Making ends meet at its most basic level involves having a home, food, health, and employment. However, at a higher level, making ends meet also includes satisfying social and psychological needs such as friendships and entertainment. Although the question of how low-income Black populations make ends meet has been well studied (Edin \& Lein, 1997; Roschelle, 1997; Stack, 1975), most studies on the subject took place prior to welfare reform in 1996, and there are gaps in the topics covered. The focus in the past was on how the effects of segregation, poverty, and poverty among their neighbors and families factored into their own struggles and strategies in coping with poverty. Times have changed the situation. Redevelopment through gentrification and demolition of public housing has changed the character of many urban ghettos (Goetz, 2003). When coupled with the growth in use of Section 8 housing vouchers poor populations have been dispersed across metro areas (Goetz, 2003; Kneebone \& Berube, 2013). With the large increase in suburban poverty since 2000 (Kneebone \& Berube, 2013), the changing geography of poverty potentially changes the ways and abilities in which poor households make ends meet. Dispersion from the urban ghetto can lead poor populations to become disconnected from their social support networks while also distancing them from social services and limiting their transportation choices (Buron et al., 2002; Clampet-Lundquist, 2004; González de la Rocha, 1994; Wilson, 1987). This study will explore what strategies how transportation is used by low-income Black populations to make ends meet and how those strategies differ between inner-city and suburban neighborhoods. 
A comparative case-study design allows for several levels of analysis. On one level, each case site is likely to exhibit trends in how households utilize transportation to make ends meet in their respective areas of the city. On another level, differences are likely to exist between the sites as Albina is transportation-rich while East Portland is transportation-sparse. By using maximum variability sampling, this study can explore a wide range of possible household situations and how each one can experience transportation and gentrification differently (Seidman, 2013). This will also help to uncover similarities between households even when base factors are different. The factors of highest priority for variability are housing location, income, household structure, and whether they own a car.

By gaining an understanding of how poor Black populations in East Portland make ends meet when compared to their inner-city peers it becomes possible to better guide policy decisions. Policy makers will be able to get a better idea of what services and types of businesses are lacking in certain areas of the city. Investigating the transportation choices of low-income Black households and how they tie to access to services brings a holistic approach to understanding what is lacking or working in their neighborhoods and how the situation can change. In particular, while gentrification is removing many cultural staples such as barbershops and churches that were present in Albina in the past (Bates, 2013), those that remain likely continue to draw patronage from Black households that moved elsewhere (Sullivan \& Shaw, 2011; Wood \& Brunson, 2011).

Although improved transit options have been a common policy prescription from past studies of the needs of those living in poverty, through this study, I broadened the 
scope to consider how personal vehicles and alternatives such as carsharing or bicycles may factor in as important strategies to increase the mobility of the suburban poor. The exploration of their strategies in how they make ends meet also explores gaps in how much their social support networks can aid them especially for those with highly dispersed networks and how they may or may not be utilizing the internet to bridge those gaps. Rising housing prices in central city neighborhoods will continue to push poor populations to the suburbs. This study will be useful in beginning to understand the changes needed to poverty policy to address the problem in a new geography if policy solutions are not found to stem the shift in housing location.

This study is useful for policy makers and community groups in Portland in trying to address the complications surrounding gentrification. It provides useful information in showing how gentrification impacts households who remain in the gentrifying neighborhood and those displaced. Additionally, the implications of gentrification in this case is highly important to the Black community as gentrification is eliminating their presence and cultural establishments in a neighborhood Black Portlanders have long called home (Scott, 2012) even if it was due to issues of structural racism. By focusing upon race in Portland, I bring to attention the problems with unequal investment in transportation alternatives and how forcing Black populations to move can creates additional racialized issues within the city.

Within the academic literature, this study positions itself in transportation, housing, and poverty literature. By looking at the transportation aspects of how low-income households meet their daily needs, I fill a substantial hole in the existing literature on social 
reproduction. Examining the geographical implications of segregation and dispersion as a result of gentrification adds to the housing literature as current literature on the subject has typically been confined to studies on housing mobility programs. Additionally, no literature found by this author covered the implications of displacement for households displaced by gentrification. This study will correct for that. For the transportation literature, this study provides an understanding of how social processes such as gentrification can impact low-income households in terms of their transportation options and how they adapt to those differences in options. Transportation academics will also get a better idea of how low-income Black populations utilize different transportation modes in a city with many alternatives available. This is a valued perspective as most existing datasets fail to capture low-income Black travel behavior adequately or with enough nuance.

\section{Research Questions}

In this study, I ask the following research questions:

1. How does access to their daily needs and services and their transportation choices affect low-income black households' strategies to make ends meet?

a. What transportation options are they using? Why?

b. How do those choices affect their daily lives?

c. What tradeoffs do they make in deciding to use one mode over another?

2. How has gentrification and displacement affected strategies to make ends meet?

a. How has access to services and daily needs changed since they have noticed gentrification?

b. How has their interaction with and the composition of their social support network changed since they have noticed gentrification?

The first question looks into the transportation choices and the tradeoffs low-income households make to meet their regular needs. I not only sought to understand their choices around transportation, but I also asked about the places they go to meet their regular needs. 
Setting up the question this way allowed me to understand how the places they went regularly differed based on where they lived in the city. Through the section question, I ask about how gentrification has impacted the lives of low-income Black populations in Portland. I asked this explicitly because gentrification has explicitly coded language tied to it that elicits responses different than asking generally about places and people. Lastly, race is an important component to the questions. While the problems of poverty are universally felt by populations of all races and ethnicities, Black populations face 
additional impacts from gentrification than White populations considering discrimination continues to limit where Black populations can live (Rich, 2014).

Figure 4-1 shows the conceptual model developed for understanding how the various factors involved in this study come together. Any household should attempt to meet

\section{Figure 4-1: Conceptual Model}

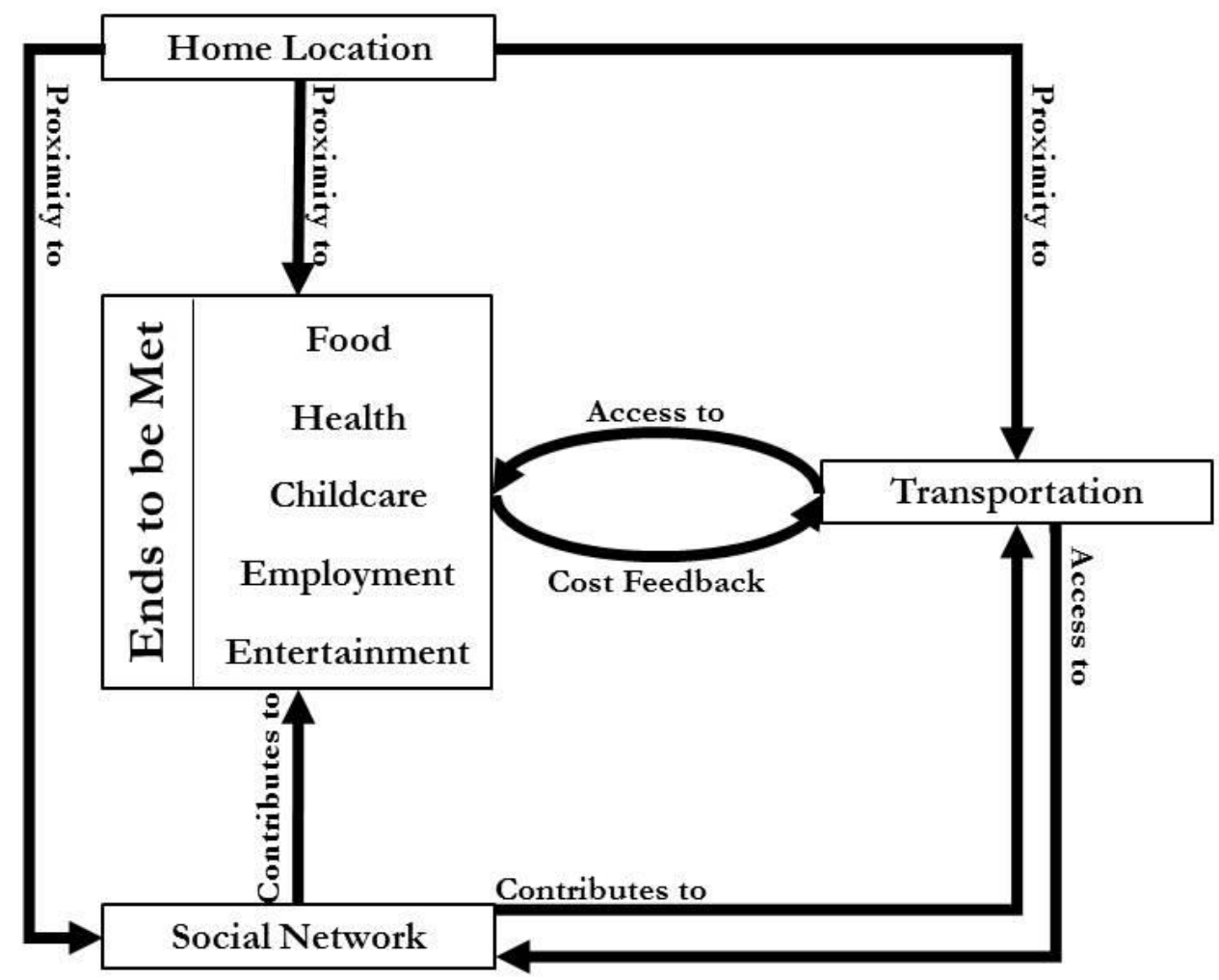

their basic needs of shelter, food, health, childcare, entertainment, socialization, and employment/school. The home location of study participants determines how proximate households are to basic services they need to meet their other needs, their social network, and alternative transportation options. Social networks provide non-market services to 
households such as food sharing, childcare services, linkages to employment, as well as transportation options not available to them otherwise (Edin \& Lein, 1997; Lein \& Sussman, 1983; Roschelle, 1997; Stack, 1975). Transportation is a means to making ends meet rather than an end in itself. Households must decide where they want to go for their services, but also whether they have the means to get there. Transportation decisions come with a cost of time, money, convenience, and frustration. When weighed against one another and to the costs associated with meeting other needs, transportation costs further determine where and how a household goes to meet a need (Agrawal et al., 2011).

\section{Conducting the Study}

To adequately answer the questions posed in this study, a comparative case study is necessary. The effect of geography on how transportation factors into households' ability to make ends meet requires data from households in at least two different locations within the metropolitan area. Portland has two very distinct geographies where low-income Black households can have very different experiences in regards to transportation expenditures and behaviors. These geographies are the case-study sites I selected, shown in Error!

\section{Reference source not found..}




\section{Figure 4-2 Case Study Sites}

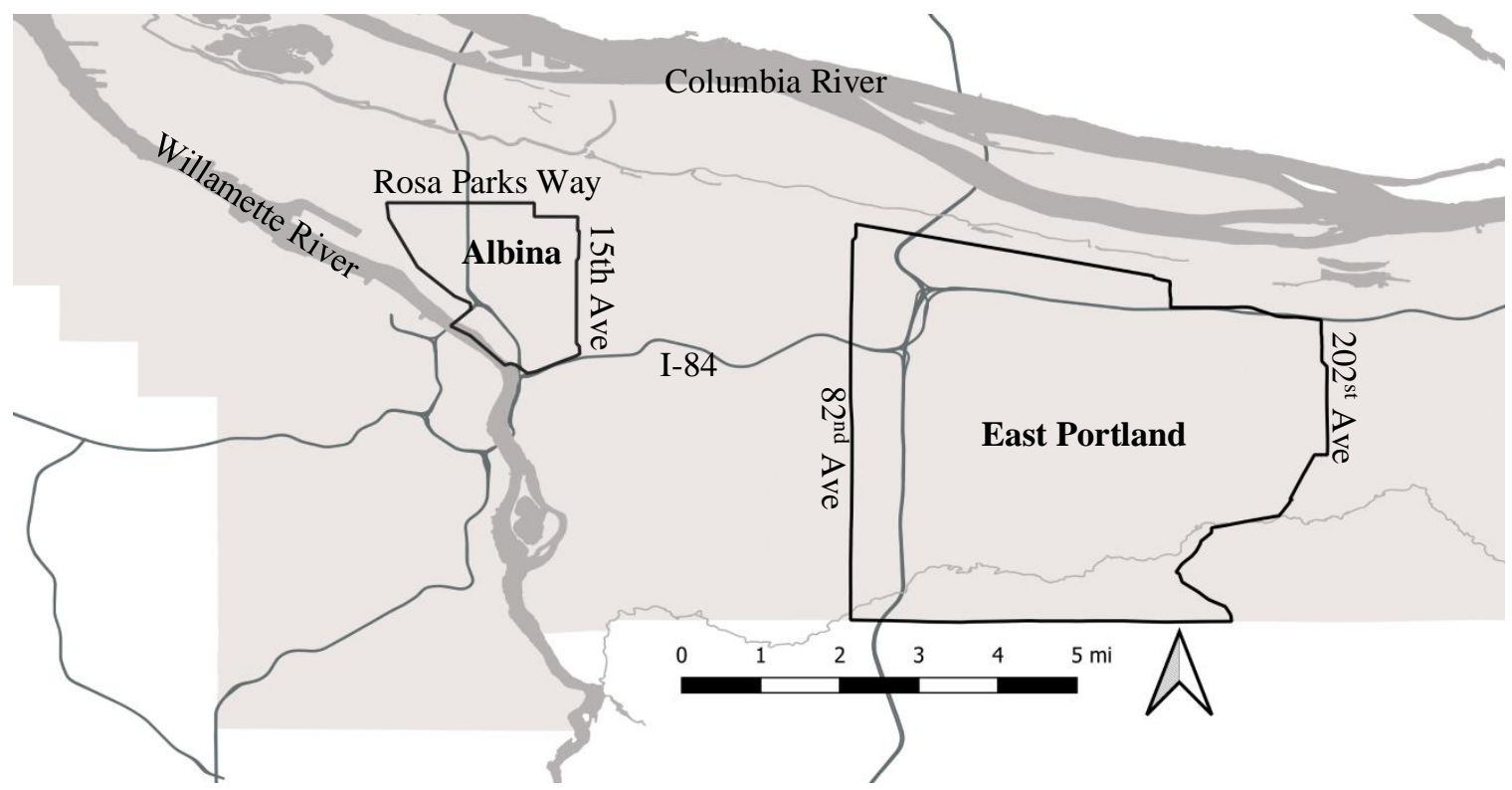

Low-income Black residents remaining in Albina, the study site in the western part of the map to the north of downtown, are able to utilize the amenities that have come to the neighborhood as a result of gentrification. Meanwhile, East Portland, from $82^{\text {nd }}$ Ave. to roughly $202^{\text {nd }}$ Ave, has seen a large influx of Black population during the same time period in which Albina has been gentrifying. This boundary selection of East Portland does extend partly into Gresham to include participants that lived on the fuzzy border between Portland and Gresham but spend most of their time in Portland proper. One participant was selected who lived just west of the $82^{\text {nd }}$ Ave. Where she lived had many built environment similarities to other areas of East Portland, and as such I made the exception to include her story in this study. These two sites are separated by approximately five miles and few direct transit connections between them. In addition to the difference in location, I expected participant responses from East Portland to reflect the more suburbanized built 
environment and its effect on their ability to make ends meet. The distance between the two study sites may cause low-income households to struggle to reach friends and family that may be living in the other location given the time necessary to get between the sites.

\section{Participants}

The unit of analysis for this study is the household. Participant selection focused exclusively on low-income Black populations in the two study areas identified in Figure 4-2. Participants were eligible for participating if their income met the requirements, they were employed or in school full-time, and they had at least one child or dependent adult in the home.

Income requirements were set at approximately $150 \%$ of the poverty line (in 2016 the poverty line was $\$ 24,250$ for a family of 4 , thus $150 \%$ of the poverty line was $\$ 36,375$ ). Given the difficulty of recruiting by " $150 \%$ of poverty," I simplified the income requirement to $\$ 35,000$ or less. By setting the limit to $150 \%$ of the poverty level, I was able to capture households on the edge of poverty who were also ineligible for many public assistance programs yet still struggled to meet their daily needs. The poverty line is a relatively arbitrary construct that has not been adjusted for modern day life in America and does not account for vast differences in cost of living between cities (Edelman, 2012). The inadequacy of the poverty line to capture elements of living life at the bottom of the income ladder has led the National Academy of Sciences and the U.S. Census Bureau to develop the supplemental poverty measure (SPM) that makes an attempt to adjust the official poverty measure to account for many of its shortcomings (Edelman, 2012; Fox, 2019). However, the measure is not used for policy setting. While limiting this study only to those 
with incomes of $\$ 25,000$ or less would almost certainly capture only people that qualify for public benefits, that was not the goal of this study. Public benefits help households get by when they are low-income, but not all poor households seek those benefits or can claim them. The best example of that being Section 8 vouchers for which only about one in four eligible households can obtain a voucher due to budgetary limitations in the program (CBPP, 2009). As such qualification for public programs can only go so far. And for those on the edge of the poverty line, they can still be considered living in poverty. As such, this study recruited people on a $\$ 35,000$ limit.

Only households with children were asked to participate as they have the most difficult circumstances to navigate and are eligible for many more government assistance programs. Considering nearly $70 \%$ of Black households with children in Portland were single-parent households according to the American Community Survey 2009-2013, I did not anticipate too many participants living in partnered households. The $70 \%$ figure about held for my participants as only 4 of the people I interviewed lived in partnered households, meaning around $85 \%$ of my participants were single-parents.

\section{Recruitment}

This study looked at a very small piece of the Portland population. Looking specifically for low-income Black people with children and who were in the labor force really cut the potential pool of candidates down when the Portland population is only 5\% Black. I knew it was going to take a lot to recruit the people I was looking for. This section describes the ways I recruited participants to the study and the challenges and modifications I made to my plans along the way. 
I set out to recruit 30 households with an even split between Albina and East Portland. Transportation studies that used in-depth interviews typically had an interview sample size between 20 and 40 with most on the low end of that range (Buys \& Miller, 2011; Clifton, 2004; Wood \& Brunson, 2011). Higher sample sizes were only used in cases where multiple interviewers were used (Chapple, 2001; Roy et al., 2004). Participants were compensated with a $\$ 50$ Visa gift card for their involvement. Given the split sample, 15 households from each area may be too few people. With time and resource constraints, it was not possible to go after more. When getting my final interviews, it was noticeable that I was reaching near saturation as I was getting a lot of similar responses to questions. I conducted 32 interviews, but ended with 27 usable interviews (13 from Albina and 14 from East Portland). The interviews I excluded were due to eligibility issues that were revealed during the interview or issues of inconsistencies in their stories that I could not reconcile. Each of those participants were still provided $\$ 50$ for their time as not all issues were discovered until transcribing the interviews.

Recruitment was a large challenge for conducting this study. My positionality created larger problems than I anticipated due to current events in Portland at the time. White supremacists in the Portland area made themselves a large component of life in Portland at the time I was recruiting people for this study and conducting interviews. I describe these events and the effect on my study in more detail later. The events, spectacles, and violence from white supremacists substantially decreased trust in the community between Black and White populations, especially a White male looking to talk to Black folks. 
Because of the difficulty of finding such a specific sample from an already small population proportionally, I approached recruitment with a multi-pronged strategy. I planned on attending public events and setting up in public places in the communities in order to hand out flyers and postcards and allow potential participants to ask questions and see the face behind an otherwise anonymous recruitment advertisement. I also set up a Facebook page for the study to provide another point of contact, advertising, and bridge the anonymity of regular advertisements. I reached out to multiple non-profit agencies and churches in the communities to help spread the word about the study and recruit through them. I also printed about 500 flyers to post throughout Albina and East Portland. I ended up posting about 200 flyers in Albina before ending my flyer campaign there. I intended to post flyers throughout East Portland as well, but the dispersed nature of the area and an inability to post flyers on TriMet property (MAX stations in particular), I was limited in my ability to really target where I could post flyers. Thus, I opted not to conduct a flyer campaign in East Portland. Lastly, I asked participants to spread the word to their friends and family leading to a large snowball sampling effort.

The racist activities in Portland made the public appearances a non-starter for the most part. I went to a few places and events toward the start of the study to recruit people, but people were largely apprehensive in talking to me. It was also difficult for me to get into churches. Only one church opened their doors to me with the opportunity to make a recruiting pitch to the congregants, but even there the happenings at the church the day I was there led to the pastor cutting out public announcements. I stuck around after services to talk to some people, but I did not end up recruiting anybody from my effort there. Other 
pastors I contacted were unwilling to put me on the agenda during their public announcements period, and I did not want to go to their services to recruit people afterward without the permission of the pastor. The flyer campaign in Albina was marginally effective. Many people called me with interest in the study but I may have recruited only about 5 people through the 200 flyers I posted. That was on top of having to go back out to re-post flyers that had been torn down. I suspect the vandalism of the flyers was due to the white supremacist activities. I had an early participant tell me that some white supremacists were also posting flyers to recruit Black people and then commit acts of violence against them when they showed up. I did not see any such flyers when I was posting mine nor did I hear any reports of such violence happening, but after that comment I ceased my flyer campaign. If the perception was there among even a few, I did not want to risk further problems.

The two much more successful recruitment methods came from contacts with nonprofits and snowball sampling. In Albina, I got in contact with Portland Community Reinvestment Initiatives, Inc, an affordable housing provider in the area. With multiple properties in the area, they had a large enough presence to be effective and not overly cluster my sample. They distributed my recruitment flyer through their newsletter and posted on their bulletin boards at their properties in Albina. From what I could tell, about half the people I recruited in Albina were recruited through that housing provider. Also, in Albina, I got in contact with the Healthy Birth's Initiative, a program associated with the Women, Infants, and Children program. Through them, I recruited two participants. In East Portland, a staff member at a prominent community development corporation (CDC), the 
Rosewood Initiative, helped me with recruiting. I provided him with my study criteria on who I was looking for and he made calls to people he knew and scheduled for them to come to the Rosewood Initiative where I would conduct the interviews. This process had some trial and error as the first round of interviews I did with people he scheduled proved to be hit-and-miss on whether they fit the population I was looking for. Only about half the interviews I did that day were useable for my study. After I talked with him some more, the recruitment got much better. Nine of my participants for East Portland came through my contact at the CDC. I also reached out to a contact with the Urban League that was posted in East Portland. That contact helped me with two interviews. All the remaining participants I got through snowball sampling. Even with my interviews asking participants questions about people that helped them regularly, the snowball sampling effort had no effect on the results because none of them ended up mentioning a person that recommended them to the study as someone that helped them regularly. If participants were part of the same support network, it could have limited my ability to capture a wider breadth of experiences for the social support network questions.

With the exception of recruits through my contact at Rosewood Initiative and the Urban League, all initial contact with participants was made with them calling me. I used that call to establish their eligibility for the study and set up a meeting day, time, and place. I kept the time and days flexible to allow potential participants to fit the hour I was asking of them into their schedules that would not fit a typical 9-5 Monday-Friday work schedule. I allowed participants to offer places they would be comfortable for the interview. I only required that it was indoors as to cut down on outside noises, was quite enough inside that 
there would not be too much interference with the recording, and was a place where we would not be overly disruptive by being there for an hour or more. This led to interviews taking place at coffee shops or restaurants. Restaurants were a more common occurrence in East Portland given the lack of coffee shops there. I did one interview on a participant's friend's front lawn while he was on his break from his place of work around $200^{\text {th }}$ Ave where there were no other options for places to conduct the interview. I made the exception as no other times were working out for him to sit down for an interview. Thankfully the audio was not too compromised.

Who I recruited is shown in Table 4-1Error! Reference source not found. with supplemental data about them in Table 4-2. All the demographics presented here were collected as part of the interview. Albina recruits were on average older, and slightly more likely to be employed, have a car, and live in subsidized housing. While Albina residents were also more likely to have lived in Albina all their lives, it was a small difference and few had that experience. It is more important to note how long they have lived in Portland overall. East Portland participants were much younger than Albina participants and more likely to have younger children (a factor likely contributing to their higher unemployment rate). Both age and tenure related to Albina are important parts of the demographic structure to keep in mind throughout the findings of this study. Albina residents being older likely meant they had support networks in Albina and those members of their network were as old or older which could mean more time and resources available to help take care of their kids or provide financial assistance. On the opposite side, East Portland residents being younger with younger kids increased their child care needs. However, the housing 
instability that led to them living in East Portland likely also affected their support network members also in East Portland. This means those members were likely less resourceful in their aid. The overall sample was overwhelmingly women, but this did not appear to have as substantial of an effect on understanding the findings as the other two pieces of data. 
Table 4-1 Sample Demographics Part 1

\begin{tabular}{|c|c|c|c|c|c|c|}
\hline Pseudonymn & Neighborhood & Age & Gender & Employed & Income & Education \\
\hline Don & Albina & 37 & Male & Yes & $10-15,000$ & High School \\
\hline Leslee & Albina & 34 & Female & No & $5-10,000$ & Some College \\
\hline Tawnya & Albina & 26 & Female & Yes & $10-15,000$ & High School \\
\hline Olivia & Albina & 24 & Female & Yes & $30-35,000$ & Some College \\
\hline Carol & Albina & 60 & Female & Yes & $10-15,000$ & Some College \\
\hline Troy & Albina & 48 & Male & Yes & $5-10,000$ & Some College \\
\hline Marcus & Albina & 25 & Male & Yes & $15-20,000$ & GED \\
\hline Angela & Albina & 46 & Female & Yes & $35-45,000$ & High School \\
\hline Jacqueline & Albina & 62 & Female & Yes & $30-35,000$ & Master's Degree \\
\hline Margaret & Albina & 51 & Female & Yes & $45-55,000$ & Associates Degree \\
\hline Ruth & Albina & 33 & Female & Yes & $10-15,000$ & GED \\
\hline Amber & Albina & 35 & Female & Yes & $10-15,000$ & Less than High School \\
\hline Rosie & Albina & 53 & Female & No & $5-10,000$ & GED \\
\hline Vanessa & East Portland & 32 & Female & Yes & $25-30,000$ & High School \\
\hline Jasmine & East Portland & 32 & Female & No & $10-15,000$ & GED \\
\hline Robert & East Portland & 45 & Male & Yes & $10-15,000$ & Some College \\
\hline Denise & East Portland & 42 & Female & Yes & $30-35,000$ & GED \\
\hline Joseph & East Portland & 31 & Male & Yes & $25-30,000$ & High School \\
\hline Darius & East Portland & 26 & Male & Yes & $25-30,000$ & Some College \\
\hline Destiny & East Portland & 38 & Female & Yes & $15-20,000$ & High School \\
\hline Ashley & East Portland & 23 & Female & No & $25-30,000$ & Some College \\
\hline Diana & East Portland & 27 & Female & Yes & $20-25,000$ & Some College \\
\hline Nikki & East Portland & 25 & Female & No & $20-25,000$ & High School \\
\hline Gail & East Portland & 62 & Female & No & $5-10,000$ & High School \\
\hline Wanda & East Portland & 41 & Female & No & $20-25,000$ & Some College \\
\hline Derrick & East Portland & 31 & Male & Yes & $45-50,000$ & Some College \\
\hline Joyce & East Portland & 44 & Female & Yes & $35-40,000$ & Some College \\
\hline
\end{tabular}


Table 4-2 Sample Demographics Part 2

\begin{tabular}{|c|c|c|c|c|c|c|c|c|c|}
\hline Pseudonymn & $\begin{array}{c}\text { Has } \\
\text { Vehicle }\end{array}$ & $\begin{array}{c}\text { Has } \\
\text { Bicycles }\end{array}$ & $\begin{array}{c}\text { Portland } \\
\text { Tenure } \\
\text { (Years) } \\
\end{array}$ & $\begin{array}{c}\text { Subsidized } \\
\text { Housing }\end{array}$ & $\begin{array}{c}\text { Always } \\
\text { Lived in } \\
\text { Current } \\
\text { Area }\end{array}$ & $\begin{array}{c}\text { Infant } \\
(0-3) \\
\end{array}$ & $\begin{array}{l}\text { Young } \\
\text { Child } \\
(4-10) \\
\end{array}$ & $\begin{array}{c}\begin{array}{c}\text { Pre- } \\
\text { Teen } \\
(11-14)\end{array} \\
\end{array}$ & $\begin{array}{c}\text { Teen } \\
(15+) \\
\end{array}$ \\
\hline Don & Yes & No & Life & Yes & No & & 2 & & \\
\hline Leslee & No & No & Life & Yes & No & & 1 & & \\
\hline Tawnya & No & Yes & Life & Yes & Yes & & 1 & & \\
\hline Olivia & Yes & No & Life & Other & No & 1 & & & \\
\hline Carol & Yes & Kids & Life & Yes & Yes & & 1 & & \\
\hline Troy & No & No & 40 & Yes & No & & & & 1 \\
\hline Marcus & Yes & No & 4 & Yes & No & & 2 & & \\
\hline Angela & Yes & No & 22 & No & No & & & & 1 \\
\hline Jacqueline & Yes & No & 42 & No & Yes & & & 1 & 1 \\
\hline Margaret & Yes & Kids & Life & No & Yes & & & 2 & \\
\hline Ruth & No & Kids & Life & Yes & No & & & 2 & \\
\hline Amber & Yes & No & Life & No & No & & 2 & & \\
\hline Rosie & No & No & 35 & No & Yes & & 1 & & \\
\hline Vanessa & No & Yes & Life & Yes & No & & 2 & & \\
\hline Jasmine & Yes & No & Life & Yes & No & & 2 & & \\
\hline Robert & No & Yes & 25 & No & No & & 2 & 1 & \\
\hline Denise & No & Yes & Life & Yes & No & & & 1 & 1 \\
\hline Joseph & No & No & 3 & Yes & Yes & & 2 & & \\
\hline Earius & Yes & No & 15 & No & Yes & 1 & 1 & & \\
\hline Destiny & No & Kids & Life & No & Yes & & 1 & & 2 \\
\hline Ashley & No & No & Life & No & Yes & & 1 & & \\
\hline Diana & Yes & Kids & Life & No & No & & 3 & & \\
\hline Nikki & No & No & Life & Yes & No & 1 & 1 & & \\
\hline Gail & Yes & No & 50 & No & No & & & 1 & \\
\hline Wanda & Yes & Yes & Life & No & No & & 1 & 1 & 1 \\
\hline Derrick & Yes & Kids & 10 & Yes & No & & 1 & 1 & \\
\hline Joyce & Yes & Yes & 19 & No & No & & & 1 & 1 \\
\hline
\end{tabular}




\section{Interviews}

I conducted interviews to get in-depth information into participants' struggles and decision making than surveys allow. The interview process was modified from the phenomenological interviewing process described in Seidman (2013). The phenomenological process as described by Seidman captures the experiences of participants around a certain phenomenon, in this case how low-income Black populations transportation relates to their ability to meet their daily needs and how gentrification impacts that, and the meaning of those experiences. Seidman utilized a 3-interview method which was too intensive for the participants in this study. I expected participants in my study to be time-burdened with children and potentially multiple jobs and opted for a single interview with a time ranging from 1-2 hours. There was not an exact time limit on the interviews, but I asked participants to schedule at least one hour of their day with the possibility of the interview going two hours. Clifton (2004) conducted two one-hour interviews around a similar question as this study. Both Edin and Lein (1997) and HalpernMeekin, Edin, Tach, and Sykes (2014) used differing methods but did not keep to a set time to their interviews. Edin and Lein used multiple interviews over time to gain the trust they needed with the households they were interviewing. Halpern-Meekin et al. used a single long interview session ranging from 1 to 5 hours with most lasting two and a half hours. I had two interviews go beyond the two-hour expectation. Most of the interviews lasted an hour or less. As expected, those that lasted at least an hour proved to be the most fruitful interviews. 
I structured the interviews in three parts. The first part focused on their travel behaviors and where they were going. The second part focused on tradeoffs they made to get around and survive from day-to-day and how certain decisions affected them and their children. The last part asked them specifically about who they turn to for help in their daily needs and how gentrification has impacted them and their network. I provided participants the opportunity to take a break between parts one and two as the first part was approximately half the interview time. No one opted for breaks during the interview. All interviews were audio recorded and I took limited notes during the interview coupled with writing post-interview notes where I noticed something to pay attention to for the interview or to record something that did not get picked up by audio. For instance, some participants, after I had turned off the recorder, would mention something else they wanted me to know.

While other studies used multiple interviews to gain the trust of participants, I did not. But I also did not perceive any trust barriers to obtain truthful answers as I was conducting my interviews. My interviewees were surprisingly open with me about details into their lives not ordinarily shared with strangers. Part of this may have been the trust barrier was relieved by the recruitment methods where someone they trusted referred them to me. Only a couple interviews seemed to really be affected by trust. Those interviews were not very useful, and I potentially could have used follow-up interviews with them to have better narratives with them. Based on my experiences during those interviews with them, it was unlikely the narrative would have gotten better and they were likely just there because of the compensation. I still elicited some useful information from them and they remained participants in the study. 
I could not ignore the effect my positionality as a well-educated white male had on the process either. Most of the participants were women and single. Who agreed to meet with me, a total stranger to them, was going to be limited by that, particularly with what was going on in the Portland area at the time. There were some instances in how I framed or asked questions where the interactions with my participants became difficult. As much consistency as I tried to have with how I asked questions, what worked for some did not work for others, but I prepared with alternative ways to ask questions and opened up conversation around areas that made them uncomfortable. None of the interactions led to problems in the interviews and in some cases actually led to more trust building conversations with participants that led them to share more information with me than they otherwise probably would have. A couple of them even admitted that they asked me certain questions to feel out my potential racism, a defense mechanism they really heightened because of the happenings in Portland.

\section{Analysis of the Data}

All interviews were audio recorded and the audio was later transcribed to provide a full-text document for analyzing the interviews. Data analysis was comprised of coding interview transcripts and conducting thematic analysis of the coding. This section discusses the coding and analysis process used for this study.

The interview script (Appendix A) asked participants a range of questions around their demographics along with useful information about their household composition and living situation. Sample size constraints did not make for meaningful statistical analysis on these or other pieces of data from the interviews. Through the interview, I asked 
participants about their daily lives from what modes of transportation they used, where they went regularly, how they made choices between modes and places to go, tradeoffs they made to get around the way they did, and difficulties they faced throughout it all. Additionally, I asked them about their social support network, who did they turn to for help, how they helped them, how often they got help, how reliable that help was, how it affected them, and specifically if that help had changed with moves either their network or themselves had made recently.

I coded the transcripts using both deductive and inductive coding processes. A priori codes did exist for deductive coding, especially thanks to the work of Agrawal et al. (2011). Given the lack of knowledge around the phenomenon being studied here, I could not rely on deductive coding to produce a comprehensive analysis of what I captured. Agrawal et al. (2011) noted their use of deductive coding as one of their largest shortcomings. Deductive codes, as presented in Table 4-3, helped organize the data to answer the primary questions (Fereday \& Muir-Cochrane, 2008), but inductive coding helped capture more nuances to the research questions while helping better understand the phenomenon of gentrification and its impact on households. Considering little previous theory is available for understanding gentrification's impact on displaced populations, inductive coding helped avoid overlooking important situations going on within the phenomenon (Boyatzis, 1998; Crabtree \& Miller, 1992). 


\section{Table 4-3 Interview Coding}

\begin{tabular}{|c|c|c|c|}
\hline Topic & Code & Sub-Code 1 & Description \\
\hline \multirow{6}{*}{ Access } & \multirow{2}{*}{ Choice } & Regular & Mention they went to that place regularly. \\
\hline & & Occasional & Mention they went to that place occasionally. \\
\hline & \multirow{3}{*}{ Tradeoff } & Cost & $\begin{array}{l}\text { Mentioned they sacrifice cost or take on more } \\
\text { cost (monetary or time cost) in order to go. }\end{array}$ \\
\hline & & Distance/Time & $\begin{array}{l}\text { Mentioned they go to this place because of } \\
\text { distance or time constraints. Perhaps explicit } \\
\text { mention that it was not preferable. }\end{array}$ \\
\hline & & $\begin{array}{l}\text { Selection/ } \\
\text { Comfort }\end{array}$ & $\begin{array}{l}\text { Mentioned they go to this place because they } \\
\text { lacked other options or were uncomfortable } \\
\text { with other places. }\end{array}$ \\
\hline & Change & & $\begin{array}{l}\text { Mentioned they changed the place they went } \\
\text { because of gentrification. }\end{array}$ \\
\hline \multirow{15}{*}{$\begin{array}{l}\text { Transportation } \\
\text { Mode }\end{array}$} & \multirow{5}{*}{ Barriers } & Access & $\begin{array}{l}\text { Mentioned their ability or willingness to use a } \\
\text { mode is limited by access to it. }\end{array}$ \\
\hline & & Time & $\begin{array}{l}\text { Mentioned their ability or willingness to use a } \\
\text { mode is limited by the time it takes to use it. }\end{array}$ \\
\hline & & Money & $\begin{array}{l}\text { Mentioned their ability or willingness to use a } \\
\text { mode is limited by the money it takes to use. }\end{array}$ \\
\hline & & Reliability & $\begin{array}{l}\text { Mentioned their ability or willingness to use a } \\
\text { mode is limited by the reliability of the mode. }\end{array}$ \\
\hline & & Safety & $\begin{array}{l}\text { Mentioned their ability or willingness to use a } \\
\text { mode is limited by the safety of the mode. }\end{array}$ \\
\hline & \multirow{4}{*}{ Emotions } & Anger & Mode made them angry. \\
\hline & & Fun/Happiness & Mode made them happy or was fun. \\
\hline & & Relaxation & Mode was relaxing. \\
\hline & & Worry/Fear & Mode made them worried or fearful. \\
\hline & \multirow{5}{*}{$\begin{array}{l}\text { Managing } \\
\text { Expenses }\end{array}$} & $\begin{array}{l}\text { Cut back on } \\
\text { travel }\end{array}$ & $\begin{array}{l}\text { Mentioned they cut back on their travel } \\
\text { because of cost. }\end{array}$ \\
\hline & & Cut back on food & $\begin{array}{l}\text { Mentioned they cut back on food because of } \\
\text { travel cost. }\end{array}$ \\
\hline & & $\begin{array}{l}\text { Cut back on } \\
\text { other }\end{array}$ & Mentioned they cut back on other expenses. \\
\hline & & $\begin{array}{l}\text { Alternative } \\
\text { payments }\end{array}$ & $\begin{array}{l}\text { Used alternative ways to afford traveling. } \\
\text { (Collecting cans/bottles, fare jumping, etc.). }\end{array}$ \\
\hline & & Budgeting & Specifically budgeted for cost of travel. \\
\hline & Tradeoffs & & $\begin{array}{l}\text { Made the tradeoff of something to get around } \\
\text { easier. (e.g. Higher costs in order to get } \\
\text { around by car). }\end{array}$ \\
\hline \multirow{3}{*}{$\begin{array}{l}\text { Social Support } \\
\text { Networks }\end{array}$} & \multirow[b]{3}{*}{ People } & Aid type & The type of aid they get from a person. \\
\hline & & Reliability of aid & How reliably they can get aid from them. \\
\hline & & $\begin{array}{l}\text { Change in aid } \\
\text { availability due } \\
\text { to moves }\end{array}$ & $\begin{array}{l}\text { Mention of whether the relationship has } \\
\text { changed because of them moving or the } \\
\text { person they rely on moving. }\end{array}$ \\
\hline
\end{tabular}

Source: Table adapted from Agrawal et al. (2011); Boyatzis (1998); Fereday \& Muir-Cochrane (2008) and author's inductive coding of interviews. 
The coding structure started with three main categories as seen in Table 4-3: Access, transportation, and social networks. The coding from there was influenced by the

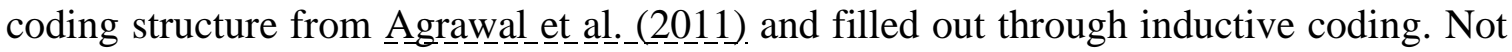
all codes are shown as there were over 60 codes used for organizing the data, but they all generally fall into the above structure. Accessibility codes tied interview data to where people were going, why they were going to those places, and problems they faced in getting to the places they went. Under transportation, I coded interviews for mode taken, barriers to use, emotions they felt using the mode, and tradeoffs they made in order to use certain modes. Social networks codes linked data to who was helpful in their lives, what kind of help they got from people, the reliability of the help, and difficulties in getting help from the people in their lives. This included linking to quotes where people stated they had no one available to help them. Gentrification ended up a more subdued coding block. Instead of it being a major category, it was tied explicitly into the categories of access and social networks. Much of this was due to the structure of my interviews and how I asked questions about gentrification. It did not make sense to separate it from those coding blocks. Gentrification in accessibility appeared as data that mentioned no longer going to a place they used to because it didn't exist anymore, whether they moved and it changed their accessibility to particular places, their general feelings about changes in the neighborhood, or going to places that were new to the neighborhood as a result of gentrification. Within social networks, I coded interview data for gentrification for whether they felt their ability 
to get help from friends and family was affected by either their own moves or the moves of people they turned to for help.

I primarily used thematic analysis to examine the interviews for descriptive evidence of how low-income Black populations experienced transportation in Portland and how gentrification has impacted their experience. This analysis method was the best to use for the survey style interviews that I conducted. Even so, the themes only offer piecemeal information on the experience. As such, I constructed narratives from the interviews to demonstrate the holistic experiences of the people I interviewed. For instance, it is useful to understand the decision making and experiences in driving as a primary mode of transportation for low-income Black populations in Portland, but it makes more sense to understand it in the context of what they feel about other modes, whether they use them, for what reasons, and why they may not. The narrative structure I used to demonstrate these experiences works to tie together the themes while allowing them to stand on their own given the widely varying experiences discovered through the interviews.

The primary themes of analysis stuck to components of the research questions for this study: How are low-income Black populations in Portland experiencing transportation, and how is gentrification impacting that experience. Describing their experiences was set in the context of social reproduction (the daily activities people perform to make a living and continue living their lives while supporting their families). Thus, the analysis covered a wide range of activities families performed and each piece of the puzzle was looked at as a separate entity within a larger narrative. 
Chapter 5 looked at the transportation narrative and the importance of transportation in the lives of the people in interviewed and their ability to socially reproduce. This involved a deep examination of the modes they used, why they used them and not others, the barriers they faced in using those modes, tradeoffs they made to use those modes, the emotions they experienced by using those modes, and how the use of those modes ultimately impacted their lives. I structured that chapter as such with a focus on the divided narrative between people who primarily drove and those who primarily used transit. I examined these experiences with the interacting effects of whether they lived in Albina or East Portland, gender, and other life factors.

Chapter 6 focused more on the tasks of social reproduction: where were people going, who were they turning to for help in their lives, and how was gentrification impacting those places and people. Where Chapter 5 incorporated some of this with how people were getting to certain places, I focus entirely on the places people were going with less emphasis on how. This analysis looked at where people were going and the choices they made for making ends meet. This involved the tradeoffs they made such as choosing to go to one grocery store over another and the impacts that choice had on their ability to make ends meet. This chapter also included looking at the people of the community and the support networks of the participants. People of the community impact the ability for a place to feel like home and ultimately a person's psychological state of mind. As shown in Chapter 6, my participants did not usually have welcoming experiences with new-comers to the neighborhood and those in East Portland rarely had interactions with their neighbors. I looked at transportation more generally in this chapter to emphasize the difficulties people 
faced getting to certain places or their support network based on the mode of transportation they used. Again, the interest here was examining not just the phenomenon but how it differed by geography. There were less differences in this topic for gender and other life factors, so I gave them much less emphasis than in Chapter 5.

\section{Racism in Portland}

It is difficult to study Black populations in the U.S. without any emphasis on the role of racism. Examining the experiences of the Black population in Portland is no different, and with the history of racism in Portland coupled with the small Black population, it took on a more amplified role. However, I was unprepared for how much racism would influence this study. During the summer of 2017, events in Portland took on a notably overt tone of racism.

All but a few of the interviews for this study were done during or shortly after what I have come to call the "summer of white supremacy" in Portland (keeping in mind that white supremacists have always had a prominent presence in Portland and Oregon as a whole, and continue to, but the activities of that summer were exceptional). The summer of 2017 consisted of one of the most publicized multiple murders by a white supremacist in the nation where a known white supremacist killed two people and severely wounded another on a MAX train. Those attacked by this man stood up in defense of two Black girls, one of whom was wearing a hijab indicating her Muslim beliefs, being accosted by this man because of their beliefs and skin color. That summer had multiple other events around white supremacy that put the matter front and center in the minds of my interviewees. But 
the most prominent one, and one that affected them the most in terms of the content of this study was the murders on the MAX.

The other events going on in Portland centered around the activities of the Proud Boys, a group that emphasizes they are not racists, yet they routinely invite to their events other groups identified by the Southern Poverty Law Center as racist groups. Their events held in various locations throughout Portland have attracted negative attention, involved multiple melees, hate spewing, and directed violence while also attracting attention from anti-fascists groups that routinely counter-protest at their events. Multiple reports have also brought attention to possible police bias in response to the Proud Boys compared to police response to anti-fascist protesters. This has painted the Portland Police in a negative light as doing more to protect racists than of those looking to tamp down hateful messaging and actions.

Capping off the summer I was conducting interviews, news broke of a credible threat against the wildly popular "Good in the Hood" festival that takes place in Albina and is a celebration of Black life in Portland. There was uncertainty for a period of time as to whether the festival would go on, whether there would be extensive security measures put in place, or whether it would be safe for Black people to attend if the festival did go on. The threat on the festival came up multiple times in my interviews with people and was just another threat on their daily security that influenced their daily activities. The festival did go on and no violence occurred.

Combined, the situation in Portland hugely impacted my study. So many of the people I interviewed expressed severe anxiety and fear of going out, taking MAX, or even 
visiting their neighborhood park. Even though the people killed on the MAX were not Black, no threats for the Good in the Hood festival were followed through, and the violent clashes between Proud Boys and anti-fascists generally involved White people, the effect was quite marked on the Black population. The point was the attack happened because of threats to Black people; the threats to Good in the Hood were because it was a Black-centric event; and the Proud Boys rallies were heavily attended by individuals with racist ideologies, including Jeremy Christian, creating an ever-present threat for Black people in Portland. This was all in addition to the historical elements of racism that have existed in Oregon since its founding.

As such, I cautiously interpreted the findings in this study that may have been influenced by the racist activities going on in Portland at the time. For instance, isolation and the effects of it were an interesting issue that has come up in theory and in the interviews, but given the events that were going on in Portland, it was difficult to tease out how much of it was due to the fresh attacks on the psyche of the Black population and how much was long-standing. 


\section{Chapter 5 Getting Around}

Being mobile is a critical part of life. Whether one gets around by foot, transit, car, or some other mode, they have to remain mobile in order to go to work, get food, go to school, see friends or family, or even to just get out of the house. But not everyone's ability to be mobile is equal, and this is the focus of social exclusion theory (Kenyon et al., 2002; Lucas, 2012). In this chapter, I focus on the mobilities of the low-income Black people I interviewed in Portland and examine the way they made their choices on how to get around, the effects those choices had on their lives and ability to conduct daily life maintenance, and the strategies they adopted to maintain their mobility.

Understanding the mobility of low-income Black populations is incredibly important for researchers, policy makers, and transportation planners. The low-income Black experience often get washed out or mis-represented in the existing data due to unreliability of the data for their populations and the seemingly inevitable result of transportation modeling to develop policy around the relatively high-income White male experience (Karner et al., 2016; Lubitow et al., 2019). By understanding their lived experience, policy makers and planners can intervene to alleviate particular burdens borne by low-income Black populations that do not normally show up in the data.

In this chapter, I focus on transportation in the lives of the people I interviewed. I evaluated their transportation choices in relation to where they lived, where their social support networks lived, the resources available to them from their support networks, and the various costs, tradeoffs, and strategies they had in order to remain mobile (as seen in 
Figure 5-1: Conceptual Model - Chapter Highlights

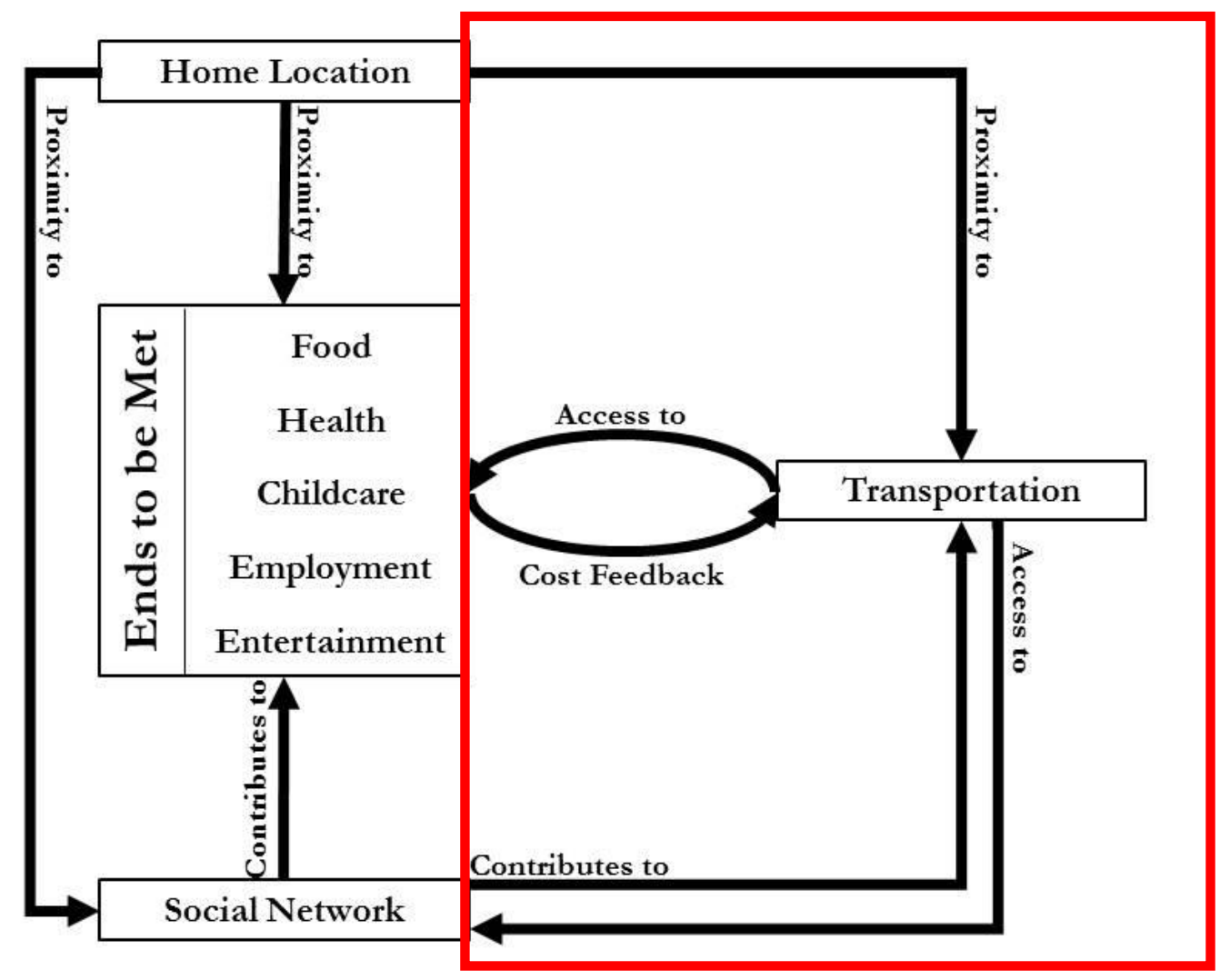

the highlighted right side of the conceptual model in Figure 5-1). I evaluated the actual places of life maintenance in the next chapter.

Through this examination of travel behaviors, I found that Albina residents were the best off, but they still struggled in a number of aspects of transportation (see Table 5-1 for a list of main findings for this chapter). I found that Albina residents in this sample were more likely to drive than East Portlanders. I attributed this to what appeared to be a lower level of struggle in their lives. I also found that there was a near universal dislike of TriMet which spurred not only a high desire to own a car but also led to many people dependent on transit cutting back their ridership because they did not want to take transit. 
The dislike was heavily weighted on issues of safety on transit related to both negative experiences on transit as well as the perception of unsafe conditions heightened by the racially-motivated attack. Drivers were more likely to take transit as an alternative while those dependent on transit were more likely to call someone for a ride. This difference was likely due to a greater sense of independence among drivers - they did not want to burden other people with their problems. That's not to say people that were dependent on transit did not want to express independence, it was more that they had no other choice.

Lastly, East Portland residents suffered under the suburban form of that part of the city. Everything was much more spread out which made everything harder to get to. Their support networks were also bifurcated. Many had people they knew in East Portland, but those people often did not have the resources to help them very much. Thus, they would seek help from their better resourced kin in Albina which added to the transport burden.

\section{Table 5-1 Mobility Chapter Findings Highlights}

\section{Findings Highlights:}

- Albina Residents were more likely to drive (62\% vs $36 \%$ ).

- Nearly universal dislike of Tri-Met.

- Nearly everyone had safety concerns taking transit. No drivers expressed safety issues driving.

- Albina residents struggled less in their daily life maintenance giving them more means to own a car.

- East Portland residents gained marginally more benefit from car ownership, but struggled more to own.

- Drivers were more likely to use transit as an alternative.

- Transit riders were more likely to turn to getting rides as an alternative.

- East Portland residents had more difficulty getting rides.

- Albina residents had positive associations with walking.

- East Portland residents would walk, but with higher cost due to distances and multiple safety issues.

- Very few people rode a bike, but it was more common for their kids - mostly limited to Albina.

- In sacrificing to afford their mobility, East Portland residents cut deeper because of lack of alternatives.

This chapter is organized by mode of travel with driving and transit being the main sections. Within the driving and transit sections, I discuss the positives and negatives of 
the mode, employment access, expenses, strategies to get by with that mode, and the psychological effects of using that mode and the associated costs and sacrifices using it requires. Throughout, I bring attention to the geographical differences between those living in Albina and those in East Portland.

\section{Driving}

Amber was a single-mother of two living in the northern section of Albina. She lived with a roommate, another single mother. They split the $\$ 2240$ a month in rent plus utilities. With her near 40 hour a week job at a fast food restaurant earning $\$ 11$ an hour, she was spending nearly $70 \%$ of her paycheck on rent. Adding to her struggles, she had a disability that made standing for hours on-end day-after-day exhausting and painful. In order to cope, she cut back on hours at work to have the energy at the end of the day to take care of her kids. She had been on a waiting list for public housing for three years and recently found out she was a top candidate for a subsidized apartment in one of Portland's suburbs, a very different and distant location from where she currently lived. But she was still worried because "nothing is guaranteed until they hand you the keys", and she had not been able to get any confirmation. Even though living further out would likely be cheaper for her, she continued to suffer from a massive rent burden in order to keep her son in his school where he was comfortable and the teachers knew his quirks. She constantly worried about any disruptions in her life that may break that stability for her son and send him off course in school. Even when she was homeless and sleeping on a family member's couch in Gresham, she commuted to North Portland to take her son to school. As she said, "I at least want that stability in their lives." Her daughter was just starting elementary school 
when we talked, so the same concerns had not come up with her yet. But with the difficulties Black kids face in schools in Portland, she wanted her daughter and son going to school nearby one another "just in case."

Getting around, Amber relied on driving a very run-down van she bought from her uncle on a family loan. She gave him money whenever she could, but she often did not have anything extra. Driving was very expensive for her. It added a considerable amount of stress as well because she knew at any moment her van would break down. She got by putting in $\$ 5$ of gas at a time, “just to get me to and fro. Because I don't want to put too much money in here and it breaks down and I'm out of coins."

Much of her decision to drive was because of her kids and her work schedule. Her daughter was too young to ride the bus to school alone and she did not feel comfortable letting her son ride the bus to school on his own. Instead, she chauffeured her kids to and from school. Between her kids' start time at school and her work schedule, she was often late to work. If she were taking her kids to school by bus and trying to get to work, it would be impossible. At least one night a week she had to work past midnight. But working that shift meant she would be stranded if relying on the bus as it had stopped running by the time she got out of the store. Her driving also came with a great risk. She was unlicensed (suspended due to offenses long in her past, but not paid off) and had no insurance, meaning being pulled over by the police could mean going to jail.

Amber's story was an extreme case among those I talked to as she had multiple compounded effects of her past and poverty that most others did not. But her story had many parallels to most that I talked to. Her story highlighted how having kids, being 
employed in precarious labor, and where someone lived could impact the daily need for travel. It also pointed out the precarity of a mode transportation and how everything in life hinged on being able to get around efficiently. She happened to do so by driving.

The proportion of people I interviewed who primarily drove was only slightly lower than the ACS, 2017 5-year estimate for low-income Black populations of approximately $60 \%$. Geographically, more of my participants in Albina primarily drove than did in East Portland (62\% vs $35 \%$ ). I could not compare this to ACS data due to the unreliability of the data. However, everything suggested I would have a reverse finding. For instance, the population and destination density in Albina should encourage transit use (Ewing \& Cervero, 2010; Handy et al., 2005). Other research has shown that sheer need for overcoming the lack of accessibility from transit leads to car use (Clifton, 2004; Edin \& Lein, 1997; Pendall et al., 2014). Similarly, there was not an unemployment difference between the people I interviewed in Albina and East Portland. So, even in a destination scarce area like East Portland, people were finding jobs but not driving to them even though in past studies, the best employment outcomes came from car ownership (Blumenberg, 2002; Smart \& Klein, 2018). To make sense of the divergence from the prior literature, I had to delve deeper into why people drove, how they were affected by driving, how they made it work with their meager earnings, and whether the strength of their social support network impacted their ability or decision to drive and whether any of these factors differed by where they lived in Portland.

Table 5-2 provides a glimpse of how drivers saw the positives and negatives of their driving. Largely, driving was a matter of convenience and flexibility that the bus could not 
provide. Nearly all of them were eager to get away from using the bus (primarily because of safety issues which I discuss more in the transit section). However, driving was very costly both monetarily and in terms of stress. Not everyone had all the stressors listed, but it was not apparent that additional stressors took away from the overall advantages they found from driving.

\section{Table 5-2 Positives and Negatives for Driving}

\begin{tabular}{|l|l|}
\hline \multicolumn{2}{|c|}{ Positives } \\
\hline Convenient & Costly \\
Fast & Addegatives \\
Flexible & Traffic \\
Dependable (at least more-so than transit) & Parking \\
Was not transit & Sacrifices to afford gas/other car expenses \\
Expands range of travel & Sacrificing travel because of driving expense \\
Good for grocery shopping & Getting pulled over \\
Gets kids around easier for extra-curriculars & Inconvenience/cost if car does break down \\
\hline
\end{tabular}

\section{Convenience, Speed, and Flexibility}

When asked why they chose to drive rather than something else, the response was similar among those in Albina and East Portland. Simply put, it was easier for them to get around by car. In Albina, Don responded to why he drove rather than used a different mode:

It's very convenient. For instance, the buses don't come when they say they're going to come. You have to wait for the bus, and they aren't going to stop. If you're having to be at a place at a certain time you can't depend on the bus to get you there on time. - Don, Albina

Don brought up a common the split between those who drove and those who took the bus. Many of those who primarily drove felt the bus was not dependable enough for them. The convenience of the car more than outweighed any of the negatives associated with it, like cost or getting frustrated with traffic. 
One of the largest conveniences was having a car helped them expand what they could do and where they could go in ways that made their life easier. For instance, Jacqueline talked about the way driving helps her,

If I'm going to do laundry like I said, I'm going to drive because there's no way I'm going to catch the bus with baskets of clothes...If it's summer then I'll catch MAX to the grocery store because it's pretty simple. If it's like this rainy and cold I'm going to drive more than likely. If I'm going someplace different than WinCo, I'm probably going to drive because the bargain grocery store, I go to over on Sandy, I'm not going to catch 2 or 3 buses to get there. I'm going to more than likely drive there. - Jacqueline, Albina

Jacqueline was one of the two that primarily used both her car and transit. She very confidently rode transit for many of her activities, but she fully recognized the deficiencies of transit for her life and relied upon her car to fill those deficiencies. Others, such as Amber, were highly reliant upon the flexibility and speed of the car to be able to get to work and have a work schedule amenable to her and her family's needs. Transit was not able to provide that for her.

Those in East Portland, however, were greatly inconvenienced by the distance barriers in that part of the city. They would only walk a mile out of necessity and doing so came with a much higher safety risk than for those in Albina. Fewer sidewalks, less lighting, less population density, higher vehicle travel speed limits, and fewer signaled street crossings by area have made East Portland one of the most dangerous places for pedestrians in the region (City of Portland, 2019a). Additionally, they were less likely than their Albina counterparts to be able to reach the places they wanted within a mile of their home. Both population and employment densities in East Portland were much lower than 
in Albina leading to more distance between people and places of business. Cars helped East Portlanders greatly overcome those disadvantages.

For two of the East Portland parents, kids were a main reason they drove so much, but that was also related to distances they had to travel. One of them, Diana, drove her children to school in Albina every day from East Portland. This was an arrangement she maintained in order to keep her kid in a program that helped her daughter with her special needs. I am not versed in the landscape of the programs offered in schools in the Portland area, but it was apparent that parents I talked to were more trusting of the value of the programs in schools in and near Albina than they were in East Portland.

The other East Portland parent, Derrick, had two daughters involved in extracurricular activities that essentially required him to drive them around due to the time restrictions on their schedules. Their extra-curricular activities took place near the airport - approximately 6 miles from his home or about 15 minutes by car versus nearly an hour by transit. He also had part-time custody of two boys who lived in Albina which meant getting them all on transit would be very costly and time consuming. With only part-time custody, those lost hours taking transit could be very valuable to him as a father potentially leading to him feeling he was not fulfilling his role as a "good dad" (Troilo \& Coleman, 2012).

Much of past research has extolled the benefits of car ownership for low-income populations (Agrawal et al., 2011; Blumenberg \& Manville, 2004; Blumenberg \& Pierce, 2012; Pendall et al., 2014; Smart \& Klein, 2018). However, much of it had focused on accessibility to jobs and shopping. I found that the conveniences low-income Black 
populations found in driving extended to many different aspects of the lives. As described above, parents found convenience and flexibility from car ownership that allowed them several perks in their lives:

- Access to preferred grocery shopping;

- Getting their kids to schools and extra-curricular activities they felt had more accommodating programs than nearby options;

- Being able to have a work schedule that better accommodated the needs of their kids;

- Allowing them to feel like they were being a good parent.

The central theme from the parents I interviewed on the convenience and flexibility of car ownership came down to their kids. Studies on the motivations for transportation mode choice rarely considered motivations brought about by their kids beyond getting them to school.

\section{Dependability}

Having a working car was critical to be able to reap the advantages it brought. However, as much of past research has shown, low-income populations tended to only be able to afford older high-mileage cars that had a greater tendency to break down (Blumenberg \& Manville, 2004)

Most of the drivers I talked to banked on having a reliable car around, and for the most part they did. Only three of them had cars that had reliability issues severe enough they were unsure if their car would start the next time they tried. The reliability issues were 
a huge stressor for them. In responding to what her plan was if her car broke down, Amber responded:

...I haven't mapped that out but I would have to get up pretty early to get them [her kids] to school by 9 and my shift starts at 9. So, it's cutting it close. And I get off at 4:30 and I have get her [daughter] by 5. I would probably have to cut hours, become part time, and become homeless again because I wouldn't be able to pay rent. - Amber, Albina

Her expectation was that if her car broke down, that was it. She would not be able to afford to fix it or get another one. Her life would change in an instant. Similarly, Don responded to how he coped when his car broke down:

It's real difficult. Just have to rearrange my whole life pretty much. Because I'm dependent on that car to get there [work and kids' school] on a certain time... Most the time I don't have the funds to get it fixed right away.

- Don, Albina

Long gaps without a car was a common issue found in past research for low-income populations that owned a car (Fletcher et al., 2005). The high cost of car repairs in particular made it difficult for low-income people to get their car fixed in a timely manner. This was prevalent in the people I talked to who had cars broken down at the time we talked.

Five people I talked to had cars that were currently broken down. Their cars had all been broken down for more than a month. And only one of them had prospects to get their car fixed anytime soon; he just needed the time to do the repairs himself. Some of them, like Jasmine, had no prospect of getting their car running again. She bought her car through someone on Facebook, but it broke down less than a block away from the person's house. That person had no interest in helping her get the car running again. Additionally, she found that the license plate did not belong to the car thus she would have to pay for new plate, 
registration tags, and emissions check (expenses she specifically sought to avoid by purchasing a car that had tags good for two more years).

There has not been much recent research on the reliability of the cars low-income populations buy today. But we do know that cars these days are much more reliable (Bomey, 2019) and that financing schemes (ignoring the risks) have made newer cars more affordable for those at the bottom end of the income scale (Eisen \& Roberts, 2019). This may explain why so many of the car owners I talked to stated they did not have any issues with their vehicles. Given the lower annual mileage low-income populations tend to travel (Blumenberg \& Pierce, 2012), they put less stress on their vehicles which prolong the car's life.

\section{Expanded Range of Travel - Employment}

I found grocery stores and employment destinations were the two most critical destinations in a household's daily life maintenance that people would go out of their way to reach them. And driving made those destinations much easier to reach, and for some was the only possible way they were getting there. Driving to groceries could give them a greater array of stores to choose from and allowed them to "shop for deals." Driving to employment could allow them to take a job with better pay in a location they would not have been able to easily or reliably get to by transit.

The general finding from research on job access and mobility has concluded that having a car greatly increased employment by making it easier to get to jobs (Blumenberg \& Ong, 2001; Chapple, 2006; Gurley \& Bruce, 2005; Pendall et al., 2014). However, in 
this study, I did not find supportive evidence for that. People with cars were no more or less employed than those without cars.

Of the seven unemployed people I interviewed, three had cars. Generally, their lack of job appeared to be unrelated to being able to reach jobs. Two of those without jobs were unemployed because had recently given birth. Three were without a job because of various health-related issues. Another had just been fired from a job the week before we talked, and since she was taking college classes, she was not in a rush to get into another job. As Blumenberg (2002) found, obtaining employment was about overcoming barriers. Mobility being but just one. Barriers also compound as a person has more of them. Mobility in this case happened to not appear to be a barrier to employment. However, it did appear to be a barrier to gainful employment.

Among those I interviewed, almost no one driving their car was regularly driving it very far to work at the time we talked. The furthest anyone in Albina was driving to work was about five miles, but most of them were driving three or fewer mile to work. No one in East Portland was driving further than three miles to work. Derrick was commuting 18 miles, but recently changed jobs to be closer to work. For two of them, their cars were more integral to their employment as one worked for an app-based restaurant delivery service and the other was an on-call shift worker that had to work at various convenience stores across the city.

The low mileage of the commutes in this study were about consistent with past findings that mothers tend to work close to home because of their domestic duties (Blumenberg, 2004; Edin \& Lein, 1997; P. Ong \& Blumenberg, 1998). Not all the drivers 
in my sample were mothers, but most were, and they all stated a desire to be near their kids and home in case they had to be called out of work. However, their low mileage driving commutes were contrary to past findings that low-income Black workers tend to work outside their immediate communities (Blumenberg \& Pierce, 2012; P. Ong \& Blumenberg, 1998). Less than one-in-five drive-alone commuters in Portland spent less than 10 minutes driving to work (ACS, 2018 1-year estimates), suggesting that most drivers in this study drove way less than most people in Portland. The low mileage they drove to work could be a matter of the Portland job market being good enough they could find work nearby. They were also aided by their neighborhoods not being distressed communities that tend to be devoid of job opportunities.

For most of them their jobs were precarious. They did not explicitly say as much, but owning a car opened up their job opportunities should something happen in their current job. So even though they were not driving far for work currently, it did not mean they would not be driving further in the future. There was also hope that at some point their car could get them to a better paying job. Don experienced that when he was last unemployed and without a car and wanting to get a job that paid better than his last one,

...there was certain jobs that weren't along a transit line. Maybe a mile or two miles off the line. I didn't have a car to get there so I couldn't take the job - Don, Albina

Don has a car now and could potentially seek out the better paying jobs like he's given up in the past. However, his car was too unreliable, and he did not feel confident he could take a job further out. Indeed, for nearly every driver, they based their housing location based on proximity to a bus line so they would always have that backup available 
to get to work in case something happened to their car. The precarity of their jobs meant they had to ensure they could get to work, otherwise they could be without a job.

In terms of employment, I found many nuanced results in comparison with past research. They did not drive very far to work, but they recognized the potential of better pay if they would drive further even though they did not take advantage of that opportunity. At the same time, they really did not want to risk taking a job that was not on a transit line in case something happened to their car. Also, the desire to be near home and their kids appeared to be a big hurdle to overcome for most mothers - consistent with past research. But for policy makers wanting to reduce poverty, it is a difficult finding to contend with as low-income Black mothers continued to work in precarious and low-wage jobs even though they had a mode of transportation that could get them into a better job.

\section{Expanded Range of Travel - Shopping}

In the next chapter, you will see that East Portland residents had to go the furthest for all their activities. But regardless of residential location, people were able to open up their options a lot more by driving than if they were relying on transit. This followed with the literature (Alwitt \& Donley, 1997; Clifton, 2004; Hillier et al., 2011; Walker et al., 2010) even though the neighborhood contexts in those studies differed greatly from the neighborhoods studied here. Those studies looked at inner-city neighborhoods that were exemplary of concentrated poverty. In this case there is a gentrified community that was once exemplary of concentrated poverty and another community that is much more spread out and suburban than neighborhoods of concentrated poverty. 
Most studies on retail and grocery access focused on disadvantaged neighborhoods that were heavily populated by low-income and minority populations. But in Portland,

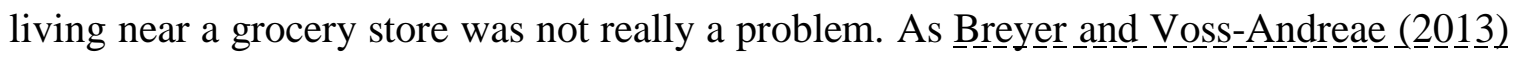
found in their study on Portland, food price mattered more for access. And most the stores with lower prices clustered along the I-205 corridor in East Portland. I found similar results, in that nearly all those with access to cars in Albina traveled to East Portland for groceries seeking out lower-cost food. In East Portland, drivers would go to those low-cost stores as well. For those without cars in East Portland, they desired to go to stores further away but feasibly could not make those trips work.

\section{Cost}

Being able to pay for the daily operations of their car was the biggest concern they had. On average, the people dependent on their car spent about $\$ 300$ a month on their car, excluding regular or emergency maintenance. But one person was spending as little as $\$ 70 /$ month while three people spent upwards of $\$ 500 /$ month. Those that spent the least often did not have insurance. They understood the huge risk involved with that, but it was the only way they could make their finances work with driving. Based on what my other interviewees were paying for insurance, that was about a $\$ 100 /$ month savings. On average, vehicle expenditures were about $16 \%$ of their stated income (ranging between 6 and 38\%) and the three without insurance were spending about $11 \%$ of their stated income. For the seven people primarily driving and earning less than $\$ 25,000$ a year, three were spending more than $20 \%$ of their income on their car with two of those spending more than $30 \%$. On average, drivers earning less than $\$ 25,000$ a year spent about $20 \%$ of their income on 
driving. No body earning more than $\$ 25,000$ a year was spending more than $20 \%$ of their income toward driving and on average spent about $11 \%$ of their income on driving.

Those costs were highly dependent on the use of their vehicle and the kind of vehicle they drove. All of them tried to be as conservative as possible with driving because of the cost of gas and the potential of their car breaking down. Derrick for instance found a job much closer to home in order to save money on gas,

At a time, I used to drive all the way to Happy Valley for work. That used to be a killer every time. That's 18 miles. From where I'm staying, that's a killer. It's crazy. I used to do that every time. And then driving back home every morning. That's a killer on gas. - Derrick, East Portland

He went from having to commute 18 miles one-way to commuting about three miles. He drove a truck as well, which tend to have much lower gas mileage than sedans. Assuming an efficiency of 17 miles per gallon (mpg), working five days a week, and gas costing \$3 per gallon, he would spend about $\$ 30$ a week on gas for commuting. A car getting $25 \mathrm{mpg}$ could have saved him about $\$ 10$ per week. However, by switching to a job closer to home, he saved about $\$ 24$ a week on gas for commuting.

Derrick also expressed the need for much higher pay if he were to work in the suburbs,

I've been hit up with offers, but they be in Tigard and shit like that. Man, I can't drive all the way out there... if you want me to work in Tigard, you got to pay me at least $\$ 16$ to $\$ 17$ per hour - Derrick, East Portland

But the security guard jobs in the suburbs did not offer the pay premium he needed to make the job work for his needs. 


\section{Want to Avoid Transit}

Albina and East Portland drivers largely detested TriMet. Two-thirds of the drivers I talked to had very little interest in ever using transit. Driving helped them feel safer and less stressed about something happening on transit. And safety issues were the overwhelming reason most of them avoided transit. This was not uncommon in the literature, but safety on transit was primarily a concern among women (Gardner et al., 2017; Loukaitou-Sideris, 2014). Here too, concerns about safety were higher with women than with men, but men also became attuned to safety issues when they had their kids with them. Margaret expressed her extreme dislike of transit this way,

It's scary. And it takes too long. Even when my car broke down, I would just ask somebody for a ride. It takes too long and the situations...the circumstances they having now on buses is scary. I have a fear for my kids riding the bus so I very seldom let them ride the bus. There's too much going on and with them being girls...no. no. Public transportation isn't safe like it used to be. - Margaret, Albina

Some of her concerns were related to the race-motivated stabbing I mentioned in

Chapter 4, but she was also referring to the many issues related to homelessness, mental health, and drug-abuse. While the race-motivated stabbing certainly had a large effect on the people I talked to, many of their opinions on safety on transit were formed long before that, stemming largely from the behaviors of other riders experiencing homelessness and exemplifying effects untreated mental illness or drug-abuse. The behaviors they saw scared them. Having their kids with them on transit only amplified their safety concerns. As Margaret mentioned, she kept her kids off transit as much as possible, a common refrain from those who did not take transit regularly, and common in the literature (Gardner et al., 2017; Loukaitou-Sideris, 2014). Their reactions were often not without personal 
experience of events on transit as exemplified by the experience Angela had one time on transit.

...last time we rode public transportation there's this dude on there and he was just crazy. Tweaking out really bad. And he kept looking at my son and I'm like you say something to him I'm going to jail today. - Angela, Albina

One mom in East Portland, Joyce, had an experience with one of her older children

that had impacted her willingness to expose her youngest to transit,

My 18-year-old, he rode it all the time... But it's a point where I pulled up a time I was driving home and I seen this fight going on, on the platform of the TriMet [MAX stop]. This grown man fighting kids. I pulled up and it was my son [one of the kids]. Some Caucasian guy fighting some black kids and the black kids get in trouble. - Joyce, East Portland

Even if their kids wanted to take transit, many of them, like Margaret pushed back

on the idea because of safety issues,

Even this summer my kids were like "let's take the bus" I was like nope. I can't. Just being around all them strange people... after seeing all the stuff on the news and all the stuff happening on the bus. If something were to happen like somebody attack me or my kids. Nu uh. It's scary. - Margaret, Albina

Derrick kept his kids off transit as much as possible because of what he had seen coupled with his experience as a security guard having to deal with some of the same people,

It's so much that you deal with on public transportation, and like I said it doesn't have to be actually violent. But it could be violent conversation. I mean TV shows are enough. I don't want them to hear it too. They got to see it and hear it and then even if they out there in the public and they see it and hear it at the same time. I don't want to have to go through that. I don't want to have to sit up there and them asking why that happen, why they do that. I don't know. I don't know why they were crazy. They just crazy. But they're still human. They're still people. - Derrick, East Portland 
When I asked in the interviews whether additional security on the MAX or buses would make them feel safer, many of them reacted affirmatively. They thought it would help the safety problems, but it was not necessarily enough to get them to use transit. That was likely because adding security to transit was only treating the symptoms of larger societal issues such as homelessness, untreated mental illness, drug-abuse, and white supremacy (Gardner et al., 2017). Others also saw the addition of security likely creating additional issues for people of color. Joyce, was very explicit in her belief:

Just like when the stabbing happened and so forth and they say more security. It makes it worse for us. We're the ones that are targeted. It's not that I'm scared to be on the bus or MAX, that's not it. Maybe scared for the people that may act retarded. But I just don't want to put myself in a situation. Period. To have to defend myself or defend my child or anything like that. So, when I ride the bus, it's absolutely an emergency. - Joyce, East Portland

Organizers at OPAL, a statewide transit and environmental justice advocacy agency, felt similar to her. Given a call for additional security on transit following the racebased stabbing, OPAL conducted a series of public meetings to work through alternative solutions to the armed police that are currently used to enforce TriMet's rules - including fare enforcement on the MAX (Andrew Riley, 2018). Their concerns were primarily based in the history of racially-biased police enforcement on the transit system, and they did not want to see people of color become further burdened by an ever-present security force that would be more likely to target them rather than white supremacists that spurred the call for more security.

The drivers I talked to drove to have control. Driving gave them control over their schedule. It gave them control over where they went. It gave them control over how, when, 
and where they could work. Being on transit, though, they felt the safety issues were largely out of their control. Thus, there was a sense they also gained control over their safety by driving. But none of them brought up any fears of safety when driving such as getting in a crash. I did not ask them explicit questions about safety while driving, but I did not do so with transit either until they brought it up first. This omission showed a disparity in how people felt about the dangers between the modes even though the risks are likely higher that they would get in a car crash than be involved in a violent attack on transit. It is also evident of the psychological toll that low-income Black populations face with racist attacks compared to harm they may experience in their vehicle.

\section{Strategies to Cope with Negatives of Driving}

The costs of driving were extreme. It required people to make substantial adjustments to their lives in order afford the use of their cars. The strategies followed much of the same as those stated in the literature (Agrawal et al., 2011; Curl et al., 2018; Edin \& Lein, 1997; P. M. Ong, 2002). People limited the amount the drove to save money on gas. They did this by cutting back on going to places and also switching modes. They also sacrificed other things in their lives such as cable, food amount and quality, and entertainment in order to continue driving when funds were running short.

Only a couple of them had actual plans in place or savings set aside if something were to happen to their car. Most would go into emergency mode to quickly evaluate what could be done to save money. However, the strategies differed substantially between those in Albina and those in East Portland. Angela, lived in Albina primarily for the convenience of accessing everything she needed by walking. 
I guess I should put away a rainy-day fund for something like that. I actually haven't even thought about it because I'm thinking worst case scenario something happens to my car, I just walk to work. That's why I keep everything within walking distance. Like if I ain't got a car...well I did all those things before I got the car. That's one of the reasons I got this place. - Angela, Albina

That was a very common experience for people in Albina. The urban form in Albina, being much denser than in East Portland, made walking a good alternative for them as it was easy to walk to get things done, and it was free. I cover this more thoroughly in the next chapter, but most of them were walking less than a mile to any single destination when getting around without a car. The cost was a big issue for being able to switch modes as the bus still cost money, and if they asked for a ride, it often came with having to chip in some money for gas. Those often were not good alternatives if funds were so low they could not afford gas for their own car.

Most people regardless of where they lived chose to limit how much they left the house, similar to if their car had broken down. This was often associated with rearranging activities to better line up with other outings. Margaret explained her strategy this way,

And the gas is real expensive. So, it depends on where I got to go, why I got to go, and if I can put it off, I will. Especially with the gas price. I'll be like, I can't afford it right now. Wait a couple days for pay day. All depends on what I have to do. - Margaret, Albina

She also rearranged activities to be able to trip-chain:

Just arrange my day to day of what I need to do. I put my stuff on the calendar. And if it's something that...like if I have an appointment for a different day, but I can get it done this day, I'll call them to see if I can do it the same time I'm in that area. Rather than waste gas. - Margaret, Albina

Even employing those strategies continuously (rather than only during lean times), she still spent nearly $\$ 300$ a month on driving. 
Meanwhile, Jacqueline cut back on driving and switched to bus for a lot of activities in order to save money. Much of that was because she took a financial planning class that helped her realize areas of her budget where she was wasting money, and transportation was the biggest area. Through that, she found she could save a lot of money by taking the bus, but she still drove for many activities. Thus, she had already sacrificed a lot in her life to save money and would only cut back on driving if funds got really low. Her employer also paid for a monthly bus pass, which made taking the bus a viable alternative when she had no money for gas. As a result of her every day strategies, she only spent about \$200 a month on driving with about half of that being insurance.

Amber on the other hand always struggled with paying for gas. She only spent about $\$ 120$ a month on driving, and she never used any other mode. Being at the low end of what people spent per month on driving, there was not much room to cut expenses on driving further without giving it up all together. But she still tried to cut back on driving as much as possible to put aside those couple dollars,

Somebody come pick up my son or, I don't know. Trying not to drive. Trying to find shortcuts. Go straight there. I just do my triangle: work, home and school. - Amber, Albina

But she also had to resort to saving money in several other areas of her life in order to meet all her obligations including the cost of driving,

I cut back on buying things for my kids sometimes. Going out. I cut back on...I go to the Goodwill to get a lot of stuff. Find the cheapest gas they got, watered down gas...I haven't bought anything for myself in so long. I get a lot of stuff from other family members. - Amber, Albina 
For Albina residents, like Amber, the "triangle" of activities (home, work, and school) was incredibly common. It was a feature of having so many of their activities nearby. It was instrumental to them being able to limit how much they drove.

East Portlanders were much more likely to say they "don't go nowhere" or try to accomplish multiple tasks in a single outing (trip chain). Even Wanda who depended about equally on her car and transit was likely to just stay home.

Cause if I'm not driving, I'm just mostly home. Sometimes I'll be like "do I really need to go there" If I don't then ok, I'm just going to stay at home. So that saves me gas and bus fare. - Wanda, East Portland

Nearly all East Portland residents I talked to lived too far from places like grocery stores or work to save money and walk. The densities of places there did not support any other option when they did not have the funds for gas. And not having the money for a gallon of gas meant also not having the money for one-way bus fare. This lack of alternative would hurt them much more than it would someone in Albina.

On-going strategies allowed people to fit the cost of a car into their lives and still benefit from it. However, living in poverty often meant having to deal with fluctuations in money on hand either from working fewer hours or an emergency bill came up. This put further stress on their ability to get around.

In those cases, most people resorted to cuts in other parts of their lives in order to continue affording the cost of their car. Entertainment activities were typically the first to go. But a few people already had bare bones budgets and did not partake much in paid entertainment. Without taking part in entertainment options they had to pay for, they often 
turned to food as their most common sacrifice. Carol was one of those that frequently cut back on food in order to afford gas.

Food! It's either food or gas a lot of the time. Yea, so that make you not go nowhere because you gotta yea. So definitely trade-off for that. Carol, Albina

She was not skipping meals in order to do so, but the quality of the food she picked up was much lower.

I just end up buying stuff I shouldn't be buying. Like hot dogs and noodles and all this stuff that's so cheap. Lunch meat. I feel horrible eating it and buying it. But you know. - Carol, Albina

Similarly, Jacqueline weighted the tradeoffs of various items she could cut in her budget, but food was almost always the item cut,

Most the time it's expenses I shouldn't be cutting back on. Like it's usually the grocery bill. And we need food more than we need cable, but I never think to cut back the cable bill. - Jacqueline, Albina

Cell phone bills were another common expense to cut.

Like if the cell phone bill is due, screw that phone, I'm putting in gas. I'll worry about that later...I would never do it with a major like necessity bill...And my bill and his [her son's phone] bill ain't that much. It's only $\$ 44 /$ month for both our phone. So, I can afford to take a 20 and put some gas in my car. - Angela, Albina

She viewed the cell phone as something she chose to have. For several people, their phone was a necessity so they could not cut it. Being unemployed meant needing to have a phone to receive a call from a potential employer. One person worked for an app-based business, thus without a phone she would not have her job. A few others worked as temps or on-call which required them to be available by phone. 
Even with on-going cost saving strategies and the strategies to save money when funds were tight, it was still a struggle to make driving work for their budget. Derrick was in that position,

I try! It ain't like it work. I try to put money away to save. I try to limit driving you know, but it's like you know. Something always comes up! Daughter has gymnastic practice. Oh, you got to pick them up from grandma's. It's always something. It's always something. Doctors' appointments. Something like that. Damn I can't take public transportation to all that. So, I got to drive. I've cut off packages on cable. I've cut off a whole lot of shit. A whole lot of shit. Even my smoking habit. I've gone from buying packs to getting singles. Shit like that. None of that shit even taking effect yet. Hopefully one of these days something will go right. - Derrick, East Portland

It would also be fair to say that a lot of that struggle had to do with living in East Portland. He recognized transit could not get him around to the places he needed to go, and he surely could not walk. However, walking may have been an option had he lived in Albina. Many of his experiences were also a result of his having to drive 18 miles to work. His new closer job should hopefully take a lot of that strain off him and his budget as it should save him about $\$ 100$ per month. But between car payments and insurance, he still had about $\$ 350$ a month in fixed costs, still at the high end of what people were paying per month.

Another sacrifice people made in order to save money on driving was seeing their friends and family. This was something Kenyon et_al._(2002) brought up in discussing social exclusion, which included a mobility exclusion element. Through mobility exclusion, people could face disconnect from their social support networks. However, few have actually studied how this phenomenon could or would manifest. Nearly half the 
drivers I talked to sacrificed seeing friends or family on the other side of the city. Amber put it this way:

It's a long drive. Money's tight. Distance. It plays a lot. But a lot of people didn't have no choice but to move out that way. My dad stays out there. My dad is who I really frequent the most. But we do a lot more talking on the phone a lot because he doesn't like driving out here and I don't like driving there. - Amber, Albina

Jacqueline also expressed that distance difficulty.

I normally don't visit too much. They usually come see me because I'm not into driving. My son lives all the way out east Portland. So, I'm not going to drive out there. And I have two grandsons that live out that way too. Forget that! - Jacqueline, Albina

Even though both Amber and Jacqueline lived in Albina, East Portland families similarly struggled to bridge that distance gap,

I would go see family more often if I had the gas money to get all the way over like that. But I don't be having the gas like that to get all the way over there. - Derrick, East Portland

Those that did not cut back on seeing their friends and family typically lived near their friends and family so the costs of visiting them were not that high. Another alternative was asking their friends and family to come to them, but this was mostly limited to Albina residents, especially older mothers of adult children.

\section{Psychological Effect of Driving}

As per the findings of Steg (2005), people choose to drive based on instrumental, symbolic, and affective motives. Instrumental motives are motives like discussed above on convenience and expanded range of mobility. Symbolic motives are those where people can attach a level of success to their owning a car, even if it was run-down. Affective motives are trickier, less explicit motives that people have for driving a car such as feelings 
of freedom or loving driving. All of these motives were psychological affirmations for driving, but drivers faced a number of negative psychological influences from driving as well.

Incorporating driving into the lifestyles of those living in poverty had particular effects on the psyche. The literature pointed out the importance of psychological affects for a study like this (Laslett \& Brenner, 1989; Steg, 2005), but to study them in-depth was outside my wheelhouse of expertise. However, it was still important to point out particularly poignant psychological effects that driving had the people I talked to.

I found drivers had many positive affective motives for driving. Drivers felt much safer in their mobility by driving mostly because they were avoiding taking transit. While driving helped them get places they wanted to go easier and on a schedule they felt was better, there was an affective quality to it as well as the ease it brought to accomplishing their daily life maintenance relieved a lot of stress. Similarly, they could get their kids to and from school and extra curriculars easier, but it also provided an affective motive through feeling like they were putting their kids on a better foot than they had growing up by making life just a little bit easier. The stress relief they found from those three items were especially strong as they kept driving even considering the negative affective motives.

For negative motives, I found most drivers were incredibly stressed with traffic.

[In the 1980's] I could leave home with 15 minutes to get to work and be there on time. Can't do that anymore. Traffic. That is the biggest, biggest problem at all that I face when I drive. Because even in the evenings here getting from my street up to Safeway [about 2 miles away] can take you 30 minutes. - Jacqueline, Albina 
Drivers were also very stressed worrying their car's reliability, the cost of gas, and whether they would have the money to continue paying for gas and other associated costs of driving. The strategies they took in order to maintain their driving also took a toll. As Amber mentioned in the context of shopping at Goodwill, not having bought anything for herself in forever, and various other strategies she had incorporated to make driving work for her, "I look like a bum...My life is pretty pitiful." She was clearly sad and depressed about her life, and she was trying to be as bright about her future as she could be. But everything in her life of living in poverty, including the way driving has affected her, was taking a big toll on her. Whether driving was helping or hurting more was a toss-up from a research perspective. What mattered was she found benefits of it that outweighed the costs.

\section{Summary}

In this study, I found low-income Black drivers in Portland certainly used cars in all three motivation areas identified by $\underline{\text { Steg }}(2005$ ). Drivers used cars because the speed, flexibility, and convenience of them over transit allowed them to comfortable fulfill their daily life maintenance. In at least the case of Derrick, his car allowed him to fill the role of "good dad" to his sons to whom he had part-time custody (Troilo \& Coleman, 2012). Their use of cars had a deep psychological role in their lives through feelings of safety, doing right by their kids, and trying to get ahead.

But in determining why people in Albina drove more than people in East Portland, I suspect it was due to social network strength (discussed more in the next chapter) and the alternatives to driving available to them should something happen to their car. The strength of their network in Albina meant they got more support with a lot more ease than people 
in East Portland due to the proximity to well-resourced friends and family that were willing to help them in times of need. That would give them more material leeway in order to afford driving, or at least get to the point of stability in their lives where they could afford to own a car (Heflin et al., 2011). Additionally, the ability to walk instead of drive if money was tight gave Albina drivers a huge advantage over those in East Portland. The precarious nature of work coupled with living in poverty always meant money on hand was never certain. Having those strategies as a back-up could provide more confidence in owning a car tipping the scales into the positive for people living in Albina.

While there were many benefits to driving for low-income Black populations in Portland, they came at a great cost. In order to drive, people had to make room in their budgets for owning a car. Compared to a monthly transit pass from TriMet, $\$ 100$, driving could be about as comparable in cost to costing nearly five times more. Those that spent toward the bottom of the range generally did not use their vehicle as much as others and they cut back on insurance which put them at a great risk should they be pulled over or get into a crash. Meanwhile, those that spent at the top of the range had to sacrifice more often and stress over every dollar in order to make driving work for them through good times and bad.

\section{Bus Dependency}

Denise lived in the heart of East Portland about a mile from the MAX line on Burnside. Every day she would hop on the bus to get to the MAX station and ride the train for an hour to get to work in Beaverton. Her trip home had her detour to Albina to pick up her daughter from after-school activities. In total, she commuted about three hours a day, 
provided everything on transit was working as it should. Luckily, her employer paid for her transit pass, so she rarely faced difficulty getting around because of cost. However, she was unwittingly paying for her daughter even though she qualified for school passes through Portland Public Schools. Her son would qualify come the new school year thanks to an agreement Portland reached to expand the youth pass to East Portland schools.

At the same time, though, she did not want to be riding transit anymore, and even more so did not want her kids riding it anymore. Safety on transit was a huge concern for her leading her to take defensive maneuvers such as avoiding transit at night and preventing engagement with others. She had also been riding transit all her life, struggled through using it, and wanted better for her kids.

Transit also limited her range of daily life maintenance destinations. She was unable to shop for groceries at her preferred stores because of difficulties of catching transit to them. Her oldest son lived in Vancouver, and her bus dependency has substantially limited her ability to see him.

Denise had the longest commuter of anyone in this study. But her transit use otherwise was very similar to other transit dependent people I talked to. Safety rose to the top of everyone's concerns about taking transit, similar to findings from Spe-ars $\underline{\text { et_al. }}$. (2013ㄴ. Juggling kids was a major task for transit dependent parents, and it often meant substantial sacrifices to accommodate. Transit dependency often also meant sacrificing choice for what was possible to get to.

Over half the people I talked to used transit as their primary way to get around transit dependent. This was much higher than the ACS estimates of $31 \%$ for commuting 
by transit for low-income Black workers. Based on a multitude of studies (Cao, 2015; Ewing \& Cervero, 2010; Giuliano, 2003), the densities of people and destinations in Albina supported hypothesizing high transit usage while a relative scarcity of transit and long distances between destinations in East Portland was more conducive to driving. However, I found that East Portland residents were more likely to use transit than Albina residents. And the reasons that would be the case were largely absent from the literature.

Transit dependent populations tend to be low-income, people of color living in the inner-city (S_anchez_et_al.,__2007). Indeed, a substantial share of low-income Black populations primarily ride transit, more so than for any other demographic group (Giuliano, 2003). Decades of segregation continue to concentrate Black populations in the inner city. However, Black populations have been spreading out from the inner city, and a substantial number of them live in suburban areas in regions across the U.S. (Kneebone \& Berube, 2013). Large questions remain in understanding why they use transit at such a high rate or why it has held up to shifting geographies of Black populations. Spears et al. (2013) suggested that Black populations held more positive associations with riding transit than White populations which led them to ride it more. There was a causality issue in their suggestion as they did not determine whether the positive attitudes were associated or independent of ridership. As Giuliano_(2005) found, low-income populations tended dislike transit more than higher-income populations, but because of their lack of choice, they rode it anyway.

Through this section, I highlight the stories of those of that were transit dependent in Albina and East Portland to identify why many low-income Black populations in 
Portland depended upon transit, the barriers they faced in being dependent upon transit, and how they coped with the shortcomings of transit. Unlike with driving, few people found positives with taking transit, as shown in Table 5-3. The ability to reach destinations was split between Albina and East Portland with those in Albina more likely to feel they could get where they wanted to go. The negatives to transit drove many to find other options.

\section{Table 5-3 Positives and Negatives of Transit}

\begin{tabular}{|l|l|}
\hline Positives & Negatives \\
\hline Could get everywhere they wanted to go & Unsafe \\
Could find housing near transit lines & Could not get everywhere they wanted to go \\
& Expensive \\
& Slow, unreliable, restrictive \\
& Unable to reach better paying jobs \\
& Exposed to the weather \\
& Difficult to take with kids \\
\hline
\end{tabular}

\section{Aspiring for Better}

Unlike drivers in this study who tended to have several back-up options if their car was not going to work for them that day, transit dependent populations were not as lucky. Their options were limited to taking transit, not going anywhere, or hoping they could find someone to give them a ride. Walking was mostly limited to those living in Albina. East Portland residents also walked, but not as much and at a much greater cost given the long distances and risks to personal safety. Support networks were also not equally effective leaving some people much more able to call people for a ride. But again, this tended to be the case mostly for people living in Albina. Their choice for getting around, if it could be considered that, was to try to make transit work as best they could. 
Transit dependency manifested in many ways, but the most common way was that when weighing the other options available, transit made the most sense. Most of them were not in a position (financially or legally) to drive. Cars were expensive for them, and while four of them were aspiring to get a car, they had no means to do so yet. Five of them already had cars. Two of them had operating cars and used them about equally as transit. The other three had cars that were broken down to the point they had not driven them in months ${ }^{2}$. The disrepair of their cars was dictated by money, primarily the lack of it to pay someone else to do repairs.

Having a car that broke down brought with it many hardships which were reminiscent of not having a car at all. This was evident from those that expressed a desire to own a car in the future. Those expressing a desire to own a car in the future had a deep dislike of transit borne from past experiences like unreliable busses, not being able to get where they needed to go, or even just having to deal with the weather more than drivers did. Finding weather appropriate gear for them and their kids was a difficult struggle for people in poverty. Denise had this experience:

One day it was raining so bad by the time we got from my house to the MAX over there he was soaking wet. And he was just a kid. Then I was just like "I'm done!" ...Even though he had his hat on and everything on he was just soaked. I was done. I was like "no more!" Now he's 23. He drives now. He doesn't ever want to be on the bus. - Denise, East Portland

There is little public assistance available to outfit families living in poverty in cold and rain appropriate clothing, and charities are first-come first serve meaning many families go without or have to cope with ill-fitting gear (Edin \& Lein, 1997). Plus, none of

\footnotetext{
${ }^{2}$ See Chapter 5: Driving: Dependability for a brief on their situations.
} 
the clothes from charity organizations are ever guaranteed to be protective for both the cold and rain, a weather affliction that affects the Pacific Northwest for at least nine months of the year. Being exposed to the rain also means having to dry out coats, gloves, hats, etc. each night, which for people living in poverty, that is easier said than done. Not having the resources to adequately protect your child from the weather can mentally break a person. That was the feeling I picked up from Denise.

Most of those desiring a car wanted to take advantage of the speed and convenience of it, like that expressed by current drivers. Nikki acknowledged a car would make it easier for her to get around places. While she used the bus frequently, being in East Portland meant the places to go by bus were limited, and as a result she was not leaving the house much. Denise commuted from East Portland to Beaverton (about 18 miles, which took about an hour by train or half hour by car, but rush hour traffic and train breakdowns added much more variability into the times) and would like a car to make that commute better.

Most the others dependent on transit did not express feelings of transit in Portland different from those that were aspiring to own a car. There were a lot of negative feelings toward transit, consistent with the findings from (Giuliano, 2005).

\section{Transit Delays}

Busses and trains arriving late or not at all based on the schedule were a common problem faced by the people I talked to. Across the system in 2017, buses had an on-time performance of $84 \%$ and MAX was on-time $89 \%$ of the time; performance had risen substantially since 2015 from $80 \%$ and $78 \%$, respectively (Kea, 2017, 2018). That meant in 2015, over one-in-five buses and trains were leaving their stops either more than a minute 
early or five minutes late. From the interviews I conducted, the problem seemed much more substantial in East Portland than in Albina. In East Portland, everyone I talked to experienced late or missing buses or trains on a regular basis. Whereas in Albina, only one person, Troy, had issue with late buses to the extent it was a problem in their mind. It's about 50/50. To be honest. Like when I really need to get somewhere, it could get me on time, but I'm not going to be on time because of the bus. I'm going to be on time because I leave early. And the bus is always late. And the bus may not come at all sometimes. Says three minutes and it doesn't come for 16 minutes. I've had that happen multiple times. Troy, Albina

Part of the geographic difference was related to the level of service available in Albina. Most of the bus lines running through Albina were frequent service and did not have a severely altered schedule on the weekends. Redundancy in bus lines in Albina also meant walking a couple blocks could get you on a different bus in the same direction. Even with that redundancy though, no one in Albina did that because the buses they sought to use were reliable and frequent enough that walking to a different line did not make sense. In East Portland, most of the people I talked to relied the most on the Blue Line MAX because it ran frequently and had a consistent schedule through the weekend. But the bus lines were a different story.

A late or missing a bus could result in a walk of miles, as was the regular experience for Destiny when she was trying to get to work.

He [boyfriend] usually takes me. So, if he doesn't, I usually walk from Powell all the way up here to Burnside [about 2 miles] and then I catch the Burnside bus up to [confidential] and walk up. That's a long walk, but I'm used to the walk. - Destiny, East Portland 
To add to her experience in that commute, that walk was through what she identified as a dangerous area along $162^{\text {nd }}$ Ave.

It's worse when you get up here [on Burnside]. I don't feel safe walking up here, that's why I carry mace. But from Powell to Mill is cool, but from Mill all the way up to here [Burnside] is terrible. - Destiny, East Portland

The walk she faced was especially scary at night since there was little to no street lighting. She refused to walk that stretch at night and would instead get a ride from her boyfriend or her cousin that lived down the street. Luckily for her, getting rides home was more likely than going to work. This experience was very common among transit riders especially women. It was also common in the literature with women the most likely to express feelings of fear for their safety (Loukaitou-Sideris, 2006, 2014). I cover this more below in a sub-section on safety.

Consistent bus delays affected people's lives in multiple ways. Jasmine had experienced that struggle when trying to look for a job.

Because buses are always late and it's really hard to get out there and go searching for jobs all day long on the bus with a kid. It's just...it's a lot... When you're on the bus, you have to get off every two stops, turn in this application. It's just...it's crazy. - Jasmine, East Portland

Delays also forced people to cut even more time out of their schedules. The bus already took a lot of time out of their schedule because of its slow speed and how far they were going. Denise was one of many that planned their bus trips by getting on an earlier bus than they needed to in order to ensure they could get where they were going on time.

I always have to leave earlier than I have to because I need to know I'm going to connect on all my buses. Or if it's raining, I know I can catch the [bus] right there to take me to the MAX, but if I miss that I have to walk all the way because I can't afford to wait for that next [bus]. So, I always try to leave a bus before I have to leave. - Denise, East Portland 
Having to leave for work earlier than she should have to impacted her further in that she had to be out the door at about the same time her daughter would be picked up for school. If the person picking up her daughter showed up late, she was going to have to walk the two miles. Those long transit trips like Denise took out to Beaverton were not uncommon. As Ashley stated:

It takes forever. It takes like two hours to do anything. And stay on time. Say you have a job interview or school, you can't be late to those kinds of things. So, you have to plan. And be early. You're cutting it close [with a 9am interview]. Waking up at like 5:30-6am just to make it. And the bus is getting more and more irreliable [sic] than it used to. It used to be more timely to me. Like it comes when it's going to come. - Ashley, East Portland

Transit delays caused many frustrations, but they were the tip of the iceberg compared to much larger issues around being transit dependent. Certainly, a late or missing bus could throw off their entire schedule for a day, but overall, such issues did not present enough of an issue that people tried to find ways to avoid transit. Typically, delayed or missing transit compounded other issues, such as getting to work (Blumenberg, 2002).

\section{Transit and Employment}

Beyond late transit, the lack of quality transit presented many drawbacks for those dependent upon transit, especially those in East Portland. This was best represented by the employment situations of the people I talked to. Quality transit is transit that is available, frequent, and runs on a schedule that accommodates late night and weekend workers. None of the people I talked to had need for late night service at the time. But they had been in that position before, and transit absolutely did not serve their needs since most buses stopped running before they got off work. Frequency of transit further affected them by 
experiencing severe delays if the bus was late or leaving them stranded for long periods of time because the bus only ran once an hour. Job choice was also impacted by whether transit could get them to the job. Without transit, they could not feasibly accept the job.

About half of the people I talked to had turned down jobs that would pay higher wages than they currently received due those jobs not being accessible by transit. Consistent with the theory that women tend to work closer to home (Gilbert, 1998), most who looked for higher paying work in the suburbs were men. Troy worked a temp job where he was sent to be a cook at restaurants all over the city. However, being bus dependent, he could not take all the jobs he was offered.

It limits me on where I can go if I don't have a car. And some jobs there's no bus accessible to it. I had one offer at Riverbank at Kelly Point Park, but there's no busses that run to it. So, I couldn't take that job. So, I had that difficulty before. And that's right on the North side. - Troy, Albina

He had no control over the jobs offered to him through the temp agency except to say no to those he did not want. He would sometimes go weeks without work because all the jobs he was offered were inaccessible by transit. Even when a bus was available, the lack of reliability of the bus meant he also limited his jobs for anything that would be too far away by bus.

Went without work for a while because I couldn't get there. And what's available ain't by me. At one point I had to work in Wilsonville. Had to be there by 9 am. I had to leave here at 7 am. An hour and 45 minutes every day to get to work. Miss one bus you're late. And miss one bus and be late, they're not calling you back. So that's why I avoid that. I'm not putting myself in that situation. - Troy, Albina

He made multiple attempts to work in those far flung jobs, but he could not make them work for his budget. 
I get a job they say is way out there, and the bus ain 't available after 12 or 10 at night I'm probably not going to take that job. Unless it's really good money and I can afford to pay it. I can't pay every day. I've been in jobs like that. Where I was working at 257th in Gresham. The bus didn't go all the way out there. I had to walk from Mt Hood CC around this bend that was almost a mile. Every day. Just to get to work. And after work, they had this little private cab company I had to pay this dude to pick me up and take me to the MAX. He'd charge me \$5 just to take me to the MAX. Every day. So that's $\$ 25$ a week just to get home [on top of transit fare]. That only lasted like 2 months. Couldn't afford it no more. - Troy, Albina

Troy had to constantly weigh the potential of accepting a job, being late, and losing his work through the temp agency, or just going without that job for the time being. Being a temp worker added to the pressure as the job offers were unpredictable. That meant if he went without work for a while, he may not even have the bus fare to get to work for the next offer he got.

And a lot of times when you first get a job and you don't have no two weeks' worth of bus fare, you have to wait two-three weeks before you get your first check. So, I ran into that situation where I barely had enough money to get to work paying the bus every day. Think about it $\$ 5$ a day, 5 days a week, $\$ 25$ a week. If you have no money trying to come up with $\$ 25 \ldots$ and that's just getting to work. Not even counting lunch money. It can be very hard being very poor. - Troy, Albina

That lack of predictability in his work also meant there was no way he could plan ahead and get a monthly pass. His experience showcased the problems of suburbanization of jobs, the lack of transit to those jobs, unreliable transit when it did exist, and the fiscal instability of being low-wage contingent labor. Not everyone worked in temp jobs or even ones where the place they work could change from one day to the next. But these problems existed for anyone looking for work, changing jobs, or changing where they lived. Being poor was a constant struggle to find better paying jobs. And those better paying jobs were almost 
always determined by whether or not they could get to them (Gurley \& Bruce, 2005; P. Ong \& Blumenberg, 1998; Smart \& Klein, 2018).

Robert was an ex-felon, which made finding jobs even more difficult for him. Finding good paying jobs was a rarity for him, and that was complicated by the fact that many jobs willing to accept his criminal history were inaccessible by bus. So, he had to turn them down.

Robert: Yea. Good jobs. Very good jobs. I've had good jobs where I couldn't even do it because there was no bus to get there. I'd have to walk four miles. Nobody wants to walk that far. It was a good gig, but it's not worth it. Because what if I got a shift where the buses didn't run?

Me: What kind of jobs were those?

Robert: Like all the way out in like Damascus like warehouse jobs. Financially that probably would have broke me in the long run. - Robert, East Portland

Ashley, who lived in Gresham, turned down a job at the Amazon warehouse in the Northwest Industrial District adjacent to downtown Portland, where she could only access it by transferring buses in downtown. For her, that would have been about an hour and a half transit trip one-way. If she worked a shift after 5pm, her trip home could become much more hectic as the busses she could use to get there switched to once-an-hour runs shortly after $5 \mathrm{pm}$.

Joseph did not have a choice but to accept the job he was offered. He worked parttime in a warehouse at the port in North Portland. It took him over an hour and a half on transit to get from East Portland to North Portland for work. He was desperate for money as he had another baby on the way. Funds were so low he had to hunt down cans to turn in for cash for bus fare in order to get to work. Often times, he would come up short and 
would try to call around for a ride. Since he had only lived in Portland for three years, he did not have many people he could call up and would instead need to spend more time hunting for cans. His work was amenable to the situation as he just needed to show up at some point, but it was clear if he did not show up, he would be out of a job. Needless to say, he was not satisfied with his job, and was seeking any opportunity to get out of it. However, with an outstanding warrant and very low-educational attainment, his options were limited.

The problems associated with jobs and transit affected everyone I talked to, including drivers. At some point in time, everyone had taken transit to their job. They all made sure they had jobs where that was an option because they never wanted to be in a situation where they could not make it to work. But, because of that restriction of needing a transit connection to work, it held them back financially. The problem of transit delays added to their stress level, but at least they knew they would get to work at some point.

\section{Constrained by Transit}

Getting to jobs was only part of the inconvenience of being transit dependent. Unreliable, infrequent, or non-existent buses constrained folks in numerous ways. Most of the time, the inconveniences of transit meant they would just not go anywhere. Other times it meant they could not or would not go to places they wanted to go and instead went someplace else. For folks living in Albina, it often meant they were not going further East than Gateway Transit Center (a large transit hub in East Portland at $99^{\text {th }}$ and Halsey), but folks in East Portland were at times forced to make the long trip west past Gateway and to Albina in order to partake in culturally relevant destinations like church and hair salons. 
Getting to grocery stores by transit was a major hurdle for most transit dependent people. Jasmine lived in Cully. Bus availability and being restricted to the bus impacted the grocery stores she went to, a common tradeoff transit dependent folks made.

I normally go to Albertsons. Sometimes Safeway. But because of where I live, even though it's [Safeway] really close, it's in an odd location bus wise. So, it's literally only like 10-12 minutes away but I have to take 2 different buses to get there because of where it's at. And Albertson's there isn't a bus that goes there from my apartment. So, whenever I go there, I just have to walk...I don't really get down to WinCo or Wal-Mart anymore. Because those are like big grocery trips. That's just too much on the bus with or without a kid. - Jasmine, East Portland

Grocery access was a particularly difficult issue for East Portland residents. While many of them could, and did, hop on a single bus to get to WinCo for cheap groceries, it was rarely that simple, as evidenced by Denise.

It's a challenge for me. Monday through Friday when I get off work, I don't want to go to the grocery store. And weekends...Saturdays are ok for me, but Sundays the buses run funny, like every hour, so that's not really an option for me. So, I try to do it on Saturdays if possible. But I try to get food to last us about two weeks so I don't have to go back. If I need to get milk or something for the kids, I'll just go across the street to the corner store.

- Denise, East Portland

And those in East Portland that did not shop at WinCo were shopping at places they did not prefer. Usually that was because they would prefer to be shopping at WinCo or Costco, but they were unable to realistically do their grocery shopping at those places while taking transit. As such, their typical response was along the lines of "We just go where it's closest." They want to get the deals on food, but their transportation situation did not make that a realistic option for them between having to get there and back, carrying groceries, and usually with kids in tow. On the savings side of the equation, Vanessa explained it this way: 
I come here [Safeway] because it's the closest. I appreciate the fact that they offer...if you spend so much you can get delivery service. But even if I spent one-hundred dollars that hundred dollars I spend here that's not even $50 \%$ if I would have went to a WinCo or a Costco or just somewhere else. So, I don't win. - Vanessa, East Portland

The savings could be quite substantial, but she could not realistically make that trip further from her house. The savings aspect of stores like WinCo, Costco, or Wal-Mart also encouraged them to pick up more groceries while they were there. But making those trips on the bus was nigh impossible because of the limits of what they could carry.

Going to the closest grocery store was a common finding among studies on food access for disadvantaged central city neighborhoods (Allard et al., 2015; Alwitt \& Donley, 1997; Walker et al., 2010). However, East Portland was suburban with a high share of the population being poor (23\% there lived in poverty and they made up $37 \%$ of all persons living in poverty in Multnomah County) and people of color (see Figure 5-2 for the distribution of overall poverty in the county). It mimicked many of the qualities of disadvantaged central city neighborhoods that were often the targets of studies on unequal access. Unlike those neighborhoods often in studies of disadvantage, East Portland was not nearly as dense, and the transit network was not nearly as good as most central city neighborhoods. So, while the findings of those food studies were similar to what I found here, the suburban environment of East Portland created different challenges to similar issues. 
Figure 5-2 Portland Poverty Rates, 2017

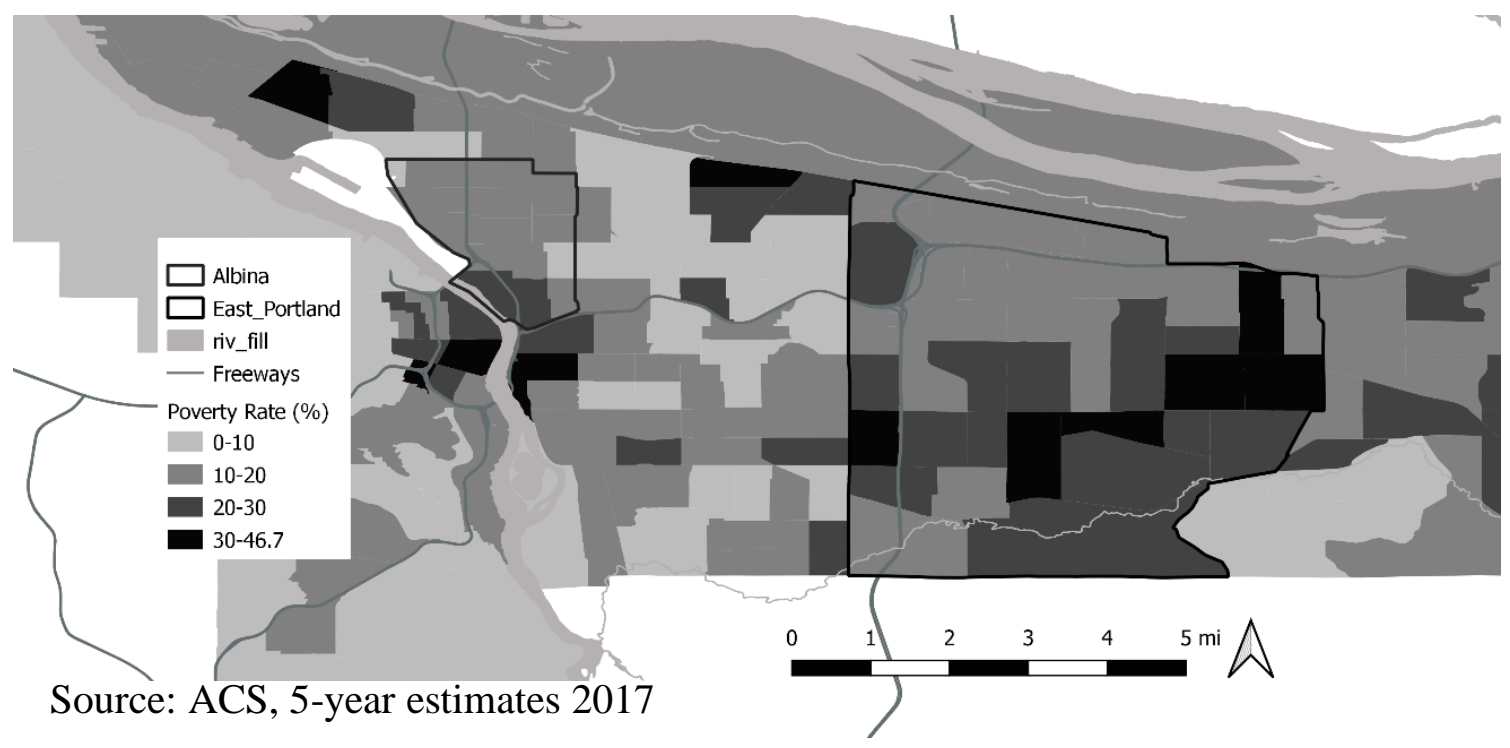

One way to get around the limits of what they could carry for their shopping trips and where they could go for groceries was to call someone for a ride (Clifton, 2004). Only one transit dependent person in East Portland relied upon someone to give them a ride to the store, but half of the transit dependent folks I talked to in Albina got rides. Because of that, everyone dependent on transit in Albina was shopping at their preferred store while only half of them in East Portland were.

This was largely an effect of their support networks. As Rogalskㅡ﹎__(2010) found, support networks were critical in making up the difference in what transit could get them. Without adequately resourced support networks, they were worse off (Turney \& Harknett, 2010). For people in East Portland, their support networks were either too far away, too unreliable, or did not have cars (likely because they were poorer than support network members in Albina) so their ability to get rides was much lower than for people in Albina. 
Their suburbanization in effect either isolated them from the better resourced members of their support network or the entirety of their network.

It was not just grocery stores that people felt they could not get to where they wanted to go. Restaurants, church, and hair salons were the most common places folks said they could not reach by bus. And it was much more of a problem for East Portland residents. The lack of such establishments in East Portland contributed to that problem, and I cover that more in the next chapter. But without such amenities in the neighborhood, residents made adaptations in order to reach them, such as how Ashley got to restaurants to enjoy a night out with friends.

There's nowhere to eat around here. So, you got to make a trip. When I go out to eat, I hopefully go with my friends, so they can drive me. Or I'll catch Uber sometimes. As far as on the bus, there's not that...it's inconvenient. - Ashley, East Portland

She lived in Gresham and did not feel any of the places around where she lived accommodated her desires for places to enjoy a night out. Being poor, she did not have the money to go out often, but the stress of life when living in poverty required ways to decompress, and that was her preferred way to do so. But it was hard for her. Her friends lived in Albina, and she would rely on them coming out to Gresham to give her a ride to the place they were going to go that night, most likely in the Albina area. This was also the case with "catching an Uber" because she did not have a credit card required to pay for an Uber. Without her friends to get her around, she would have stayed home a lot more.

It makes me feel like I'm missing out but maybe I should also be looking for different routes or different ways so I can keep my money. That's why you end up asking your friends to go with you or carpooling. Because $\$ 5$ spent on the bus versus $\$ 5$ for "hey, I'll pay for gas" will get you a bit further.

- Ashley, East Portland 
The constraints of transit availability heavily impacted the bus dependent people I talked to, especially those in East Portland. They were sacrificing money on things that were more expensive purely because the bus could not get them where they wanted to go in a reasonable manner. East Portland residents also had the added cost of getting to Albina in order to make it to Black churches or hair salons, establishments that they could not find in East Portland. However, the opposite was only true for some in Albina who preferred the lower cost grocery stores in East Portland. These constraints of transit ultimately added to the base costs of using transit as they took time and added a lot of stress.

\section{Safety}

Aside from not being able to reach destinations, the people I talked to felt more restricted in getting around because they did not feel safe on transit in Portland. Denise expressed that she felt about $75 \%$ of her hesitancy to take transit was because of fear for her personal safety. She even took several days off from work after the racially-motivated stabbings on the MAX. Safety had both a tangible and psychological effect on folks, especially those living in East Portland. In East Portland, folks had many reservations around transit because of the safety both on transit itself and getting to it. In Albina, their concerns were mostly restricted to transit, especially at night, and if they had to go out to East Portland.

With gentrification in Albina, many of the gangs present in the neighborhood in the 1980's and 1990's were moved out to East Portland (Gibson, 2007a). No one referred to Albina with monikers that suggested the crime of the past was an issue anymore. However, several people referred to East Portland as "the numbers," "felony flats," and "little 
Saigon." While only felony flats had an explicit descriptor of crime in the area, the other descriptors were laden with associations of crime. Such identifiers of East Portland were also indicative of the fact that many folks in Albina did not want to spend time in East Portland and many East Portland residents feared walking down the street on their way to

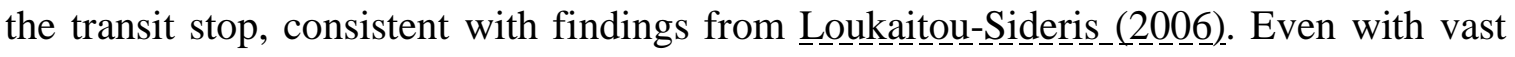
area of East Portland, no one seemed to feel any one part of East Portland was safer than another.

Even with nearly all of the people I talked to having concerns about safety on transit in Portland, some of them were not all that worried about it. Jacqueline got around by both car and transit. She began using transit as a substantial cost saver, especially since she had a monthly transit pass through work. But one of her main barriers to not using transit for so long was the safety issues.

Initially, when I first started taking it, I was nervous because I was hearing all this stuff on the news about this incident happening and this incident happening. So, I was a little nervous about taking it. As I took it, I started to relax on it, but now when you think about it, I don't really think about what might happen on the bus or the MAX anymore. I just get on, sit down, and mind my own business. - Jacqueline, Albina

She was one of the few people I talked to that were relatively comfortable on transit with safety concerns not being too much of an issue for her. Her daughters, both teenagers, regularly used the bus on their own as well. Altogether, only four people I talked to either were undeterred by safety issues or did not feel there were any issues. Two of them lived in Albina and two were in East Portland. Their kids were of all different ages as well with some needing to accompany their kids on the bus while others let them go alone. Interestingly, both of the people that drove and used transit as their main modes to get 
around were undeterred by safety issues. Considering other drivers overwhelmingly put safety at the top of their reasons why they did not want to use transit, it made sense that the two that equally split their time between transit and driving would likely be undeterred by safety issues. But I was unable to ascertain how or why they were able to overcome that hurdle when most other drivers were not.

Nearly every bus dependent person I talked to described behaviors they would adopt on transit, such as putting their headphones in, not making eye contact with other people, not talking to other people, and even staying out of conflicts they see on transit. In general, their strategy was to avoid other people by all means possible. This was a fairly universal finding in transit safety research (Gardner et al., 2017). They felt there was no way they could trust another person on transit, and thus closed themselves off as much as possible. Such attitudes likely contributed to the comments from people who longed for a nostalgic ideal of transit when they felt it was more of a "community." It is difficult to have a community atmosphere when no one can trust one another.

In addition to their behaviors to close themselves off from other riders, they tried to adjust the timing of when they were using it so they would not be on it when it was dark, as Vanessa did.

It's generally just fitting it in within the daytime. I want to get there and back during the daytime so I'm not traveling at night. It's a lot of stuff I'm trying to avoid at night time. There is a very big difference between the day time and the evening time. Or night time. With the other occupants. Let's just say that. - Vanessa, East Portland

Safety when the sun was not out was a serious enough concern that people changed major aspects of their life because of it, such as Denise. 
I've quit a job because it was just too early getting on the bus. It was too dark. I was with my kids' dad and sometimes he would want to walk me to the bus stop. - Denise, East Portland

In both those examples, East Portland women were deterred from transit because of either perceived safety risks on transit or on the way to it, and they substantially altered their activities because of it. Generally, women I talked to were more fearful of the situation on transit at night, and this was common in the literature (Fenster, 2005; Gardner et al., 2017; Loukaitou-Sideris, 2006, 2014). Albina residents were not as apprehensive, but generally they still avoided transit at night. Unlike their East Portland peers, Albina residents' activities were easier to arrange in a way that they did not have to worry as much about being on transit at night. There was a huge difference between trying to catch the bus for 5-10 blocks compared to 60 blocks.

Men were not as likely to be deterred from transit because of safety issues. While the literature generally agreed with that sentiment (Gardner et al., 2017), men have not received much attention in the safety literature for when they travel with their kids. They were considerably more concerned when they had their kids with them though. In several cases, it was such an issue they refused to take transit with their kids. Darius had many examples of situations on transit that caused him great concern, especially with his kids, but his dependence on transit left him no other choice.

You're forced to interact with someone you don't have to...And then you'll get that one person that'll try to mix up everything. It's like "bro just stop. Calm down." I've had it plenty of times especially right here. One day we were coming off the MAX, white dude gets on the MAX "oh you're a dumb nigger" this that and what not. I'm looking around like "who you talking to?" This other white lady across from him is like "is he talking to you guys?" I don't know this guy. Either he's high off something or he's completely lost his mind. And then he comes up closer. And finally calls me 
out "yea you super ignorant bastard something this that there." I'm like "hold on bro. First, chill out you're not going to sit here and disrespect me in front of my kids and my family. If you want to say something or feel you have something against me, we can step off the MAX and talk it out like men." He kept it going. That old lady was like "why don't you be smart and sit down. Can't you tell these people don't want nothing to do with you?" And what really got me was when he started going after that old lady. I threw him off the MAX. And I handled it out there. I never really had to deal with ignorance like that really. I understand it, it's Portland, you have so many experimental drugs out here. But you got people just completely losing it. - Darius, East Portland

Homeless populations or those with mental health or drug abuse issues were a concern for most of the bus dependent people I talked to, more so than the racist MAX stabbing. Part of the concern was being afraid of their erratic behaviors because there was a feeling that one wrong move, statement, or even look could set them off. These were issues that existed long before the racist attack happened. At the same time, as demonstrated by Darius, the racism and homeless/drug abuse issues were not always mutually exclusive. The fears of the people I talked to were only exacerbated by the attack.

The racism going on in Portland in the Summer of 2017 was a severe deterrent to transit usage for many of the people I talked to. Nearly all those that were transit dependent had safety concerns about transit prior to the racist stabbing, but the stabbing itself put people over the edge. Jasmine was already vulnerable from other personal situations and a history of homelessness. When the stabbing happened, she was severely affected.

And, honestly, I'm kind of scared every time I get on the bus or train now after all of the craziness that's happened the last couple weeks. I don't even want to leave my house. Especially being not completely white. I could have been a target for that guy myself. - Jasmine, East Portland

After the racist attack on the MAX, many of the people I talked to cut back their use of transit either to specific times of day (even though the attack happened in the middle 
of the day) or entirely. Ruth had cut back nearly all of her transit usage after the attack and coped by getting rides instead.

Well back when them stabbings happened, I didn't ride it for a long time. And when I rode, and even now, I still be kinda nervous. I won't ride it at night. Yea, I won't ride it at night. I'd rather not ride it at all. That's why I'd rather go broke paying for rides. But if I ride it, I really need to get to where I'm going. - Ruth, Albina

Considering the attack happened as a result of folks standing up in defense of two school-aged girls that were being harassed, it especially struck the parents I talked to that had children around the same age. Vanessa expressed her reaction:

When he's [her son] got an after-school activity, I have to go pick him up. Because he's not catching the bus. At least not by himself. I have trust issues especially with all the shit going on. With this whole black and white thing. This whole hate shit. I want my kids to come up with a school bag and not in a body bag. And it's really crazy because it wasn't like that before. But we grew up, even I grew up in an era, where the whole clan and whole extra shit didn't exist. Well it existed but you never heard em. So, it wasn't a big thing. But now they're trying to make a point and show you "we're here and we're serious about that shit" I won't be that parent putting their kid in the dirt. I just won't. I refuse. - Vanessa, East Portland

Their kids being on transit was a concern for most of them regardless of the threats

of racism. Darius had one such incident that while it did not keep him from taking his kids

on transit, it was something the was aware of and intolerant to, for entirely understandable reasons.

We get a lot of perverted people out there. And with me having beautiful little girls. One time my wife had to stop me from smashing this dude who was licking his tongue at my daughter and playing with himself. And I'm sitting there and my wife is like we're going to get off at the next stop and you're not going to turn around and look. But off instinct I'm going to turn around and look if you tell me not to look. Then all hell broke loose.

- Darius, East Portland 
There is not much that can be done to prevent dangerous people or predators from using transit unless there is someone there to catch them and stop them in the act. Nearly everyone I talked to was supportive of security personnel being ever-present on the MAX in hopes it could deter people from acting stupid and doing the things that spurred their fears. Indeed, most transit security literature suggested that security personnel had the largest effect on feelings of safety for riders (Gardner et al., 2017; Loukaitou-Sideris \& Fink, 2009). At the same time though, nearly all the people I talked to that supported a security presence also doubted that the presence of security would be enough to change their feelings about transit safety. Even if there was a way to prevent dangerous people or predators from using transit, there are a lot of ethical issues that surround the idea of banning someone from transit when they are likely unable to get around in any other way.

TriMet has seen declining ridership on its system over the past few years. In their most recent report on the issue, they cited "economic displacement" as a contributing factor to the ridership decline (Mills \& Steele, 2017). But they failed to recognize safety as a substantial contributor to ridership declines. It is likely that until the perception of safety on transit is improved, TriMet will continue to see ridership declines. That will likely be especially true among low-income Black populations, considering the mixture of safety concerns with racism from other passengers. One area that may improve relations with such populations may be TriMet's institution of a low-income fare. With cheaper fare, what they are willing to put up with in riding transit may increase, as suggested by some of the people I talked to. But for most the people I talked to, they said it would not matter if transit 
were free, they still would have a severely negative view of transit if safety was still an issue.

\section{Expenses $^{3}$}

Riding transit in Portland would not cost anyone more than $\$ 100$ per person per month provided they had a monthly pass. Of the 16 bus dependent folks I talked to, only four had monthly passes. Two of them had passes through work, one had a pass through a special arrangement where they did not have to pay anything, and the other paid for it out of pocket. While so few had a monthly pass, all of them felt they should have a monthly pass.

The advantages of a monthly pass were clear. It took away one of the hassles of getting on transit: trying to get together the money to get on the bus each time. It also ensured you could ride the bus as much as you wanted and not spend more than $\$ 100$. However, the large upfront cost presented substantial issues for the people I talked to. Few other studies have addressed the upfront cost of monthly bus passes, but Agrawalal et (2011) did and also found the upfront cost of monthly passes was a huge barrier.

None of the people I talked to spent more than $\$ 100$ a month per person on transit. And most of them spent substantially less than that. On average, they were only spending about $\$ 55$ a month. At that expenditure level, they were not using the bus enough to make

\footnotetext{
3 TriMet started their transit card program in July 2017 (in the middle of my interview process) which changed how people could pay for rides. That particular program tracked a user's rides throughout the month and would automatically roll over to a day-pass once they took $\$ 5$ worth of trips in a day and to a monthly pass once they took $\$ 100$ in rides for the month. All of the interviews also occurred before TriMet instituted a low-income fare program, which started in July 2018. The low-income fare cut the cost of a day-pass from $\$ 5$ to $\$ 2.50$ and a monthly pass from $\$ 100$ to $\$ 28$. The same ride tracking worked on the low-income fare as well so riders could work up to earning the monthly pass rather than paying the entire cost up front.
} 
a monthly pass worth it. But that expenditure level would earn them a monthly pass under the low-income fare program. Even though the fare card system allowed them to pay-asthey-go, their money scarcity encouraged them to save as much money as possible which meant not riding transit so they could save the $\$ 2.50$ to $\$ 5.00$ that day. Having a monthly pass could be very beneficial to them so they would not have to fret over the expense every time they got on transit, and the low-income fare program would make it easier for them to afford it. It remains to be seen though if low-income households will try to arrange expenses in a way so they can afford the monthly pass sooner in the month with the lower cost as an incentive to do so. Alternatively, since the 2.5 hour and all-day passes also got reduced to half the cost, it is possible, they may still restrict transit usage in order to save money. There is too much uncertainty around how low-income riders will respond to the low-income fare, but I would imagine it would have nothing but good effects for them, not withstanding problems with the fare card itself.

For nearly all of the transit dependent folks I talked to, coming up with $\$ 5$ a day to ride transit all day was difficult enough, and if they could get away with it, they would just buy the 2.5-hour pass.

I'm not spending that much money, but I should get a bus pass. There's some times I have to go in my mom's piggy bank for coins. Because it's a lot. And if it's every day, that's a lot of money right now. - Tawnya, Albina

Besides scrounging around the house to find that last bit of change lying around, a couple of people also went around and collected cans to turn in for cash purely to pay for transit passes. For Joseph, collecting cans was the only way him and his wife were able to get around, which was also difficult since they needed to get on the bus in order to turn the 
cans in for cash. A reduced fare monthly pass may still be difficult to afford for those living a daily struggle to afford transit fare.

In some cases, people were spending money they did not have to. Tawnya was paying for her daughter to ride transit when she was too young to be charged for rides.

Well they always charge me. I have tried to get on and not pay for her. And they ask me how old she is and when I say four, they still charge me for her. Like the past two years I've been riding on the buses with her and they charging me. - Tawnya, Albina

While Tawnya acknowledged her daughter was big for her age, it was hard to believe someone could mistake a large four-year-old with a six-year-old (the oldest a child can ride free) unless there may have been racial bias involved. While TriMet's fare enforcement efforts from transit police is known for its racial bias (Kenoyer, 2018; Renauer, 2016), racial bias among drivers has not been evaluated.

Even if Tawnya's daughter was of age to be charged for rides, with her going to Portland Public Schools, she would have been able to get a youth pass, an agreement between TriMet, the City of Portland, and Portland Public Schools that allows kids to get a free bus pass. At the time I interviewed folks, kids in East Portland could also get free TriMet passes for the first time ever. But the funding for youth passes is constantly under threat. Parents I talked to who were paying more than they should have for their kids were simply unaware of the resources available to them or the exact rules around who could and could not ride for free. Several of them were able to realize savings through our conversations after learning that they did not have to pay for their kids if they were under seven-years old or that youth passes were available through the schools. Part of that was not their fault as bus drivers should not be requesting parents pay if their kids were under 
seven-years old. And schools should be more proactive in notifying parents that youth bus passes are available.

Overall, the expenditures of people dependent upon transit were much lower than those who drove. However, much of their lower expenditures were due to limiting how much they got around. While drivers also limited their trips to save money, the extent that bus riders went to avoid trips on the bus was much greater. And even with reduced transit spending, they still had to adopt other strategies to manage the cost of getting around.

\section{Psychological Toll of Transit Dependency}

Transit did help people get around, to an extent. The restrictions in movement I have highlighted so far had material impacts. People either were or were not able to get around in the way they needed or wanted to. But the need to move, to be able to get out and about in an easy and low-stress way, also took a psychological toll when transit did not exist in an easy, low-stress format. When asked if transit made him feel restricted, Troy described the feeling.

Of course it do. I only move when the bus move. I only move as far as the bus goes. So, my life is limited to the time on the bus...As far as traveling and doing stuff on the weekend, I'm limited to the city. Can't go out to Cannon Beach. Can't go out to Mt. Hood if I wanted to. Can't go fishing when I want to. Because I don't have a car...If I had a car, I'd be able to go when I want to. Based on my time. - Troy, Albina

His overall feeling was one of being trapped. I brought up the availability of low-cost buses operated by the Oregon Department of Transportation that take folks to the coast and Mt. Hood, but he did not feel those services were worth the cost because of the time they take, the restricted schedule, and the potential of being overcrowded. For him, being able to get 
out of the city and recreate was a huge psychological hit because he could not recreate the way he wanted due to his current transportation circumstances. A large part of the barrier for him was "when he wanted to." When he was able and wanting to get out of the city was not likely going to line up with the cheaper non-car options available. He would lose three hours in recreating time round trip by taking transit to Mt. Hood rather than driving - likely turning what would otherwise be a day trip into an overnight trip. And being a temp worker only exacerbated the difficulty in getting around without a car since his schedule could change at any moment.

Jasmine was more severe in how she talked about being restricted because of having to use transit. Much of her concern was around safety issues, but her statement was a response to the overall feeling she had about being transit dependent.

Well it sucks because I feel like I'm being held hostage. But I mean at some point you just have to be ok with the fact that you're going to miss out on a lot of stuff and not do anything. Or just have to let go and go about your business and not let other crazy people dictate your life. I don't know, I think in some ways a lot of people's lives are controlled by TriMet.

- Jasmine, East Portland

Equating the experience of being bound by the bus to being a hostage is not something to take lightly. Through our conversation she thoroughly described her experiences of being depressed and being transit dependent only made life more difficult. It was why she attempted to get a car, but essentially getting scammed further exacerbated her depression and feelings of isolation. And walking was not going to get her to the places she needed to go. For instance, her son's school was three miles away and walking would require her to walk for at least an hour along $82^{\text {nd }}$ Avenue, a notoriously dangerous-forpedestrians state highway for nearly the entire route. 
Going back to Stegg_(2005), their study on affective motives for car use could be extended to transit use as well. However, they used primarily positive motives. When it came to transit, negative emotions were abundant. For most transit dependent people I talked to, being trapped into transit with virtually no other choice of movement had substantial psychological effects. Because this was not designed as a psychological analysis, I can only say so much to the matter. But it was clear from their reactions that fear, frustration, isolation, and stress were overwhelming them.

\section{Strategies to Cope with Negatives of Transit}

Transit dependent people I talked to had to adopt similar coping strategies as drivers in order to afford getting around while paying for all their other necessities. Those strategies, as described in the driver section involved cutting back on entertainment, food amount and quality, and utilities, much like the strategies found by Agrawallet However, I also found that those dependent on transit typically had to cut deeper as their limited means meant there was not much in their lives that was not essential.

Sacrificing food was always a difficult decision for folks, but without bus fare, they could not get the money they needed for food. It was a vicious cycle best described by Troy.

I sacrifice food money for bus fare. Sacrifice light. Like right now I didn't pay my light bill because I was waiting for someone to come through. Couldn't spend everything at once. Spend it as I get it. Save some. Make some more. Basically, I need bus fare to get to work. So, I have to cut back on some of that food I thought I was going to buy to pay that bus fare. Say I gotta work three weeks. \$25 gotta go to the bus. So that food money I was going to use goes to get more money so we can have some food. So, it's kind of a tradeoff. When I get that money back, I just have to go a week without. Like eat Top Ramen with eggs. - Troy, Albina 
After food, entertainment was the next most common cut back in order to afford transit, even when the entertainment itself was free. Taking the bus forced them to become much more cost aware of their trip than drivers did. Joseph put it this way:

I've definitely had to cut things out of my budget to make sure I could afford to catch the bus to even go to the park. And things like that. You don't even really think about it. You think it's something you'd do for free. Just like eating out. And entertainment. Things I would do for entertainment I would cut back. Because you have to incorporate...everywhere you go is \$5. I'm just glad my son doesn't have to pay yet. - Joseph, Albina

The stress of where the $\$ 5$ was going to come from to even get to the park weighed on people constantly. It harkened back to the psychological effects above of being restricted by transit. It was just one more thing to worry about, stress about, and having to face the tradeoff that they had to tell their kid(s) they could not afford to go to the park.

Another tradeoff that came with being transit dependent was finding cheaper alternatives to getting around. Most of the people I talked to often sought out rides from friends and family as they could either get the ride for free or get more out of their dollar than through transit. Tawnya used rides primarily so she would only have to spend a small amount of money to get around on transit. The rides she was asking for from family were free for the most part.

I already have to pay bills, but now I have to dish out another $\$ 100$ on this bus pass. So, I'll hold out and try to get some rides through the month. But keep my \$20-30 in my pocket for bus fare. Or just walk. Good exercise and it's free. So, basically, that's how I think it. I be trying to scheme and save my money. I work out different ways. Maybe I think about whether to get food and lunch. Eat kind of good. Hamburger, chicken wings. I try to make my money stretch and tell myself that I don't need one. I do pretty good without one actually. But next month I'm still busing it, I'm not spending that much money, but I should get a bus pass. - Tawnya, Albina 
Getting rides was also an alternative to trying to fare jump. When there was no money in their pocket, hopping on the train without paying was a strategy that a few folks had done somewhat regularly. But they did not want that to be the case. Most of them had been caught fare jumping before, and that ticket at $\$ 175$ was a massive burden that was not worth the cost of getting caught.

\section{Summary}

The transit dependent people I talked to largely did not want to be on transit in its current form. They did not necessarily hate transit, but the safety, speed, reliability, and coverage were all issues that led them to dread having to figure out how they were going to get around day after day. Those are all fixable issues.

Indeed, TriMet has already made substantial improvements to the system since I concluded interviews. With the implementation of the low-income fare, addition of bus routes in East Portland, improving frequency on some routes in East Portland, and approving the installation of transit priority lanes in Albina, many of the complaints brought up here will be lessened if not eliminated. However, the safety issue still looms large as nothing has been done to alleviate that issue. TriMet has put more police on the trains, but their primary purpose has been for fare enforcement rather than for the protection of passengers.

Even though improvements have been made to the transit system in East Portland, they are still a long way from parity with Albina. As it stands, East Portlanders reliant on transit struggle the most to get around and they spend a lot more time getting around than their counterparts in Albina. Additionally, the support networks of people living in East 
Portland were limited in their ability to call up people for a ride, suggesting those available to help them either did not exist nearby or were too under resourced to help them.

\section{Get Rides}

As stated through some of the above quotes, getting rides was a very common method for dealing with not wanting to take transit anymore or wanting an alternative for trips for which transit was not conducive. This was in sharp contrast to drivers who rarely asked for rides from others when driving was not an option. But getting rides was not an equally accessible option, and East Portland residents struggled more to get rides from others than their Albina peers. This is discussed more in the next chapter, but East Portlanders' struggles generally came down to their support network members either being too far away or under-resourced so they were not able to reliably get rides. As Rogalskky (20102) found, support networks were critical for filling the gaps in transportation for lowincome people. Without people with resources in their lives, their struggles were expected to be higher (Turney \& Harknett, 2010).

Getting rides was largely dependent upon having people nearby that had a car. For Albina residents, that was easier to come by than East Portland residents. Half of the transit dependent people I talked to in East Portland had issues with reliably being able to call someone for a ride whereas only one transit dependent person in Albina had that problem.

Beyond the reliability, for some people, the act of asking for a ride was a difficult one and they tried to avoid doing so if they could. Leslee prided herself on trying to be independent as much as possible and that meant not calling upon people for a ride.

I try really hard not to call anybody. And I think because of that, and I'm thankful for it, but I think I could call anybody in my phone and they would 
come. Just because I don't reach out a lot. Just because I like to be independent that way. - Leslee, Albina

Even with trying to be independent, she knew that if she needed a ride, she would be able to get one. Independence came up a few times when I asked them if they got rides from other people. It was more than just independence though. Many of them did not want to call upon others for rides because they knew it could be a burden for the people they called upon. When asking for a ride instead of taking transit, this is the thought process that went through Tawnya's mind:

Basically, I'm hoping they say yes. Hopefully the times I'm giving them they agree to it. But the main thing when you don't have a car, it comes down to I don't know if asking they can say no, but then you're on their time. Like they'll say they can't come at the time you want, but they can come sooner. It's just more being on somebody's time when you ask them. But you're not sure they're going to agree on your time. But they'll still come and get you. Because their car is up to them. - Tawnya, Albina

Getting rides was also important to parents in helping them avoid exposing their

kids to issues on transit and the hassle of trying to get around with their kids.

If it's me and my kids, I'll ask for a ride. But if it's just me I'll get on transit. I don't want them out in the cold because it's like they forever have a cough and ear infections. It's been like this since they was little, so I try to keep them out of the cold as much as possible. And they're old enough to where they can stay home by themselves for a little bit. So, I do most the running. If I don't have to take them out, I won't take them. And if it's just me I'll bundle up and hop on the bus. But if I got them, I'm going to call somebody and pay for a ride. - Ruth, Albina

Ruth's reasons were not unique in that regard. Most parents found it an incredible

hassle having the kids on the bus with them, best exemplified by what Amber said.

Overcrowded, can't sit down. They're [the kids] tired don't want to walk to the bus stop don't want to carry their backpacks, I'm tired, they don't want to move their legs kind of thing. Public transportation just sucks all around with two kids. It's probably not too bad, but it's something I would rather 
not do. It cuts into homework time, dinner time. If my commute is very far, by the time I get home, get the kids settled cook dinner do homework. It's late and then have to get right back up at 6. - Amber, Albina

While Amber currently drives, she was bound to the bus not too long ago. Her frustrations with taking kids on the bus were greatly relieved by having a car to shuttle around her kids.

Even though asking for a ride could alleviate that burden of trying to ride transit with kids, it came with additional hurdles. Depending on the age of their kids, it could mean they would have to haul around a car seat and install it on the spot when their ride arrived as would happen to Leslee.

But just not having...we have a car seat, but with us being on the bus traveling somewhere. Most people don't carry a car seat in their car. So that's sometimes been a really odd barrier. - Leslee, Albina

Asking for rides often came with a financial cost even though many people used rides to save money over transit fare (Agrawal et al., 2011; Clifton, 2004; Edin \& Lein, 1997). But I found a surprising geographic difference in the cost among the people I talked to. Bus dependent Albina residents almost always paid for their ride. Usually they would pay somewhere between $\$ 5-10$ for gas, or about equivalent to what they would have spent for an Uber as one of them said. East Portland residents though largely did not pay for rides. Part of that was related to the reliability of the rides, but most of it was due to generous family members that would give them rides without any charge. Even when asked if that created tensions between them, they often responded "no." This was often due to them moderating their use of rides a lot so they did not become seen as a burden. However, they did not moderate their use of asking folks for rides any more than people in Albina 
did. I do not know how exactly East Portland residents were reliably getting rides without having to accrue payment. As Troy said:

You got to pay your way. Gotta pay for your gas or they won't keep giving you a ride if you keep getting rides for free. I'll give them like \$5-10 to take me where I want to go. I give them \$5-10 to go to the store or appointment and then keep going because the Lyft could be a minimum of \$7-10 for a short ride. If I have to go somewhere expensive, it's not worth it for me to pay $\$ 26$ for one way. I'll just give a buddy \$10. It's much cheaper that way.

- Troy, Albina

Getting rides was a critical strategy of bus dependent people. Having someone they could reliably call up to get a ride, even if not immediately, helped them maintain their mobility over just relying on transit. It was particularly useful for them in getting to/from the grocery store so they could buy more groceries, go where they wanted, and not have to carry them on transit. But the unreliability and lack of immediate response from others meant it could not always be depended on for getting around. Taxis and Uber and Lyft helped fill that role to some extent.

\section{Taxis, Uber, and Lyft}

Over $60 \%$ of those relying on bus looked to taxis, Uber, or Lyft as options for getting around. The vast majority of them had fully transitioned to only using Uber or Lyft as they were substantially cheaper than taxis. Tawnya was one of them that stopped using taxis with the availability of Uber and Lyft.

We stopped...well probably everybody stopped using taxis because of Lyft and Uber. A lot of my friends got their credit cards connected to it. So, it's just easier...And it's just cheaper. - Tawnya, Albina

However, there were still significant barriers to those services being useful by the majority of the people I talked to. Those services require a credit card and a smart phone. As Tawnya 
mentioned, her friends have their credit cards attached to an Uber/Lyft account. But she does not have a credit card. Thus, she is dependent upon being with those friends have a credit card in order to use those services. Most the people I talked to had smart phones, but many of them struggled with storage space on their phone in order to have the app available (cheaper phones likely owned by poorer populations have lower storage limits and can easily fill up with multiple apps, photos, and music). Because the app was not always on their phone and set up for immediate use, they would turn to other options instead.

Aside from the ability to use the services, most of the people that were not using Uber or Lyft were not likely to use them because they did not trust them. They knew that the background check systems those services used were not as good as the ones used by taxis; so, they were afraid of actually getting into a vehicle from those services.

Those using Uber and Lyft were generally positive about the services. Many of them actually turn to Uber or Lyft instead of asking people for rides because the cost was about the same and was more convenient. Troy began using Lyft as a way to get back home from the grocery store instead of asking people for rides all the time.

Lyft is way better now. Before doing it on the bus or paying people you have to do it on their schedule. That's what made me do the Lyft. So, when I need the food I can get home right away. I can do it early in the morning, avoid traffic, and get everything done. - Troy, Albina

While many transit agencies across the country were fearing lost ridership because of Uber and Lyft, the people I talked to were not replacing transit trips with those services. Most of the time, the trips they were taking with those services were trips for which they would have gotten a ride instead. Transit would have been a last resort for most of the trips they were taking. These were trips where they either felt unsafe taking transit, such as late 
at night, or taking transit would have been burdensome, such as getting home from the grocery store. While transit systems may lose ridership from other users of those services, among low-income Black populations, it seemed unlikely to make much difference in their use of transit.

\section{Walking}

Nearly every one walked to some extent. However, the ease of walking was highly skewed toward those in Albina. This was largely because Albina was much denser than East Portland and had substantial density of safe street crossings, a critical piece of the urban environment to encourage walking (Cervero \& Kockelman, 1997; Handy et al., 2006). As mentioned in the above cases, Albina residents often walked in order to save money on either gas or transit fare. They were able to do so largely because of the convenience of location of the places they were going, an advantage not available to many of those living in East Portland.

The safety of walking was particularly different for those living in Albina and East Portland. There had been many safety improvements made to streets around Albina that slowed cars down and added crosswalks. In East Portland, there were some improvements made over previous years, but there were still substantial gaps that existed. The density of improvements was substantially lower than in Albina as well. Many people in East Portland could easily walk a half-mile or more and not have a safe crossing, but from nearly every corner in Albina it was possible to see a safe crossing. Tawnya expressed her ability to walk in the neighborhood this way: 
It's Portland, so everything is walking distance. Like my house is, let's be honest, I could really walk to Safeway on MLK if I wanted to. It's really not that far at all. It's down the way some times. But it's not too far. - Tawnya, Albina

She found it very easy to walk around her neighborhood and so did a lot of people in Albina, such as Olivia.

They've made all these things for pedestrians. Even in the middle of the road on Willamette there's a little walkway. Before there wasn't and you had to walk all this way. But they have them all along Willamette where you have to stop and a light will flash. I love that! Because it makes people want to walk more. - Olivia, Albina

Even though Olivia drove most places, and her mom encouraged the driving, she enjoyed walking to the store. She found it relaxing and much better than having to deal with other drivers. She added, "There's no equal to walking."

The situation in East Portland was not as optimistic. Most of the people I talked to also walked around their neighborhood and generally felt okay about it, but it was nothing that got them excited. When I asked Jasmine, who lived in Cully, if she felt the places she tries to go to were too far away to walk to, she responded,

Some of them are, some of them aren't. There's a nice little church that has a big huge grassy area on 52nd and Killingsworth I think. So technically, it's not that far. And then there's a couple little stores and places, Plaid Pantry, little fast food places. But most of it is too far. - Jasmine, Albina

Places to go in East Portland were much more spaced out than in Albina. And with that spacing, walking meant having to walk much further distances. That created additional problems in that many people in East Portland expressed a lot of issues with safety when walking out there, especially at night. For instance, Destiny did not like walking because she felt unsafe from multiple issues. 
Yea, the drivers. You never know with the drivers. Like at night you really need them reflectors, because they drive like crazy down 162nd. It's bad. Even where I stay, they're bad. But all of 162nd is terrible. So that is a safety concern of mine. I'm scared to just walk with the people. It's a lot of unsafe people. I just be scared of the homeless people because you never know. You might get robbed. You never know. You just don't know. Especially at night. Yea, it's not safe. - Destiny, East Portland

Ashley also walked a lot because of what she described as "poor bus stop spacing," but also encountered a lot of safety issues. Some of the issues were with "there's a lot of weirdos out. But I try to stay positive and pray." Other issues were with drivers.

There's not that many crosswalks. I'm glad they just made one at 165th where I live. But crossing the street at night, it's like you either have to walk all the way to 162nd or to 174th to properly cross the street. But I end up crossing the middle of the block. And people aren't following the speed limits. Or they're always pulling out the bar drunk or something. No matter what you're doing you just have to be more cautious because people are being crazier and crazier these days. - Ashley, East Portland

The issues were abundant. Even with crosswalks in place, the poor design of them and the lack of concern by drivers led them to be unusable. The people I talked to really did not feel safe crossing unless there was a light that would stop drivers. Gail felt very put out by the lack of safety in being able to cross the street in front of where she lived.

Because to cross the street where I live you got to run! Because there's no button. You gotta run! The buttons [are] on 162nd and 174th. I live on 170th so I either got to walk down to cross. And that's a long walk! - Gail, East Portland

Unlike in Albina where the average block length is among the shortest in the country, the blocks in East Portland are much longer. This is a legacy of East Portland being planned and developed separately from Portland before Portland annexed it in the 80s and 90s. Thus, two blocks in either direction represents a much larger distance in East Portland than in Albina. And that distance can be enough to deter someone from trying to cross at the 
safer intersections (even though every intersection is supposed to be a legal crosswalk based on Oregon state law).

It was clear from my interviews that East Portland had a long way to go in order to resonate the same feeling of safety and joy from walking as those in Albina had. Steps were being made to improve the situation. Outer Powell Blvd is getting a safety overhaul thanks to a large amount of state funding approved in 2017. And Outer Stark St is getting a lot of attention as well with Rosewood Initiative leading the charge to prevent more people from getting killed trying to cross the street. These projects only make a small dent in what is needed to make East Portland as comfortable and joyful to walk in as Albina.

\section{Bicycling}

Both income and race have substantial predictive power on who does and who does not ride a bike. Lus ride a bike, have confidence in riding a bike, and even have interest in riding a bike in their study on Roxbury, MA. Similarly, Mc_Neil et al al__(2017) found in their study of bike share equity in Brooklyn, Chicago, and Philadelphia that Black respondents were much less likely to have biked in the past week than White respondents and low-income Black respondents were much less likely to plan on biking in the future. The low rates of bicycling, interest, and confidence by Black populations tends to have a lot to do with the lack of safe bicycling infrastructure built in minority neighborhoods (Day, 2006; Lee et al., 2017). But also, a lot is still unknown in the area of bicycling and minority populations including detailed travel behavior and preference studies (Lee et al., 2017) 
Only three people I talking to rode a bike. None of them rode one to regularly get places. Instead, most of them were using a bike to ride around recreationally with their kids. Surprisingly, the bike riders I talked to were primarily in East Portland.

In East Portland, one mother rode her bike along the I-205 trail nearly every weekend with her kids. Another mother used to ride her bike for more than recreation, but her bike was stolen. While the recreational rider felt rather safe when riding, much of that was because she lived in an area where she was almost right on the trail, so connecting to it was very easy with little need to interact with cars. The other woman always rode her bike on the sidewalk, and slowly because she did not trust riding next to cars in East Portland.

In Albina, one mother had a Biketown bikeshare membership and rode on the bike share bikes sparingly. While she went through the classes at Community Cycling Center and their attempts to help her become a more confident cyclist, she was still uncomfortable riding in traffic, even on low-stress neighborhood streets. Instead, she always rode on the sidewalk at a very leisurely pace. She felt there was really no chance she would ever become confident enough to ride in traffic even though slowly she was getting more and more comfortable riding the bike.

Generally, the people I talked to did not feel riding a bike was for them. Tawnya, who did a little bit of recreational riding with her kids, put it this way when I asked her what kept her from riding more than a few blocks,

Because I'm lazy. I'm older now. I feel like I'm 26 but I get tired, winded, out of breath. Yea I'm not doing that. This is not Survivor [The reality television show]. I'm not doing that. Sweating. People looking at me, I'm sweating, pedal pedal pedal. You know. Before it gets to that point, I would 
rather just walk to my destination. Because then I'll have my purse with me where I'll have a bottle of water or something. But yea I'm not biking it.

- Tawnya, Albina

Part of the hesitancy was about confidence in cycling and just being out of shape.

She was also very concerned about appearances and not wanting to appear sweaty. Confidence issues in biking were very common among the people I talked to. Most of them had not ridden a bike since they were children and had no interest in getting back on one. Even though they were not interested, most parents were comfortable with their kids riding around on bikes.

There were few households where kids did not have bikes available to them. Many of the parents I talked to said their kids had not ridden their bikes much and it was always a pain to get them to do so, but several kids did ride their bikes regularly. However, in Albina, parents were much more likely to let their kids have a little bit more territory they could cover on their bikes than parents in East Portland. In East Portland, parents were concerned about the lack of infrastructure for biking and a lack of driver attention. One dad, Derrick, would not let his kids ride their bikes at all around their house and would instead load the bikes into his truck when they went to visit family in Albina to let the kids ride them around there.

My daughters have bikes, but they be asking to ride em. But where we stay at it's real crazy. We tell em ride them at your grandmas [who lives in Albina] because the area over there is safer. We got this busy intersection here and these other cars that be speeding down the damn street, a residential street. They be doing 50 down a $25 \mathrm{mph}$. Don't ride it out here. I don't trust it out here. They understand that. - Derrick, East Portland 


\section{Getting Around}

A household juggling its transportation decisions has to weigh a lot of factors. Throughout this chapter, I showed that the availability of transportation was dependent upon where people lived as well as the strength and proximity of their support networks. Their transportation decisions also came with weighing where they were trying to go, where they could go, what it would cost, and what they would have to do in order to keep moving into the near future. All of which were features of the conceptual model shown at the beginning of this chapter.

\section{Car Travel}

A larger number of people in Albina were dependent on driving than I expected based on ACS data and the high availability of transit in the neighborhood. And East Portlanders were much more dependent on transit than I anticipated given the scarcity of transit in the area. It was clear that having a car made certain parts of their lives much easier, and those that were currently transit dependent seeking to have a car would likely find themselves justified in pursuing car ownership. But car ownership also came with costs that not all of them were prepared to take on. Very few car owners had a backup plan if their car broke down or had the money available to get it fixed in a timely manner.

The literature has consistently suggested that car ownership in poor households could result in better job access (Blumenberg \& Ong, 2001; Blumenberg \& Pierce, 2012; Pendall et al., 2014), higher earnings (Smart \& Klein, 2018), and general ease of accomplishing daily life maintenance (Kenyon et al., 2002; Lucas, 2012). But the findings here suggest there is a lot of nuance that goes along with those findings. Certainly, cars 
expanded the range of travel for poor households in this study. But their job acceptance was often dependent upon having available transit to that job, just in case something happened to their car. Their job acceptance also had some effect from the presence of young children in their household. Mothers with small children tend to take jobs closer to home regardless of their available transportation (Edin \& Lein, 1997). As a result, no one in this study drove more than five miles to work, and none of them with a car were more or less likely to have a job than someone without a car. Also, several people I talked to turned down higher paying jobs in locations that were inaccessible by transit even though they had cars. So, car ownership did not necessarily lead to higher earnings.

Cars also helped the drivers in this study accomplish their daily life maintenance tasks a lot easier. However, each daily life maintenance task was weighed carefully for how much gas it would take to get there, whether it was worth it to go there, and what they could also do in the trip to combine tasks and save on gas. While easier than transit because of the speed and flexibility, it still involved a substantial amount of planning. Drivers often had to make substantial sacrifices in other areas of their life in order to afford owning a car, which, on average, was about twice the monthly cost of a monthly bus pass (but that cost was after drivers had instituted their driving restrictions to save on gas). Because of the costs involved in car ownership, the "freedom" aspects of car ownership (Steg, 2005) were not well realized for people in this study.

East Portland drivers did gain a bigger advantage by owning a car due to the distances they would otherwise have to travel to via transit. But with longer distances came more gas and more wear and tear on their vehicle. With less resources among their support 
networks, East Portland drivers struggled to make up the difference, and that likely was a big reason why fewer East Portlanders in this study drove than expected (Rogalsky, 2010). Their lack of resources and people to help them out also helped to explain why all but one of the people that had cars that were broken down also lived in East Portland.

\section{Transit Travel}

Everyone I talked to had access to transit, and they nearly unanimously chose their houses based on access to transit. Even for those that were car dependent, they knew they would need to use transit at some point. That did not mean transit was ideal. Transitdependent populations were generally unsatisfied with their experience on transit. They used it out of necessity and even curtailed going places because they did not want to deal with the hassle and stress that transit brought them. This was further complicated by the fear they faced getting on transit, especially when they had their kids with them.

Studies have consistently found transit dependency leads to lower job outcomes for low-income populations (Giuliano, 2005; Kawabata \& Shen, 2007; Spears et al., 2013). That extended into the role transit played in getting people to destinations for daily life maintenance (Bader et al., 2010; Hillier et al., 2011; Walker et al., 2010). I did not find that people that were unemployed because of their mode of transportation. Rather, their unemployment was a result of many other barriers from health and having young children

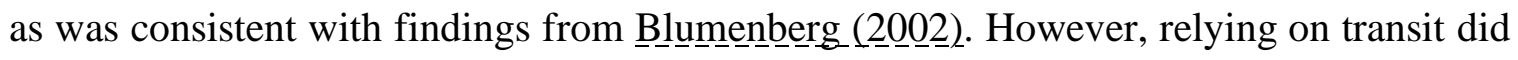
substantially hamper the ability of people to get to preferred destinations of daily life maintenance - grocery stores in particular. 
Often overlooked in the transit debate was the cost of taking transit. While recognized as an equity tool to open up travel options for those with the least (Karner et al., 2016), the costs were often still too much for those at the bottom of the economic ladder to afford (Agrawal et al., 2011). I found similar instances here. At least a couple people I talked to specifically rooted around in dumpsters to find cans to turn in for cash solely for the purpose of getting transit fare. Getting on transit with their kids was also a substantial barrier as several mothers had bus drivers charge them for their kids even though they should have been free either by age or by having a youth pass through the schools. That I found several mothers that were unaware their kids should be getting a youth pass through school suggests a large failure in getting the word out to parents on these programs and makes me curious about how things have gone with the low-income fare program instituted since this study concluded. Cost of transit was also a huge burden for people working in precarious situations. Ensuring they had enough cash on hand to pay for transit for a couple weeks while waiting for their first paycheck from a new job was incredibly difficult.

Transit dependent people in East Portland struggled the most. Distances between their homes and destinations were much longer there than in Albina requiring more time which restricted the number of tasks that could be done in a day. Albina folks had many different options for getting around, and their ease of walking led to an easy way to save money if needed. To make the most of their time and money, many transit-dependent folks would get rides from friends or family to places like the grocery store. Given the higher dependency on transit in East Portland, this was a more common occurrence there than Albina, but Albina folks also relied a lot on rides. The biggest difference between them 
was the ease of getting a ride was much easier for those living in Albina as their support networks were more reliably able to help them. Nearly every transit dependent person in Albina got a ride to the grocery store whereas only half of those in East Portland did.

\section{Alternative Modes}

Like in Stack $\underline{\text { tas_s }}$ (1975). study, taxis were an alternative some people used to get around, but in limited capacity because of the cost. While Uber/Lyft did not exist in the 1970's, neighborhood jitneys did, and they too offered rides at rates much less than taxis. This made them a more common alternative than taxis. The difference between jitney's and Uber/Lyft though is jitney drivers could be paid in cash or other alternative payment. Uber/Lyft could only be paid for through credit/debit cards, which poor people tend to not have.

Transportation network companies like Uber and Lyft were used by a few people. But they still faced substantial barriers to use like needing a credit card and a smart phone. While those companies offered lower prices than taxis, the prices have been artificially lowered due to vast capitalization of the companies from investors with no immediate need for profitability. The expectation is prices will increase as the need for profitability increases (Sherman, 2019) as well as the inevitable large-scale backlash to their labor policies (Conger \& Scheiber, 2019), and thus their advantage over taxis will diminish.

Walking and bicycling for low-income Black populations in Portland suffered from a large geographic disparity. As was often the case in past studies, disadvantaged neighborhoods tend to have less infrastructure intended to improve the safety of walking and bicycling (Day, 2006; Lusk et al., 2017). This was the case in Portland too. The main 
difference here being that the disadvantaged community was 10 miles from downtown Portland rather than downtown adjacent. That removal from downtown adjacency decreased the likelihood of adequate infrastructure for walking, transit, and bicycling. The effect has been a very low rate of walking and bicycling for people in East Portland as I found through my interviews, but also a drastically higher number of pedestrian deaths in East Portland than any other part of the city (City of Portland, 2019a).

It was clear from the people I talked to in Albina that having safe infrastructure as well as a high density of destinations encouraged them to walk. However, their bicycling rates were still very low even though some of the better bicycle infrastructure in the city was located in Albina. And while the city is working to make East Portland safer to walk and bike in (City of Portland, 2018), the efforts have a long way to go catch up to the need. In the meantime, it can be expected that people will die on the streets of East Portland from being hit by people driving in much greater numbers than in Albina or any other part of the city. In terms of equity, that is about the worst metric to have continue to exist.

\section{Social Exclusion}

Kengenon et__al_._(2002) described social exclusion as "the unique interplay of a number of factors whose consequence is the denial of access, to an individual or group, to opportunity to participate in the social and political life of the community, resulting not only in diminished material and non-material quality of life, but also in tempered life chances, choices, and reduced citizenship," (p. 209). Based on the evidence I found, East Portland exemplified this definition of social exclusion. The factors at play for East Portland residents were lack of choice in housing, inadequate transit service, low density 
of shops and services, and separation from support networks. Each factor had a role to play in the continuing disadvantage experienced by people living there. By not being able to afford a choice in housing location, they could not choose a place that would perform better for them in terms of their individual disadvantage. Inadequate transit meant they did not have a strong option in how to get around to fulfill their daily life maintenance without substantial struggle or stress added to their life. Low density of shops and services compounded the inadequacy of transit as they could not find viable alternatives that were not overly expensive for their meager earnings. Being separated from their support networks meant they could not easily tap into their networks for help when they needed it leaving them to struggle to meet their daily needs such as child care, making rent, affording and getting to food, or just meeting their psychological needs of someone to hang out with.

Church _et al. $(20 \underline{0} \underline{0})$ added another form of exclusion - fear exclusion to better demonstrate the way safety in disadvantaged neighborhoods may be a large concern for residents of them and preventing their movement around space. They found that even in areas with high levels of accessibility, fear exclusion could be substantial enough to hinder the ability of someone to fully participate in society. This was especially present in my interviews with low-income Black populations in Portland, especially those living in East Portland. Not only was fear on transit a significant hindrance to their freedom of movement, many of them actually modified their behaviors in extreme ways to avoid having to use transit. Similarly, East Portlanders became isolated from their peers in Albina because it appeared few people in Albina wished to travel into East Portland because of fear for their personal safety of being in East Portland. 
Differences in support network reliability and the places they are going are covered more in the next chapter. It was evident from how people got around that support networks have a critical role to play in being able to fulfill their daily needs, particularly in getting rides. But it is also the problem for people in East Portland that the distances they have to go are much longer, leading them to try to find some way to ease the burden of the distance. However, the distances do not just apply to the places they are going, it also applies to the people they can get help from.

Figure 5-3 gives a snapshot of the barriers faced by people in Albina and East Portland by the various exclusion factors found in Church (2002). This synthesis of the data clearly demonstrates the struggle East Portlanders faced when getting around by transit, the primary mode of travel for most East Portlanders. But even with a car, they faced continued relative disadvantage.

\section{Figure 5-3 Social Exclusion by Mode and Place}

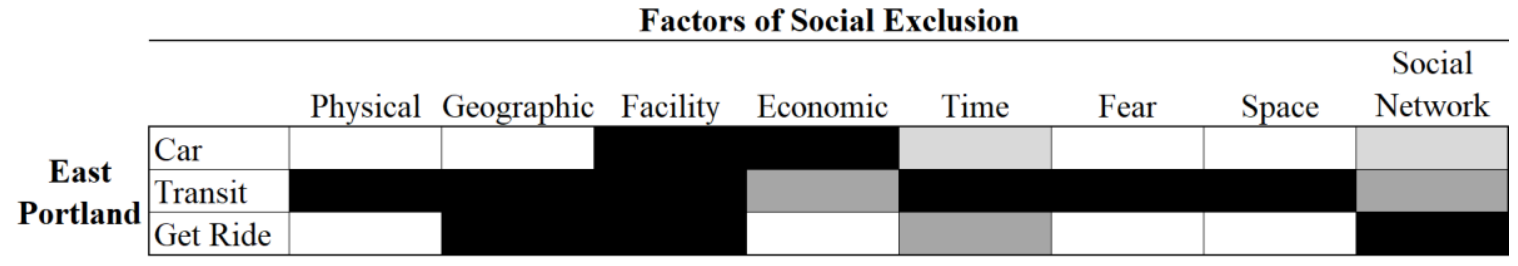

\begin{tabular}{|c|c|c|c|c|c|c|c|c|c|}
\hline & & Physical & Geographic & Facility & Economic & Time & Fear & Space & $\begin{array}{c}\text { Social } \\
\text { Network }\end{array}$ \\
\hline \multirow{3}{*}{ Albina } & Car & & & & & & & & \\
\hline & Transit & & & & & & & & \\
\hline & Get Ride & & & & & & & & \\
\hline
\end{tabular}

Note: Exclusion factors are adapted from Church et al. (2000) and Kenyon et al. (2002) and barriers to getting around were categorized into these factors. Black $=$ majority of people, dark grey $=$ more than 2 people, light grey $=2$ or fewer people, and white $=$ not mentioned.

What was most notable from the exclusion factors was that for a majority of people in East Portland, the geographic issues of the area created spillover effects into other 
barriers. Time would not be as much of a factor if the area was not so spread out. Similarly, the geographic sprawl of the area has contributed to deficiencies in infrastructure investments (facility factor) such as sidewalks, transit stops and lines, and the potential of where someone in their support network could live. 


\section{Chapter 6 Neighborhoods, People, and Gentrification}

It's important to remember a home is not just the place someone rests their head at night. Their home is the embodiment of that place, its surroundings, and its people, and Mindy Fullilove demonstrated the importance of that connection in her book Root Shock (2004). Having places to go to fulfill your daily needs was only one part of having a place that felt like home. Home was also being able to see people that you connect with: family, friends, people that make you feel rooted in a place. Fullilove argued that "root shock" was what one experienced when their home was heavily disrupted by forced relocation because of top-down urban renewal. This chapter revolves around many of the same issues Fullilove discussed in her book on Black districts in Pittsburgh and Newark. One person she interviewed, Arleen Ollie, spoke of her childhood neighborhood being torn down and how people were glad it was torn down.

I don't believe that can really be many people's feelings, because if it were, then it wouldn't have had such a negative, isolating effect. Because...I couldn't get with the same friends. You know, I couldn't get up in the morning, after breakfast, and run down the street and play with these people. But the majority of them were within walking distance, but I guess the physical distance was more important than I had actually thought about, (Fullilove, 2004, pg. 100)

This captured the essence of what I found in my interviews of low-income Black folks in Portland. Albina has always been changing. It was not always the heart of Black Portland either. With the flooding of Vanport in 1948, coupled with the redlining instituted by the Home Owner's Loan Corporation, Albina became home for a majority of Black households in Portland. Albina began to decline due to multiple structural and societal pressures inflicted by racism (Gibson, 2007a). Subject to redlining, predatory lending, 
housing speculation, and sapped of investment, crime rates increased, and a gradual decline of the population and abandonment of housing ensued. Government and private actors came forward to try to "fix" the ills of Albina and cure its blight. Instead, they sped its decline, at least in terms of creating a stronger Black community. Black households were dispersed through the demolition of their homes for multiple urban renewal projects in the area. In that wave of neighborhood change, Black households largely moved north, but some migrated east. Albina remained affordable for the most part allowing some level of community to continue existing. It was not until the 1990's when development pressures and population growth in the greater city led to increased housing prices in the neighborhood (See Chapter 3 to revisit this history). This led to large scale shifts in where Black households lived in Portland. Northern reaches of the city where first wave of displaced Black households moved were increasing in cost at the same time Albina was. Ultimately, many Black households unable to afford housing in Albina found themselves living in East Portland, approximately five miles removed from a hollowed out yet still beating heart of Black Portland.

For low-income Black households in Portland, that five miles was often an insurmountable distance (see Chapter 5) and created a rift in the Black community along with very different lived experiences in living out their daily life. Those that stayed behind in Albina could potentially benefit from the renewed community with new stores, improved transportation infrastructure, and increased numbers of jobs nearby. Meanwhile, those that moved to East Portland would have to contend with living in an area they were largely unfamiliar with where everything was much more spread out, and the ability to get around 
was severely limited. Residents of both areas would have to contend with having parts of their support networks removed from their immediate vicinity whether they moved or people in their support networks moved. As Rogals $\underline{k} \underline{k} \_$_(2010). and Turney_and (2010) found, social networks were critical for filling the gaps in transportation experienced by low-income populations. But when that social network was not able to be accessed to fill that gap, a struggle ensued. This chapter describes the lived experience of low-income Black Portlanders through where they went and how they interacted with those proximally and emotionally close to them.

Highlights of what I found are shown in Table 6-1. A lot of change was happening in Portland because of gentrification, and the reactions to those changes among the lowincome Black people I talked to varied a lot by age. Younger residents of Albina generally did not have much problem with the changes going on in Albina. But older residents who had developed strong roots in Albina before many of the changes wiped out the Black community were affected much more.

Gentrification affected their ability to fulfill their daily needs in several ways. Lowcost grocers became locked out of locating in the neighborhood because of the high land and rent prices, forcing Albina residents seeking cheaper food options to travel to East Portland. Prices at barbershops and salons had to rise with inflation and rent increases on their spaces making the cost of haircuts too expensive for low-income Black populations seeking to get their hair done, thus blunting the culturally notable impact such places have in Black communities (Harris-Lacewell, 2004). Church closures related to declining congregations - a direct result of gentrification - led a few people to state they stopped 
attending church because their church home no longer existed. But churches were still a central part of Black life in Portland with a about half of church-going East Portlanders traveling to Albina for church. It begs the question of what will happen should more Black churches close due to the continued geographic shift of Black populations in Portland. Very few people traveled outside their respective areas for parks or restaurants, but East Portlanders, having to travel long distances for both, opted not to go to either type of destination to a larger extent than those in Albina. This suggested that East Portlanders may be experiencing a heightened level of isolation related to inadequate amenities in the area.

\section{Table 6-1 Places, People, and Gentrification Findings Highlights}

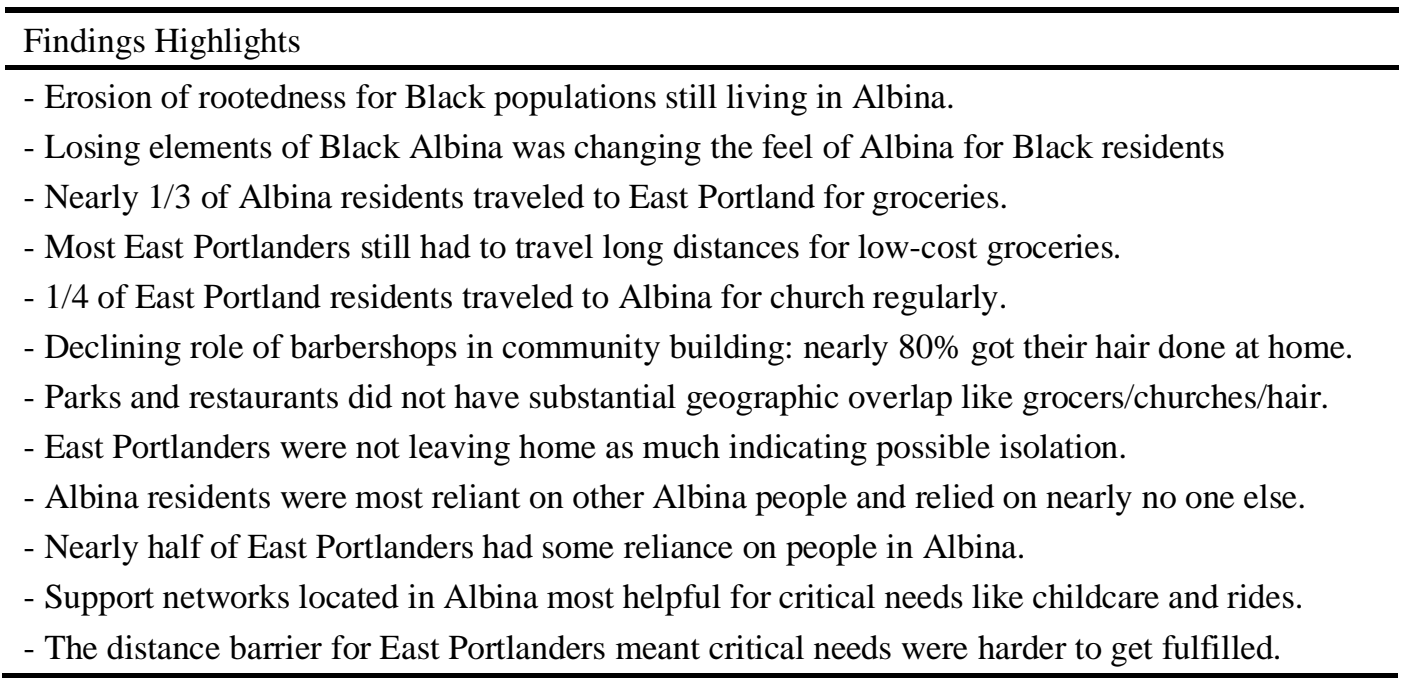

Social support networks were incredibly important to the daily maintenance of the people I talked to. However, their support networks were unevenly distributed. East Portlanders relied much more on Albina segments of their network than vice-versa. Their support segments in Albina were also better resourced than those living nearer to them, forcing them to find some way to get to Albina in order to utilize that help which often 
came in the form of childcare. When asking for rides, their Albina people could usually come to East Portland to pick them up, but it was not a reliable ask due to the distance.

This chapter focuses on social reproduction of low-income Black populations in Portland through two particular ways: the places they go for their daily needs and the people in their lives as shown in the highlighted left side of the conceptual model (Figure 6-1) from Chapter 4. Inevitably, the people and places in their lives are affected by the neighborhood in which they live. Thus, gentrification is a central piece of this story because of its impact on Albina. 
Figure 6-1: Conceptual Model - Chapter Highlights

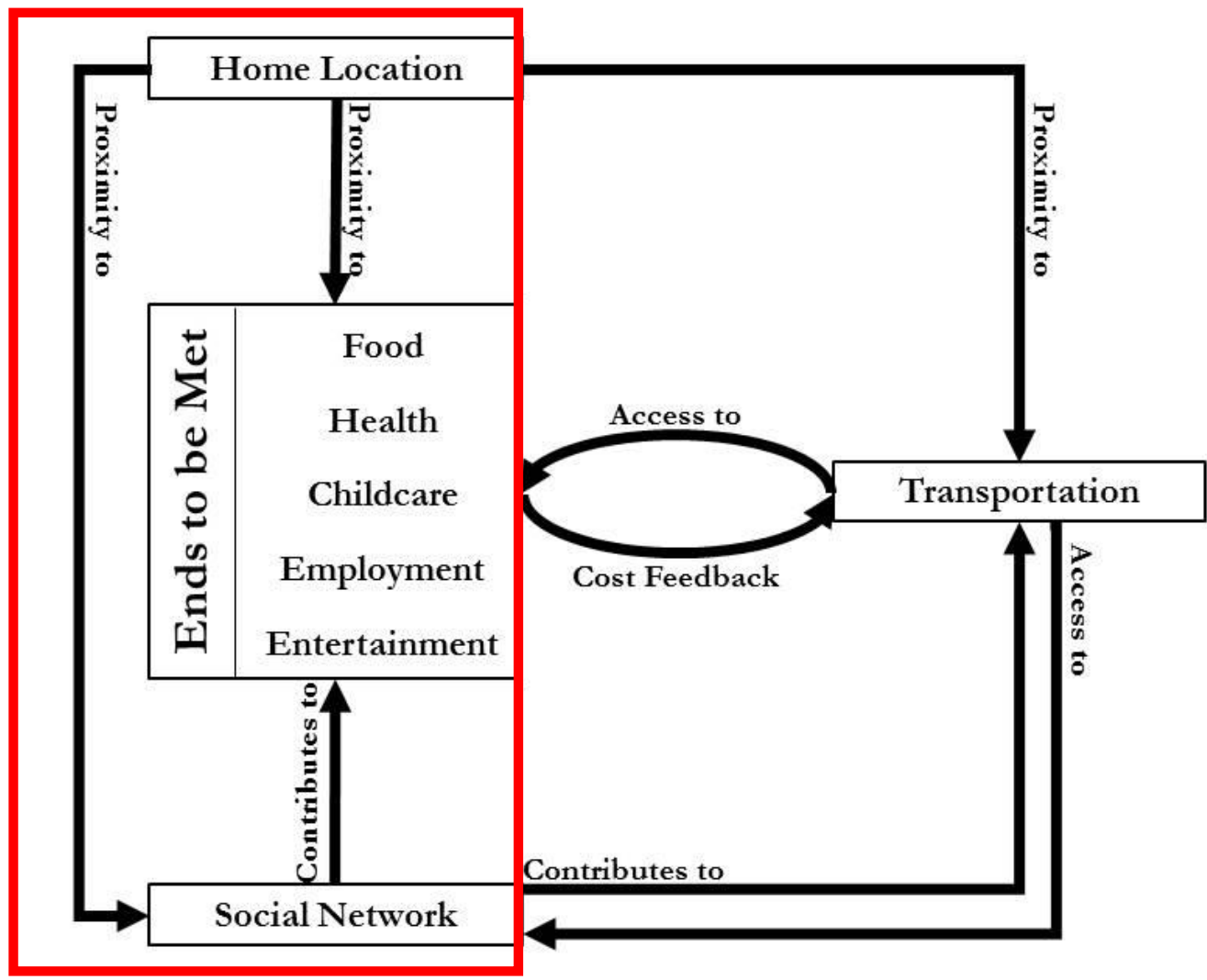

\section{Places and Neighborhood}

Carol found living in Albina was an important part of her life, but its importance was declining. It was where she grew up and had developed roots as would be described by Fullilove (2004). It was where her son was in a school that accommodated his disability, and moving further away would jeopardize his ability to stay in that school. She still went to Dean's Beauty Salon, and had been going there "since day one" and "they're still there, thank God!" The church she grew up going to, Emmanuel Church, was also still there, but she had become detached from it. Albina meant a lot to her, and she meant a lot to the area as well as she provided free childcare to her sister, neighbors, and friends. Working for a restaurant delivery app allowed her the flexibility to offer the childcare and spend the time 
she wanted with her son. She also realized she would not be able to live in Albina if it were not for subsidized housing. She had always lived in Albina with the exception of a short stent in St. Johns to the northwest of Albina.

However, Carol's roots in Albina were clearly eroding. Most the places she grew up knowing were gone.

Were there any restaurants you grew up with that are no longer there that you really miss?

Carol: Mhmm. Like Ferrell's. Right here it was on Broadway. An ice cream shop. Pietro's was right next to that. There was like you know a couple black owned businesses that's gone now. All of them basically are gone now. There was quite a few places I had gone that aren't there. - Carol, Albina

While a lot of people relied on her, she had no one left in Albina she could rely on, including her sister. Everyone else had moved to the eastern suburban city of Gresham. Her experience with new-comers to Albina made her feel alienated from the area she called home.

Carol was fraught with doubt about how much longer she would consider it home. She was not alone in beginning to feel disconnected from the community the participants most identified with. This section brings together the experiences of those still living in Albina and those living in East Portland and discusses the places they were going to fulfill their daily life maintenance needs, how the areas in which they lived served those needs, and their experiences with gentrification.

Among the people I interviewed, about $60 \%$ of them lived in Portland their entire lives with no difference in the proportion between Albina and East Portland residents. The big difference was that four people in East Portland had lived in Portland for less than 20 
years, compared to only one person in Albina. As Lewicka (2011) found in her literature review of place attachment, people that had not lived in an area for long were less likely to have a substantial friend and family network in the area or to have developed an attachment to the cultural amenities of the area. For Albina, the first wave of destruction occurred more than 60 years ago, before most people in this study were alive. The second wave of destruction occurred about 20-30 years ago with continued erosion since. Because of the loss of the community nature of Black life in Albina that still existed prior to the second wave of destruction, I argue it would be difficult for Black people that moved to Portland since the second wave would be able to develop the rootedness and similar feelings of "home" as felt by those that lived in Portland their entire lives. This argument does extrapolate the finding of Lewicka (2011) to a much longer time frame compared to her findings of three-to-five years. But, findings from Fullilove (2004) back-up the idea that the particular circumstances of destroying the Black culture of historically segregated neighborhoods may make it more difficult for Black populations that moved to the area post-destruction to develop the same sense of "home."

The rest of this chapter will discuss the relationship low-income Black Portlanders have with the places they live, specifically through the places they go and the people in their lives. I first discuss their experiences with places they go regularly. Generally, their experiences with place is split between three types: grocery stores, cultural amenities (churches and barbershops), and other places (parks and restaurants). The second half of this chapter discusses their experiences with people. In this analysis, I focused on their interactions with the general populace in their neighborhood and their friends and family. 
Both sets of people factor into how connected they feel to their neighborhood and how gentrification has affected their relationship with the neighborhood.

\section{Places}

The physical amenities of a place are a critical component of place attachment and survival (Lewicka, 2011). For this study I looked at grocery stores, churches, barbershops and salons, parks, and restaurants and where people were going and how they chose between. The relationship people had with those places was greatly dependent upon where they lived. Grocery store importance varied based on its proximity to where someone lived as well as the price and quality of the foods available there. Churches were mostly important to people if they had gone to them for a significant portion of their life, and most of those churches were located in Albina. A summary of where people went is shown in Table 6-2.

\section{Table 6-2 Where were they going?}

\begin{tabular}{ll}
\hline Place & Activity \\
\hline Grocers & Went to closest store \\
& Went to lowest-cost store, which were in East Portland \\
Church & Went to one they had gone to most their life \\
& One-quarter of East Portlanders went to church in Albina \\
Barbershops and Salons & Only those specializing in Black hair. Very few outside of Albina \\
& Nearly 80\% had hair done at home \\
Parks & Went to nearest one \\
& Went to one near family \\
Restaurants & Mostly chain restaurants and fast-food \\
& Few went very far to go out to eat, emphasizing time and energy savings \\
\hline
\end{tabular}

In Albina, place was being altered by gentrification. Where the place used to be a neighborhood for Black people in the communal aspect, gentrification was altering place to make Albina for White people, especially White people with money. For Carol and 
several others in Albina, the changing neighborhood was affecting their attachment to Albina.

I used to go to this store up by where I live on Mississippi, oh man it's like a million dollars for anything. It's ridiculous...And I see all these people. And I wonder where they get all this money to spend and keep going out and eating and so full. So many people. Where's all this money coming from? It's crazy. But yea, prices have really gone up. And rent has changed around here. Everything makes me mad! Really is does. It's crazy. - Carol, Albina

She could no longer go to some places because they had either disappeared altogether, or she felt they had changed culturally and she was no longer welcome or comfortable going to them. Given the ever-present phenomenon of gentrification in Albina and its spillover effects on those living in East Portland, I focused on the way gentrification impacted the relationship my interviewees had with where they lived.

\section{Grocery Stores.}

The volumes of literature on "food deserts" suggest grocery stores should be

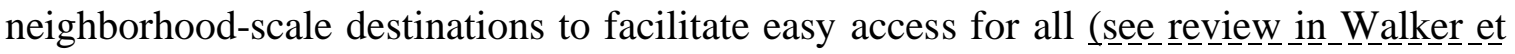
al..2 2010). However, not all grocery stores have the same food quality, selection, and price (Chung \& Myers, 1999), and proximity has no bearing on whether it can accommodate all equally (McKenzie, 2014; Widener, 2018). While traditional supermarkets are seen as lowcost healthier alternatives to neighborhood grocers, especially those in poor neighborhoods (Alwitt \& Donley, 1997; Chung \& Myers, 1999), they do not always offer the lowest price, as you will see below.

Grocery stores also have a substantial impact on social reproduction. As part of daily life maintenance, people have to make decisions on where they go for groceries and 
how they will get there. Without the selections of food they want at prices they could afford at stores nearby, poor households would often travel miles before finding a store they liked and could afford (Bader et al., 2010; Clifton, 2004; Edin \& Lein, 1997; Hillier et al., 2011). When bound by transit, poor households tended to shop at stores closer to home because the time cost of getting to the store could disrupt other needs in their lives like how much they have to spend on childcare. Having a car or reliable rides from their support network enabled travel to stores further away (Clifton, 2004), but those trips cost more than riding the bus. In this section, I examined the choices of grocers and how they got there among low-income Black Portlanders with children with a focus on the difference of experience between those living in Albina and those living in East Portland.

I found people prioritized proximity and price when shopping for groceries. Their ability to choose in Albina was dependent on how they could get to stores, while in East Portland it was dependent on where exactly they lived. To understand the choices they made, I categorized the stores people shopped at between low-cost grocers (e.g. WinCo, Grocery Outlet, Wal-Mart, Costco, and Dollar Tree) and other grocers (e.g. Safeway, Fred Meyer, Albertsons, New Seasons, and Whole Foods), and diagramed which stores they were going to as shown in Figure 6-2 Grocery Destination by Area and Price. Less than half the people in Albina and East Portland shopped at other grocers. Most of them shopped at other grocers because they were close to where they lived. Over half the people in this study shopped for groceries based on price, and most of them had to put in more effort to reach a low-cost store. 


\section{Figure 6-2 Grocery Destination by Area and Price}

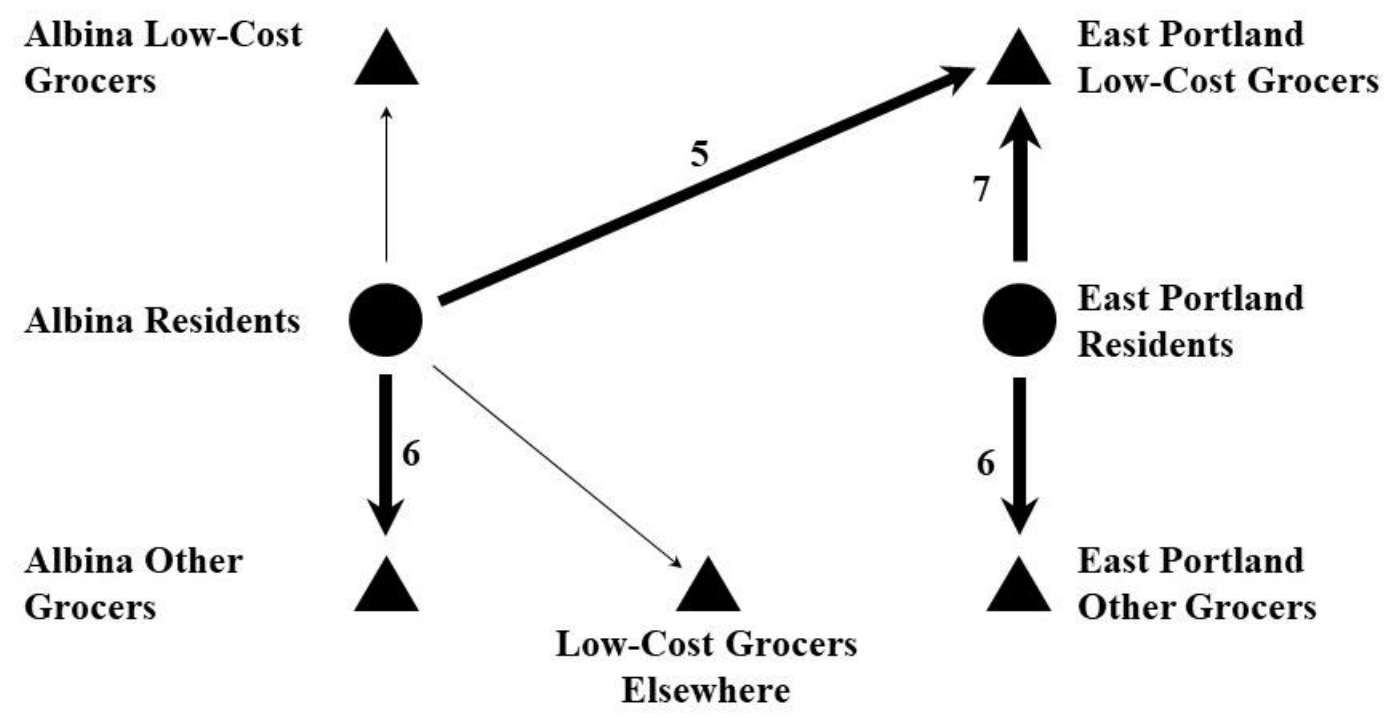

Note: Line thickness is determined by the number of participants that utilized those stores. For thicker lines, the number is displayed.

Carol was one of the people that put in the effort to reach an affordable grocer she liked. She shopped at Grocery Outlet in East Portland, and drove to get there. The cost of gas getting there plus traffic were big impediments to her going out to Grocery Outlet often. Instead, she would turn to Safeway for immediate needs, and that was only a couple blocks from home. Like all others that went out of their way to shop regularly at a preferred grocer with lower costs, they always had a store nearby they would shop at for more immediate needs between their big shopping trips.

In terms of social reproduction, Carol was making the most of her food dollar by shopping for what she deemed high-quality food at lower prices than Safeway. Even with the cost of gas and the frustration of dealing with traffic, she could justify those costs by saving a lot of money on food for her and her girls, money she could then put into other needs. 
Four people from Albina made the drive to East Portland for affordable groceries regularly. Jaqueline was one of them,

I actually drive out to get my food because Safeway and Fred Meyer and Albertsons to me are kinda expensive unless you really catch sales. They do have some sales that you can catch. But I actually go to WinCo. Because WinCo you always going to catch a deal in there. - Jaqueline, Albina

Jaqueline was very cost conscious, and she would shop at other stores when she needed to, but she preferred WinCo. Being able to drive ensured she could go there reliably and regularly. Reliability in mode was critical to Ruth's ability to get to WinCo, and she managed to get rides very reliably. However, she was the only person without a car in Albina that shopped outside of Albina.

People in Albina had to put in the extra effort to get affordable groceries because there were no low-cost grocers with good food quality in Albina. Gentrification had all but assured the private market would not locate a low-cost grocer there because land and rent prices were too high. Indeed, at the time of this study, Prosper Portland (formerly the Portland Development Commission) was working to bring an affordable and healthy grocer to Albina with a significant subsidy attached to the development site (McCurdy, 2019; Silvis, 2013).

East Portland had a different problem. The area had low-cost grocers, but they were all located toward the southern and western edges of the area. Given the vast area of East Portland, that made it very difficult for East Portlanders not near those stores to get to affordable grocers. Still, five East Portlanders frequented WinCo (one to $102^{\text {nd }}$ Ave and Halsey and the other to $82^{\text {nd }}$ Ave and Powell) and two others frequented Wal-Mart (at $182^{\text {nd }}$ Ave and Powell). Only Diana drove to the store, but she never used transit or walked for 
anything in her daily life. Transit users were spending anywhere from 15 to 30 minutes on transit to get to affordable grocers. Two others walked to WinCo, one three blocks, the other 70 blocks (see Chapter 5 for Gail's story on why she walked 70 blocks).

The spread-out built environment of East Portland made getting around difficult. The low rate of car ownership in East Portland made any trip that much more difficult. The uneven distribution of affordable groceries added yet another barrier to access. Those barriers were insurmountable for nearly half of East Portlanders who chose to shop at other grocers closer to where they lived. Nearly half of Albina residents also chose to shop closer to home, but their barriers to affordable groceries was affected even more by distance and lack of access to a car due to the difficulty and time cost of getting to East Portland by transit.

Almost no one shopping close to home was shopping at their preferred store, like Derrick. Derrick lived on the eastern edge of East Portland where only Albertson's was easily accessible. When I asked him if he would prefer cheaper stores, he responded,

Derrick: "Like I would like to go to some cheaper grocery stores. Like if they got some cheaper stores than Safeway, I would like to go there."

"Like if WinCo were 30 blocks closer?"

Derrick: "Hell yea! If it were closer, I would go there. Even Wal-Mart. I'd go to Wal-Mart if it were closer."

- Derrick, East Portland

He would have to drive over four miles to get to WinCo, nearly as far as people in Albina had to go. As such, he never shopped at WinCo or Wal-Mart because he did not want to spend the money on gas. 
People shopped at other grocers almost purely because of convenience. As Tawnya, who lived in Albina, said, "Safeway is easy for me to get to because it's just one bus there and back." Troy, also of Albina, added that going to the closest store saved him money, "If I can walk down the hill to Fred Meyer or Safeway, why would I need to pay the bus fare? The bus don't go to Safeway. But I can walk there in 7-12 minutes." Shopping close did not mean they were not always thinking of other options, as stated by Ashley,

I usually just go to Fred Meyers because it's off the MAX and I don't have to walk hella far with my bags. It depends on what I'm going for. Like I'm going to WinCo to get a good deal. Or to Safeway if I want better meat or something. I guess it just depends on how much of a journey. - Ashley, East Portland

Most of the research on grocery access in historically segregated neighborhoods has highlighted the lack of supermarkets in such neighborhoods and the need to travel large distances to find affordable and healthy foods. That was not the case in Albina as it did have easily accessed grocery stores nearby. Mid-market supermarkets like Safeway and Fred Meyer were available, but gentrification brought the upscale supermarkets, New Seasons and Whole Foods, to the area. Albina residents seeking low-cost foods highquality had to go to East Portland.

Meanwhile, East Portland had its own food deserts (places with low levels of food access). Most people there had to travel a long distance in order to reach a grocery store, and typically had to go further for an affordable store. Even though East Portland neighborhoods were growing in populations living in poverty, few low-cost grocers have entered into the market there, and those that did located mostly along edges of the area in order to also capitalize on proximity to higher-income populations. Following the 
conclusion of this study, WinCo took over a former Safeway store (122 $2^{\text {nd }}$ and Halsey) close to the center of East Portland. But people living on the Gresham border, where a substantial number of people in poverty live, still had to travel 60 blocks to get there.

\section{Cultural Amenities}

Communities need experiences that can root people in a culture and a neighborhood. As is typical for most ethnic groups, cultural amenities that help create those experiences tend to be clustered in their traditional neighborhoods. In Portland, this was no different as the majority of Black churches, barbershops, and other black-owned businesses are clustered in Albina. But the effects of displacement and shifting Black populations has meant many Black cultural amenities have closed down or relocated. The amenities that remain continue to be a magnet for Black populations across Portland.

\section{Churches.}

Churches are the most culturally rooted establishments in Albina. Black populations are among the most religious communities in the U.S., and churches in Black communities have substantial influence on community building and social reproduction (Taylor et al., 2005, 2013). Even though the number of churches in Albina has been dwindling over the years, and many of the remaining churches have shrinking congregations, they are still an important part of Black life in Portland. Nearly $80 \%$ of participants attended church at least semi-regularly, and all but three had a church that was Black (see Figure 6-3). 
Figure 6-3 Church Destinations

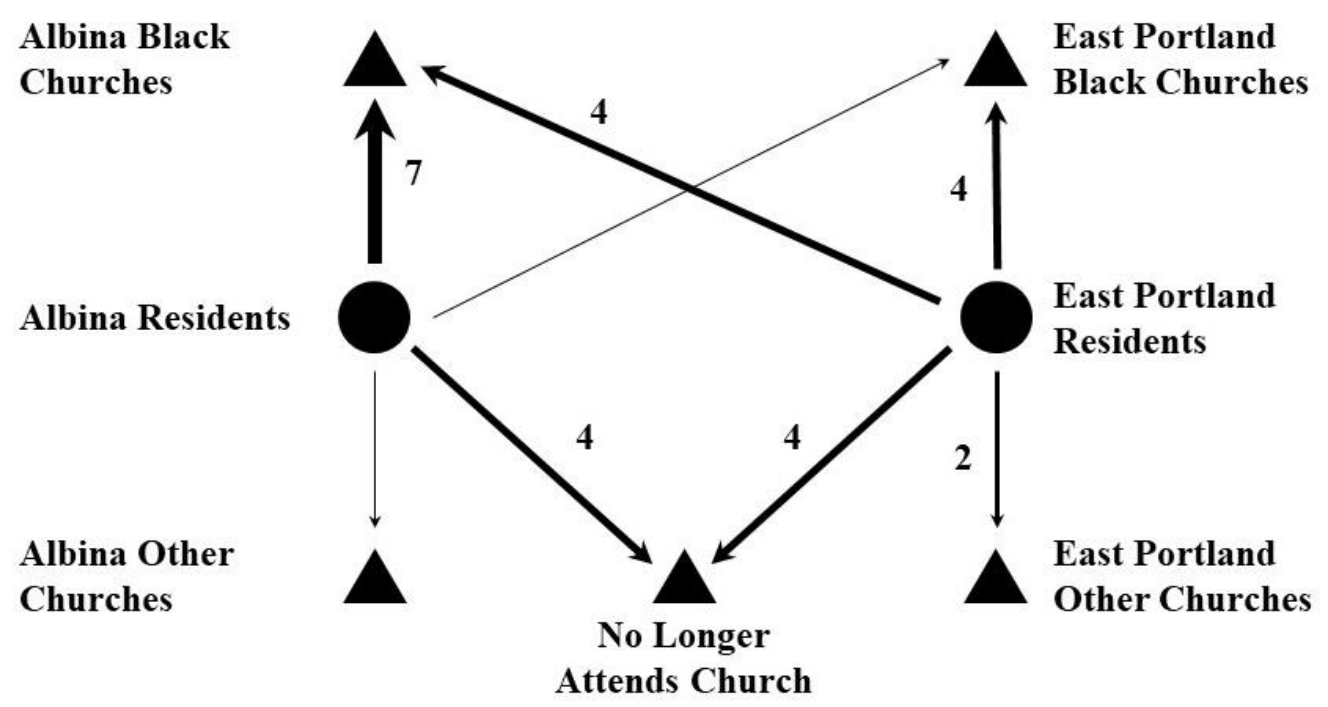

Note: Line thickness is determined by number of respondents going to those churches. Thicker lines have the number of participants displayed.

My church is on this side...But it's changing. A lot less people are going to church than I remember. Because they moved and they might just make it for certain services. - Olivia, Albina

Olivia was one of the few participants that remarked on the declining congregations. Troy also said of his church closing and moving that it was getting problematic before it closed. The neighborhood was changing the church and "it makes the church not feel like church anymore... and if the community ain't there it's not much of a church anymore." I noticed the difficulty myself when I went to the First AME (African Methodist Episcopal) Zion church for recruitment on N. Vancouver Ave and Skidmore. For a Sunday morning service, there were only ten congregants. Half the sermon seemed related in one way or another to the declining congregation and the changing neighborhood. It was such a tragedy for the church that the pastor was unable to make it through the sermon without coming to tears. 
Indeed, the neighborhood has changed so much that at least one major Black church, Highland Christian Church, relocated from Albina to $76^{\text {th }}$ Ave and Glisan to be closer to its congregation.

The church is a real driver of the Black community, and people and the churches go above and beyond to keep the congregation together. Margaret volunteers to drive out to East Portland to pick up congregants for Sunday service, and it is the only time she really goes out to East Portland.

I have some [friends and family] living way out there. I try not to go out there. But there's a church lady way out there that I go out there and get her on Sundays. I try not to go out that far. I don't like driving long ways. - Margaret, Albina

She won't even drive to East Portland for visiting friends and family out there. But for the people she picks up for church, she considers it an honor for them to be at the church. She was the only interviewee I had that volunteered to pick up members for church, but many more were picked up by either family or church provided transportation in order to get to church. Only four of the people from Albina got rides, and all of them were rides from family. Most East Portlanders were much reliant on getting rides to church in Albina. Over a quarter of the East Portland church-goers used church provided transportation, and they likely were not going to participate in that church anymore given the difficulty in getting there if not for that option, as described by Ashley,

I don't catch the bus to church because it's usually easy to catch a ride to church with family. So, it's not really something I worry about for transportation. And people are always willing to give you ride to church. But my church is on 79th and Glisan [Highland Christian]. It's kind of far. If you had to catch the bus there I wouldn't. - Ashley, East Portland 
Even though Highland Christian had moved closer to East Portland to remain connected with their congregation, Ashley still struggled with the distance. The church was five miles from where she lived and the bus trip would take over almost 30 minutes.

While fewer people were attending church than they had in the past, for most people, church was still very important to their lives and the community. The churches provided one of the few spaces in Portland where they could be Black and not feel uncomfortable or policed. In an overwhelmingly White city and a historically Black community that was no longer majority Black, those spaces were necessary, as you will read below. The Black population in Albina is aging, and coupled with continued displacement pressures, it will be harder for the churches still there to remain active. Fewer congregants living in Albina also makes it more difficult for the East Portlanders relying on their volunteerism to come pick them up for church. A lot of pressures are working against the remaining churches in Albina like congregation loss, trying to serve an ever more dispersed population, and the development pressures behind gentrification also coming after their land. It is a big question mark as to if and how long most churches may last in Albina and what that will mean for the larger Black community of Portland to have one of their last central gathering places lost. And what will it mean if only a handful of churches remain? Would their tents be large enough to accommodate the community? Probably not as evidenced by the number of people I talked to that decided to stop going to church instead. Given the sensitivity of the subject, I did not ask people why they stopped going to church. For those that offered the information voluntarily, it was a combination 
of their church environment changing, their ability to access their church of choice, and their changed personal orientation toward the church.

\section{Barbershops and Beauty Salons.}

Another neighborhood mainstay is the barbershop and beauty salon. They play a critical role in Black communities ranging from culturally appropriate hair care, maintenance of community, and social-networks (Harris-Lacewell, 2004; Wood \& Brunson, 2011). Very few barbershops and beauty salons catering to culturally appropriate hair care for Black people were located outside of Albina. For East Portlanders that did not want to go to Albina for a haircut, they would have to endure a troubled trial-and-error process to find a decent barber or find an alternative to a formal shop.

Nearly all of the people I interviewed opted to find some other means to take care

of their hair (see Figure 6-4), often due to the cost. Most either did their own hair or would rely on "kitchen beauticians" to get a better cut for much cheaper than a formal shop. However, having that service depended on knowing folks they could call up to come to them. Which, again, length of residence matters for having that developed network. 


\section{Figure 6-4 Hair Care Destinations}

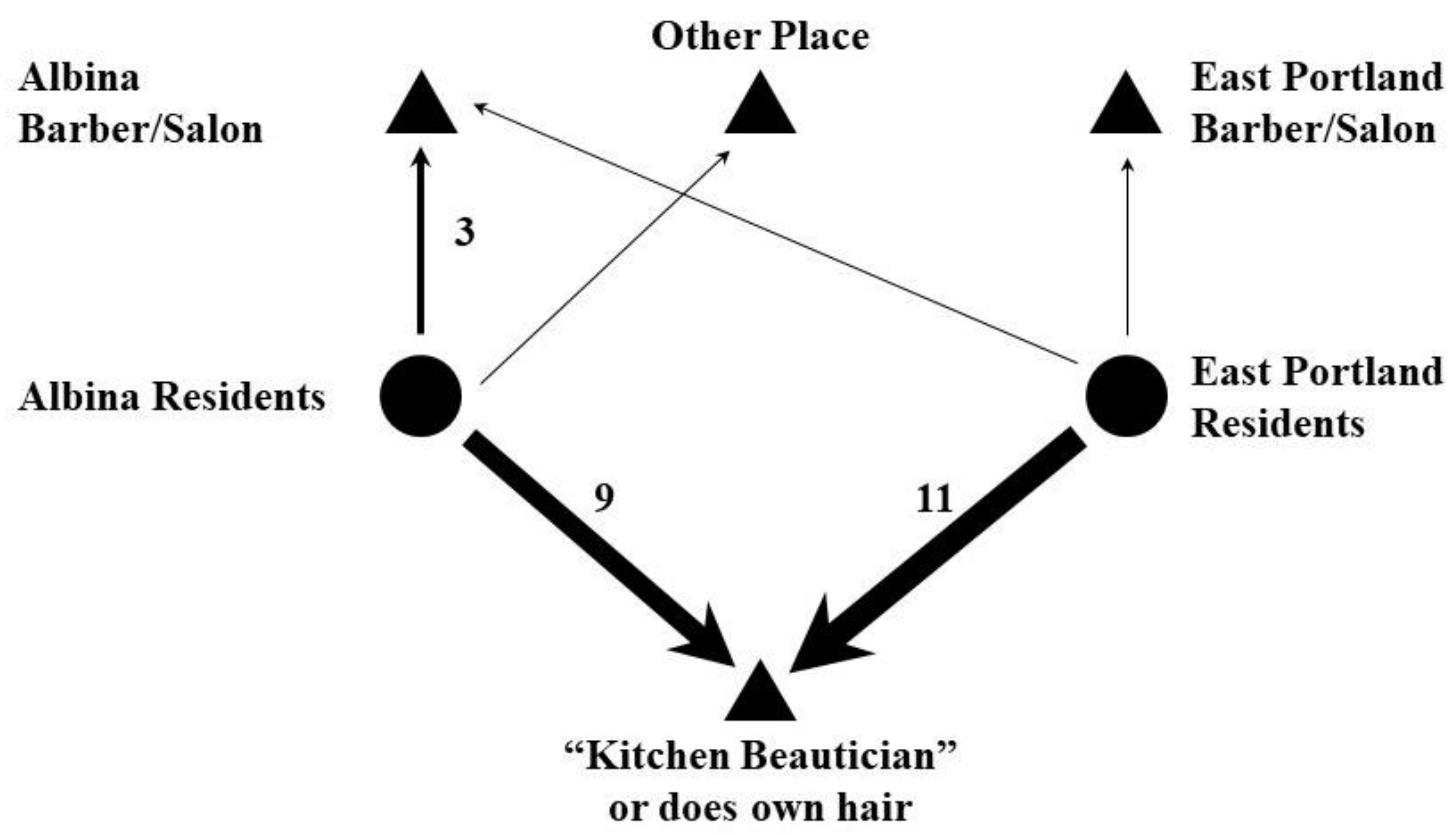

Note: Line thickness is determined by the number of participants that utilized the hair service. Thicker lines have the number of participants displayed.

But some did utilize formal services. Even folks that typically took care of their own hair, several said they would go to a barber/salon maybe once a year, but this was mostly common among folks in Albina. In Albina, the act of getting their hair done in a formal hair place was fairly easy as they all went to someplace in the neighborhood or knew of a shop they could go to reliably. Carol, at 60 years old, was going to the same spot she had been going to since "Day 1," Dean's Beauty Shop, which is the oldest barber shop in Oregon (City of Portland, 2019b). Just do not go to Geneva's shop according to Olivia,

It's easy because everybody is over here. Even though you don't go to Geneva's. It's like a running joke about how you don't go to Geneva's. But Geneva and everybody is here. That's convenient. - Olivia, Albina 
For East Portland folks, the lack of culturally appropriate barbershops and beauty salons was a constant struggle. A couple people went to shops that located around Highland Christian Church, but their other choice was to go into deep Gresham or to Albina, as Ashley said,

Usually try to find places close to home. But for hair you have to go all the way to North Portland. Basically, anytime you want to do something nice it's going to take you two hours to get there...In Gresham they don't really have anything unless you go out to 242nd. It's drastic either way. They need to work on that. You can't trust that many people with your hair here. And with everybody getting spread out...you pick that one barber. They know when you don't go back to them. - Ashley, East Portland

The experience was not much better for Derrick. He constantly struggled with the cost of getting his hair done and knew getting a good cut would require going to Albina. But driving all that way would cost him too much in gas. "What am I doing!? I think I'm just going to go bald man. Don't have to deal with it no more. Just cut it all off. Don't even care!" Finding a barber in East Portland was really tough for him,

Maaaann. I go to this same usual spot [near Highland Christian]. But to find something that's real real good, yea it is [difficult]. Because I don't know where one could be out here...my first 5 years were out in NE Portland. And that's where I know where all the barbers at. And many of them have broke off and went this way and that way. I don't know which way they went out this way. - Derrick, East Portland

He had lived in Portland for 10 years, but his length of time in Portland stunted his connection to people he could call up for a cut compared to others that had lived in Portland for all their lives. "I wish I had a person where I could be like 'I need to get faded real quick'. I wish. But I don't have that." 
The frustration of finding a Black barber/salon in East Portland was likely what led to nearly everyone there relying on "kitchen beauticians," family, or themselves to do their hair.

While distance to most Black barbershops/salons was a big frustration for folks living in East Portland, cost was almost always an overwhelming concern when it came to getting their hair done. It was a shared concern with those in Albina even though more of them were likely to participate in getting their hair done formally. The prevalence and persistence of barbershops and beauty salons in Albina signaled the importance of them to the community. However, there were large class differences in being able to interact with them and gain from the secondary benefits of community that had been a notable part of going to Black barbershops/salons (Harris-Lacewell, 2004; Wood \& Brunson, 2011). This may be a Portland anomaly due to the small size of the Black population. The small Black population limits the ability for a variety of barbershops/salons to operate with enough customer base. This allows a handful of shops to dominate the market with less incentive to compete on price. The gentrifying nature of Albina also does not lend itself to low-cost hair services.

In terms of social reproduction, it also made sense that participation by those in poverty would be limited. Spending $\$ 30$ or more to a haircut would be hard to justify when cutting back on food in order to afford bus fare. At the same time though, Black hair is a constant point of discrimination in the workplace and restrictions on hair styling restricts freedom of expression of their Black identity (Powell, 2018). Beyond the obvious 
implications for earnings, such discrimination has impacts on psychological health, a critical need in order to socially reproduce.

\section{Parks and Restaurants}

Other places, such as parks and restaurants have impacts on community building and the facilitation of social reproduction. As Sharonon Zub (2010), public spaces and restaurants were among the most impacted places in Harlem and Brooklyn as gentrification took hold. The neighborhood landmarks that were pieces of the authenticity of Black life in Harlem were under threat from new developments and the influx of national chains.

Parks act as community gathering spaces offering among the most egalitarian experiences in a neighborhood as they are also free entertainment places for parents to take their kids. In the areas studied here, parks in Albina appeared to be much more a part of the community character. Everyone knew the name of the park they went to regularly whether it was Dawson, Irving, Alberta, Peninsula, or Woodlawn Parks. No one in East Portland knew the name of the park they went to regularly. Instead, their park was "the one down the street."

Restaurants can hit a poor person's budget, but they offer an outlet for stress relief for parents by not having to plan and cook a meal. They also have the ability to be landmarks in the community, places that exemplify the neighborhood character and every one goes to them (Zubin, 2010). As mentioned at the beginning of this chapter, Carol longed for places like Ferrell's and Pietro's that were no longer in the community. Even though they were chain restaurants, they held a place in her heart. They were part of what 
made Albina feel like a community to her. Their disappearance was yet another sign that the community was changing. While many Black-owned restaurants existed in Albina over the years, the crack epidemic, rising violence, and emptying neighborhood made their survival nigh impossible. Most of the people in this study grew up in Albina during the crack epidemic, so many of the participants here were not able to partake in historically important restaurants in the area like Citizen's Fountain Lunch, Rudy's Tavern, or Wallace's Barbeque (City of Portland, 2019b). What made Albina a home differed from that of their parents. And while it is indicative of how no community is immune from change, the changes that take place can have drastic cultural repercussions.

Figure 6-5 shows the relationship Albina and East Portland residents had with parks and restaurants. Parks were utilized by as many people as restaurants, but people would use parks more often (frequency of use is not shown in the chart). East Portlanders were more likely to leave their area in order to get to a park and less likely to go to parks at all. East Portlanders were also less likely to go out to eat. Nearly everyone frequented restaurants near them with little geographic crossover. 


\section{Figure 6-5 Parks and Restaurant Destinations}

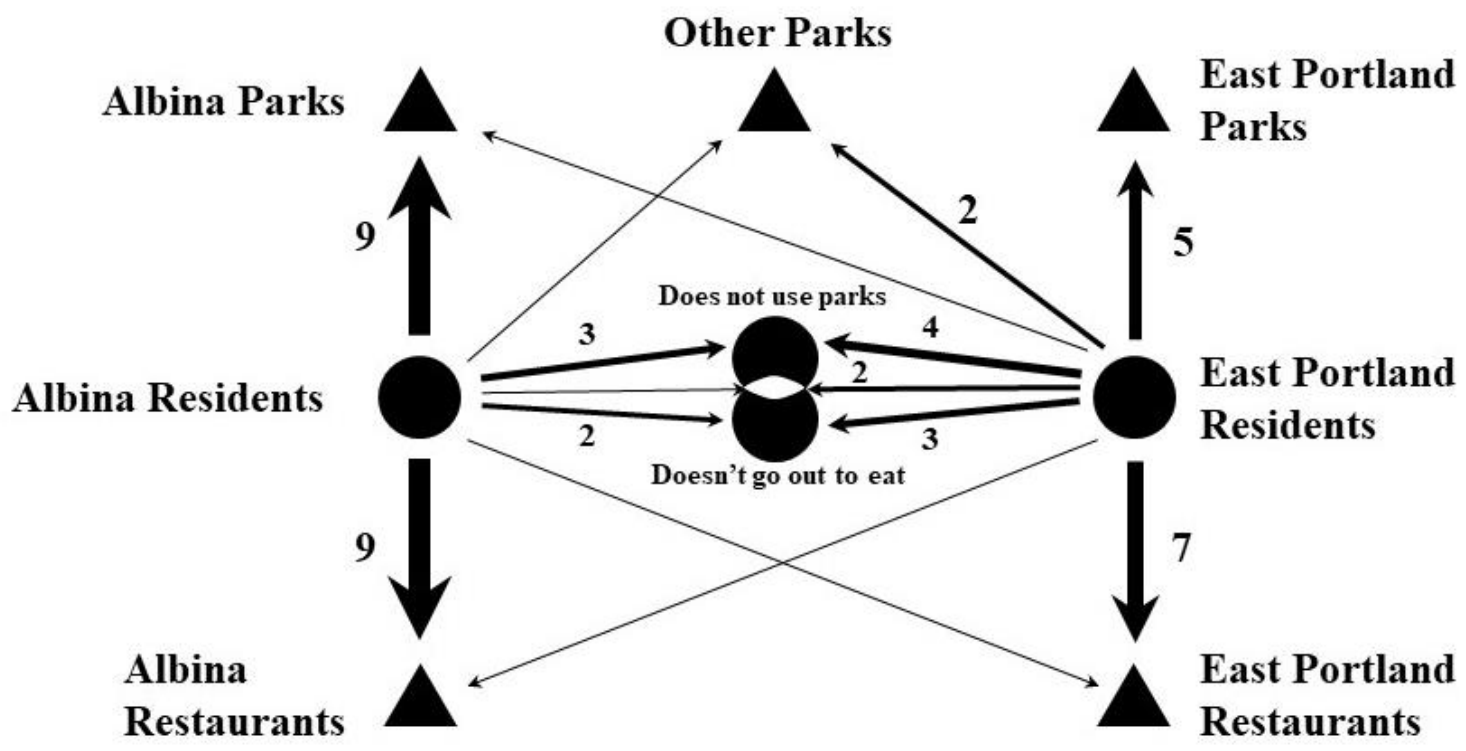

Note: Line thickness is determined by the number of participants that said they were going to that destination. Thicker lines have the number displayed. The overlapping circles in the middle are people who do not use parks or go to restaurants.

Parks were the most important amenity people relied on for entertainment, but utilization was highly dependent on the age of their children. For the few people I talked to that only had teenagers, they did not use parks much at all. Meanwhile, those with younger children typically found parks good for not just day time activities, but the summer night-time programming such as movies in the park gave them opportunities for free entertainment. Wanda utilized the summer park programming for the first time as she was recently unemployed,

I know for the summer time they have the like family park days or concert in the park or movies in the park. So, we was doing that all summer. Yea that was pretty fun. It was actually my first time doing it because usually I am at work until late at night during the summer. This time I was like "ok! I can finally do some things with you guys. " - Wanda, East Portland 
Most people went to parks nearest their house, but nearby parks in Albina and East Portland at the time of this study also had distinct problems for Black residents. In Albina, Jacqueline frequently walks in the parks in her neighborhood, and sees a very racially divided experience based on the park she goes to in the neighborhood.

...people will see us walking and wondering "why are you guys walking in this neighborhood" "because this is the neighborhood we grew up in." We've had a couple people stop us asking us [while in Alberta Park] 'what are you guys doing walking through this neighborhood.' I guess they're not used to seeing people of color in those neighborhoods anymore. Whereas it used to be we wouldn't see people like them in our neighborhood. Yea, it's changed a lot. It's no longer that same neighborhood that you remember. Some things are still the same though. Like Dawson Park, I don't think they'll ever get Black folk out of Dawson Park. I don't care how far out they live, they will come back to that park for whatever reason. - Jacqueline, Albina

Different concerns arose for Vanessa who has changed the park she regularly takes her kids to because of what has been going on in the one nearest her on SE Stark St. and $117^{\text {th }}$ Ave,

But my kids do like that place [Ventura Park]. But like a few weeks ago, maybe a month ago, when they did that Trump rally and they was walking down Stark. And the clan and everybody that's Trump supporters. They were rallying at that park. So that's deterred me from going over there because that's some random shit. - Vanessa, East Portland

Her concerns about the pro-Trump rally put on by the Proud Boys (a notoriously confrontational group associated with white supremacist ideologies and which frequently invites well known white supremacist groups to their rallies) made the park no longer feel safe to her or her kids. This rally was also followed by white supremacist threats to turn the popular block party in Albina, Good in the Hood, into a "bloodbath" which lead the FBI to suggest event organizers substantially increase security protocols for the event (Solomon, 2017). 
Restaurants were lowest on the importance scale, but they still had a role to play in social reproduction. Living in poverty required stress relief, and the parents in this study sought that through taking an hour out of their day to go to a restaurant, but their choice of restaurant was ultimately one of convenience. A few did partake in mid-range restaurants regularly and they had to specifically plan and budget for that. For everyone else, they looked for the most bang for their buck which meant fast food, cheap casual chains (such as Applebee's - especially their happy hour deals), and all-you-can-eat restaurants.

In both Albina and East Portland, interviewees were going to places either directly in the neighborhood or in a nearby major shopping center. That was mostly because both neighborhoods had the establishments they wanted to go to nearby, and given the low level of importance of these establishments in most of their lives, they were not going to travel very far to go to them. One of the bigger differences between the neighborhoods though was fast-food restaurants in East Portland still almost always required getting on transit to get to them. But even then, the distance was too much for some of them, like Ashley.

There's nowhere to eat around here. So, you got to make a trip. When I go out to eat, I hopefully go with my friends so they can drive me. Or I'll catch Uber sometimes. As far as on the bus, there's not that...it's inconvenient.

- Ashley, East Portland

Albina residents had a different variety of fast-food establishments and could find them within walking distance in most cases. For instance, only a couple of the people I interviewed in Albina would have to walk more than 10 minutes to get to a Popeye's (a commonly stated fast-food choice). Conversely, all but one of the people in East Portland were well outside of walking distance to a Popeye's. 
Cheap casual restaurants like Applebee's were brought up quite often as a place people would go to regularly. In Albina, they would go to the one by Lloyd Center just outside the south side of the neighborhood. East Portland residents would go to the one in Gateway. This was a popular destination for them because "the food is good" and "you can get a deal." Specifically, they would go to places for happy hour prices to get a substantial discount off regular priced food items.

I like Buffalo Wild Wings [where the interview took place]. Because I'm so close to everything on the bus. It's just like here and Lloyd Center. And I go to Applebee's and Red Robin. These are all places that I love a lot. And I'll get down here [Buffalo Wild Wings] with friends for a happy hour and do like their 10 cent wings. - Tawnya, Albina

In East Portland, the casual sit-down restaurants clustered a much like affordable grocers did, on the edges of the west side of the area. For most, that meant quite a trip to get to them. Therefore, it was still more of a treat than grabbing fast food which was almost entirely out of convenience.

Beyond places like fast-food and Applebee's, buffets were a restaurant option brought up by four of my interviewees. Given their limited means and need to satisfy their growing children's' appetites, these restaurants provided what they considered a good “bang-for-your-buck." For Derrick, Hometown Buffet was seen as one of the few places he could have a sit-down meal with his family and afford it.

I keep it kind of basic and cheap. Or like I might come up here to Hometown Buffet and get more for my buck. Keep it close, keep it cheap. Everything's right here in the vicinity. I don't really see too many other spots I could sit down. - Derrick, East Portland 
However, the only traditional buffet in Portland is Hometown Buffet at SE Stark and $102^{\text {nd }}$ Ave (just to the south of Gateway). Thus, like with grocery stores, people in Albina would struggle to get to it.

Restaurants were also a trigger of nostalgia for some of the people living in Albina. They grew up knowing a very different neighborhood than what is there today. As I mentioned earlier, Carol was nostalgic for Ferrell's and Pietro's. Similarly, Troy noticed the changes and was not fond of them,

A lot of small businesses are getting pushed out. A lot of businesses I used to go to have lost ownership. New owners come in, it's not the same. People not doing customer service no more when they look at you as just a number. It's more corporate like Starbucks and Nike instead of small businesses. Just seeing them get pushed out. - Troy, Albina

Seeing all those businesses they frequented years ago disappear has made them angry and sad for the neighborhood they once knew. But not everyone was sad about the changes they were seeing.

You know, most of those places we use to frequent as kids, I didn't really feel safe or that their quality was the best that it could be. So, I feel that everything that's been upgraded in those areas to me has been to my benefit rather than a downfall. So, I'm thankful for a lot of the change. - Leslee, Albina

Leslee was the only one that expressed seeing the change in the neighborhood as an "improvement." And while not everyone was explicit with how they saw the changes in the neighborhood, it was easy to tell from the way they talked about the other aspects of the neighborhood that not all of them were appreciative of the way the neighborhood was changing. At least that was the case with places. The people changing in the neighborhood elicited far more explicit reactions. 


\section{People and Neighborhood}

Social support networks are a critical part of how people maintain their daily life (Edin \& Lein, 1997; Roschelle, 1997; Stack, 1975). Without friends and family they could turn to for things like childcare, a ride to the grocery store, or just the availability to socialize, their lives would be much more difficult. Additionally, it matters where they live in conjunction to their support networks. Turney_and_Harknett__2010) found that Black women living in advantaged neighborhoods received less help from their networks than Black women who lived in relatively stable disadvantaged neighborhoods.

There is also the possibility that new neighbors could mean new people they could access for their support networks. In neighborhood integration theory, the idea is that mixing incomes and races in a neighborhood will lead those populations to interact and develop supportive networks (Galster, 2007). The benefit from that being that developing networks with higher-income populations could help those living in poverty more than if their networks consisted only of people in poverty. While there is evidence that low-income networks consisting of only other low-income people do tend to be under-resourced (Edin \& Lein, 1997; Stack, 1975; Turney \& Harknett, 2010), there has been little evidence of integration helping social networks (Clampet-Lundquist, 2004; Kissane \& ClampetLundquist, 2012; Kleit \& Manzo, 2006).

Carol was very attuned to the way the people around her were important to her life. Most of her family lived in Gresham, an even longer journey than getting to East Portland. She struggled to overcome the distance, and it has impacted her family relationships. 
Although Albina was where she grew up, the neighborhood and its people have changed drastically leaving her isolated "I feel like an alien now."

Hers was not an isolated experience. Due to displacement from gentrification, there were two types of support network losses to observe. People in Albina experienced their networks moving east and new neighbors moving in that looked very different. East Portlanders, on the other hand, experienced removing themselves from proximate contact with their networks. The two types of network losses had different impacts as most people in Albina were able to tap into other people in their network still living in Albina. East Portlanders, on average, did not have people they could rely on in East Portland and still relied a lot on those living in Albina.

Not many of the people I interviewed were as forthcoming with explicitly talking about the people of the neighborhood as Carol, but a few of them did. What was noticeably missing from this analysis were comments from folks in East Portland. For reasons I will explain later, the absence of their comments is itself a commentary on the difference in the lives of folks living in East Portland.

\section{Neighborhood People}

Gentrification, by definition, brought a new class of people to Albina over the years. And for those like Carol that grew up in Albina, those new people were not as welcome an addition to the neighborhood as the businesses that moved in. The mere presence of newcomers in the neighborhood did not lead to the resentment, it was the attitude of the newcomers. Specifically, it was their attitude toward the poor and Black populations that had populated the neighborhood for decades. Carol put it this way, 
I feel like an alien now. I feel weird. Like I'm not supposed to be here anymore. Like especially on Alberta sometimes when I do deliveries for Postmates. It's weird. Because the whole area is not what it used to be. And so now I'm an alien. When it used to be vice versa. And now it just, I just look around and I feel like I'm in some other place. Like, it don't even feel like where I grew up anymore. It's weird. Just weird. And I feel like it wouldn't be so bad maybe if these white people were maybe more friendly and would say "Hi, how are you" But they just act like I don't exist. [crying] I felt like this is my area. Why do I feel... why do you come here? ... at least say hi. Or I don't know. It's just weird. So, yea, it's just crazy. I feel sad. And you know, it used to be when I would go up to the store or different places or something like that, I would always see people I know. But now, it's nobody. Nobody. It's just sad. You know sometimes here and there. But it's not really like it used to be. It's just weird. - Carol, Albina

While her feelings about the people in the neighborhood were compounded by the lack of people she used to know, that was part of what made the interactions with the new people so impactful. Rather than an overt racism, they are being confronted with a kind of racism that chooses to erase their existence. The lack of people familiar to them, and the lack of Black people in general, left them feeling alone. As Carol further stated when reflecting on places in the neighborhood that are no longer there (she did not name specific places),

Yea, there's a couple places, mainly one that's gone now. I used to always go to. And it's not there. Like there's been quite a few places where I'd see people I know, Black people, that's not there anymore. So that even makes it worse because now everybody moved out, at least everybody had a spot or two that we would go. And you still see people from the hood that did you didn't see. But now they're gone. So, you don't see nobody no more. - Carol, Albina

Similarly, Jacqueline remarked,

None of the people you knew growing up in this neighborhood are living in this neighborhood anymore. They're all further out. Yea, it has changed. It has changed the way you visit or hang out with friends...In the past you used 
to just walk to someone's house because they lived down the block, around the corner...Yea, it's changed a lot. It's no longer that same neighborhood that you remember. - Jacqueline, Albina

Not everyone was sad with the changeover of people in the area. Several, including Carol, recalled the days when the neighborhood was inundated with gangs and lots of violent crime. And having those people pushed out of the neighborhood was a welcome relief. However, the gangs did not just disappear. Many were pushed to East Portland where their presence was now felt, such as Gail,

It's very bad. The crime is up. It's very dangerous out there. Because they done pushed everybody out there. Every one's just angry. All the drug addicts. Every body's mad. Mad black people. Not even just black people. Everybody. - Gail, East Portland

East Portland folks were much less likely to talk about the people in their neighborhood. It is difficult to attribute their lack of words on the people of their neighborhood without explicitly asking them about it, but it was clear in how they talked about their neighborhood that it was much different for those living in Albina. There was more of a detached association with the neighborhood for those living in East Portland. There really was not much there that gave them a rootedness. None of them grew up in East Portland. Its relative newness and rapid change has not allowed the community to develop a history or sense of attachment. The suburban land-use of East Portland likely contributed to that as well given the distances they had to go in order to get to places. It would be difficult to encounter the same people on a regular basis in that environment. Similarly, the environment encouraged less activity, as seen in the above sections, because the time, energy, and cost of going anywhere was much higher than it was in Albina. 
Even though the time, energy, and cost of going places in Albina was lower, that sense of alienation made them feel that they were no longer welcome; that the new places in the neighborhood were not accepting to their presence. It prevented them from wanting to go out into the neighborhood. This was only compounded by the other racist events going on throughout the city and their struggle to afford the basic necessities let alone being able to eat out at restaurants or go shopping in the neighborhood.

\section{Family and Friends}

Daily survival for the people in this study required childcare, getting to work, having groceries, and having the money to pay the electric bill or fill the car with gas. Having friends and family to help fulfill those tasks makes life easier. But that ease requires being able to get that help. A few people in this study did not have any support network. Others were physically separated from their support network to a point the distance was nearly too much to overcome. But most had friends and family nearby they could turn to in a time of need. Figure 6-6 shows how reliant people were on their support networks based on where their network lived. Each person in the sample is represented by two line thicknesses in the diagram (one line for their network in Albina and another for East Portland) unless they had no one in their network. Thus, the thicker the line, the more people had a person in their network in that area with that level of reliance on that person.

Overall, most people in Albina had friends and family that lived in East Portland, but they never relied on them. Instead, most relied on friends and family in Albina. A near equal number of them did not rely on their Albina network either and tried to be as independent as possible. In East Portland, their reliance on friends and family was based 
on who they had available regardless of where they lived. The plurality of them relied on someone proximate to them, but as many of them relied on someone in Albina at least a little.

\section{Figure 6-6 Support Network Diagram by Geography}

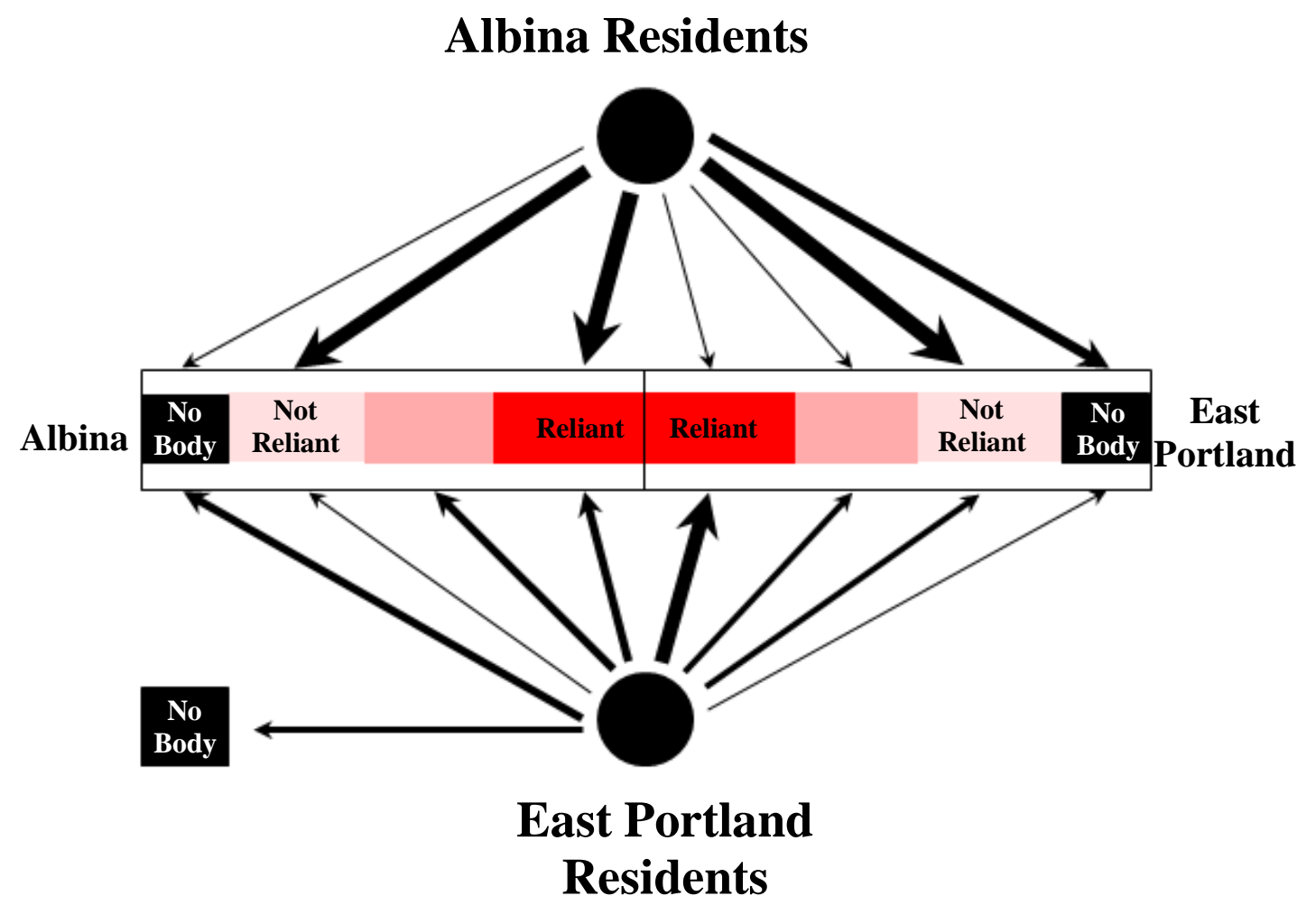

Note: Line thickness is determined by the number of participants in that grouping. Each participant could have 2 possible lines. Thus, numbers are not displayed to minimize confusion. The separate box "No Body" is for two people that did not have support network members at all.

Carol relied on her mom, who lived in East Portland, for money to get by day-today. She never liked asking her mom for money, and so she limits her asks. But her son was going through growth spurts making it difficult for her to keep him clothed, and her mom was the only resource she had to meet that need. 
It used to be that her mom could help with a lot more in her life. But that was when her mom lived just up the street from her. Carol could stop by her mom's place whenever they wanted and partake in family meals or just general family time. Her mom's move to East Portland has put a strain on that lifeline.

"Do you feel like that distance does impact the amount that they're able to help you out?

Carol: Uhhhhh...maybe. Never really thought about it. Actually, you know it does. Because I like I said, I don't be going over there anymore. I'd be taking my son to see her more. If I had something to do, I could take him to her. I'm [not] going to take him way way over there for that. So, it does impact. Because he's missing out. Like I said, when grandma was there on 8th and Killingsworth, we could go over there anytime. Eat. Whatever. But now can't just stop in anymore. So, it does impact. Definitely.

- Carol, Albina

An understated, but deeply important part of having her mom nearby was the time her son and his grandmother could spend together. She wanted him to know his grandmother and it hurt her to not be able to foster that relationship. While her mother still came to Albina to go to church and uses that opportunity to spend time with her, it is not as much time as Carol wants or needs.

"Do you feel it's affecting your relationship with her at all?"

Carol: Yea! Because that's my mom! And my son, I'd like him to see his grandma more. But I don't want to waste a whole tank of gas going there and back. But if she was still over here, I could go over there every other day. But now, it's only every few months. - Carol, Albina

Similar to the relationship difficulties Carol had with her mother, Carol's grown daughter lived in Gresham. Her relationship with her daughter has been strained by the distance because her daughter needs help often, but Carol cannot always meet that need because of the distance. 
"How did it affect you when your daughter was calling you up asking for rides to the grocery store?"

Carol: Well of course I didn't want to do it. But I didn't let her know that. Because all I was thinking about was the traffic. And she gets off work at four or five [pm] right in the middle of it. So, I'd pick her up and take her to the store and blah blah blah and wait. And she was getting everything in the store. So, yea. But I have to do it. - Carol, Albina

Carol said that all she was thinking about was the traffic. But it was more than that. Traffic meant time. Time her car was idling. Time her car was sucking up gas. Gas she struggled to afford. But it was her daughter. She was not going to turn down her daughter's call for help. The asks were so burdensome for her, she had to find another solution to overcome the difficulties brought on by the distance between her and her daughter. So, she pulled together the money to help her daughter buy a car.

I hypothesized that the divided nature of the Black community in Portland based on distance would sever networks and leave people living in East Portland worse off, the evidence was a bit more nuanced. The effort it took to have reliance on others was certainly more difficult for those living in East Portland. People in Albina were much less likely to seek help from or travel out to people living in East Portland. Meanwhile, most people in East Portland that had to make the trip to Albina in order to get help (because their Albina network would not come to them) would claim the distance was no problem.

\section{Reliance.}

People who relied on their network a lot generally needed help from their network to meet critical needs like childcare, getting rides, and even money to cover bills. Beyond that, they also leaned on their family for emotional support. Having emotional support in 
particular led people to appear more composed and put-together. I did not interview any one that had a strong support network that expressed feelings of extreme isolation.

Having a strong support network made a noticeable difference in the lives of the people who had it. Many of them had few other outlets they could turn to if their network started to fall apart. Don moved from East Portland to Albina with the help of subsidized housing. This move put him closer to his mom, making it much easier for him to turn to her for help, especially for childcare.

"You mentioned you moved from [East Portland] to here, how did that impact your ability to get your family's help with child care?"

Don: Oh, it's better! Because when I was [on] 92nd I was brought up and raised in N/NE my whole life. So, I know this area. Even though most people moving that way, my family is still here. I got more help once I moved over here because I was closer to my family. - Don, Albina

The move also made it much easier for him to get rides from friends as most of them still lived in Albina as well. Given his constant dealings with his car breaking down, having a more proximate support system helped him overcome many difficulties in his life. While the move did not change his daily needs, it certainly made getting them fulfilled much easier. He also claimed that if it came to the point his mother could not help him with childcare anymore, he would probably have to quit his job, a sign of the fragility of his system of support. This was very common, and I go into more later.

In East Portland, Ashley had a multipronged childcare strategy in order to attend college, got to work, and conduct her errands. She had two cousins to watch her son while she was in class, but for all other times she relied on her other family in Albina. It was a huge stressor for her to have to make that trip to Albina for childcare. 
"Does that present any issues trying to get there?"

Ashley: Yea. It takes forever. It takes like 2 hours to do anything. And stay on time. Say you have a job interview or school; you can't be late to those kinds of things. So, you have to plan. And be early. - Ashley, East Portland

Ashley may have to make that two-hour round trip more often as one of her cousins recently moved further out to Gresham. With that move, she felt like her cousin cut her off. Her cousin no longer wanted to hang out, she could not get rides from her anymore, and generally felt like her cousin did not want to help her at all anymore. So, while Ashley had a strong network, it took a lot to use it. On top of that, there was a fragility to her network that could quickly devolve to the point of her having nowhere to turn to for help. Because of the fragility of her network, she was trying everything to make her Albina network work for her.

When I ask for help, usually they come to me because I'm the one really in need. But if I needed help and had the ability to get to them, I would be more than willing to go get it. - Ashley, East Portland

In a somewhat opposite vein, Derrick experienced his mother-in-law moving to East Portland making his ability to get help with childcare much easier. From that he felt more secure in being able to get help, reliably. But he still feels an immense amount of pressure with the rest of his family living in Albina.

"With your family living on the other side of Portland, do you feel that distance affects your relationship with them?"

Derrick: It do. Because I don't get to see them as often. They be wanting to see me. Lately over the past year, I've been kind of on high demand with people. They been high demanding to see me. I just don't have the time. I can't say I don't really have the time. Because now I do, you know working day shift schedules. When I was working graveyards, I would sleep all day. Now I'm on the day schedules, I kinda do have the time, but I ain't got the gas. I do have to deal with that. They fuss about that. I do understand they 
want to see me. I want to make it happen. I'll make it happen. - Derrick, East Portland

Derrick's family wanted to spend time with him and his family, but between his household's schedule and the need for gas, he could never find the ability to get over there. And as I've brought up in both this chapter and Chapter 5, people in Albina generally avoided coming out to East Portland.

\section{Weak Reliance.}

People with weak reliance on their networks were those that exhibited a limited network on which they could rely and they utilized it as best they could. Carol was someone with weak reliance on her network. Carol only had her mom to rely on and only saw her at most, once a week. Had her grandmother still been alive when I interviewed her, she would have a reliant network based on how she talked about her relationship with her grandmother.

Others with weak reliance in their network typically only had one person they could really rely on for maybe one or two needs in their life. Amber was one of these people, and even then, the reliance she had on her support network was limited and fragile. She really struggled with supporting herself and spent some time homeless staying on her dad's couch with her two kids. Her dad was very important to her survival, but he had limited capacity to help her with many of her basic needs. He was on limited income, disabled, and in too poor of health to make trips to Albina or be able to watch her kids. He mostly could only help by having frequent phone calls with her. Aside from her dad, her son's stepmom picked up Ashley's son from school since she was not able to do so because of her work schedule. It was a little thing and she had limited interaction with her son's stepmom, but 
without that deed, she would lose an hour of work each day. Not being able to work that extra hour could also mean the loss of her fast-food job. That hour was also earnings she would not have in order to pay her $\$ 1200 /$ month rent. She recognized the fragility of her situation and the limited time she may have left with her dad around given his health. With the high rents she faces, the prolonged process of getting subsidized housing, a car that was about to break down permanently, and her dad likely to pass away soon, she had contemplated moving to Texas to be near more of her family.

A factor that led people to have weak reliance on their networks was their poor relationships with family in the area. Either they did not get along well enough to be able to ask for help, or they felt their family was too untrustworthy to take on a task like watching their kids for a few hours. Vanessa relied more on her best friend than she did her family because she did not trust them at all. While she could get rides to or from family in Albina, it was only for the purpose of visiting with them. She could not ask them for help in the form of childcare or money. At the same time, she recognized her life was much easier when she lived in Albina. She moved to East Portland with the aid of Section 8, but she felt like a fish out of water when she moved out there.

And honestly not until recently I got more familiar with SE Portland situation. Because I was always like if I can't do this then I'd go back over here [Albina] and figure it out. But slowly but surely people were helping me. Like neighbors were telling me oh just go here or there. I was like ok. I just didn't know. I really don't know and I'm not trying to be cute or funny, I just don't know. - Vanessa, East Portland

Not only did she move away from her support network, she moved to a place she was completely unfamiliar with. One or the other would have been bad enough, but the combination really set her back. It made everything more difficult. 
But yea it's not the same per se because I have to do a little more to get there. And also, since I have to catch the MAX or bus to get $x, y, z$ it makes it harder...And I have to listen to know what to do and whatever. But because they've kind of pushed us out of the hood per se I really got to figure it out myself. It's ok, well it's not ok they pushed us out, but it would be a little bit easier if you kind of gave us a guide of what to do when you're in this new place. Because they don't really give you that and you really have to figure it out yourself. Unless you know somebody. - Vanessa, East Portland

This was a common sentiment among households that took part in housing mobility programs across the United States and specifically a problem that programs like the Baltimore Mobility Program sought to fix (Darrah \& DeLuca, 2014). Portland's housing agency, Home Forward, had wrap-around services like job training and childcare assistance, but from what I could find out, they did not work with housing voucher recipients to help them adjust to living in an unfamiliar place. Perhaps with that help, having a limited support network would not have been as hard, but as things stood, she was struggling to make it work in East Portland.

\section{No Reliance.}

There were nine people I talked to that said they did not rely on anybody. Nearly all of them had family in the area they could potentially turn to for help, but they chose not to for various reasons. Three of them were actually the givers in their networks, and all three lived in Albina.

One of them was Troy, whose mother was in a nursing home and he helped her out. He struggled greatly on his own and was barely getting by. As mentioned in the grocery store section of this chapter, he was consistently buying low-quality food from the Dollar Tree in order to save enough to afford bus fare. 
The other two, Angela and Jacqueline, had grown kids living in East Portland, Gresham, and Vancouver that came to them for help regularly. Unlike Carol, when they helped out their grown kids, they made their kids come to them for help, continuing the trend that people in Albina refused to go east. This was a strategic decision on their part as it kept their kids from always asking for help since they had to put in the extra effort to get it. Angela and Jacqueline had extensive family in the area aside from their kids. And they got along with their family. They just did not feel the need to tap into their network for help. That Angela and Jaqueline both earned over $\$ 30,000$ a year helped as well, but that was still meager earnings. In 2017 the estimated the self-sufficiency wage necessary to meet all basic needs in Multnomah County for a single adult with two school-age children, like Jaqueline's household, was $\$ 53,710$.

Jaqueline also was not receiving any public assistance that could offset the difference. She had informal custody of her grandchildren (her son's kids) because their mom was not doing well with the kids. Their mom had applied for TANF and SNAP and was eligible because she claimed the kids were still living with her, but she was not sending any money to Jaqueline. That also meant Jaqueline could not apply for benefits herself or the kids.

The story for East Portlanders was a mixed bag. Jasmine only had her mother left in Portland, and she lived in Wilsonville, an inconceivably long transit ride from where she lived in Cully. Still, her mom came by every once in a while and watched after her son. Even though she felt her mom would help out as much as she could, the distance was too much to expect much help for very long. As such, she basically had no support network. 
Darius did not have any of his own family in the area, and his wife's family was entirely unreliable. He once called one of them up for a ride to the grocery store. They agreed but blew him off and called back three days later asking if he still needed the ride. Thus, they also had no support network. Instead, they relied on getting every bit of public assistance they could so not to become homeless again. Their biggest remaining hurdle was finding childcare.

We were looking for a daycare to put her in so we can go out and lookfor stuff. And every daycare was full or not taking infants and things like that. And it's hard for us to rely on people in our neighborhood because we're always out. We don't associate with our neighbors like that and our neighbors are always working like that too. It's just us and families and who else knows what else is going on in the rest of the world you know. Childcare is real hard because we don't have any family out here in this area to help us out with anything. - Darius, East Portland

Beyond not having family, even finding a daycare that was accepting new kids was difficult for him. It was not clear to me if they had childcare assistance either. As others I interviewed pointed out, even the co-pay on daycare with assistance was daunting at about \$250-350/month.

Diana lived in the same apartment building as her sister and mother, but they had a strained relationship to the point she never asked for help from them. However, a friend of hers also lived in the same building. He was always helping her out. He was the one that helped her get a replacement car within three days of her old one dying.

Gail was the only one in East Portland who did not rely on a network but still had friends and family in Albina. She said they were too unreliable to help her out when she needed them. But she did go to Albina often to visit with them. She was not nearly as open 
about her situation as others I talked to, so the effect her lack of support network was unknown.

Without having a support network they could rely on, it was clear East Portlanders struggled much more than people in Albina. Troy was the exception as he was the only person in Albina that did not have someone he could rely on there. East Portlanders seemed to have more difficulty with their family which blocked their access to help.

\section{People, Places, and Survival}

Carol wanted to be in Albina. It was the place she grew up in. It was the place she knew. It was the place that brought her the best opportunity for success for her and her son. She was successful in her restaurant delivery job because of her centralized location, her son was in a school that accepted him and helped him be his best even with his learning disability. And the urban structure of Albina let her reach the places she needed to get to with relative ease.

But she knew the place she grew up in may not be recognizable for much longer. The people she knew in the neighborhood were no longer there. The family members she could rely on had moved East. From the way she described it, she rarely saw a Black face in the area, let alone a friendly face. Needless to say, her relationship with the neighborhood was complicated.

For most Albina folks I talked to, they did not feel as isolated as Carol. Most of them had substantial support networks they could rely on and were easy to access. In other words, their roots were still strong when it came to having people to help them through tough times. But the changes in the area were threatening that stability. About a third of 
them lacked subsidized housing meaning they had to absorb the extraordinary costs of rent in the area. People like Amber demonstrated that just one thing going wrong could collapse their house of cards.

Living in Albina did help to keep the house of cards standing though. The combined advantages of living in Albina saved time, money, and stress all of which relate to a person's ability to socially reproduce. Their and their kids' futures depend on their ability to accomplish those tasks. For instance, if someone in Albina was called into work for a shift they did not plan on, their strong nearby support network would be more likely to rise to action to watch their kids for them. Saving time on conducting errands spills over into time they could spend with their kids either playing, reading to them, helping with homework, or just watching a movie. As Phillips (2011) found, there is was a relatively large disparity between Black and White children in how much time their parents spend with them. And while it was only part of the puzzle of low-academic achievement for Black kids, there was an association between time spent with their kids and academic achievement. As seen with several of the parents in this study, adult children that continue to struggle also become a drag on their ability to socially reproduce.

East Portlanders had a more difficult time accomplishing their daily tasks. They could not expect someone to be there last minute if they got called into work. The amount of time they spent getting anywhere meant their ability to fulfill their daily tasks was limited. Going grocery shopping could be an hour round trip just in transit, compared to about half that for someone in Albina. That half hour is another trip people in Albina could make that day that East Portlanders had to sacrifice, much like the experiment Rogalskky 
(2010) conducted that showed one mother took 12 trips in a day by car, but if those trips were converted to transit, she would have to eliminate five of those trips because of the time it would take.

Mindy Fullilove described in Root Shock that home was the combination of places, people, and history that connected people to a place. Having the places and people torn away could lead to significant harm to a person's psychological state. In this chapter, I found most people living in Albina considered it their home and liked living there. They had a strong attachment to the area through the places they went and identified with and had strong localized support networks. But it was setting them up for "root shock" if things started to go wrong. While gentrification presented itself in a different way than the wholesale destruction Fullilove described in Pittsburgh's urban renewal phases, the same damage was being done as Albina transformed and was replaced with a new and very different culture.

East Portlanders on the other hand did not necessarily have a home as Fullilove would describe it. They had a place to sleep at night, but they lacked a connection with their surroundings. Indeed, the built environment of East Portland was not set up to easily connect with it. They lived there almost entirely because that was where they could find housing they could afford. The people they knew in East Portland were also displaced from Albina or its nearby neighborhoods. As Ashley's situation with her support network demonstrated, the support networks in East Portland may be more transient in nature as there was nothing about East Portland that would make them want to pay $70 \%$ of their income on rent like Amber did in Albina. Rents were on the rise in East Portland too as the 
region's housing crisis caught up to the suburbs (Portland Housing Bureau, 2017) leading to possible displacement pressures. There was not a collective history in East Portland given how new the area was. There were virtually no culturally relevant landmarks or retail shops. For people in East Portland, if they had to move again, it would be hard, as having to move always is, but it would not have the same psychological effect of being removed from Albina. 


\section{Chapter 7 Social Reproduction and the Role of Gentrification and Transportation}

To conclude this study, I wanted to revisit the questions and theoretical arguments

that started it, provide insight into other research questions this study could help, and discuss potential policy implications. Throughout this study, I answered the following questions:

1. How does access to daily needs and services and transportation choices affect low-income black households' strategies to make ends meet?

a. What transportation options are they using? Why?

b. How do those choices affect their daily lives?

c. What tradeoffs do they make in deciding to use one mode over another?

2. How has gentrification and displacement affected strategies to make ends meet?

a. How has access to services and daily needs changed since they have noticed gentrification?

b. How has their interaction with and the composition of their social support network changed since they have noticed gentrification?

In the next section I revisit those above questions with a synthesis of the findings in the bigger picture. I frame the synthesis around implications for understanding social reproduction and social exclusion. Following that section, I respond to how the results of this study are important for theory beyond the main theoretical framing such as dispersal of poverty programs, spatial mismatch, and gentrification. I then discuss the policy and planning implications for what I learned from this study. Lastly, I discuss the limitations on interpreting the results and how the results can be applied.

\section{Answering the Research Questions}

I started this study with the goal of learning about how low-income Black people with children were getting around while factoring in the gentrification component to how experiences would differ. Based on prior studies like Edin_and_Lein__(1997)_and _ _Stack 
(19752), it was clear that low-income households struggled to make ends meet. Whether it was falling behind on rent, cutting back on the quality or amount of food, cutting off a utility, compromising their health and well-being putting off health care or seeing to their psychological needs, families in poverty have seriously compromised abilities to social reproduce. They have to weigh each decision with the tradeoffs of choosing another way to accomplish the task which may compromise another part of their life. And each decision often involved a transportation component.

Social exclusion theory evolved from analyzing the socio-geographic factors that were keeping people from succeeding in their everyday life tasks. Travel became a central research focus as it became clearer that people's inabilities to participate in social and political life important to basic survival were being inhibited by transport disadvantage (Kenyon et al., 2002; Lucas, 2012). Through this study, I contributed to further understanding how transportation barriers manifested in low-income Black people's lives and how they adapted to those barriers.

While there is a wide base of knowledge around how low-income populations are at a greater disadvantage to life success (Lucas, 2012), there is a lack of knowledge around how exactly those disadvantages manifest and how low-income populations adapt to the disadvantage.

As stressed by social exclusion theorists like Lucas_(2012), social exclusion is always relative. The low-income Black populations examined in this study are relative not just between the geographies studied here, but also to other populations not studied. So, 
while Albina populations look better off in comparison to East Portlanders, it does not mean they face equal access to opportunity as perhaps a low-income White person living in Albina. Better understanding the racialized relationship of transportation in Portland could give a clearer understanding of relative need, especially as it would pertain to a Title VI equity analysis.

By virtue of living where they did, East Portlanders were excluded from the opportunity to live the life expected of them in order to survive. In explaining Figure 5-3 further, Table 7-1 took the social exclusion factors and summarized ways East Portlanders dependent on Transit were excluded from life's basic necessities and the risks that presented in their lives. The implications for their exclusion were wide ranging from foregoing a trip that would mean the difference between eating chicken or ramen to possible death because they had to walk in the street due to the lack of adequate sidewalks. For each possible implication of a decision, they had to weigh the tradeoffs for deciding how they were going to get somewhere, where they were going to go, and whether the task was worth it. And they would never face just one barrier at a time. Each time they left their house for transit, they would stress over whether the bus or train would show up on time or whether something would happen to them on the way to or on transit. These were constants in their life. Each additional barrier would affect their stress levels and psychological state of mind, furthering their disadvantage through declining health. As Fullilove $(2004)$ demonstrated, stress and psychological damage manifest in worse health outcomes and poorer life chances. 
Table 7-1 The Effects of Social Exclusion on Transit Dependent East Portlanders

\begin{tabular}{|c|c|c|}
\hline $\begin{array}{l}\text { Forms of } \\
\text { Exclusion } \\
\end{array}$ & $\begin{array}{l}\text { Dimension of } \\
\text { Exclusion }\end{array}$ & Effect \\
\hline Physical & $\begin{array}{l}\text { Transit delays } \\
\text { Missing or non- } \\
\text { ADA sidewalks } \\
\text { Transit driver } \\
\text { may not accept } \\
\text { stroller }\end{array}$ & $\begin{array}{l}\text { - } \quad \text { Late to work - possible job loss } \\
\text { - Cannot get to transit stop - Have to find other } \\
\text { way } \\
\text { - } \quad \text { Go another way may mean walking in street - } \\
\text { possibly hit by person driving. }\end{array}$ \\
\hline Geographical & $\begin{array}{l}\text { Inadequate bus } \\
\text { lines from low- } \\
\text { density service } \\
\text { provision }\end{array}$ & $\begin{array}{l}\text { - Long waits for bus - takes up time that could be } \\
\text { spent on more valuable activities like their kids. } \\
\text { - } \quad \text { Transit may not get you where you need to go. }\end{array}$ \\
\hline Facilities & $\begin{array}{l}\text { Retail clustering } \\
\text { far away from } \\
\text { residences }\end{array}$ & $\begin{array}{l}\text { - More time - more valuably spent on other things } \\
\text { - Choose closer store - spend more on food }\end{array}$ \\
\hline Economic & $\begin{array}{l}\text { Not enough } \\
\text { money for fare }\end{array}$ & $\begin{array}{l}\text { - Risk } \$ 180 \text { ticket and not pay fare - possible } \\
\text { suspension from riding in future } \\
\text { - } \quad \text { Pay fare but cut back on food or entertainment } \\
\text { to come up with money }\end{array}$ \\
\hline Time & $\begin{array}{l}\text { Places are too } \\
\text { time intensive to } \\
\text { get to }\end{array}$ & $\begin{array}{l}\text { - Forego seeing family - damage relationship, } \\
\text { possible loss of help in future } \\
\text { - Go anyway - spend more on childcare because } \\
\text { it takes longer } \\
\text { - Go anyway - have less time to help kids with } \\
\text { homework or read to them -affecting their } \\
\text { academic achievement }\end{array}$ \\
\hline Fear & $\begin{array}{l}\text { Unsafe feeling } \\
\text { on transit }\end{array}$ & $\begin{array}{l}\text { - Becoming a victim/witness of crime - time } \\
\text { away from work if injured (probable loss of } \\
\text { job), loss of money, furthered insecurities - } \\
\text { refuse to take transit again } \\
\text { - Avoid transit based on perception - have to rely } \\
\text { on alternatives not readily available - social } \\
\text { isolation }\end{array}$ \\
\hline Space & Transit police & $\begin{array}{l}\text { - Fear of racial bias in policing - refuse to take } \\
\text { transit } \\
\text { - Actual bias in policing and you paid - } \\
\text { harassment to show fare immediately, } \\
\text { persecution if you do not. } \\
\text { - Ticketed and removed from transit. }\end{array}$ \\
\hline $\begin{array}{l}\text { Social } \\
\text { Networks }\end{array}$ & $\begin{array}{l}\text { They live too far } \\
\text { away }\end{array}$ & $\begin{array}{l}\text { - May not get to them in time to get money to } \\
\text { prevent utility shut off or eviction } \\
\text { - } \quad \text { Social network cannot reach them so they } \\
\text { cannot get a ride or childcare. } \\
\text { - Spend the time and lose opportunity to do } \\
\text { something else. }\end{array}$ \\
\hline
\end{tabular}


Table 7-2 shows a similar table for transit-dependent Albina residents. There are certainly universal exclusionary factors like fear, space, and physical restrictions. Racial bias in policing and the issues encountered that lead to safety concerns on transit do not have a geographic component. Similarly, a person with physical limitations will have the same difficulty getting on transit whether they catch it in Albina or East Portland. Available infrastructure in Albina contributed to fewer restrictions in use though. For virtually every other dimension of exclusion, Albina residents had other alternatives to get around the problem they faced that excluded them from getting around by transit. For instance, the ability to walk places safely and easily presented ways to get around not having enough money for fare. Walking also allowed them to overcome their fear of safety on transit. Neither option was viable for East Portlanders, even though it did occur out of absolute necessity. Most Albina residents had social networks nearby that were well resourced meaning they did not have to rely on those living in East Portland.

Albina residents also had fewer compounding exclusions. While low-cost grocers were not nearby, the higher-cost options nearby were at least easy to get to. This took one stressor away that East Portlanders consistent faced. Opting not to visit friends or family in the suburbs did not substantially debilitate their ability to find help from friends and family. This was because almost everyone had people in Albina or surrounding neighborhoods that they could rely on. The resources they could get from those nearby were also of better quality meaning they could get more substantial needs met more easily. 
Table 7-2 Implications of Social Exclusion for Transit Dependent Albina Residents

\begin{tabular}{|c|c|c|}
\hline $\begin{array}{l}\text { Forms of } \\
\text { Exclusion }\end{array}$ & $\begin{array}{l}\text { Dimension of } \\
\text { Exclusion }\end{array}$ & Effect \\
\hline Physical & $\begin{array}{l}\text { Transit delays } \\
\text { Transit driver } \\
\text { may not accept } \\
\text { stroller on-board }\end{array}$ & $\begin{array}{l}\text { - Late to work } \\
\text { - Have to try to get on bus with } \\
\text { folded stroller, limiting ability to } \\
\text { carry other items }\end{array}$ \\
\hline Geographical & $\begin{array}{l}\text { Lack of good } \\
\text { transit lines to get } \\
\text { to suburbs for } \\
\text { work or people }\end{array}$ & $\begin{array}{l}\text { - Have to find alternative way to get } \\
\text { there } \\
\text { - Opt to not find work in suburbs } \\
\text { - Opt to not visit people in suburbs }\end{array}$ \\
\hline Facilities & $\begin{array}{l}\text { Low-cost grocers } \\
\text { far away }\end{array}$ & $\begin{array}{l}\text { - Choose to shop closer for higher } \\
\text { cost } \\
\text { - Absorb the travel cost to go far for } \\
\text { groceries }\end{array}$ \\
\hline Economic & $\begin{array}{l}\text { Not enough } \\
\text { money for fare }\end{array}$ & $\begin{array}{l}\text { - Walk instead } \\
\text { - Cut back in other areas to afford } \\
\text { fare }\end{array}$ \\
\hline Time & $\begin{array}{l}\text { Transit takes } \\
\text { considerable } \\
\text { amount of time }\end{array}$ & $\begin{array}{l}\text { - Travel by car instead } \\
\text { - Limit travel to places nearby }\end{array}$ \\
\hline Fear & $\begin{array}{l}\text { Unsafe feeling on } \\
\text { transit }\end{array}$ & $\begin{array}{l}\text { - Becoming a victim/witness of crime } \\
\text { leads to time away from work if } \\
\text { injured (probable loss of job), loss } \\
\text { of money, furthered insecurities - } \\
\text { refuse to take transit again } \\
\text { - Avoid transit based on perception - } \\
\text { have to rely on alternatives }\end{array}$ \\
\hline Space & Transit police & $\begin{array}{l}\text { - Fear of racial bias in policing - } \\
\text { refuse to take transit } \\
\text { - Actual bias in policing and you } \\
\text { paid - harassment to show fare } \\
\text { immediately, persecution if you do } \\
\text { not. } \\
\text { - Ticketed and removed from transit. }\end{array}$ \\
\hline Social Networks & $\begin{array}{l}\text { Some people } \\
\text { have moved away }\end{array}$ & $\begin{array}{l}\text { - Rely more on others - may not be as } \\
\text { reliable or resourced } \\
\text { - Rely on other resources like social } \\
\text { services }\end{array}$ \\
\hline
\end{tabular}


In terms of the conceptual model of social reproduction presented in Chapter 4, it held up for the most part. But many elements need to be added to such as the external forces that influenced their available housing, transit, and key facilities. Gentrification does not Figure 7-1 Conceptual Model of Social Reproduction

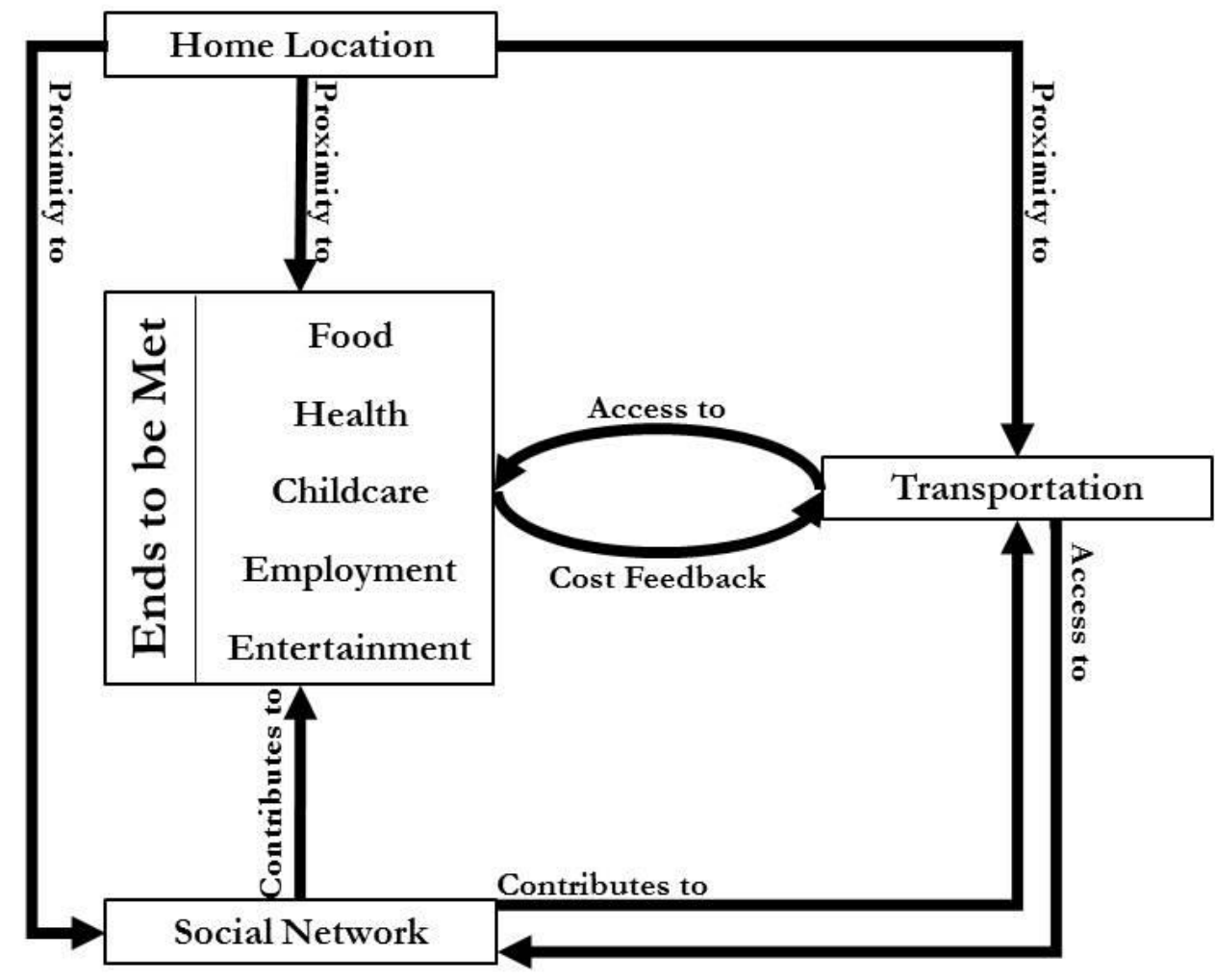

happen in a vacuum. Nor does how East Portland developed happen in a vacuum. City policies, real-estate actors, and banks combined to create a perfect storm for Black households in Portland. Between the city not intervening when it knew gentrification was leading to mass displacement of Black households in Albina, and complete inaction to bring equitable city infrastructure spending and adequate planning to East Portland for over 20 years, there was no winning scenario for most Black households that had lived in Albina. 
While investments are being made to add affordable housing to Albina, the investments came far too late with too little to offer. The result is an Albina population that still has family left in the area, but more and more of them are moving away. And East Portlanders are severely excluded from the systems that could help them better survive on meager wages. As the systems they developed for social reproduction continue to stand, residents of Albina have for the most part found the means to socially reproduce. They are finding work, their kids seem to be doing well, they tend to have support networks they can fall back to for childcare or even occasionally money to cover bills, and they are living in their more ideal location in the city. As long as their system holds up, they can hang on to the life they have in Albina. But expected increased costs could up-end that delicate balance.

East Portlanders on the other hand have to go the extra mile to socially reproduce, figuratively and literally. For the most part, they are stretched to the max in terms of time, money, and psychological will. Even though East Portlanders could benefit much more from public assistance, they were no more or less likely to be receiving public supports than those in Albina. Additionally, their social support networks were not as well-resourced or as easily accessible as for people living in Albina, but many were still able to get something from them with extra work necessary to get it. Without that extra assistance from both public and non-profit sources and their social support networks, their systems of social reproduction would likely collapse. Several of them were homeless relatively recently. Being as stretched as they were, it is not far-fetched that some of them are likely 
to end up homeless again. Indeed, I came across a news article of one of my participants who was living in a homeless camp less than a year after I interviewed them ${ }^{4}$.

\section{Demographic Effects on Travel and Making Ends Meet}

In Chapter 4, I discussed the demographic differences in the sample I recruited between Albina and East Portland. The primary demographic effect I found was related to the age of participants. Age had a cross-cutting effect on multiple aspects of the analysis as it affected multiple parts of their life from work and housing stability to the number and age of kids they had. This translated into possible effects on how Albina and East Portlanders appeared to struggle in their day-to-day life.

Half of the people I recruited in Albina were 45 years old or older. This put them at a later stage in their work-life, which would lend itself to possibly being more stable in employment. For populations in poverty though, stable employment is never a given. Only about half of those in Albina 45 or older had not changed jobs in the last few years. Jaqueline and Margaret had the most stability in their jobs as they were the only ones that worked in office environments, aided by their completion of a college degree.

The older age of people in Albina likely also expanded to their support networks. Older members of their support network were likely in retirement or had more material resources related to their longevity in the neighborhood (many participants referred to the family home still in the neighborhood). This meant older members of their support network potentially had more ability to provide immediate financial aid as well as provide childcare.

\footnotetext{
${ }^{4}$ For their privacy I will not link to the article or reveal which participant it was.
} 
This is a potential understanding as I did not interview members of the same support network to know for sure the constructs of their support networks.

Meanwhile, half the people I recruited in East Portland were 25-34 years old. East Portlanders also had a total of eleven more kids than those in Albina. Those additional kids were most likely to be 10 years old or younger. Kids that young require child care when the parent is not in the home and the kids are not in school. However, the biggest difficulty East Portlanders faced was getting child care. Their support networks that could and would watch their kids typically lived in Albina. Additionally, for the few that got day-care assistance, the cost was still excessive for living on poverty wages. That does not even consider the difficulty of finding day-care slots in places they trusted. As such, the lack of child care options substantially increased the level of struggle among East Portland parents.

Having more kids was not the only effect of youth on those in East Portland. Their young age was related to issues in work. They either had not been able to complete a college degree yet in order to get into better and more stable employment, or they had not been in a job for long enough to get into a management position that could offer more stability and wage benefits. Living in poverty also meant working in lower-tier jobs that are less forgiving on taking parental-leave. Their higher instance of kids in younger age groups meant they had more recent work disruptions most likely due to their childbirth. Income changes related to childbirth and child ages also could have substantial impacts on the amount families struggled. Women, Infants, and Children (WIC) was a critical resource every new mother I talked to was utilizing. However, as kids age out of WIC the programs 
at age five, the programs they transitioned to (if they transitioned to any other programs) were not as supportive.

Housing assistance and tenure in the area were also impactful demographic variables on interpreting their level of struggle. Subsidized housing made a substantial difference in the lives of the people that had it. Only one person owned their own home (a house they inherited), and they lived in Albina. This could also be considered a housing subsidy as they were insulated from most of the housing cost struggles their peers faced in the area. While subsidized housing through public housing or Section 8 can get rent payments down to $30 \%$ of their income, paying market rent has no controls as noted by Amber paying over \$1200 a month and Jaqueline paying \$1150 a month which equated to about $50-70 \%$ of their income.

Paying high rents created a huge housing stability problem in Portland. It is arguably the largest reason gentrification has resulted in a loss of half the Black population in Albina since 1990. Housing stability over time had a distinct impact on rootedness to an area and the availability of well-resourced people in their social support networks. People who had not spent most their lives in Portland did not have as much of an attachment to the Albina of yore, nor were they likely to have family in the area they could rely on. Nearly every one that had lived in Portland all their life had some history of living in Albina. The exceptions were Destiny and Ashley, both of whom were living in East Portland. Destiny was not clear in how she talked about Albina and her history with it, but at the same time, she did not have any family currently living in Albina. Ashley on the other hand grew up in Troutdale and had never lived closer to Albina than NE $60^{\text {th }}$ Ave. That meant most 
people in East Portland and even many of those living in Albina had been displaced from Albina at some point in their lives and were relatively recent movers to East Portland. I did not ask people about how many times they moved, so their housing stability is subjective in interpretation. However, it was clear from how East Portlanders talked about their current home as "it was what was available" that their current home was not likely to be permanent. Additionally, they were faced with the reality that many of the market-rate apartment buildings in Portland were under threat of a change of ownership which tended to result in mass evictions and/or rent increases (Sung \& Bates, 2017; Templeton, 2017).

Housing instability creates additional struggles to get by as each move costs money. Even if their possessions were so minimal as to be moved by transit, they still needed deposits for new apartments along with application fees. With the precarity of their housing situation resulting in having to move at any moment, fostered by state and local tenant laws that are more favorable to landlords, that is a huge stress that has additional psychological and economic effects on the family (Desmond, 2016). Being in subsidized housing that was run by a non-profit provider or the city's housing agency, Home Forward, ensured a much more secure future in their home. Section 8 renters were not as lucky.

Considering the potential number of moves East Portland residents made, it only contributed to their high level of household level struggle. However, housing instability also affected their social support networks. East Portlanders' support network members also living in East Portland were likely also impacted by the effects of housing instability. This sapped the ability of their East Portland-based support networks to provide them with the level of aid they needed. This put them at an additional disadvantage. 


\section{Limitations}

Even though the results hold substantial implications for policy and the lives of low-income Black people in Portland and in places with similar contexts, the limitations cannot be ignored. The primary limitations are as follows:

1. Concentrated recruitment limited the geographic understanding of East Portland;

2. Portland's transit system for suburban East Portland is not as limited as suburban areas further out or in suburbs of many other metropolitan areas;

3. I did not interview people within the same social network, blunting the understanding of how their networks function;

4. Racist activities were in a heightened state as I was conducting interviews affecting both transit use, activity levels, and experiences with White people.

The understandings of the Black experience in the suburbs of Portland was moderated by the recruitment strategy I adopted there. Most of my East Portland interviewees were recruited through a single non-profit agency. And most of those participants lived along E. Burnside St along the MAX line. Thus, a lot of the experiences of people I talked to were in relation to easy access to the MAX. Part of that may have been due to the concentration of affordable housing along the MAX line and not an effect of my recruitment, but it is difficult to isolate that effect. Overall, about half of the East Portland sample lived within a half mile of the MAX line. I did collect interviews from a few people that did not live close to the MAX, and their lived experience did appear to differ heavily from those concentrated around the MAX. It would be worthwhile to get a better range of geographic experiences in East Portland to better understand how the experience differs across that area, if at all. 
I cannot say with any certainty what affect the East Portland sample had on my findings without having a counter-narrative of those that did not live near the MAX. However, looking at Destiny's experience from living near Powell (about 2 miles from the MAX line), she did exhibit some differences worth exploring further. She relied on a bus to get her to the MAX which she took further east to get to work. However, Destiny often needed to walk the distance because the bus would not be on time or would not show up at all. During that walk, she expressed having very different experiences in safety with feeling much more on-guard near her home than near the MAX. Could there be substantial safety issues different than those expressed by residents living near the MAX? Additionally, Powell is a state-managed highway that does not have any sidewalks or safe crossings for pedestrians.

Powell also has a different commercial development pattern than that along Burnside. There were very few restaurants and retail locations within easy access of a single transit line.

Probably most impactful is the potential for further social support network fragmentation. Getting from anywhere along Powell Blvd to Albina is not an easy feat by transit. For comparison, someone living on $122^{\text {nd }}$ and Burnside could get to Fremont and MLK in Albina in about 40 minutes in the best of circumstances. A trip from $122^{\text {nd }}$ and Powell Blvd to the same location would take an hour, but with two transit transfers, something would be likely cause the trip to go long.

Portland is also exceptional in its transit system. For most cities, suburban areas have very limited transit networks. While the transit density in East Portland is 
substantially less than it is in Albina, the transit that existed in East Portland was more than most suburban areas had. It is also unfortunate my study did not take place a year or two later than it did. Then I could have captured the effects of the low-income fare, transition to an electronic fare system, and expanded transit service in the study area. As it is, I do not anticipate the findings to be nullified by the changes that have occurred as many of the issues are still relevant. In particular, the safety issues are still very much present.

As I did not interview people within the same support network, it is difficult to say how exactly those support networks work with the distance and resource constraints within their networks. While the experiences captured from those living in Albina and East Portland provided some guidance on how the support networks differ and operate differently based on geography and resources, there does appear to be a large variability in strength of network that determines how the networks work internally. I could not adequately capture that by interviewing only one person from that network. For instance, the suggested findings around resourcefulness of their networks was implied from the stated reliability of their networks and being able to receive multiple kinds of help. While that may hold up as a useful metric, it is not precise in understanding the amount of resources available in an individual's network. A much more thorough study is needed to truly understand the breadth and depth of social support networks and how they were affected by the geographical differences caused by gentrification.

At the time of this study, racism was affecting the hearts and minds of Black populations across the city. The events that occurred had a severe impact on the lives of the people I talked to with most of them curtailing their activity levels and modifying their 
transport behaviors in response. That gentrification was also tearing Black people from their homes and the Black cultural center of the city only heightened the psychological sensitivity to the subject matter of this study. At $5 \%$ of the city's population, their share of the population was small compared to most major cities. Their experience with racism and associated threat to their existence has to be understood in that context. I cannot say to what extent racism and being a small share of the population affected their lived experience compared to a city with a larger share of Black people, but it is not something to ignore when extending findings to other places.

Lastly, the fear factor for transit use in this study was skewed by a racially motivated attack on the MAX that resulted in two white-people being killed and one other being stabbed when they stood up to a man threatening a couple of Black girls. I tried to manage the effects of that attack as best I could by trying to get to how they felt prior to those activities being ever-present, but the racially-motivated attack was still a huge influence in how they responded. I cannot say how lasting of an effect those activities will have on my interviewees' behaviors or whether there will be a permanent effect. It was a very unique contextual issue for Portland at the time, and there needs to be follow up to truly understand the effects of insecurity on transit ridership.

\section{Implications for Theory}

\section{Dispersal of Poverty}

For decades, U.S. housing policy has been oriented toward dispersing low-income populations in an effort to reduce concentrated poverty which was also an effort to reduce concentrated Blackness. Section 8 housing vouchers, public housing redevelopment 
projects through HOPE VI, and most recently the Choice Neighborhoods Initiative, have all worked toward the goal of deconcentrating poverty. However, the effects have not been overly positive (Boyd et al., 2010; Goetz \& Chapple, 2010; Kissane \& Clampet-Lundquist, 2012). Those removed from such projects have not, on average, had better life chances. And removing public housing residents has come at the cost of upending neighborhood cultures, social support networks, and life stability for those forced to move.

Black businesses and Black culture in Albina were disappearing through decades of urban renewal and then furthered along by decades of gentrification. While some of the institutions will remain as long as Black populations can maintain some presence in the neighborhood, many will continue to disappear. Black Churches remain highly relevant in the lives of Black Portlanders with many traveling across the city to get to church every week. But more and more Black churches struggle to continue offering services as their congregations continue to move further away. For each Black church that closes, that is a community social support network lost (Taylor et al., 2005). Similarly, while Black barbershops/salons are touted as a community asset to Black neighborhoods (HarrisLacewell, 2004), many of them have been closing around Albina as well. These were neighborhoods where the concentrated Blackness allowed Black-oriented businesses to survive. The need for services in the neighborhoods created opportunities for Black entrepreneurship since White people were unwilling to invest in the neighborhoods. Once White people invested though, those opportunities declined precipitously.

Between the affordable housing initiatives of the city, efforts by Prosper Portland to make up for the harms of their past destruction caused by urban renewal, and the private 
development adding retail, grocers, restaurants, and thousands of people to consume those new goods, lower-income Black people in Albina still have less available to them. Private development has only brought too-expensive consumerism. Too few affordable units are being built to undo the thousands of Black Albina households that have left. And the few Black businesses that opened in the Alberta Commons project by Prosper Portland were already-existing Black businesses in Albina and just a drop in the bucket compared to the number of businesses lost to the destruction of the area (Morrison, 2019).

The problem here gets into the fundamental issues between "people vs. place" solutions for poverty in economic development and housing policy. With the dispersal of the Black population and an undermining of the cultural foundation of the Black community in Portland, it is difficult to say whether there is much "place" left to preserve. Indeed, looking through the City of Portland's application for historical preservation of sites of importance for Black history in Portland featured several addresses where the history was torn down or replaced with new development (City of Portland, 2019b).

We need more research on the effect of preservation of Black history and its effects on the preservation or revitalization of Black communities. As displaced populations struggle to find a footing in other parts of the city, there is also the question of whether it is possible a Black business corridor could survive in a place like East Portland. The small Black population in Portland makes that questionable. There is a lot of research need around community economic development for displaced populations to help understand what could and would not work. This study provides a jumping off point to understand the baseline issues. 


\section{Spatial Mismatch}

The spatial mismatch hypothesis has been thoroughly debated for decades now. But few studies have gone into the effects of actually moving poor, Black workers to the suburbs to theoretically be closer to jobs. This study provided a few primers for understanding the hypothesis as it deals with increasing suburbanization of poverty.

1. Portland's poor, Black workers have not necessarily moved closer to jobs by moving to the suburbs - they have essentially moved to the wrong suburbs for that effect;

2. The low-unemployment environment in Portland at the time of this study likely skewed the ability to see whether job competition pushed a necessity for poor, Black workers to seek work in the suburbs;

3. Cars can be a vital resource for accessing jobs in the suburbs, but this study found that they were mostly a convenience factor. The people I interviewed did not seek jobs they could not access by transit because of their known vehicle reliability problems;

4. Suburban jobs they could access by car did not necessarily offer enough of a pay premium to offset the time and gas it took to get there;

5. Even when accessible by transit, suburban jobs were often warehouse work that came with shift hours that did not line up with transit schedules.

While this study did not seek to provide an answer on the spatial mismatch hypothesis for Portland, the evidence suggests there is still a spatial mismatch in as much as the jobs people had were not paying enough to get them out of poverty, and several of them had turned down suburban jobs that had a pay premium because they could not get to them.

\section{Gentrification}

Research on displacement related to gentrification will continue for the foreseeable future as there are still many vectors and effects of displacement we do not fully understand. As some researchers try to downplay the effect displacement has on those removed from a neighborhood, we need to move beyond the idea that just because people 
that remain in the neighborhood may benefit from the changes to the neighborhood that everything is good in the hood. Each place will have a different impact from the threat of gentrification. And the impacts will determine how those displaced are affected.

It remains true that gentrification is a relatively contained phenomenon. Few poor neighborhoods will see gentrification at least on a wholesale scale such as seen in Portland or Brooklyn. However, the context matters. For Portland, Black populations make up a very small percentage of population. Nearly every neighborhood they were forced into through segregation then got upended by capitalistic forces which forced them to move again. Gentrification has thereby threatened the existence of Black culture in Portland. Certainly, cultural changes happen in places like Brooklyn and Harlem as well, but the size of the Black population there ensure something will still exist. There is a lot we do not understand about how the psyche of a population is affected when their cultural roots are essentially destroyed. Fullilove only began to give us an idea of the breadth of the problem. And more radical gentrification theorists, like Pain (2019) are beginning to treat displacement as violence against displaced peoples. This study provided a glimpse into the necessity of Black culture in maintaining a sense of place for the Black populations in Portland. It also points to the ways in which displacement through both direct and exclusionary means enact a form of violence against Black populations that have suffered through generations of state and private violence.

\section{Policy Recommendations}

Transportation issues flow through everything I have discussed in this concluding chapter. People have to be able to get places in order to socially reproduce. The 
displacement of people living in poverty creates additional transportation barriers. Even in a city like Portland with a well-known and respected transit system, the phenomenon of gentrification and the dispersal of low-income Black populations has created a large disparity in how well the transit system performs and for whom it performs.

For relieving traffic congestion and environmental reasons, transportation policies should lean toward getting people out of cars. But even more importantly, cars are an economic burden on poor households. Census numbers show that around $40 \%$ of lowincome Black populations regularly drive to work in Portland, a much lower share than compared to White populations, but that is a substantial number of poor households that spend more than twice as much to get around. However, we cannot ignore the huge benefits driving has for those living in poverty as demonstrated by decades of study on the subject (Agrawal et al., 2011; Blumenberg \& Manville, 2004; Blumenberg \& Ong, 2001; Blumenberg \& Pierce, 2012; P. Ong \& Blumenberg, 1998). In this study, I found those reliant on driving stressed the importance of their cars through speed, convenience, and flexibility in getting around, similar to findings from other researchers looking at the benefits of car-ownership for low-income populations. However, rarely were their cars used to access jobs they would not otherwise reach by transit. Given the number of previous studies that have stressed the importance of car ownership for getting a job, this may be a finding unique to Portland or it may be unique to the economic times where unemployment was under 3\% and jobs were relatively easy to find nearby. It could also reflect Portland's transit system being robust enough for low-income Black households to get to jobs. However, most of the people I interviewed were not in jobs with high upward mobility. 
The transit robustness may be good for getting people into the jobs they were in, but not good for getting them into jobs with prospects for higher pay that may pull them out of poverty.

\section{Policy recommendation 1: Improve reliability and speed of transit.}

As long as transit, especially in East Portland, continues to be unreliable, burdensome, and slow, the incentives to drive will remain. It will also be critical in developing a transit system that can reliably get populations in poverty to well-paying jobs on the outskirts of the metropolitan area. TriMet has been doing a good job at expanding transit routes in East Portland. But the distance that needs to be covered once someone is on a bus in East Portland requires buses to travel faster through space. This means buses need to stop less and have dedicated lanes to improve travel speeds. There is a lot of controversy around transit stop removal, but even spacing stops to be every $1 / 3$ mile instead of every quarter mile could make a huge difference on transit speed. If the speeds of transit improve enough, the extra effort needed to get to a transit stop could be perceived as worth it. Any stop changes need to take into consideration the effects on populations with limited mobility. There will be no perfect solution that enhances the experience for everyone along every portion of their experience with using transit, but there is a lot of room for improvement over what currently exists.

Policy Recommendation 2: Improve safety on transit.

Beyond the common criticisms of transit being slow and unreliable, far too many of the people I talked to felt transit was too unsafe for them to use comfortably and regularly. While there was some influence on how people felt about the safety of transit 
from the racially-motivated attack, their concerns about safety preceded that event. TriMet's current efforts in utilizing police to conduct fare enforcement is not an adequate measure, and in actuality produces a counter-effect on how safe people feel on transit, especially for Black and Brown riders. TriMet needs to drastically change how they approach this issue. Between their captive riders moving to an area with less transit and less ability to use it regularly to get around, and the fear component of using transit, TriMet should continue to expect to lose considerable ridership. OPAL suggested the use of rider advocates (non-police uniformed people that can intervene in disruptions and provide assistance to riders). I wholly agree with this approach, and it is not unprecedented in TriMet's history. Such rider advocates could greatly improve the face of TriMet while providing a greater sense of security on transit, both of which TriMet needs.

Policy Recommendation 3: Adequately incentivize, fund, and implement the goals in the East Portland Action Plan and provide an update to the plan.

There is no way to undo the harms already done to the Black community in Portland through various forms of "slum" clearance, gentrification, and under and disinvestment in Black neighborhoods. However, that does not mean things cannot be made better. There is already a plan for East Portland to make the area more of what the residents need. The City of Portland has started providing money to East Portland through the "Fixing Our Streets" program as well as through parks and public safety, but it took far too long to get started and provides only a portion of the money needed to get East Portland to where those involved in making the plan envisioned. 
The East Portland Action Plan is more than just those investments though. It is a vision for neighborhoods that better accommodate their people after decades of neglect. The East Portland Action Plan was intended to be a 5-year plan that 10 years later still has not been fully realized. And in those 10 years, the area has grown considerably. The City needs to invest in an East Portland Action Plan update for the growing needs of the area as it has solidified its role as housing the majority of the city's poor and people of color. The City also needs to ensure the update is immediately followed with funding and deliberate action to ensure its implementation.

One of the primary goals of the EPAP was to get more people living in "complete neighborhoods." easily maintain their daily life within a reasonable distance from home was very evident in this study. Failure to act on that goal alone has substantial consequences for the livability of the area in a way in which crosswalks provide little to no help.

Policy Recommendation 4: Work with Albina Vision leaders to ensure the center of Black culture in Portland can be retained and reclaimed.

The Albina Vision is led by a group of visionary Black leaders in Portland that envision transforming the Rose Quarter District into reclaimed space for the neighborhood that was destroyed in order to build it. The City would be smart to work with them to preserve remaining historical assets, reclaim space that was forcibly taken from Black

\footnotetext{
5 As defined by the Portland Plan, complete neighborhoods are "areas where residents have safe and
} convenient access to goods and services they need on a daily or regular basis." (City of Portland, 2013) 
households, and ensure that Black Portlanders can continue calling Albina home, one that would be better than it was in the past.

\section{Concluding}

Low-income Black Portlanders are facing a difficult time no matter where they live in the city. While getting around and getting to services may be easier for those in Albina than in East Portland, the social fabric of the Black community in Portland is in jeopardy if gentrification of Albina continues displacing people and closing down the last vestiges of Black culture. Some policies going into action may be able to help, but for many it is too little, too late. There is still a lot to better understand as part of social reproduction as it concerns geographical differences among Black populations, but this study provides a jumping off point.

The results from this study also bring into question the real benefits of dispersing people living in poverty as a strategy to overcome the problems of concentrated poverty. With Black populations in particular, cultural amenities are a large part of the lived experience and moving them far away from those amenities can create additional burdens in their lives. Is it too much of a burden to counteract living in a higher opportunity neighborhood? I cannot say from this study, as East Portland where the displaced population I studied is not by any definition an opportunity area. But as was the case with the Gautreaux program, many people did not move to a higher opportunity neighborhood and thus their situations were generally not improved by their moves (Pashup et al., 2005; Popkin et al., 2000). 
Through this study, I have added to the knowledge the effects of scarcity of amenities in low-income suburban locales. East Portland is by all definitions a suburban location. Retail development is highly concentrated toward the western side of the area leaving those living a hundred blocks or further east with very few options for where they can go to meet their daily needs. As part of the scarcity of amenities in East Portland, it is ever present that there are virtually no businesses catering to the needs of Black people and no churches that I know of. Even the one church I know of that moved east is still not in what most would consider East Portland.

Lastly, transit equity is a serious issue when considering geographical differences among low-income Black populations in a very White city. TriMet is making an effort to bring more parity to the system in East Portland as compared to Albina, but there is still a long way to go. As it is, though, it is unlikely that transit improvements alone will help the situation of low-income Black East Portlanders. The built environment of East Portland gets in the way of making major in-roads to seeing those live there have less burdens on their travel needs and feeling more freedom in their movement. 


\section{References}

Agrawal, A., Blumenberg, E., Abel, S., Pierce, G., \& Darrah, C. N. (2011). Getting Around When You're Just Getting By: The Travel Behavior and Transportation Expenditures of Low-Income Adults (MTI Report 10-02). Mineta Transportation Institute. http://transweb.sjsu.edu/project/2806.html

Allard, S. W. (2017). Places in Need: The Changing Geography of Poverty. Russell Sage Foundation.

Allard, S. W., Wathen, M. V., Danziger, S. K., \& Shaefer, H. L. (2015). Finding food assistance and food retailers in Detroit. Focus, 31(1), 7-12.

Alwitt, L. F., \& Donley, T. D. (1997). Retail stores in poor urban neighborhoods. Journal of Consumer Affairs, 31(1), 139-164.

Anderson, M. (2014, October 13). New Maps Show Which Streets Would Be Improved by Proposed Income Tax. Bike Portland. http://bikeportland.org/2014/10/13/newmaps-show-streets-improved-proposed-income-tax-112117

Andrew Riley, A. (2018, March 16). ATU Announces Partnership with OPAL Environmental Justice to Improve Safety on Transit. Amalgamated Transit Union 757. https://www.atu757.org/atu-announces-partnership-with-opal-environmentaljustice-to-improve-safety-on-transit/

Bader, M. D. M., Purciel, M., Yousefzadeh, P., \& Neckerman, K. M. (2010). Disparities in Neighborhood Food Environments: Implications of Measurement Strategies. Economic Geography, 86(4), 409-430. https://doi.org/10.1111/j.19448287.2010.01084.x

Bailey, Z. D., Krieger, N., Agénor, M., Graves, J., Linos, N., \& Bassett, M. T. (2017). Structural racism and health inequities in the USA: Evidence and interventions. The Lancet, 389(10077), 1453-1463. https://doi.org/10.1016/S0140-6736(17)30569-X

Bates, L. (2013). Gentrification and Displacement Study: Implementing an Equitable Inclusive Development Strategy in the Context of Gentrification. Portland Bureau of Planning and Sustainability. http://pdxscholar.library.pdx.edu/usp_fac/83

Bezanson, K., \& Luxton, M. (2006). Social Reproduction and Feminist Political Economy. In Social Reproduction: Feminist Political Economy Challenges Neo-Liberalism (pp. 3-10). McGill-Queens Press.

Blumenberg, E. (2002). On the Way to Work: Welfare Participants and Barriers to Employment. Economic Development Quarterly, 16(4), 314-325. https://doi.org/10.1177/089124202237196 
Blumenberg, E. (2004). En-gendering Effective Planning: Spatial Mismatch, Low-Income Women, and Transportation Policy. Journal of the American Planning Association, 70(3), 269-281. https://doi.org/10.1080/01944360408976378

Blumenberg, E., \& Hess, D. (2003). Measuring the Role of Transportation in Facilitating Welfare-to-Work Transition: Evidence from Three California Counties. Transportation Research Record, 1859, 93-101. https://doi.org/10.3141/1859-12

Blumenberg, E., \& Manville, M. (2004). Beyond the Spatial Mismatch: Welfare Recipients and Transportation Policy. Journal of Planning Literature, 19(2), 182-205. https://doi.org/10.1177/0885412204269103

Blumenberg, E., \& Ong, P. (2001). Cars, Buses, and Jobs: Welfare Participants and Employment Access in Los Angeles. Transportation Research Record, 1756, $22-$ 31. https://doi.org/10.3141/1756-03

Blumenberg, E., \& Pierce, G. (2012). Automobile Ownership and Travel by the Poor. Transportation Research Record: Journal of the Transportation Research Board, 2320, 28-36. https://doi.org/10.3141/2320-04

Bomey, N. (2019, September 29). Cars have a problem: They last longer, and that means the insides get grubby and outmoded. USA Today. https://www.usatoday.com/story/money/cars/2019/09/27/new-cars-last-longerand-interiors-need-more-durable-materials/2211617001/

Boyatzis, R. E. (1998). Transforming Qualitative Information: Thematic Analysis and Code Development. Sage Publications.

Boyd, M. L., Edin, K. J., Clampet-Lundquist, S., \& Duncan, G. J. (2010). The durability of gains from the Gautreaux Two residential mobility program: A qualitative analysis of who stays and who moves from low-poverty neighborhoods*. Housing Policy Debate, 20(1), 119-146. https://doi.org/10.1080/10511481003599902

Breyer, B., \& Voss-Andreae, A. (2013). Food mirages: Geographic and economic barriers to healthful food access in Portland, Oregon. Health \& Place, 24, 131-139. https://doi.org/10.1016/j.healthplace.2013.07.008

Briggs, X. de S., Comey, J., \& Weismann, G. (2010). Struggling to stay out of high-poverty neighborhoods: Housing choice and locations in moving to opportunity's first decade. Housing Policy Debate, 20(3), 383-427. https://doi.org/10.1080/10511481003788745

Buron, L., Popkin, S. J., Levy, Diane K., Harris, Laura E., \& Khudduri, Jill. (2002). The HOPE VI Resident Tracking Study: A Snapshot of the Current Living Situation of 
Original Residents from Eight Sites [Text]. The Urban Institute. http://www.urban.org/publications/410591.html

Butz, A., \& Zuberi, D. (2012). Local approaches to counter a wider pattern? Urban poverty in Portland, Oregon. The Social Science Journal, 49(3), 359-367. https://doi.org/10.1016/j.soscij.2011.12.001

Buys, L., \& Miller, E. (2011). Conceptualising convenience: Transportation practices and perceptions of inner-urban high density residents in Brisbane, Australia. Transport Policy, 18(1), 289-297.

Cao, X. (Jason). (2015). Examining the impacts of neighborhood design and residential self-selection on active travel: A methodological assessment. Urban Geography, 36(2), 236-255. https://doi.org/10.1080/02723638.2014.956420

CBPP. (2009). Introduction to the Housing Voucher Program. Center on Budget and Policy Priorities. https://www.cbpp.org/research/introduction-to-the-housingvoucher-program

CBPP. (2019). Chart Book: SNAP Helps Struggling Families Put Food on the Table. Center on Budget and Policy Priorities. https://www.cbpp.org/sites/default/files/atoms/files/3-13-12fa-chartbook.pdf

Cervero, R., \& Kockelman, K. (1997). Travel demand and the 3Ds: Density, diversity, and design. Transportation Research Part D: Transport and Environment, 2(3), 199219. https://doi.org/10.1016/S1361-9209(97)00009-6

Chapple, K. (2001). Time To Work: Job Search Strategies and Commute Time for Women on Welfare in San Francisco. Journal of Urban Affairs, 23(2), 155-173. https://doi.org/10.1111/0735-2166.00081

Chapple, K. (2006). Overcoming Spatial Mismatch: Beyond Dispersal, Mobility, and Development Strategies. Journal of the American Planning Association, 72(3), 322-336.

Chung, C., \& Myers, S. L. (1999). Do the poor pay more for food? An analysis of grocery store availability and food price disparities. Journal of Consumer Affairs, 33(2), 276-296.

Church, A., Frost, M., \& Sullivan, K. (2000). Transport and social exclusion in London. Transport Policy, 7(3), 195-205. https://doi.org/10.1016/S0967-070X(00)00024$\mathrm{X}$

City of Portland. (2013). My Portland Plan: What Makes a Neighborhood Complete? https://www.portlandonline.com/portlandplan/?a=437441 
City of Portland. (2014). Annexations by Decade [Map]. https://www.portlandoregon.gov/bps/article/51673

City of Portland. (2018). East Portland In Motion. https://www.portlandoregon.gov/transportation/54306?utm_medium=email\&utm _source=govdelivery

City of Portland. (2019a). Saving Lives with Safe Streets: Vision Zero Traffic Crash Report 2018. Portland Bureau of Transportation. https://www.portlandoregon.gov/transportation/article/729483

City of Portland. (2019b). National Register of Historic Places Multiple Property Documentation Form: African American Resources in Portland, Oregon from 1965 to 1973. https://www.oregon.gov/oprd/OH/Documents/2020Feb_OR_MultnomahCounty_ AfricanAmericanResourcesinPortlandMPD.pdf

Clampet-Lundquist, S. (2004). HOPE VI relocation: Moving to new neighborhoods and building new ties. Housing Policy Debate, 15(2), 415-447. https://doi.org/10.1080/10511482.2004.9521507

Clampet-Lundquist, S., \& Massey, D. S. (2008). Neighborhood Effects on Economic SelfSufficiency: A Reconsideration of the Moving to Opportunity Experiment. American Journal of Sociology, 114(1), 107-143. https://doi.org/10.1086/588740

Clifton, K. J. (2004). Mobility Strategies and Food Shopping for Low-Income Families A Case Study. Journal of Planning Education and Research, 23(4), 402-413. https://doi.org/10.1177/0739456X04264919

Coalition for a Livable Future. (2014). Equity Atlas 2.0. Equity Atlas. https://gis.oregonmetro.gov/equityAtlas/

Conger, K., \& Scheiber, N. (2019, September 11). California Bill Makes App-Based Companies Treat Workers as Employees. The New York Times. https://www.nytimes.com/2019/09/11/technology/california-gig-economybill.html

Cortright, J., \& Mahmoudi, D. (2014). Lost in Place: Why the Persistence and Spread of Concentrated Poverty - Not Gentrification-Is Our Biggest Urban Challenge. City Observatory. content/uploads/2014/12/LostinPlace_12.4.pdf

Covington, K., Freeman, L., \& Stoll, M. A. (2011). The Suburbanization of Housing Choice Voucher Recipients (Metropolitan Opportunity Series). Brookings Institute. 
Crabtree, B. F., \& Miller, W. L. (1992). A Template Approach to Text Analysis: Developing and Using Codebooks. In B. F. Crabtree \& W. L. Miller (Eds.), Doing Qualitative Research (pp. 93-109). Sage Publications.

Crump, J. (2002). Deconcentration by Demolition: Public Housing, Poverty, and Urban Policy. Environment and Planning D: Society and Space, 20, 581-596.

Curl, A., Clark, J., \& Kearns, A. (2018). Household car adoption and financial distress in deprived urban communities: A case of forced car ownership? Transport Policy, 65, 61-71. https://doi.org/10.1016/j.tranpol.2017.01.002

Daly, M. C., Hobijn, B., \& Pedtke, J. H. (2020). Labor market dynamics and black-white $\begin{array}{lllll}\text { earnings } & \text { gaps. } & \text { Economics }\end{array}$ https://doi.org/10.1016/j.econlet.2019.108807

Darrah, J., \& DeLuca, S. (2014). "Living Here Has Changed My Whole Perspective": How Escaping Inner-City Poverty Shapes Neighborhood and Housing Choice. Journal of Policy Analysis and Management, 33(2), 350-384.

Day, K. (2006). Active living and social justice: Planning for physical activity in lowincome, Black, and Latino communities. Journal of the American Planning Association, 72(1), 88-99.

Desmond, M. (2016). Evicted: Poverty and Profit in the American City. Crown Publishers.

Edelman, P. (2012). So Rich, So Poor: Why It's So Hard to End Poverty in America. The New Press.

Edin, K. J., \& Lein, L. (1997). Making Ends meet: How Single Mothers Survive Welfare and Low-Wage Work. Russell Sage Foundation.

Edin, K. J., \& Shaefer, H. L. (2015). \$2.00 a Day: Living on Almost Nothing in America. Houghton Mifflin Harcourt.

Eisen, B., \& Roberts, A. (2019, October 1). The Seven-Year Auto Loan: America's Middle Class Can't Afford Its Cars. Wall Street Journal. https://www.wsj.com/articles/theseven-year-auto-loan-americas-middle-class-cant-afford-their-cars-11569941215

Elliott-Cooper, A., Hubbard, P., \& Lees, L. (2019). Moving beyond Marcuse: Gentrification, displacement and the violence of un-homing. Progress in Human Geography, 0309132519830511. https://doi.org/10.1177/0309132519830511

Ewing, R., \& Cervero, R. (2010). Travel and the Built Environment. Journal of the American Planning Association, 76(3), 265-294. https://doi.org/10.1080/01944361003766766 
Fenster, T. (2005). The Right to the Gendered City: Different Formations of Belonging in Everyday Life. Journal of Gender Studies, 14(3), 217-231. https://doi.org/10.1080/09589230500264109

Fereday, J., \& Muir-Cochrane, E. (2008). Demonstrating Rigor Using Thematic Analysis: A Hybrid Approach of Inductive and Deductive Coding and Theme Development. International Journal of Qualitative Methods, 5(1), 80-92.

Fletcher, C. N., Garasky, S. B., \& Nielsen, R. B. (2005). Transportation Hardship: Are You Better off with a Car? Journal of Family and Economic Issues, 26(3), 323-343. https://doi.org/10.1007/s10834-005-5901-x

Fox, L. (2019). The Supplemental Poverty Measure: 2018 (p. 33). U.S. Census Bureau.

Freeman, L. (2006). There Goes the 'Hood: Views of Gentrification from the Ground Up. Temple University Press.

Freeman, L., \& Braconi, F. (2004). Gentrification and Displacement in New York City in the 1990s. Journal of the American Planning Association, 70(1), 39-52.

Fullilove, M. T. (2004). Root Shock: How Tearing up City Neighborhoods Hurts America, and What We Can Do About It. One World/Ballantine.

Galster, G. (2007). Neighbourhood Social Mix as a Goal of Housing Policy: A Theoretical Analysis. European Journal of Housing Policy, 7(1), 19-43. https://doi.org/10.1080/14616710601132526

Gardner, N., Cui, J., \& Coiacetto, E. (2017). Harassment on public transport and its impacts on women's travel behaviour. Australian Planner, 54(1), 8-15. https://doi.org/10.1080/07293682.2017.1299189

Gibson, K. J. (2007a). Bleeding Albina: A History of Community Disinvestment, 19402000. Transforming Anthropology, 15(1), 3-25. https://doi.org/10.1525/tran.2007.15.1.03

Gibson, K. J. (2007b). The Relocation of the Columbia Villa Community Views from Residents. Journal of Planning Education and Research, 27(1), 5-19. https://doi.org/10.1177/0739456X07299845

Gilbert, M. R. (1998). "Race," Space, and Power: The Survival Strategies of Working Poor Women. Annals of the Association of American Geographers, 88(4), 595-621. https://doi.org/10.1111/0004-5608.00114

Giuliano, G. (2003). Travel, location and race/ethnicity. Transportation Research Part A: Policy and Practice, 37(4), 351-372. 
Giuliano, G. (2005). Low Income, Public Transit, and Mobility. Transportation Research Record, 1927, 63-70.

Goetz, E. G. (2003). Clearing the Way: Deconcentrating the Poor in Urban America. The Urban Institute Press.

Goetz, E. G. (2010). Better Neighborhoods, Better Outcomes? Explaining Relocation Outcomes in HOPE VI. Cityscape, 12(1), 5-31. JSTOR.

Goetz, E. G., \& Chapple, K. (2010). You gotta move: Advancing the debate on the record of dispersal. Housing Policy Debate, 20(2), 209-236. https://doi.org/10.1080/10511481003779876

González de la Rocha, M. (1994). The resources of poverty: Women and survival in a Mexican city. Blackwell.

Greer, T. M., \& Spalding, A. (2017). The role of age in understanding the psychological effects of racism for African Americans. Cultural Diversity and Ethnic Minority Psychology, 23(4), 588-594. https://doi.org/10.1037/cdp0000148

Grengs, J. (2001). Does Public Transit Counteract the Segregation of Carless Households? Measuring Spatial Patterns of Accessibility. Transportation Research Record, 1753(1), 3-10. https://doi.org/10.3141/1753-01

Gurley, T., \& Bruce, D. (2005). The effects of car access on employment outcomes for welfare recipients. Journal of Urban Economics, 58(2), 250-272. https://doi.org/10.1016/j.jue.2005.05.002

Haggerty, B. (2014). The Suburbanization of Poverty in the Portland-Vancouver Metropolitan Region. Coalition for a Livable Future. https://clfuture.org/sites/clfuture.org/files/pdfs/suburbanization_of_poverty_final. pdf

Halpern-Meekin, S., Edin, K. J., Tach, L., \& Sykes, J. (2014). It's Not Like I'm Poor: How Working Families Make Ends Meet In A Post-Welfare World. University of California Press.

Hamnett, C. (2003). Gentrification and the Middle-class Remaking of Inner London, 19612001. Urban Studies, 40(12), 2401-2426. https://doi.org/10.1080/0042098032000136138

Handy, S. (1996). Methodologies for exploring the link between urban form and travel behavior. Transportation Research Part D: Transport and Environment, 1(2), 151165. https://doi.org/10.1016/S1361-9209(96)00010-7 
Handy, S., Cao, X., \& Mokhtarian, P. (2005). Correlation or causality between the built environment and travel behavior? Evidence from Northern California. Transportation Research Part D: Transport and Environment, 10(6), 427-444. https://doi.org/10.1016/j.trd.2005.05.002

Handy, S., Xinyu Cao, \& Mokhtarian, P. L. (2006). Self-Selection in the Relationship between the Built Environment and Walking. Journal of the American Planning Association, 72(1), 55-74. https://doi.org/10.1080/01944360608976724

Hanushek, E. A., Peterson, P. E., Talpey, L. M., \& Woessmann, L. (2019). The Unwavering SES Achievement Gap: Trends in U.S. Student Performance (Working Paper No. 25648). National Bureau of Economic Research. https://doi.org/10.3386/w25648

Harris-Lacewell, M. (2004). Barbershops, Bibles, and BET: Everyday Talk and Black Political Thought. Princeton University Press.

Heflin, C., London, A. S., \& Scott, E. K. (2011). Mitigating Material Hardship: The Strategies Low-Income Families Employ to Reduce the Consequences of Poverty*. Sociological Inquiry, $81(2), \quad 223-246 . \quad$ https://doi.org/10.1111/j.1475682X.2011.00369.x

Hillier, A., Cannuscio, C. C., Karpyn, A., McLaughlin, J., Chilton, M., \& Glanz, K. (2011). How Far Do Low-Income Parents Travel to Shop for Food? Empirical Evidence from Two Urban Neighborhoods. Urban Geography, 32(5), 712-729. https://doi.org/10.2747/0272-3638.32.5.712

Hu, L. (2015). Job Accessibility of the Poor in Los Angeles. Journal of the American Planning Association, 81(1), 30-45. https://doi.org/10.1080/01944363.2015.1042014

Ihlanfeldt, K. R., \& Sjoquist, D. L. (1998). The spatial mismatch hypothesis: A review of recent studies and their implications for welfare reform. Housing Policy Debate, 9(4), 849-892. https://doi.org/10.1080/10511482.1998.9521321

Jargowsky, P. A. (1997). Poverty and Place: Ghettos, Barrios, and the American City. Russell Sage.

Jeon, J. S. (2019). Moving away from opportunity? Social networks and access to social services. Urban Studies, 0042098019844197. https://doi.org/10.1177/0042098019844197

Jeong, J., \& Liu, C. Y. (2019). Neighborhood Diversity and Food Access in a Changing Urban Spatial Structure. City \& Community. https://doi.org/10.1111/cico.12426 
Jurjevich, J., Griffin, A. L., Spielman, S. E., Folch, D. C., Merrick, M., \& Nagle, N. N. (2018). Navigating statistical uncertainty: How urban and regional planners understand and work with American Community Survey (ACS) data for guiding policy. Journal of the American Planning Association, 84(2), 112-126.

Kain, J. F. (1968). Housing Segregation, Negro Employment, and Metropolitan Decentralization. The Quarterly Journal of Economics, 82(2), 175-197. https://doi.org/10.2307/1885893

Karner, A., Rowangould, D., \& London, J. (2016). We can get there from here: New perspectives on transportation equity. University of California - Davis. https://escholarship-org.proxy.lib.pdx.edu/content/qt9zp565xr/qt9zp565xr.pdf

Kawabata, M., \& Shen, Q. (2007). Commuting Inequality between Cars and Public Transit: The Case of the San Francisco Bay Area, 1990-2000. Urban Studies, 44(9), 17591780. https://doi.org/10.1080/00420980701426616

Kea, T. (2017). Tri-Met December 2016 Monthly Performance Report. https://trimet.org/about/pdf/2016/2016-12.pdf

Kea, T. (2018). Tri-Met December 2017 Monthly Performance Report. https://rimet.org/about/pdf/2017/2017-12.pdf

Kenoyer, K. (2018, August 10). TriMet Study On Racial Bias Based on Incomplete Data [News]. Portland Mercury. https://www.portlandmercury.com/blogtown/2018/08/10/21973518/trimet-studyon-racial-bias-based-on-incomplete-data

Kenyon, S., Lyons, G., \& Rafferty, J. (2002). Transport and social exclusion: Investigating the possibility of promoting inclusion through virtual mobility. Journal of Transport Geography, 10(3), 207-219. https://doi.org/10.1016/S09666923(02)00012-1

Kissane, R. J., \& Clampet-Lundquist, S. (2012). Social Ties, Social Support, and Collective Efficacy among Families from Public Housing in Chicago and Baltimore. Journal of Sociology and Social Welfare, 39(4), 157-182.

Kleit, R. G., \& Manzo, L. C. (2006). To Move or Not to Move: Relationships to Place and Relocation Choices in HOPE VI. Housing Policy Debate, 17(2), 271-308.

Kneebone, E., \& Berube, A. (2013). Confronting Suburban Poverty in America. Brookings Institution Press.

Kolak, M., Bradley, M., Block, D. R., Pool, L., Garg, G., Toman, C. K., Boatright, K., Lipiszko, D., Koschinsky, J., Kershaw, K., Carnethon, M., Isakova, T., \& Wolf, M. 
(2018). Urban foodscape trends: Disparities in healthy food access in Chicago, 2007-2014. Health \& Place, 52, 231-239. https://doi.org/10.1016/j.healthplace.2018.06.003

Laslett, B., \& Brenner, J. (1989). Gender and Social Reproduction: Historical Perspectives. Annual Review of Sociology, 15, 381-404.

Lee, R. J., Sener, I. N., \& Jones, S. N. (2017). Understanding the role of equity in active transportation planning in the United States. Transport Reviews, 37(2), 211-226. https://doi.org/10.1080/01441647.2016.1239660

Lein, L., Schexnayder, D. T., Douglas, K. N., \& Schroeder, D. G. (2007). Life After Welfare: Reform and the Persistence of Poverty. University of Texas Press.

Lein, L., \& Sussman, M. B. (1983). The Ties that Bind: Men's and Women's Social Networks. The Haworth Press.

Lewicka, M. (2011). Place attachment: How far have we come in the last 40 years? Journal of Environmental Psychology, 31(3), 207-230. https://doi.org/10.1016/j.jenvp.2010.10.001

Loukaitou-Sideris, A. (2006). Is it Safe to Walk?1 Neighborhood Safety and Security Considerations and Their Effects on Walking. Journal of Planning Literature, 20(3), 219-232. https://doi.org/10.1177/0885412205282770

Loukaitou-Sideris, A. (2014). Fear and safety in transit environments from the women's perspective. Security Journal, 27(2), 242-256. https://doi.org/10.1057/sj.2014.9

Loukaitou-Sideris, A., \& Fink, C. (2009). Addressing Women's Fear of Victimization in Transportation Settings: A Survey of U.S. Transit Agencies. Urban Affairs Review, 44(4), 554-587. https://doi.org/10.1177/1078087408322874

Lubitow, A., Lievanos, R., McGee, J., \& Carpenter, E. (2019). Developing Data, Models, and Tools to Enhance Transportation Equity (NITC-RR-1122). Transportation Research and Education Center. https://ppms.trec.pdx.edu/media/project_files/NITC-RR-

1122_Developing_Data_Models_and_Tools_to_Enhance_Transportation_Equity _A5SyK36.pdf

Lubitow, A., Rainer, J., \& Bassett, S. (2017). Exclusion and vulnerability on public transit: Experiences of transit dependent riders in Portland, Oregon. Mobilities, 12(6), 924937. https://doi.org/10.1080/17450101.2016.1253816

Lucas, K. (2012). Transport and social exclusion: Where are we now? Transport Policy, 20, 105-113. https://doi.org/10.1016/j.tranpol.2012.01.013 
Lusk, A. C., Anastasio, A., Shaffer, N., Wu, J., \& Li, Y. (2017). Biking practices and preferences in a lower income, primarily minority neighborhood: Learning what residents want. Preventive Medicine Reports, 7, 232-238. https://doi.org/10.1016/j.pmedr.2017.01.006

Marcuse, P. (1986). Abandonment, Gentrification, and Displacement: The Linkages in New York City. In N. Smith \& P. Williams (Eds.), Gentrification of the City (pp. 153-177). Unwin Hyman.

Massey, D., \& Denton, N. (1993). American Apartheid: Segregation and the Making of the Underclass. Harvard University Press.

Massey, D. S. (2007). Categorically Unequal: The American Stratification System. Russell Sage Foundation.

McCurdy, C. (2019, May 2). Alberta Commons Grows. The Skanner News. https://www.theskanner.com/news/northwest/28474-alberta-commons-grows

McKenzie, B. S. (2014). Access to supermarkets among poorer neighborhoods: A comparison of time and distance measures. Urban Geography, 35(1), 133-151. https://doi.org/10.1080/02723638.2013.856195

McLaren, A. T. (2016). Families and transportation: Moving towards multimodality and altermobility? Journal of Transport Geography, 51, 218-225. https://doi.org/10.1016/j.jtrangeo.2016.01.006

McNeil, N., Dill, J., MacArthur, J., Broach, J., \& Howland, S. (2017). Breaking Barriers to Bike Share: Insights from Residents of Traditionally Underserved Neighborhoods (NITC-RR-884b). Transportation Research and Education Center.

Meltzer, R., \& Schuetz, J. (2012). Bodegas or Bagel Shops? Neighborhood Differences in Retail and Household Services. Economic Development Quarterly, 26(1), 73-94. https://doi.org/10.1177/0891242411430328

MIlls, T., \& Steele. (2017, November 14). In Portland, Economic Displacement May Be A Driver of Transit Ridership Loss. TransitCenter. http://transitcenter.org/2017/11/14/in-portland-economic-displacement-may-be-adriver-of-transit-ridership-loss/

Morrison, E. (2019, June 19). Alberta Commons: Portland's Attempt To Do Redevelopment Right In A Gentrifying Neighborhood [News]. Oregon Public Broadcasting. $\quad$ https://www.opb.org/news/article/portland-oregon-albertacommons-development-gentrification/ 
Newman, K., \& Wyly, E. K. (2006). The Right to Stay Put, Revisited: Gentrification and Resistance to Displacement in New York City. Urban Studies, 43(1), 23-57. https://doi.org/10.1080/00420980500388710

O’Neill, J. (1990). The Role of Human Capital in Earnings Differences between Black and White Men. Journal of Economic Perspectives, 4(4), 25-45. https://doi.org/10.1257/jep.4.4.25

Ong, P., \& Blumenberg, E. (1998). Job Access, Commute and Travel Burden among Welfare Recipients. Urban Studies, 35(1), 77-93. https://doi.org/10.1080/0042098985087

Ong, P. M. (2002). Car ownership and welfare-to-work. Journal of Policy Analysis and Management, 21(2), 239-252. https://doi.org/10.1002/pam.10025

Pain, R. (2019). Chronic urban trauma: The slow violence of housing dispossession. Urban Studies, 56(2), 385-400. https://doi.org/10.1177/0042098018795796

Pashup, J., Edin, K. J., Duncan, G. J., \& Burke, K. (2005). Participation in a residential mobility program from the client's perspective: Findings from Gautreaux Two. Housing Policy Debate, 16(3-4), 361-392. https://doi.org/10.1080/10511482.2005.9521550

Pattillo, M. (2007). Black on the Block: The Politics of Race and Class in the City. University of Chicago Press.

Pendall, R., George, A., McDade, Z., Dawkins, C., Jeon, J. S., Knaap, E., Blumenberg, E., Pierce, G., \& Smart, M. (2014). Driving to Opportunity: Understanding the Links among Transportation Access, Residential Outcomes, and Economic Opportunity for Housing Voucher Recipients. The Urban Institute.

Phillips, M. (2011). Parenting, time use, and disparities in academic outcomes. In G. J. Duncan \& R. J. Murnane (Eds.), Whither Opportunity?: Rising Inequality, Schools, and Children's Life Chances (pp. 207-229). Russell Sage Foundation.

Pittman, C. (2020). "Shopping while Black": Black consumers' management of racial stigma and racial profiling in retail settings. Journal of Consumer Culture, 20(1), 3-22. https://doi.org/10.1177/1469540517717777

Popkin, S. J., Buron, L. F., Levy, D. K., \& Cunningham, M. K. (2000). The Gautreaux Legacy: What Might Mixed-Income and Dispersal Strategies Mean for the Poorest Public Housing Tenants? Housing Policy Debate, 11(4), 911-942. https://doi.org/10.1080/10511482.2000.9521392 
Portland Housing Bureau. (2017). State of Housing in Portland. Portland Housing Bureau. https://www.portlandoregon.gov/phb/article/681253

Powell, C. (2018). Bias, Employment Discrimination, and Black Women's Hair: Another Way Forward. Brigham Young University Law Review, 2018(4), [i]-968.

Renauer, B., C. (2016). Analysis of Racial/Ethnic Disparity in TriMet Fare Enforcement Outcomes on the MAX 2014-2016. Criminal Justice Policy Research Institute.

Rich, J. (2014). What do field experiments of discrimination in markets tell us? A meta analysis of studies conducted since 2000 (IZA Discussion Paper No. 8584). Institute for the Study of Labor. http://www.econstor.eu/bitstream/10419/104705/1/dp8584.pdf

Rogalsky, J. (2010). The working poor and what GIS reveals about the possibilities of public transit. Journal of Transport Geography, 18(2), 226-237. https://doi.org/10.1016/j.jtrangeo.2009.06.008

Roschelle, A. R. (1997). No More Kin: Exploring Race, Class, and Gender in Family Networks. Sage Publications.

Rosenblatt, P., \& DeLuca, S. (2012). "We Don't Live Outside, We Live in Here": Neighborhood and Residential Mobility Decisions Among Low-Income Families. City \& Community, 11(3), 254-284. https://doi.org/10.1111/j.15406040.2012.01413.x

Roy, K. M., Tubbs, C. Y., \& Burton, L. M. (2004). Don't Have No Time: Daily Rhythms and the Organization of Time for Low-Income Families*. Family Relations, 53(2), 168-178. https://doi.org/10.1111/j.0022-2445.2004.00007.x

Sanbonmatsu, L., Ludwig, J., Katz, L. F., Gennetian, L. A., Duncan, G. J., Kessler, R. C., Adam, E., McDade, T. W., \& Lindau, S. T. (2011). Moving to Opportunity for Fair Housing Demonstration Project-Final Impacts Evaluation. U.S. Department of Housing and Urban Development.

Schrock, G., Bassett, E. M., \& Green, J. (2015). Pursuing Equity and Justice in a Changing Climate: Assessing Equity in Local Climate and Sustainability Plans in U.S. Cities. Journal of Planning Education and Research, 35(3), 282-295. https://doi.org/10.1177/0739456X15580022

Scott, A. (2012, February 17). By the Grace of God. http://www.portlandmonthlymag.com/news-and-profiles/culture/articles/africanamerican-churches-north-portland-march-2012 
Seidman, I. (2013). Interviewing as Qualitative Research: A Guide for Researchers in Education and the Social Sciences (Fourth Edition). Teachers College Press.

Sherman, L. (2019, June 2). Can Uber Ever be Profitable? Forbes. https://www.forbes.com/sites/lensherman/2019/06/02/can-uber-ever-beprofitable/\#5bb0af725785

Shipler, D. K. (2004). The Working Poor: Invisible in America. Vintage Books.

Shulman, B. (2003). The Betrayal of Work: How Low-Wage Jobs Fail 30 Million Americans. The New Press.

Silvis, H. (2013, November 20). Anti-Gentrification Activists Protest PDC Land Sale. The Skanner News. https://www.theskanner.com/news/northwest/20514-antigentrification-activists-protest-pdc-land-sale

Slater, T. (2009). Missing Marcuse: On Gentrification and Displacement. City: Analysis of Urban Trends, Culture, Theory, Policy, Action, 13(2-3), 292-311.

Smart, M. J., \& Klein, N. J. (2018). Disentangling the role of cars and transit in employment and labor earnings. Transportation. https://doi.org/10.1007/s11116-018-9959-3

Smith, N. (1996). The New Urban Frontier: Gentrification and the Revanchist City. Routledge.

Solomon, M. (2017, June 24). Despite Threats, Northeast Portland's "Good In The Hood" Parade Parties On. https://www.opb.org/news/article/portland-good-in-the-hoodfestival-racist-threats/

Spears, S., Houston, D., \& Boarnet, M. G. (2013). Illuminating the unseen in transit use: A framework for examining the effect of attitudes and perceptions on travel behavior. Transportation Research Part A: Policy and Practice, 58, 40-53. https://doi.org/10.1016/j.tra.2013.10.011

Stack, C. (1975). All Our Kin: Strategies for Survival in a Black Community. Basic Books Inc.

Steg, L. (2005). Car use: Lust and must. Instrumental, symbolic and affective motives for car use. Transportation Research Part A: Policy and Practice, 39(2), 147-162. https://doi.org/10.1016/j.tra.2004.07.001

Streckert, J. (2014, September 24). The Forgotten Portland-Feature-Portland Mercury. The Portland Mercury. https://www.portlandmercury.com/portland/the-forgottenportland/Content?oid=13629549 
Sullivan, D. M., \& Shaw, S. C. (2011). Retail Gentrification and Race: The Case of Alberta Street in Portland, Oregon. Urban Affairs Review, 47(3), 413-432. https://doi.org/10.1177/1078087410393472

Sung, S., \& Bates, L. (2017). Preserving Housing Choice and Opportunity: A Study of Apartment Building Sales and Rents. Portland State University Library. https://doi.org/10.15760/report-02

Taylor, R. J., Chatters, L. M., Woodward, A. T., \& Brown, E. (2013). Racial and Ethnic Differences in Extended Family, Friendship, Fictive Kin, and Congregational Informal Support Networks. Family Relations, 62(4), 609-624. https://doi.org/10.1111/fare.12030

Taylor, R. J., Lincoln, K. D., \& Chatters, L. M. (2005). Supportive Relationships with Church Members Among African Americans*. Family Relations, 54(4), 501-511. https://doi.org/10.1111/j.1741-3729.2005.00336.x

Templeton, A. (2017, February 12). Meet The Wealthy Investors Buying Cheap Portland Apartment Buildings And Driving Up Rents. https://www.opb.org/news/article/portland-oregon-gentrification-real-estateinvestors-property-apartments-affordable-housing/

Troilo, J., \& Coleman, M. (2012). Full-Time, Part-Time Full-Time, and Part-Time Fathers: Father Identities Following Divorce. Family Relations, 61(4), 601-614. https://doi.org/10.1111/j.1741-3729.2012.00722.x

Turney, K., \& Harknett, K. (2010). Neighborhood Disadvantage, Residential Stability, and Perceptions of Instrumental Support Among New Mothers. Journal of Family Issues, 31(4), 499-524. https://doi.org/10.1177/0192513X09347992

Vigdor, J. L., Massey, D. S., \& Rivlin, A. M. (2002). Does Gentrification Harm the Poor? [With Comments]. Brookings-Wharton Papers on Urban Affairs, 133-182. JSTOR.

Walker, R. E., Keane, C. R., \& Burke, J. G. (2010). Disparities and access to healthy food in the United States: A review of food deserts literature. Health \& Place, 16(5), 876-884. https://doi.org/10.1016/j.healthplace.2010.04.013

Widener, M. J. (2018). Spatial access to food: Retiring the food desert metaphor. $\begin{array}{llll}\text { Physiology } \quad \text { B } & \text { 257-260. }\end{array}$ https://doi.org/10.1016/j.physbeh.2018.02.032

Wilson, W. J. (1987). The Truly Disadvantaged: The Inner City, the Underclass, and Public Policy. The University of Chicago Press. 
Wood, P. B., \& Brunson, R. K. (2011). Geographies of Resilient Social Networks: The Role of African American Barbershops. Urban Geography, 32(2), 228-243. https://doi.org/10.2747/0272-3638.31.2.228

Yavuz, N., \& Welch, E. W. (2010). Addressing Fear of Crime in Public Space: Gender Differences in Reaction to Safety Measures in Train Transit. Urban Studies, 47(12), 2491-2515. https://doi.org/10.1177/0042098009359033

Zhang, L., Hong, J., Nasri, A., \& Shen, Q. (2012). How built environment affects travel behavior: A comparative analysis of the connections between land use and vehicle miles traveled in US cities. Journal of Transport and Land Use, 5(3), 40-52. JSTOR.

Zukin, S. (2010). Naked City: The Death and Life of Authentic Urban Places. Oxford University Press. 


\section{Appendix A: Interview Script}

Screening questions (asked during intercept or phone call):

1. Where do you live?

2. Have you lived in that neighborhood for at least 1 year?

3. Where were you born?

4. What race/ethnicity do you identify as?

5. Are you employed or looking for employment?

6. Are you the primary caregiver to a child under 18 years old or disabled adult living in your household?

7. What is your approximate household income?

Interview Guide:

1. How long have you lived in Portland?

a. Where do you live (address)?

b. How long have you lived in this house/apartment?

c. Where else in Portland have you lived?

d. What led you to move to this house/apartment?

2. Is your home owned, rented?

a. IF RENTING: Is this public housing, Section 8, or other low-income subsidy?

3. Tell me about your employment:

a. Are you employed? IF EMPLOYED

i. Where do you work: Place and location? 
ii. What is your occupation?

iii. How long have you worked there?

iv. How many hours per week do you typically work?

v. What times of day do you typically work?

vi. Do you have other jobs? What are they?

\section{b. IF UNEMPLOYED AND LOOKING FOR WORK:}

i. How long have you been unemployed?

4. Tell me a little about your household:

a. Who all lives here and what is their relation to you?

b. What jobs or work does each person do and/or where do they go to school?

c. How do the members of your household share resources or support each other?

5. What vehicles belong to members of your household that you or others in your household use for transportation, not recreation, including cars, trucks, motorcycles, and bicycles?

a. Who owns and pays for maintaining each vehicle?

b. How are the vehicles shared among household members?

6. I am going to ask you a series of questions about the places you may go, for each type of place I would like to know where you go regularly if at all, how you get there, the difficulties or frustrations, if any, you face when trying to go to those 
places, and whether you have changed the place you regularly go to within the past year, why you changed the place, and how it has affected you.

a. Places:
i. Grocery
ii. Childcare
iii. School for your children and/or yourself
iv. Work

v. Friends/Family houses

vi. Healthcare facilities

vii. Restaurants

viii. Barbershop/Salon

ix. Library

x. Church

xi. Social services

xii. Entertainment places, including parks

xiii. Any other places you consider important

Now I want to discuss different ways of getting around. Think about the many different ways you get around whether you use them regularly or only sometimes. (Pick up on cues and feel out what order modes need to be asked about. For instance, if they use other modes when their car does not work, then ask about those next.)

7. Do you drive a car belonging to your household? IF THEY DRIVE THEIR OWN

\section{CAR:}

a. For what activities do you drive your own car? 
b. Why do you drive instead of using another way to get around?

c. What difficulties do you face when deciding to drive, such as vehicle reliability, cost?

d. How much does your household typically spend each month by driving including gas, insurance, car payments, and parking?

e. Do you give rides to others?

i. Who do you give rides to and what is their relation to you?

ii. How does this affect you?

iii. Do you ask for anything in return?

f. Do you lend your car out to others?

i. Who do you let borrow your car and what is their relation to you?

ii. How does this affect you?

iii. Do you ask for anything in return?

8. Do you ever borrow a car from someone? IF THEY BORROW A CAR:

a. From whom can you borrow a car and what is their relation to you?

b. How reliably can you borrow a car?

c. Do you exchange anything for the use of their car?

d. For what activities do you borrow a car?

e. Why do you borrow a car instead of using another way to get around?

f. What difficulties do you face when using this mode?

9. Do you ever ask someone for rides to where you need to go, including work? IF THEY GET RIDES: 
a. From whom do you ask for rides and what is their relation to you?

b. How reliably can you receive rides from them?

c. Do you exchange anything for them giving you a ride?

d. For what activities do you ask for rides?

e. Why do you ask for a ride instead of using another way to get around?

f. What difficulties do you face when using this mode?

10. Do you use public transit? IF THEY USE PUBLIC TRANSIT:

a. For what activities do you use public transit?

b. How do you pay for transit?

_ Single ride

_ Daily Pass

_ Weekly Pass

_ 2-week Pass

_ Monthly Pass

c. How much do you typically spend per month on transit?

d. Why do you use transit rather than using another way to get around?

e. What difficulties do you face when using this mode?

11. Do you bicycle for transportation? IF THEY USE A BICYCLE:

a. For what non-recreational activities do you use a bicycle?

b. Why do you use a bicycle rather than using another way to get around?

c. What difficulties do you face when using this mode?

12. Do you walk for transportation? IF THEY WALK:

a. For what non-recreational activities do you walk?

b. Why do you walk instead of using another way to get around? 
c. What difficulties do you face when using this mode?

13. Do you use taxis, including options like Uber and Lyft? IF THEY USE TAXIS:

a. For what activities do you take taxis?

b. Why do you use taxis instead of using another way to get around?

c. What difficulties do you face when using this mode?

14. Are you familiar with any of the carsharing services in Portland such as Car2Go, Getaround, Turo, or ZipCar? IF THEY ARE FAMILIAR WITH THEM:

a. What are your opinions of them?

b. Did you want more information? (If they do, share basics of the various systems at end of interview)

15. Are you familiar with Biketown, the bikeshare system in Portland?

a. What are your opinions of it?

b. Did you want more information? (If they do, share the basics and where they can get more info at end of interview)

16. How much do your child(ren)/disabled adult depend on you to transport them places?

a. What tradeoffs do you make in order to meet their transportation needs?

b. What difficulties do you have in meeting their transportation needs?

17. Do you use the internet or smartphone apps to reduce your need to travel? How so?

18. Do you use the internet or smartphone apps to make your travel easier? How so?

19. How do you feel your transportation situation affects your employment? 
a. Have you been negatively impacted at work because of your transportation?

i. Were you unable to get a job or lost a job because of a problem with transportation? How so?

20. How do you feel your employment affects the transportation you use?

21. How do you feel your transportation situation affects your housing and vice versa?

a. Have you limited where you live because of transportation? How so?

b. Has your choice of housing limited your transportation options? How so?

22. In what other ways do you feel your transportation choices and availability impact your daily life?

23. What tradeoffs do you make when deciding what transportation modes to use and where you go?

24. What do you do to save money on transportation costs? (Sharing rides, carpooling, not traveling places you want or need to visit, finding cheaper ways of getting around, limiting the number of people you take along, repairing vehicles yourself or putting off maintenance, etc.)

25. What are the other major expenses besides transportation of your household each month?

a. Do you ever cut back on these expenses in order to get through the month? If so, where do you cut back? 
b. Do you ever cut back on these expenses in order to meet transportation expenses? Which expenses?

c. Do you ever cut back on transportation expenses in order to meet other household expenses? Where do you cut back?

i. How does this impact how you get around?

I now want to ask you about the people that help you manage you daily life and how they help you out.

26. In what ways do you rely upon friends/family/neighbors to save money or do things you would otherwise be prevented from doing such as childcare, cash assistance, food, etc.?

a. Who helps you and what is their relation to you?

b. How reliable is this help?

c. How often do you require their help with this?

d. Do they come to you or do you have to go to them for them to help? IF THEY HAVE TO GO TO THEM:

i. How do you get there?

ii. How does this impact you in terms of transportation and meeting your other needs?

27. Has the way in which your friends/family/neighbors help you or the amount they are able to help you been impacted by them or you moving? How so?

I would like to conclude with giving you the opportunity to think more about your own transportation situation and how you make ends meet. 
28. Considering what we have talked about today, what do you feel would make your life easier?

There are only a few more simple questions left.

29. What is your age?

30. What is the highest level of education you have completed?

31. What is your annual household income?

32. How much does your household spend on transportation each month?

33. Are there any other things you would like me to know? 